\title{
Measures of the Environmental Footprint of the Front End of the Nuclear Fuel Cycle
}

Erich Schneider

Brett W. Carlsen

Emily Tavrides

August 2010

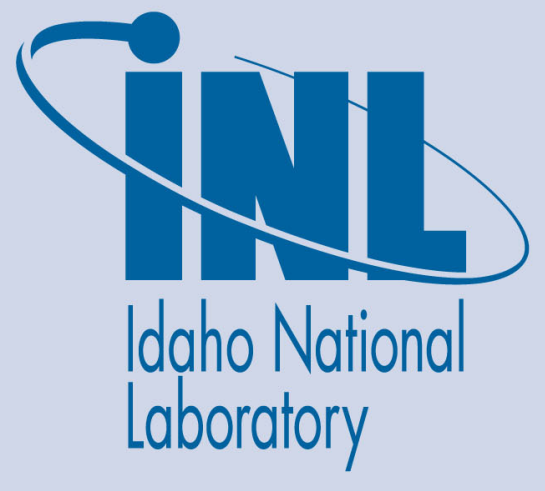

The INL is a U.S. Department of Energy National Laboratory operated by Battelle Energy Alliance 
INL/EXT-10-20652

FCRD-SYSA-2010-000104

\title{
Measures of the Environmental Footprint of the Front End of the Nuclear Fuel Cycle
}

\author{
Erich Schneider \\ Brett W. Carlsen \\ Emily Tavrides
}

August 2010

\section{Idaho National Laboratory \\ Fuel Cycle Research \& Development Idaho Falls, Idaho 83415}

http://www.inl.gov

Prepared for the

U.S. Department of Energy

Office of Nuclear Energy

Under DOE Idaho Operations Office

Contract DE-AC07-05ID14517 


\section{DISCLAIMER}

This information was prepared as an account of work sponsored by an agency of the U.S. Government. Neither the U.S. Government nor any agency thereof, nor any of their employees, makes any warranty, expressed or implied, or assumes any legal liability or responsibility for the accuracy, completeness, or usefulness, of any information, apparatus, product, or process disclosed, or represents that its use would not infringe privately owned rights. References herein to any specific commercial product, process, or service by trade name, trade mark, manufacturer, or otherwise, does not necessarily constitute or imply its endorsement, recommendation, or favoring by the U.S. Government or any agency thereof. The views and opinions of authors expressed herein do not necessarily state or reflect those of the U.S. Government or any agency thereof. 


\section{EXECUTIVE SUMMARY}

Previous estimates of environmental impacts associated with the front end of the nuclear fuel cycle (FEFC) have focused primarily on energy consumption and $\mathrm{CO}_{2}$ emissions. Results have varied widely. This study revises existing empirical correlations and their underlying assumptions to fit to a more complete set of actual data. This study also addresses land transformation, water withdrawals, and occupational and public health impacts associated with the processes of the FEFC. These processes include uranium mining, milling, refining, conversion, enrichment, and fuel fabrication.

To allow summing the impacts across processes, all impacts were normalized per tonne of natural uranium mined and then translated into impacts per $\mathrm{MWh}(\mathrm{e})$, a more conventional unit for measuring environmental impacts that facilitates comparison with other studies. This conversion was based on mass balances and process efficiencies associated with the current once-through LWR fuel cycle described in Appendix A.

Estimates of the environmental impacts of the FEFC are summarized in Table Exec-1. Quantified impacts are limited to those resulting from activities performed within the FEFC process facilities (i.e. within the plant gates). Energy embodied in material inputs such as process chemicals and fuel cladding is identified but not explicitly quantified in this study. Inclusion of indirect energy associated with embodied energy as well as construction and decommissioning of facilities could increase the FEFC energy estimate by a factor of up to $\sim 2$.

Table Exec-1. Contemporary footprint measures normalized per MWh electricity produced

\begin{tabular}{|c|c|c|c|c|c|c|c|c|}
\hline & \multicolumn{3}{|c|}{ Energy Consumption } & \multirow[b]{2}{*}{$\begin{array}{c}\mathrm{CO}_{2} \\
\text { Emissions } \\
\mathrm{kg} \mathrm{CO}_{2} / \\
\mathrm{MWh}(\mathrm{e})\end{array}$} & \multirow[b]{2}{*}{$\begin{array}{c}\text { Water } \\
\text { Use L/ } \\
\text { MWh(e) }\end{array}$} & \multirow[b]{2}{*}{$\begin{array}{c}\text { Land Use } \\
\mathrm{m}^{2} / \\
\mathrm{MWh}(\mathrm{e})\end{array}$} & \multicolumn{2}{|c|}{ Collective Dose } \\
\hline & $\begin{array}{c}\text { Electrical } \\
\text { GJ(e)/ } \\
\operatorname{MWh}(\mathrm{e})\end{array}$ & $\begin{array}{l}\text { Thermal: } \\
\text { liquid } \\
\text { carriers } \\
\text { GJ(t)/ } \\
\text { MWh(e) }\end{array}$ & $\begin{array}{l}\text { Thermal: } \\
\text { other } \\
\text { carriers } \\
\text { GJ }(\mathrm{t}) / \\
\mathrm{MWh}(\mathrm{e})\end{array}$ & & & & $\begin{array}{l}\text { Workers } \\
\text { person- } \\
\text { rem/ } \\
\text { MWh(e) }\end{array}$ & $\begin{array}{l}\text { Public } \\
\text { person- } \\
\text { rem/ } \\
\text { MWh(e) }\end{array}$ \\
\hline $\begin{array}{l}\text { Uranium } \\
\text { extraction }^{\mathrm{a}}\end{array}$ & $4.0 \times 10^{-3}$ & $1.3 \times 10^{-3}$ & $1.6 \times 10^{-3}$ & 0.78 & 130 & $7.5 \times 10^{-3}$ & $8.7 \times 10^{-6}$ & $1.4 \times 10^{-5}$ \\
\hline Conversion & $1.1 \times 10^{-3}$ & NA & $2.5 \times 10^{-2}$ & 1.45 & 2.1 & $1.2 \times 10^{-5}$ & $1.7 \times 10^{-7}$ & $2.7 \times 10^{-9}$ \\
\hline $\begin{array}{l}\text { Enrichment } \\
\text { (centrifuge) }\end{array}$ & $2.7 \times 10^{-3}$ & NA & NA & 0.41 & 0.65 & $1.3 \times 10^{-4}$ & $8.6 \times 10^{-10}$ & $2.8 \times 10^{-9}$ \\
\hline $\begin{array}{l}\text { Fuel Fab. } \\
\text { (UOX) }\end{array}$ & $5.2 \times 10^{-4}$ & NA & $1.8 \times 10^{-4}$ & 0.09 & 0.35 & $1.3 \times 10^{-5}$ & $4.7 \times 10^{-7}$ & $5.9 \times 10^{-10}$ \\
\hline $\begin{array}{l}\text { DU Man- } \\
\text { agement }^{\text {b }}\end{array}$ & $2.0 \times 10^{-4}$ & $1.8 \times 10^{-6}$ & $7.2 \times 10^{-5}$ & 0.035 & 0.23 & $1.9 \times 10^{-4}$ & \multicolumn{2}{|c|}{ Not Available } \\
\hline $\begin{array}{l}\text { Transport- } \\
\text { ation }^{c}\end{array}$ & NA & $1.6 \times 10^{-4}$ & NA & 0.011 & NA & NA & $7.9 \times 10^{-8}$ & $1.5 \times 10^{-8}$ \\
\hline Totals & $\sim 8.5 \times 10^{-3}$ & $\sim 1.5 \times 10^{-3}$ & $\sim 2.7 \times 10^{-2}$ & $\sim 2.8$ & $\sim 130$ & $\sim 8 \times 10^{-3}$ & $\sim 9.5 \times 10^{-6}$ & $\sim 1.4 \times 10^{-5}$ \\
\hline $\begin{array}{ll}\text { a. } & \text { Includes } \\
& 36 \% \text { in-s } \\
\text { b. Assumes } \\
\text { c. Assumes } \\
\text { mining } / \mathrm{n}\end{array}$ & $\begin{array}{l}\text { nining, millin } \\
\text { u leaching). } \\
\text { DU conversio } \\
\text { PWR fuel t } \\
\text { lling, convers }\end{array}$ & $\begin{array}{l}\text { and refining } \\
\text { to } \mathrm{DU}_{3} \mathrm{O}_{8} \text { an } \\
\text { asported by } \\
\text { on, enrichme }\end{array}$ & $\begin{array}{l}\text { ased on curi } \\
\text { shallow land } \\
\text { uck a dista } \\
\text { DU disposi }\end{array}$ & $\begin{array}{l}\text { at mix of mir } \\
\text { urial. } \\
\text { ce of } 1000 \\
\text { n, fuel fabric }\end{array}$ & between & $\begin{array}{l}\text { h of the } \mathrm{f} \\
\text { plant. }\end{array}$ & it, $41 \%$ und & $\begin{array}{l}\text { ground, and } \\
\text { ss facilities: }\end{array}$ \\
\hline
\end{tabular}


With the exception of water use, these impacts are very favorable relative to other competing technologies for large-scale energy production. For example, front-end processes have been estimated to account for $38 \%$ of the carbon footprint associated with production of electricity from nuclear energy (see Table 2.3). Scaling the above estimate for FEFC emissions accordingly, one estimates $7.4 \mathrm{~kg} \mathrm{CO}_{2} / \mathrm{MWh}(\mathrm{e})$ for nuclear electricity production . For comparison, current average U.S. emissions from natural gas and coalfired electricity production are 410 and $979 \mathrm{~kg} \mathrm{CO}_{2} / \mathrm{MWh}(\mathrm{e})$, respectively.

The estimates given in the foregoing table depend upon a number of parameters that are expected to evolve with time. These include the ratio of ore to overburden and grade of the ore (i.e. \% U), the mix and energy efficiency of the technologies used in the FEFC, and the rate of expansion of the nuclear industry. This study considers this time-dependency. Projections intended to bound emissions impacts for the range of plausible mid-century scenarios are summarized in Table Exec-2.

Table Exec-2. FEFC $\mathrm{CO}_{2}$ emissions, 2050 scenarios

\begin{tabular}{lccc}
\hline & \multicolumn{3}{c}{$\mathrm{kg} \mathrm{CO}_{2} / \mathrm{MWh}(\mathrm{e})$} \\
\cline { 2 - 4 } & & 2050 & 2050 \\
& Current & Low & High \\
\hline Uranium extraction & 0.78 & 0.35 & 2.17 \\
Conversion & 1.45 & 1.30 & 1.39 \\
Enrichment (centrifuge) & 0.41 & 0.01 & 0.26 \\
Fuel Fab (UOX) & 0.09 & 0.02 & 0.06 \\
DU Management & 0.035 & 0.01 & 0.02 \\
Transportation & 0.011 & 0.01 & 0.01 \\
Total & $\sim 2.8$ & $\sim 1.7$ & $\sim 3.9$ \\
\hline
\end{tabular}

The above results scale linearly (inverse relationship) with uranium utilization. Because the current oncethrough LWR fuel cycle utilizes less than 1\% of the energy in the natural uranium, the evolution of the nuclear fuel cycle is an important variable with respect to predicting future environmental impacts as well as extending the life of uranium reserves.

The nature of the debate surrounding the future of nuclear power is not politically neutral. And previously reported estimates of its environmental impacts are diverse. Consequently, an important objective of this report is to be fully transparent with respect to input data, assumptions, methods, and calculations. Thorough and open review is encouraged. Please send comments, suggestions, and feedback to brett.carlsen@inl.gov and/or eschneider@mail.utexas.edu. 


\section{CONTENTS}

EXECUTIVE SUMMARY

ACRONYMS

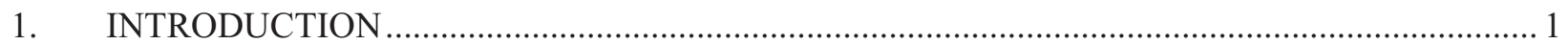

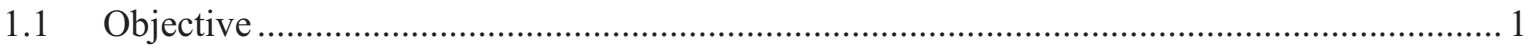

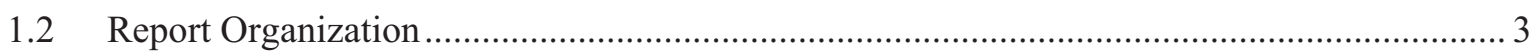

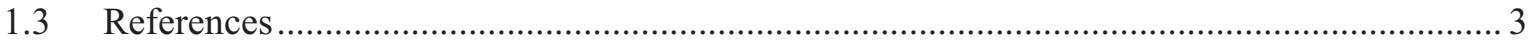

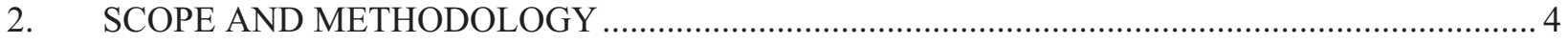

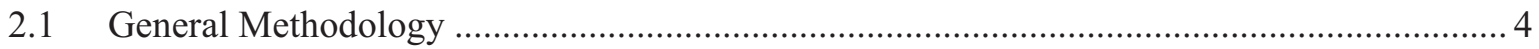

2.2 The Front End Carbon Footprint: Methods and Review of Studies ...................................... 6

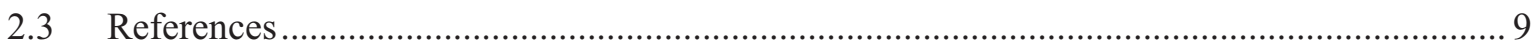

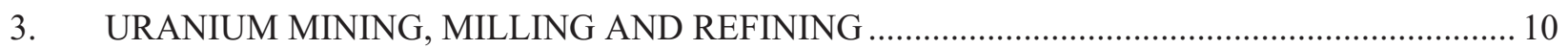

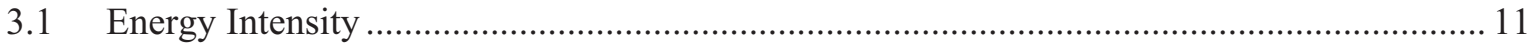

3.1.1 Consumption breakdown by energy carrier .......................................................... 17

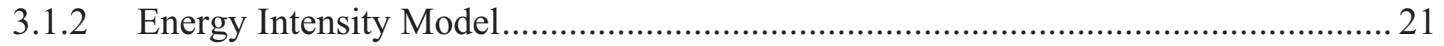

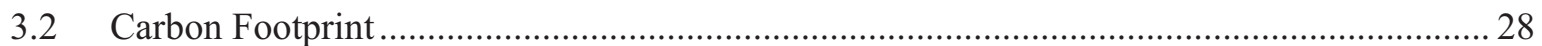

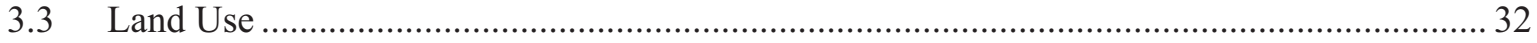

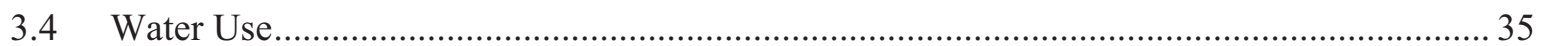

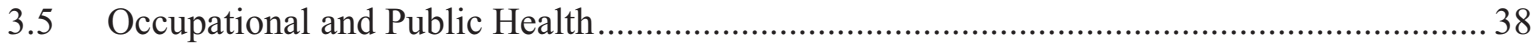

3.6 Projecting the Evolution of the Energy Balance …............................................................. 39

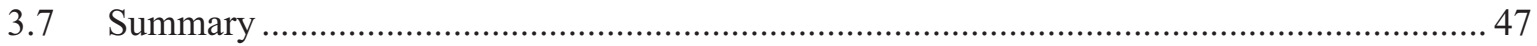

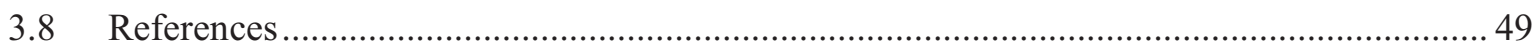

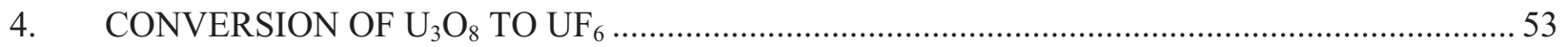

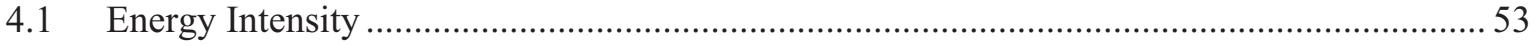

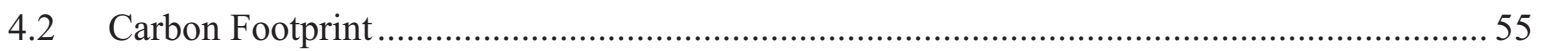

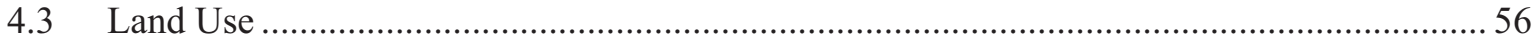

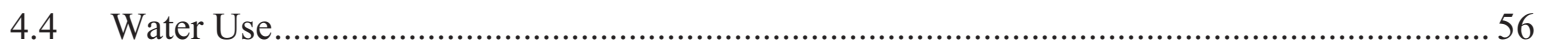

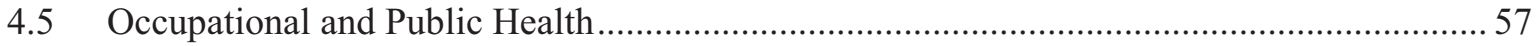

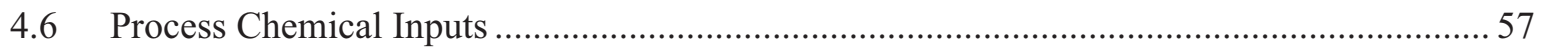

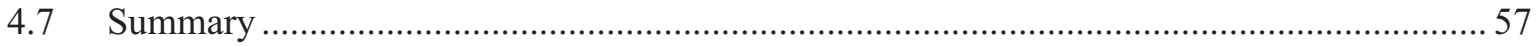

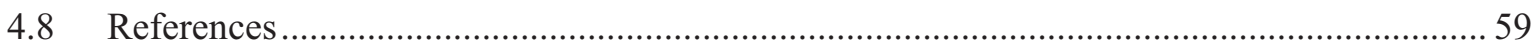

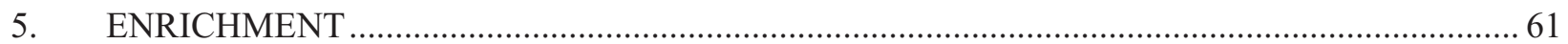

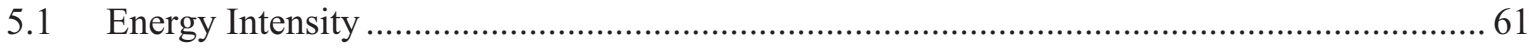

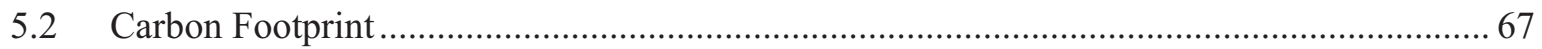

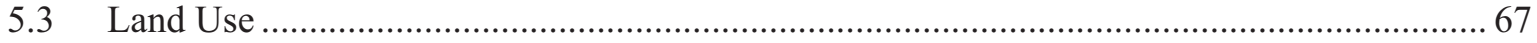

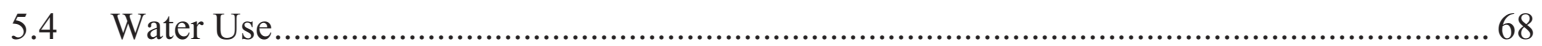

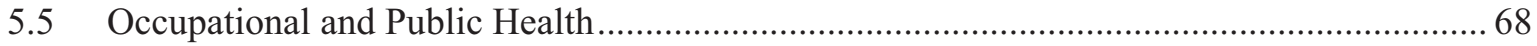




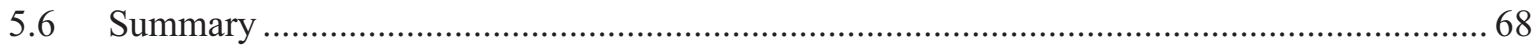

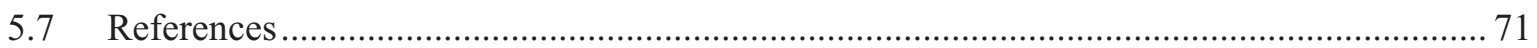

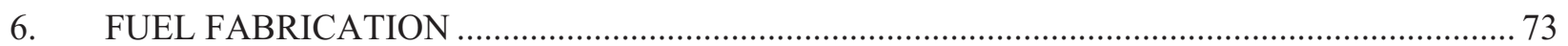

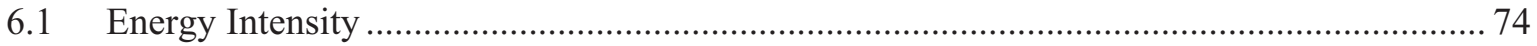

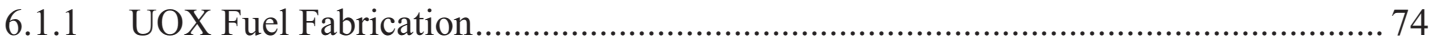

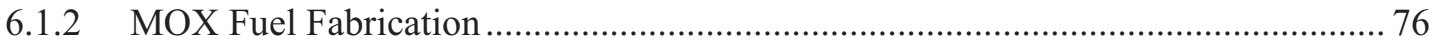

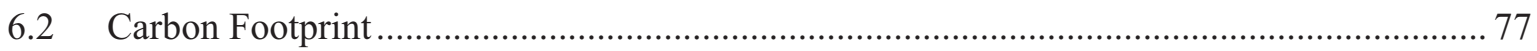

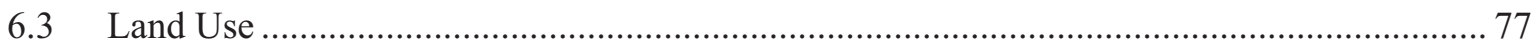

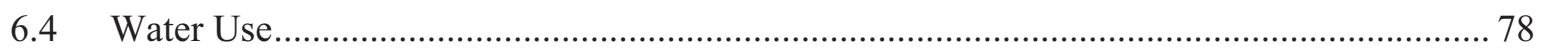

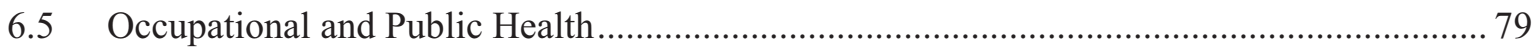

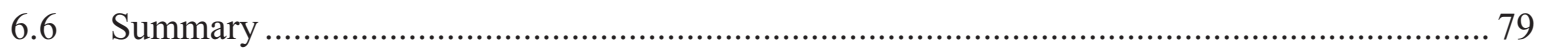

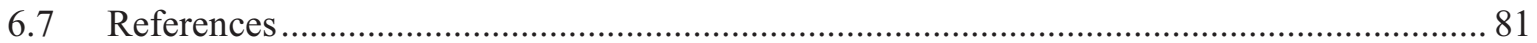

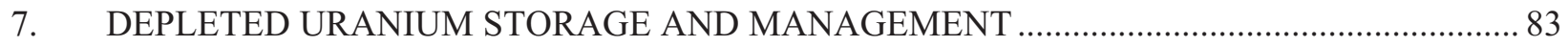

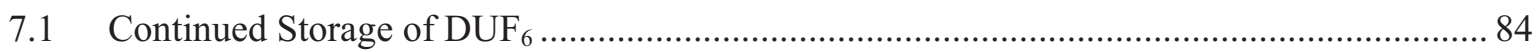

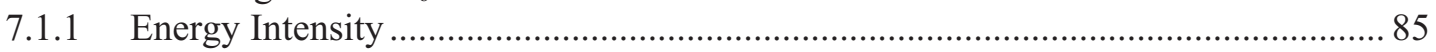

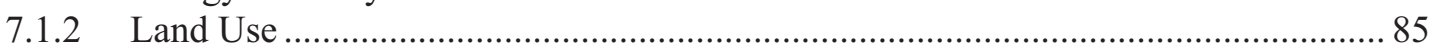

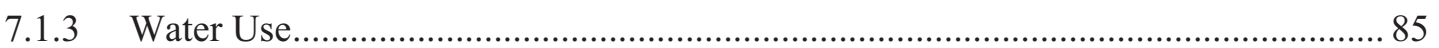

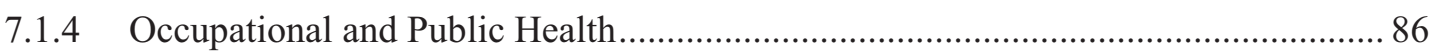

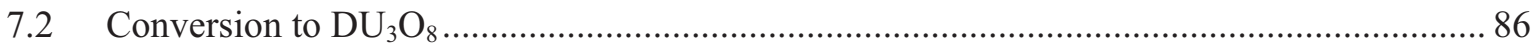

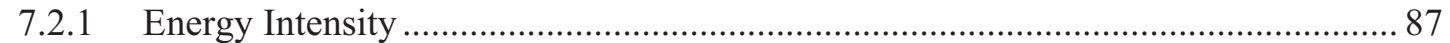

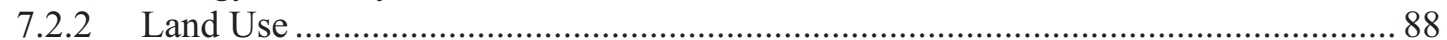

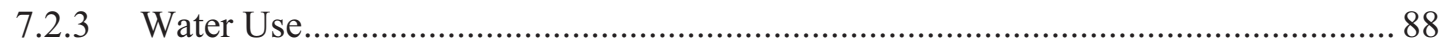

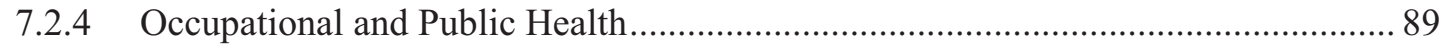

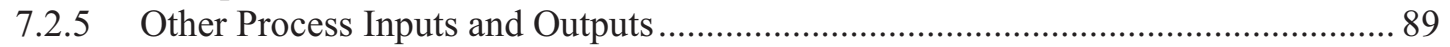

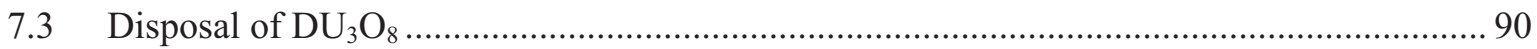

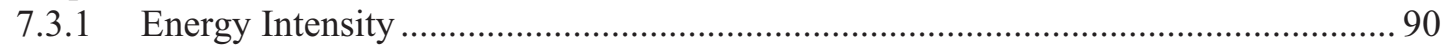

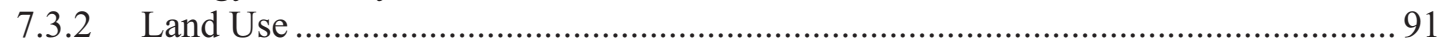

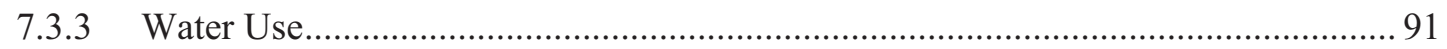

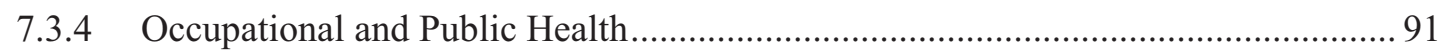

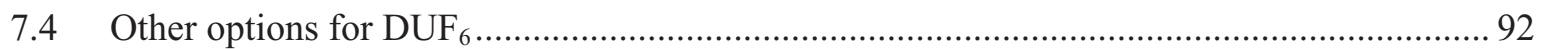

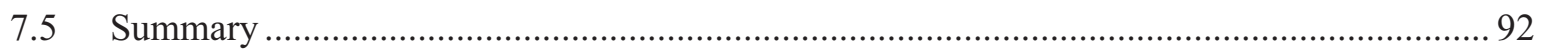

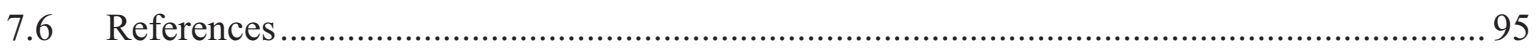

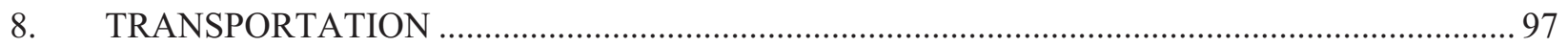

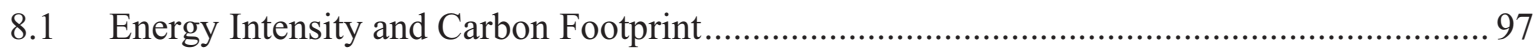

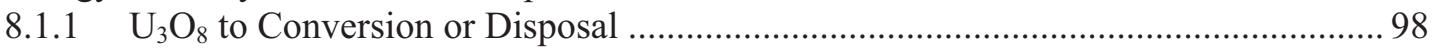

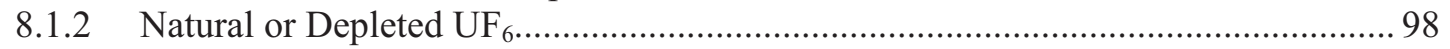

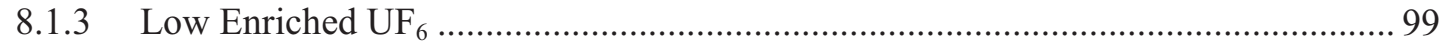

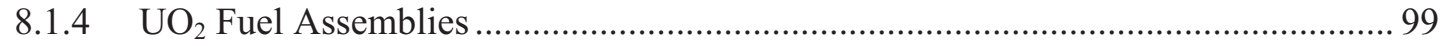

8.2 Occupational and Public Health................................................................................ 100

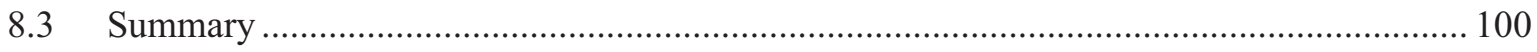

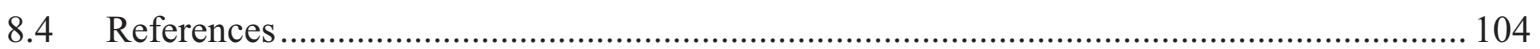

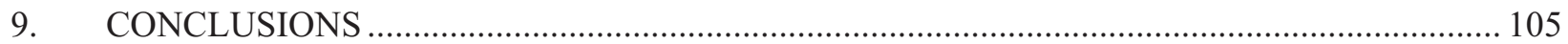




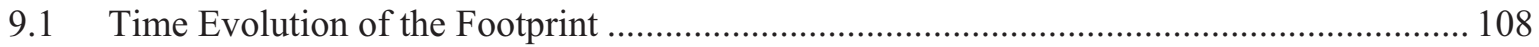

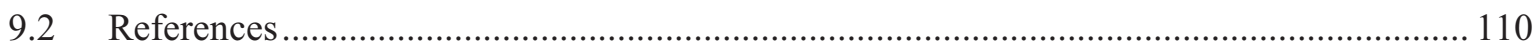

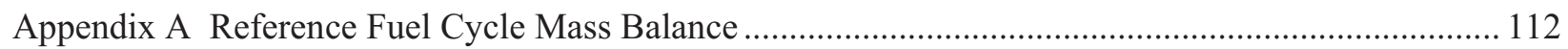

Appendix B Complete Listing of Uranium Mine and Mill Data ......................................................... 117

Appendix C Review of Energy Intensity Models for Uranium Mining, Milling and Refining.............. 123

\section{FIGURES}

Figure 1.1. Uranium mass flows and front-end technologies considered in this study........................ 2

Figure 3.1. Estimates of the carbon footprint of uranium mining, milling and refining. ..................... 10

Figure 3.2. Mass flows in uranium mining and beneficiation. After [Prasser 2008].........................11

Figure 3.3. Historical trend of mass-weighted average ore grade of mined uranium. Data

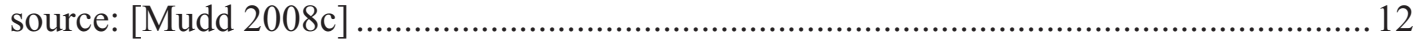

Figure 3.4. Milling yield $\mathrm{Y}$ [here shown in percent] correlated to ore grade $\left[\% \mathrm{U}_{3} \mathrm{O}_{8}\right]$. Figure: [Lenzen 2008]

Figure 3.5. Grade-to-energy models of Chapman (blue curves), Storm van Leewen (green curves) and Prasser (red curves) and data points for individual mines (Appendix C provides mathematical depictions of the three models shown)......................................... 15

Figure 3.6. Energy Consumption versus Ore Grade, Appendix B data.............................................. 16

Figure 3.7. Average energy consumption by operation, nine Canadian mines. Figure: [CIPEC 2005] 17

Figure 3.8. Energy consumption by mining/milling process step, US mineral mining industry. Figure: [EERE 2010].

Figure 3.9. Energy consumption by energy carrier in mining/milling, US mineral mining industry. Figure: [EERE 2010].

Figure 3.10. Relationship between mine and mill mass flows and top-down model terms for open pit mining

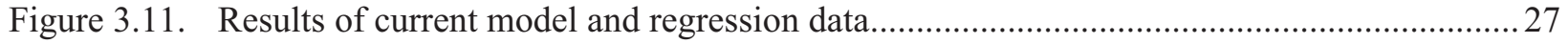

Figure 3.12. Energy consumption by energy carrier, Rossing (1999-2001 avg.).................................28

Figure 3.13. Carbon Emissions versus ore grade, all data mine-reported or independently estimated in [Mudd 2008b] 30

Figure 3.14. Carbon emissions, forecast versus data.......

Figure 3.15. Predicted correlation between carbon emissions and ore grade, mining technology mix according to 2009 breakdown, world-average emission coefficients (see Table 2.2)

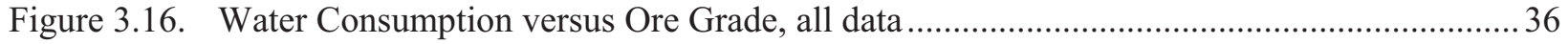

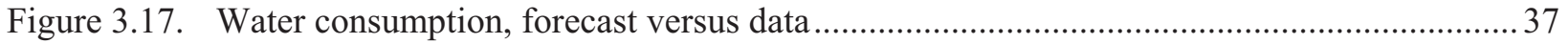

Figure 3.18. Water consumption forecast, results of current model................................................... 38 
Figure 3.19. Cumulative identified $U$ resources in the ground at or above the grade shown on the abscissa. Date source: [OECD 2008]

Figure 3.20. Identified uranium resources, in millions of tonnes, by extraction technology. Data source: [OECD 2008] 40

Figure 3.21. Deffeyes' projection of ore grade versus amount [Figure: Herring 2004]..... 42

Figure 3.22 Uranium supply curve estimates, taken from the literature, relying on Deffeyes' crustal model [Schneider 2005]

Figure 3.23. Projected average ore grade of mined uranium, $1.8 \%$ p.a. demand growth (top) and $3.2 \%$ p.a. demand growth (bottom)..... 44

Figure 3.24. Projected specific energy consumption associated with uranium mining, 1.8\% p.a. demand growth (top) and 3.2\% p.a. demand growth (bottom) ......................................... 46

Figure 4.1. Schematic representation of dry and wet processes for $\mathrm{UF}_{6}$ production............................54

Figure 4.2. Literature review of energy consumed from electrical (blue) thermal (grey) carriers

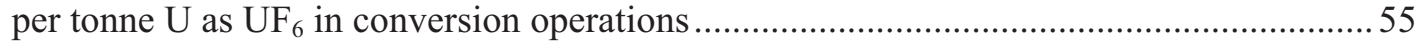

Figure 4.3. Estimates of $\mathrm{CO}_{2}$ emissions from $\mathrm{UF}_{6}$ conversion found in the literature .......................56

Figure 5.1. Urenco illustration of the Moore's Law behavior of enrichment technologies. Figure source: [Upson 2001].....

Figure 5.2. Moore's Law fit to surveyed estimates (red); comparison to Urenco operational data 2003-08

Figure 5.3. Moore's Law trend, extrapolation to the past (showing the earlier technology, diffusion) and future. Logarithmic scale. 66

Figure 5.4. Estimates of $\mathrm{CO}_{2}$ emissions from enrichment found in the literature. .67

Figure 6.1. Flow diagram of fuel fabrication process, showing points of energetic input and other major inputs/outputs. 74

Figure 6.2. Estimates of $\mathrm{CO}_{2}$ emissions from UOX fuel fabrication found in the literature.................77

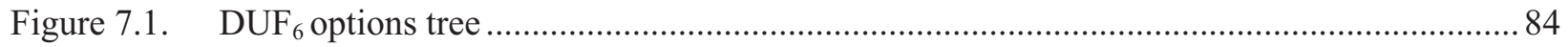

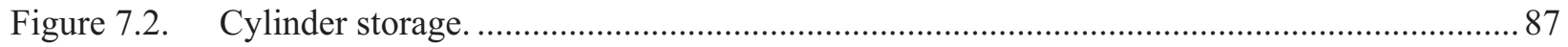

Figure 7.3. Carbon footprint of $\mathrm{DUF}_{6}$ deconversion and management - estimates from the literature 88

Figure 8.1. Transportation processes considered in this study ......................................................... 97

Figure A.1. Mass flows in the front end of the reference fuel cycle ................................................. 114

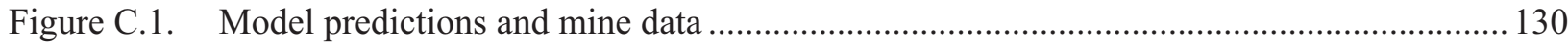




\section{TABLES}

Table Exec-1. Contemporary footprint measures normalized per MWh electricity produced..................iii

Table Exec-2. $\quad \mathrm{CO}_{2}$ emissions, 2050 scenarios ..............................................................................iv

Table 2.1. Distribution of collective doses from the French fuel cycle. Figure source:

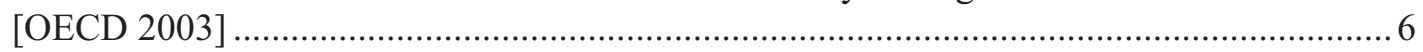

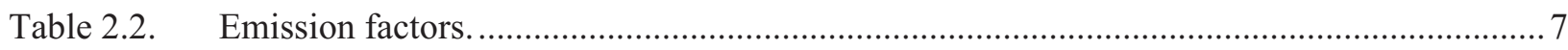

Table 2.3. Summary result of a recent survey of $\mathrm{CO}_{2}$ emissions arising from nuclear power

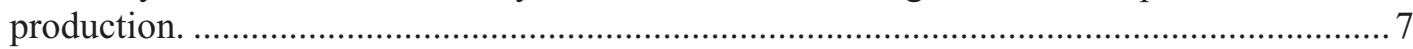

Table 2.4. Projection of $\mathrm{CO}_{2}$ emissions arising from the front end of the fuel cycle........................... 8

Table 3.1. Mining energy consumption, GJ(t+e), by carrier imputed from [EERE 2010] model

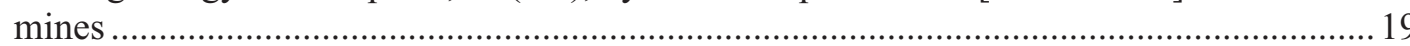

Table 3.2. Mine-reported thermal and electrical energy consumption breakdowns, uranium mining, milling and refining except where noted ........................................................ 20

Table 3.3. Imputed natural gas consumption breakdown at Beverley ..............................................2 21

Table 3.4. Energy consumption disaggregation employed in this study, by extraction

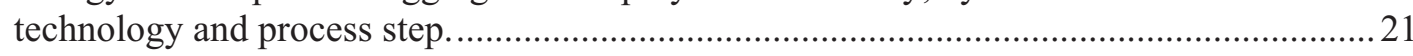

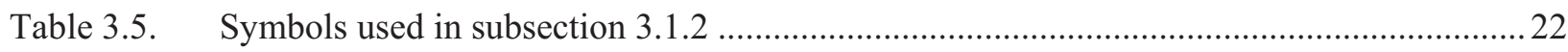

Table 3.6. Energy intensity coefficients obtained from regression analysis. ....................................2

Table 3.7. Comparison of uranium energy intensity coefficients to those reported in [CIPEC

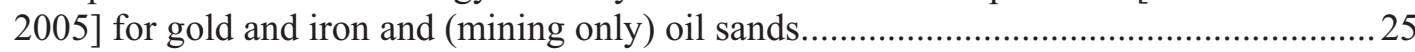

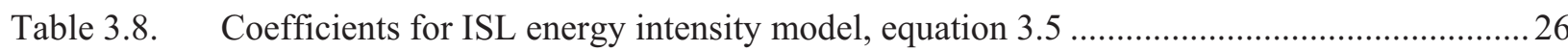

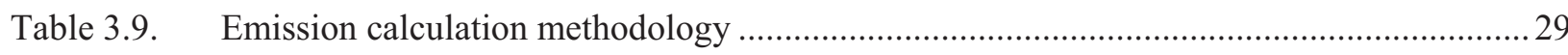

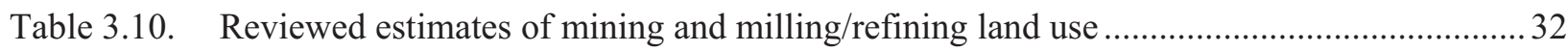

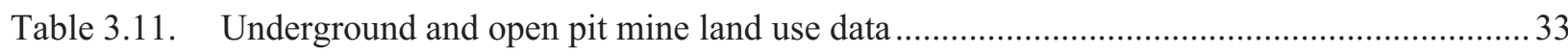

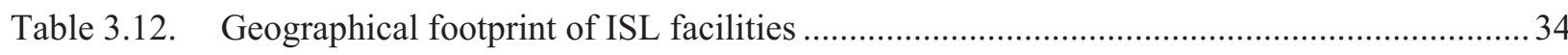

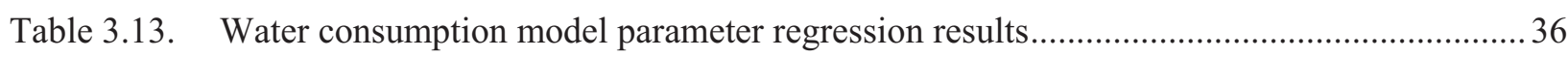

Table 3.14. Nearby member of the public dose estimates obtained from [Wise Uranium 2010] ...........39

Table 3.15. Summary of impacts resulting from contemporary mining, milling, and refining of one tonne natural uranium (based on ore grade, $\mathrm{G}=0.1 \%$ and Stripping Ratio, $\mathrm{S}=4$ ) ......... 48

Table 3.16. Roadmap to methodologies employed for estimating future impacts ................................ 48

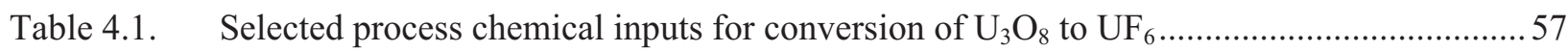

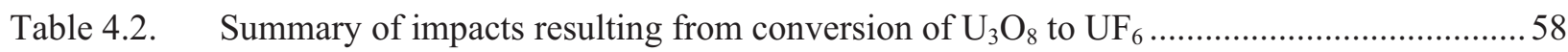

Table 5.1. Electricity consumption, gaseous diffusion, estimates from the literature..........................61

Table 5.2. Russian centrifuge performance by technology generation .............................................. 64

Table 5.3. Summary of impacts resulting from enrichment........................................................... 70

Table 6.1. Direct energy consumption, Japanese fuel fabrication complex, 1995-98 average .............75

Table 6.2. Water withdrawals at operating and planned fabrication facilities .................................. 78 
Table 6.3. Maximum annual worker doses and MEI public doses …................................................ 79

Table 6.4. Summary of impacts resulting from UOX and MOX fuel fabrication............................... 80

Table 7.1. Resource consumption over 40-year lifetime of a $\mathrm{DUF}_{6}$ storage yard for 4,683

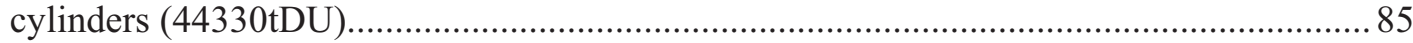

Table 7.2. Resource consumption for transfer of 4,683 cylinders $(44,330$ tDU) every 40 years........ 86

Table 7.3. DUF $_{6}$ deconversion facility operational parameters. Data from [Hartman 2004] ...............87

Table 7.4. Resource consumption for construction and operation of conversion facility with

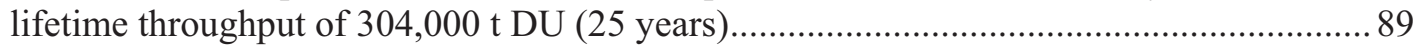

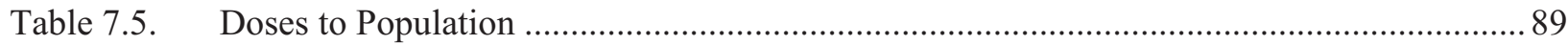

Table 7.6. Data for Paducah Conversion Facility processing 450,000 tDUF $_{6}(304,000$ tDU) ............ 90

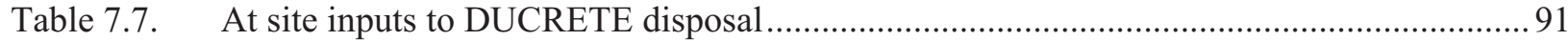

Table 7.8. Summary of impacts resulting from management of DU. ...............................................93

Table 8.1. Energy and $\mathrm{CO}_{2}$ per tonne per kilometer traveled ......................................................98

Table 8.2. $\quad \mathrm{U}_{3} \mathrm{O}_{8}$ transportation data, energy use, and carbon emissions ...........................................98

Table 8.4. $\quad$ LEUF $_{6}$ transportation data, energy use, and carbon emissions.......................................... 99

Table 8.5. $\quad \mathrm{UO}_{2}$ fuel assembly transportation data, energy use, and carbon emissions........................99

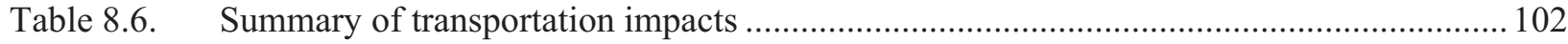

Table 9.1. Environmental footprint measures normalized to 1 tonne of extracted U........................105

Table 9.2. Energy consumption per unit electricity produced …...................................................... 106

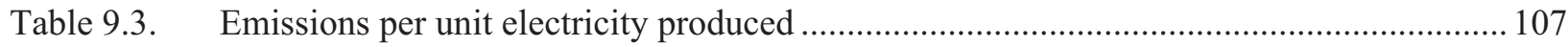

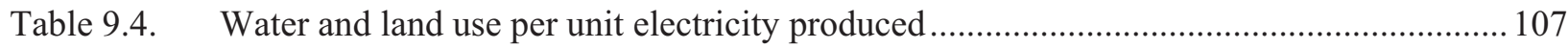

Table 9.5. Cumulative dose per unit electricity produced.............................................................. 108

Table 9.7. $\quad \mathrm{CO}_{2}$ emission time dependencies, 2050 emissions scenario …........................................ 109

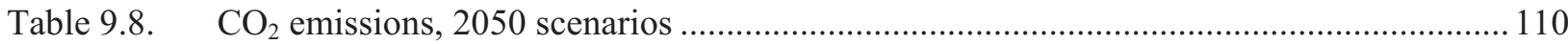

Table 9.9. Emissions, 2050 scenarios, normalized to 1 tonne of extracted U ................................. 110

Table A.1 Parameters of the reference fuel cycle ............................................................................ 113

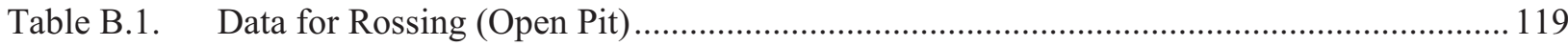

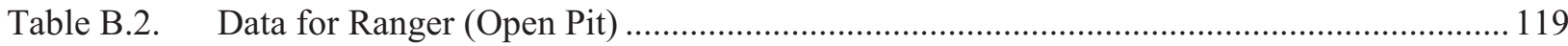

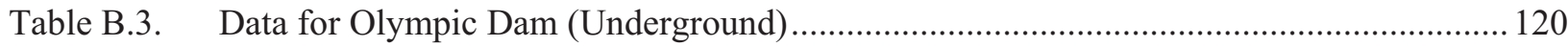

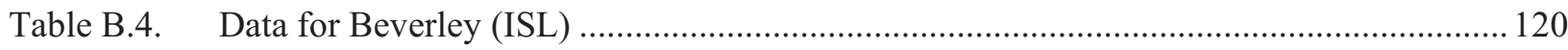

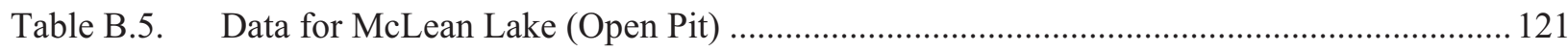

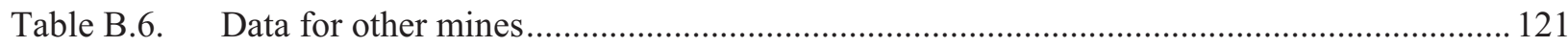

Table C.1. Quantities used in models reviewed in this appendix ................................................... 125

Table C.2. Coefficients of Chapman model (equation C.1) ............................................................. 127

Table C.3. Model coefficients for Equation C.3 …........................................................................... 128 
Table C.4. Regression coefficients reported in [Prasser 2008] ....................................................... 129 


\section{ACRONYMS}

ALARA as low as reasonably achievable

DU depleted uranium

EIS Environmental Impact Statement

GJ(e) Giga Joules Electric

GJ(t) Giga Joules Thermal

ha hectares

HEU high-enriched uranium

HF hydrofluoric acid

ISL In-situ leaching

ISO International Standards Organization

$\mathrm{J}(\mathrm{e}) \quad$ Joules(electric)

$\mathrm{J}(\mathrm{t}) \quad$ Joules(thermal)

kWh(e) kilowatt hours electric

LCA life cycle assessment

LLW low-level waste

LLWMU Low-Level Waste Management Unit

LWRs light water reactors

MEI maximally exposed individual

MOX mixed oxide

mrem millirem

MTW Metropolis Works (Uranium Conversion Faciltiy)

MWh(e) Megawatt hours electric

NEMS National Energy Modeling System

NRC Nuclear Regulatory Commission

OP open pit

RCRA Resource Conservation and Recovery Act

SWU separative work unit

tU tones Uranium

UG underground 
This page intentionally left blank. 


\section{MEASURES OF THE ENVIRONMENTAL FOOTPRINT OF THE FRONT END OF THE NUCLEAR FUEL CYCLE}

\section{INTRODUCTION}

Electricity generation costs have traditionally provided the most important measure of comparison between generation technologies. Yet monetary cost alone does not thoroughly depict the full environmental and societal impact associated with electricity production. Some resources are utilized by energy producers and consumers at no direct cost, but society may ultimately pay a price for their nonsustainable use.

One example is the atmospheric repository of carbon dioxide and other greenhouse gases. Although the complexity of the planetary ecosystem precludes a consensus on the cost that society will eventually bear for our collective use of this resource, the Intergovernmental Panel on Climate Change lists a number of impacts, including effects on water resources, crop yields and energy demand patterns as "virtually certain." [IPCC 2007]

Greenhouse gas emissions are one of several impacts that are difficult to incorporate into traditional economic analyses because their costs often cannot be quantified in monetary terms. Moreover, costs associated with environmental protection (e.g., waste storage and disposal, site reclamation) may be internalized for certain technologies but not for others.

Governments, including that of the United States, have recognized the importance of quantifying these indirect and external impacts. When the environmental effects of a project are likely to be significant, the National Energy Policy Act (1970) requires an Environmental Impact Statement (EIS) to be prepared and submitted for public review. In addition to direct effects, the EIS must address "changes in the pattern of land use and... effects on air and water" as well as "effects on natural resources... or health." [NEPA 1970] The NEPA guidelines therefore suggest that energy consumption, carbon footprint, water consumption, land use and public health impact together provide a reasonable measure of the environmental 'footprint' of a technology. Each of these measures is addressed within this report.

\subsection{Objective}

The objective of this study is to quantify this footprint for the front end processes of the nuclear fuel cycle. The front end processes include

- uranium mining, milling and refining,

- conversion of yellowcake to uranium hexafluoride,

- enrichment,

- management and/or disposal of depleted uranium,

- fuel fabrication, and

- transportation associated with the flow of materials through the front end facilities.

The study is forward-looking. Along with present-day conditions, the time evolution of the footprint is also addressed. While the processes comprising the front end of the fuel cycle are all built upon mature technologies that operate at industrial scales, the footprint of one or more processes is likely to evolve with time. For example, although centrifuge technology is not new, it has evolved through successive technology generations, each one offering better economic performance and, by some measures, a reduced environmental footprint. Entirely new technologies may also emerge for other front-end processes. Past examples include in-situ and heap leaching for uranium production, neither of which were 
in wide use as recently as the 1970s. A future example may be laser-based enrichment which, after being investigated at the laboratory scale for decades, is now moving toward commercial-scale operation.

Uranium production offers another example of the time evolution of the environmental footprint. As higher-grade and easier-to-mine uranium deposits are extracted, production will move to less economically attractive resources. Generally these deposits are associated with lower-grade or less accessible ore bodies - from which extraction and refinement of uranium is more energy-intensive.

The fuel cycle processes, along with the technology options considered for each and the flow of uranium between them, are shown in Figure 1.1. The environmental impacts for each process will be identified and normalized to a unit of uranium throughput along with the impacts of transportation between each of the process steps.

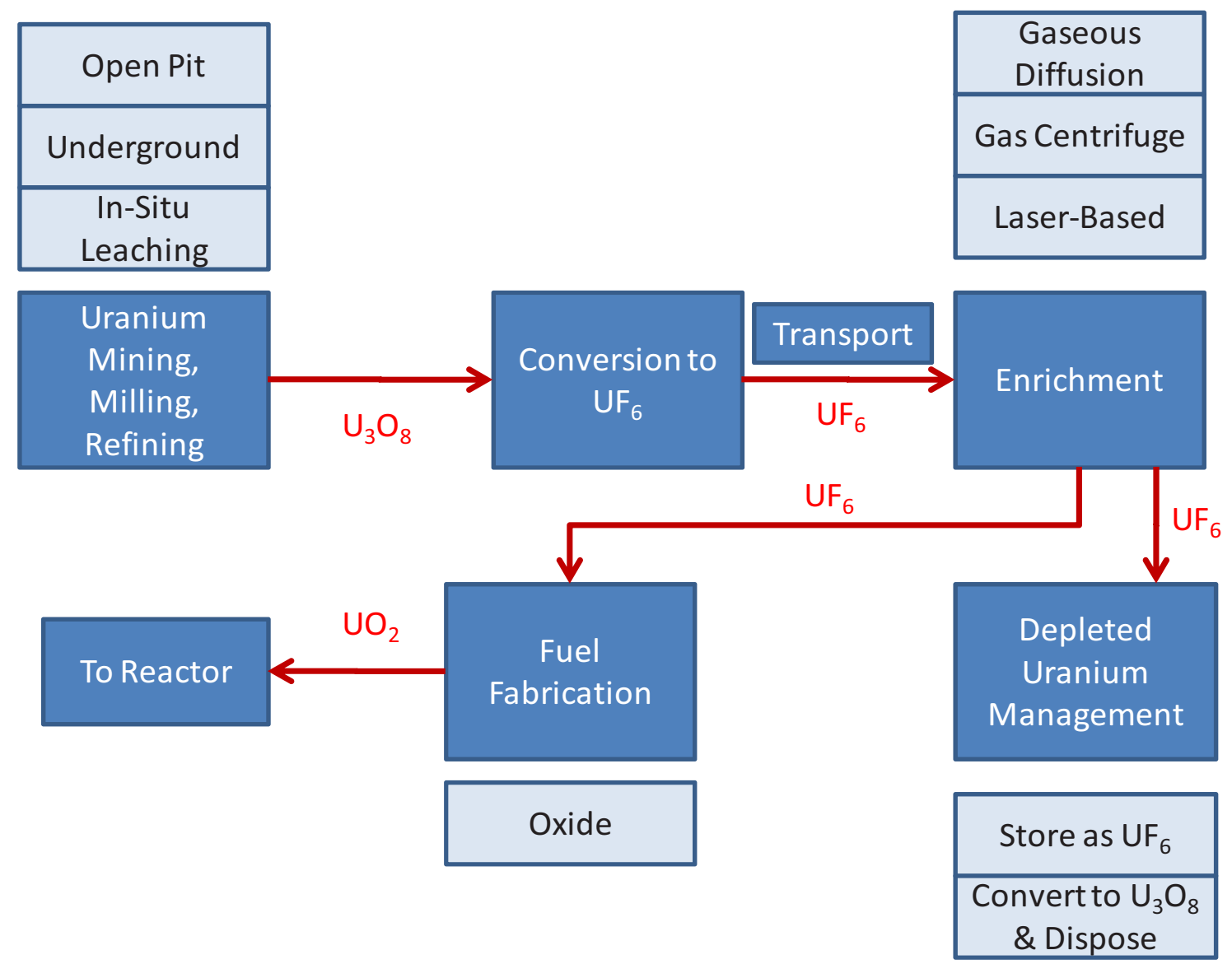

Figure 1.1. Uranium mass flows and front-end technologies considered in this study. 
For each process the following operational metrics are obtained:

- direct energy consumption [GJ/unit of throughput],

- carbon footprint from direct energy consumption [tonnes $\mathrm{CO}_{2}\left(\mathrm{tCO}_{2}\right) /$ unit of throughput],

- water withdrawal [ $\mathrm{L} \mathrm{H}_{2} \mathrm{O}$ /unit of throughput],

- land transformation [ $\mathrm{m}^{2} / \mathrm{unit}$ of throughput],

- maximum worker and public dose [mrem/year], and

- time- and population-integrated occupational and public dose [person-rem].

The metrics are compiled in summary tables at the end of each chapter. In the tables, direct energy consumption is disaggregated into electrical and thermal components. Thermal energy consumption is further broken up according to carrier: liquid fuels, i.e. diesel and other liquid hydrocarbons, are reported separately from other thermal carriers (e.g. coal, natural gas) that are predominantly employed for process heat generation.

\subsection{Report Organization}

This report is structured as follows. Section 2 provides a brief survey of the study scope and methodologies. Sections 3 through 7 apply inventory analysis techniques to estimate the environmental footprint of the technology options considered for each of the processes during their operations. Section 8 assesses the impacts of the transportation between each process step. And Section 9 provides conclusions and recommendations for further study. Mass balance calculations associated with the reference cycle used to relate process mass flows to nuclear electricity production, uranium mine and mill operating data sets, and reviews of other approaches to deriving the ore grade dependence of the energy intensity of uranium mining and milling are provided in Appendices A, B, and C, respectively.

\subsection{References}

[IPCC 2007] United Nations Intergovernmental Panel on Climate Change, "IPCC Fourth Synthesis Report, Climate Change 2007,” 2007.

[NEPA 1970] National Environmental Policy Act of 1969, as amended, 42 USC sections 4321-4337, available: www.nepa.gov . Wepbage accessed May 29, 2010. 


\section{SCOPE AND METHODOLOGY}

This study begins the inventory analysis component of a life cycle assessment (LCA) of the environmental impacts associated with nuclear electricity production. Life cycle assessment refers to a cradle-to-grave approach to the accounting of impacts from the raw material extraction, through production, and disposal stages of the life cycle for any product. The inventory analysis component of an LCA is described by the World Energy Council as "the process of quantifying the energy and raw material requirements, atmospheric emissions, waterborne emissions, solid wastes and other releases for the entire life cycle of a product, process or activity." [WEC 2004] Standards for conducting an LCA are outlined by the International Standards Organization (ISO) [ISO 1997]; these are in turn based on approaches defined by the US Environmental Protection Agency [EPA 1993].

A holistic life cycle assessment would also include the energy and other environmentally-related inputs to the industries supporting the production of the good. As examples, sulfuric acid and other chemicals consumed in uranium milling, cement utilized in plant construction, and distillate vehicle fuel employed to drive equipment at a uranium mine all contain embodied energy. Embodied energy is the energy utilized to manufacture the products and equipment that serve as an input to the production of another good. A full LCA would also consider impacts resulting from construction and decommissioning. .

Although other material inputs that contain significant embodied energy will also be identified and discussed, a full accounting for embodied energy, without omissions or double-counting of commodities, would require an integrated analysis of the energy and industrial sectors of the economy. Only a handful of modeling platforms incorporate the extensive input/output and inventory analyses that are required to achieve this level of completeness. Examples of such efforts include the ExternE project in Europe [EC 1995] and the National Energy Modeling System (NEMS) used by the Energy Information Administration to forecast energy consumption in the United States [EIA 2010a]. Therefore, the scope of this study is restricted to inventory analysis of commodities - materials and energy carriers - resulting from activities performed within the plant gates.

\subsection{General Methodology}

The general assessment methodology for each factor begins with a process mass flow analysis. The preferred data source for each technology is operating data reported by actual operating facilities. If this is not available, projections taken from facility engineering design studies are used. Such projections are typically documented in Environmental Impact Statements or their international equivalents. If neither operational nor industrial-scale design-based data are available, conceptual design level studies that base estimates upon simpler depictions of the technology are used. Secondary sources are used only when no primary data can be found.

Energy consumption as reported here therefore does not include the embodied energy of commodities such as the aforementioned process chemicals, cement, or fuel. It does include the thermal energy liberated when the fuel is combusted as well as the electrical energy transmitted into the site. While the embodied energy of the process chemicals and cement are not quantified, these and other commodities are identified, in terms of mass or volume units of the commodity per mass unit of throughput, for each process. Electrical transmission losses are not accounted for; these may vary from near zero (when electricity is generated on site or in immediately proximate facilities) to ten percent of generated electricity or more.

Land use is reported in units of square meters of land transformed per unit of throughput. Choice of this unit implies that land utilization is cumulative in the same sense as energy consumption or carbon release. It would also be possible to report land use in different units such as square meters of land occupied per unit of annual throughput capacity. This subtle change would imply that land is a fully renewable 
resource returned to its undisturbed state at some time after the capacity is retired. This measure would be meaningful only if weighted with the duration that the land was unavailable for other uses and the costs/impacts of reclamation were counted. The reality depends on the process being considered: land committed to permanent disposal of depleted uranium (DU) is essentially permanently committed, while land occupied by a uranium mine or temporary DU storage facility may be turned to other uses over a relatively short time span. Cumulative land transformation is here chosen as the more conservative measure.

A similar complication arises when water withdrawals are considered. Net water consumption may provide a more accurate depiction of local water balance impacts, as it takes into account only the water that is not treated to acceptable standards and recycled to local sources. Yet this metric is strongly affected by the strength of individual plants' water recycling programs, which are in turn governed by local conditions. Gross water withdrawals are therefore chosen as the more conservative metric with the understanding that net removal may be much lower. To provide context for the land and water use estimates, values from one water and two land use studies surveying the FEFC are reviewed in each section. As these studies rely upon sources that are at least twenty-five years old ([USAEC 1974] for [Gerbens-Leenes 2008], [DOE 1983] for [Fthenakis 2009] and [Nero 1979] for [USGS 1997]), they are not used to formulate the estimates put forth in this document unless no primary data can be found.

Land and water use are based on operational facilities and processes. The environmental and health consequences of poorly remediated mine and mill sites as well as the consequences of accidents during and after their operational period have been the subject of extensive study. Nonexistent and/or poorly enforced in the early days of the uranium industry, remediation practices are today extensively regulated in order to ensure that overburden, mill tailings and other potentially radioactive materials are isolated from the biosphere and to prevent degradation of water supplies. Impacts resulting from noncompliant or accident conditions are beyond the scope of this study.

Maximum annual worker and public doses are chosen as one occupational and public health metric. It would be misleading to normalize dose exposure to unit of throughput because the distribution of doses among individuals, the critical safety metric, would be obscured. The Nuclear Regulatory Commission (NRC) regulates the occupational and public health doses in the US established in 10 CFR part 20. These limits establish 100 millirem (mrem) per year as the dose equivalent limit to members of the public. The occupational dose limit is the more restrictive of either 5,000 mrem/year total effective dose or $50,000 \mathrm{mrem} / \mathrm{year}$ to an individual organ or tissue. Nuclear facilities in the US are required to report maximum worker doses as well as estimated doses to the maximally exposed individual (MEI) amongst the general public. These reports, taken from Environmental Assessments and EISs, serve as a primary source here. They represent a conservative limit on the dose exposure, as facilities are also required by law to follow ALARA (as low as reasonably achievable) practices that limit doses to most workers to well below reported values.

The maximum dose metric suffers from two flaws. First, it may be more strongly affected by regulatory limits and ALARA goals than the nature of the radioisotope handling involved. Second, it does not scale with process throughput. An alternative measure is the collective dose in person-rem/unit of throughput. The collective dose is defined as the dose received by all members of a group (occupational or the public) summed over time. Therefore it captures not only immediate exposure but also time-delayed effects such as those that might be associated with radioisotope release from uranium mill tailings. This metric also has a disadvantage: it provides no information about how the dose is distributed among recipients. Therefore, on its own it is not well-suited for determining health risks. Therefore, both the maximum annual dose and the collective dose are retained as metrics.

Employment of the collective dose metric is complicated by lack of primary data. Proposed US facilities are required to report annual collective doses (person-rem/year) in EISs, and operating facilities must report all measurable occupational doses, but even supplemented by international data these were not seen 
to lead to a primary data set that adhered to uniform reporting standards. Therefore, collective dose estimates obtained under a modeling activity sponsored by the ExternE project [EC 1995] will be used as the sole source of collective dose estimates in this report. Given a unified set of conditions and dose pathway criteria, the ExternE dose assessment effort constructed detailed numerical models of direct, airborne and waterborne dose pathways associated with all stages in the French fuel cycle.

The ExternE collective doses are not generic but rather tied to specific fuel cycle facilities within France, and the ExternE database does not map perfectly to the process technology depictions in this report (for example, enrichment doses considered only the existing French diffusion plant as a reference). Reference facilities, along with gaps and discrepancies with respect to the current study, will be identified in the report sections dealing with the individual technologies. Table 2.1 summarizes the main findings of the ExternE study across the entire fuel cycle, which features reprocessing (MOX use was not included). Note that the authors chose to normalize doses on a per-TWh(e) of nuclear electricity basis, so the ExternE results will be renormalized to a per-mass basis to achieve consistency with the other metrics.

Table 2.1. Distribution of collective doses from the French fuel cycle. Figure source: [OECD 2003]

\begin{tabular}{lccc}
\hline & \multicolumn{3}{c}{ Collective dose (man.Sv/TWh) } \\
\cline { 2 - 4 } \multicolumn{1}{c}{ Fuel Cycle Stage } & Public & Occupational & Total \\
Mining and Milling & $1.77 \mathrm{E}-01(1 \%)$ & $1.12 \mathrm{E}-01(32 \%)$ & $2.89 \mathrm{E}-01(2 \%)$ \\
Conversion & $3.50 \mathrm{E}-05(0 \%)$ & $2.29 \mathrm{E}-03(1 \%)$ & $2.32 \mathrm{E}-03(0 \%)$ \\
Enrichment & $2.68 \mathrm{E}-05(0 \%)$ & $8.33 \mathrm{E}-06(0 \%)$ & $3.52 \mathrm{E}-05(0 \%)$ \\
Fuel fabrication & $9.21 \mathrm{E}-06(0 \%)$ & $7.14 \mathrm{E}-03(2 \%)$ & $7.15 \mathrm{E}-03(0 \%)$ \\
Electricity generation & $2.16(17 \%)$ & $2.02 \mathrm{E}-01(58 \%)$ & $2.36(18 \%)$ \\
Decommissioning & $1.45 \mathrm{E}-04(0 \%)$ & $2.16 \mathrm{E}-02(6 \%)$ & $2.17 \mathrm{E}-02(0 \%)$ \\
Reprocessing & $1.03 \mathrm{E}+01(80 \%)$ & $1.76 \mathrm{E}-03(1 \%)$ & $1.03 \mathrm{E}+1(79 \%)$ \\
LLW disposal & $2.57 \mathrm{E}-02(0 \%)$ & $1.00 \mathrm{E}-04(0 \%)$ & $2.58 \mathrm{E}-02(0 \%)$ \\
HLW disposal & $1.36 \mathrm{E}-01(1 \%)$ & $6.00 \mathrm{E}-07(0 \%)$ & $1.36 \mathrm{E}-01(1 \%)$ \\
Transportation & $9.50 \mathrm{E}-04(0 \%)$ & $1.14 \mathrm{E}-03(0 \%)$ & $2.09 \mathrm{E}-03(0 \%)$ \\
Total & $\mathbf{1 . 2 8 E}+\mathbf{0 1}(\mathbf{1 0 0} \%)$ & $\mathbf{3 . 4 8 E}-01(\mathbf{1 0 0} \%)$ & $\mathbf{1 . 3 1 E}+\mathbf{0 1}(\mathbf{1 0 0} \%)$ \\
\hline
\end{tabular}

\subsection{The Front End Carbon Footprint: Methods and Review of Studies}

Nuclear power has been presented as both a solution to the problem of carbon emissions from electricity generation and as part of the problem. One author [Jacobson 2009] has claimed that "nuclear power results in up to 25 times more carbon emissions than wind energy, when reactor construction and uranium refining and transport are considered." The study [Storm van Leewen 2007] on which Jacobson partly based his conclusion has been strongly contested by industry experts (e.g. [WNA 2009]), but the fact remains that published works advance claims spanning multiple orders of magnitude.

The situation is emblematic of the imprecision that remains in the science of carbon footprint estimation. In this study, the carbon footprint for each process is derived from its direct energy consumption. When available, carbon emission data from other sources are used to validate or confirm the derived results. Therefore, the carbon emissions per unit throughput are obtained through a two-step calculation:

- Identify energy carrier (electricity, liquid fuel, process heat) inputs to each front-end process step,

- Apply emission factors $\mathrm{kg} \mathrm{CO}_{2} / \mathrm{GJ}($ thermal) or (electric) $]\left(\left[\mathrm{kg} \mathrm{CO}_{2} / \mathrm{GJ}(\mathrm{t})\right.\right.$ or (e) $\left.]\right)$ for each energy carrier. 
The emission factors are taken from data published by the Energy Information Administration for the fossil fuels and domestic electricity generators [EIA 2010b] and from [CARMA 2010] for foreign and world-average electricity generation. All factors employed in this study are given in Table 2.2.

Table 2.2. Emission factors.

\begin{tabular}{lrc}
\hline \multicolumn{1}{c}{ Carrier } & Factor & \multicolumn{1}{c}{$\mathrm{Unit}$} \\
\hline Gasoline $^{\mathrm{a}}$ & 68 & $\mathrm{~kg} \mathrm{CO}_{2} / \mathrm{GJ}(\mathrm{t})$ \\
Distillate Fuel $^{\mathrm{a}}$ & 79 & $\mathrm{~kg} \mathrm{CO}_{2} / \mathrm{GJ}(\mathrm{t})$ \\
Coal - Industrial Coking & 89 & $\mathrm{~kg} \mathrm{CO}_{2} / \mathrm{GJ}(\mathrm{t})$ \\
Natural Gas $^{\mathrm{a}}$ & 51 & $\mathrm{~kg} \mathrm{CO}_{2} / \mathrm{GJ}(\mathrm{t})$ \\
& & \\
Coal - fired electricity (US avg) & 272 & $\mathrm{~kg} \mathrm{CO}_{2} / \mathrm{GJ}(\mathrm{e})$ \\
Natural Gas fired elec. (US avg) & 114 & $\mathrm{~kg} \mathrm{CO}_{2} / \mathrm{GJ}(\mathrm{e})$ \\
Electricity - US Grid Average & 168 & $\mathrm{~kg} \mathrm{CO}_{2} / \mathrm{GJ}(\mathrm{e})$ \\
Electricity - Canada Grid Average & 59 & $\mathrm{~kg} \mathrm{CO}_{2} / \mathrm{GJ}(\mathrm{e})$ \\
Electricity - Australia Grid Avg & 248 & $\mathrm{~kg} \mathrm{CO}_{2} / \mathrm{GJ}(\mathrm{e})$ \\
Electricity - World Average & 153 & $\mathrm{~kg} \mathrm{CO}_{2} / \mathrm{GJ}(\mathrm{e})$ \\
\hline a. Used to compute process emissions for summary tables within this document. \\
\hline
\end{tabular}

Most carbon footprint estimates in the literature normalize the emissions against the electricity produced from the processed material. Therefore, assumptions regarding the fuel cycle mass balance - tailings and fuel enrichment, fuel burnup achieved in reactors - affect the results. Further, energy consumption and carbon accounting methods differ between studies and are sometimes not transparently defined. Varying treatments of embodied energy as well as energy inputs to construction and decommissioning also contribute to considerable disagreement among estimates of the carbon footprint of nuclear energy.

Indeed, a recent and exhaustive review [Sovacool 2008] identified vast disagreement - orders of magnitude - between past carbon footprint assessments (Table 2.3). The footprint is clearly strongly affected by front-end processes, in particular uranium mining, milling and enrichment. For example, uranium extraction becomes increasingly energy-intensive at lower ore grades, and ore grade assumptions vary between studies. Enrichment technologies are also substantial energy consumers. Centrifuges are about an order of magnitude less energy-intensive than enrichment by gaseous diffusion. Approaches relying upon laser-induced molecular excitation might further reduce energy consumption, and hence emissions. Individual studies assume differing mixes of these three enrichment technologies.

Table 2.3. Summary result of a recent survey of $\mathrm{CO}_{2}$ emissions arising from nuclear power production.

\begin{tabular}{lcccccc}
\hline \multicolumn{1}{r}{$\mathrm{MWh}_{2} /$} & & & & & & \\
Min & Frontend & Construction & Operation & Backend & Decommissioning & Total \\
Max & 0.68 & 0.27 & 0.1 & 0.4 & 0.01 & 1.36 \\
Mean & 118 & 35 & 40 & 40.75 & 54.5 & 288.25 \\
$\%$ of total & 25.1 & 8.20 & 11.6 & 9.2 & 12.0 & 66.1 \\
$\mathrm{~N}$ & $38 \%$ & $12 \%$ & $18 \%$ & $14 \%$ & $18 \%$ & $100 \%$ \\
\hline
\end{tabular}


Table 2.4 shows a breakdown of the $\mathrm{CO}_{2}$ production in each front end step presented by [Storm van Leewen 2005]. It is included here because it produces estimates that are consistently in the uppermost tier of the studies surveyed in [Sovacool 2008] and is often cited in literature emphasizing the $\mathrm{CO}_{2}$ footprint of nuclear energy. It is also useful in that it illuminates a number of steps in the fuel cycle that are omitted in many other studies. This report addresses each of these steps. Specific points where the Storm van Leewen estimates do not align with primary data from operating facilities are identified.

Table 2.4. Projection of $\mathrm{CO}_{2}$ emissions arising from the front end of the fuel cycle.

\begin{tabular}{lc}
\hline \multicolumn{1}{c}{ Process } & Estimate $\left[\mathrm{kg} \mathrm{CO}_{2} / \mathrm{MWh}(\mathrm{e})\right]$ \\
\hline Uranium mining and milling & 10.43 \\
Yellowcake refining and $\mathrm{UF}_{6}$ conversion & $2.42-7.49$ \\
Enrichment (70\% centrifuge, 30\% diffusion) & $2.83-8.03$ \\
Fuel Fabrication & $0.58-2.32$ \\
Depleted uranium reconversion and sequestration & $2.22-6.59$ \\
\hline
\end{tabular}

Although indirect energy embodied in process inputs and energy associated with construction, decommissioning and remediation of fuel cycle facilities are outside the scope of this report, it is useful to review the results of an earlier life cycle analysis that considered them. Table 2.5 depicts aggregate (thermal plus electrical) direct, embodied and construction/decommissioning energy consumption for the front end steps addressed in [Rotty 1975] ${ }^{\text {a }}$. That study identified the largest embodied energy carriers as explosives and process chemicals used in uranium recovery and the zircaloy cladding input to oxide fuel fabrication. According to [Rotty 1975], the latter dominates the life cycle energy inputs to the fabrication step. Energy inputs to decommissioning were most significant in the context of mine and mill site remediation. Note that [Rotty 1975] did not consider DU management or centrifuge enrichment.

One systematic difference that gives rise to generally lower direct process energy consumption estimates in this study is the higher PWR fuel burnup used here: $51 \mathrm{MWd}(\mathrm{t}) / \mathrm{kgIHM}$ versus $30 \mathrm{MWd}(\mathrm{t}) / \mathrm{kgIHM}$.in [Rotty 1975]. Numerous other variations in assumptions exist between the studies; these range from the enrichment of DU tails used at the centrifuge plant to distance associated with each transportation process to grade of ore extracted at mines. Generally, they reflect conditions in 2010 versus those of the early 1970s.

Table 2.5. Energy consumption per unit electricity produced, $\mathrm{GJ}(\mathrm{t}+\mathrm{e}) / \mathrm{MWh}(\mathrm{e})$, comparison of current study to [Rotty 1975]

\begin{tabular}{l|cccc}
\multicolumn{1}{c|}{ Technology } & \multicolumn{4}{|c}{ [Rotty 1975] } \\
\hline & Direct & Embodied & $\begin{array}{c}\text { Construction \& } \\
\text { Decommissioning }\end{array}$ & Total \\
\hline Uranium Extraction* & $2.0 \times 10^{-2}$ & $1.0 \times 10^{-2}$ & $4.4 \times 10^{-3}$ & $3.5 \times 10^{-2}$ \\
Conversion to UF 6 & $3.7 \times 10^{-2}$ & $3.6 \times 10^{-3}$ & $2.3 \times 10^{-4}$ & $4.1 \times 10^{-2}$ \\
Diffusion Enrichment & $1.7 \times 10^{-1}$ & $2.7 \times 10^{-3}$ & $6.0 \times 10^{-3}$ & $1.8 \times 10^{-1}$ \\
Fuel Fabrication & $2.4 \times 10^{-3}$ & $1.3 \times 10^{-2}$ & $1.8 \times 10^{-4}$ & $1.6 \times 10^{-2}$ \\
(UOX) & $4.3 \times 10^{-4}$ & $3.5 \times 10^{-4}$ & $\mathrm{NA}$ & $7.8 \times 10^{-4}$ \\
Truck Transportation & & &
\end{tabular}

\footnotetext{
${ }^{a}$ Few studies undertake to estimate embodied, construction and decommissioning energy inputs across multiple fuel cycle steps,
} and those reviewed modern studies that do continue to rely heavily on [Rotty 1975]. 


\begin{tabular}{l|llll} 
Total & $2.3 \times 10^{-1}$ & $3.0 \times 10^{-2}$ & $1.1 \times 10^{-2}$ & $2.7 \times 10^{-1}$
\end{tabular}

* Rotty assumed $59 \%$ open pit, $41 \%$ underground mining.

\subsection{References}

[CARMA 2010] Carbon Monitoring for Action, 2010, available:

http://carma.org/dig/show/world+country, webpage accessed June 10, 2010.

[ISO 1997] International Organization for Standardization (ISO), "Environmental Management - Life Cycle Assessment - Principles and Framework," ISO 14040, 1997.

[DOE 1983] US Department of Energy, Energy technology characterizations handbook: environmental pollution and control factors, technical report (1983).

[EPA 1993] US Environmental Protection Agency, "EPA 1993 Life Cycle Assessment: Inventory Guidelines and Principles," 1993.

[EIA 2010a] Energy Information Administration, “Annual Energy Outlook 2009 with Projections to 2030,” U.S. DOE Energy Information Administration. February 2009.

[EIA 2010b] Energy Information Administration, "Voluntary Reporting of Greenhouse Gases Program Fuel and Energy Source Codes and Emission Coefficients," 2010, http://www.eia.doe.gov/oiaf/1605/coefficients.html, webpage accessed June 10, 2010.

[EC 1995] European Commission, "ETSU Energy Technology Support Unit Vol. 1: Summary," and "Vol. 5: Nuclear," in ExternE - Externalities of Energy, European Commission DirectorateGeneral XII, 1995.

[Jacobson 2009] Jacobson, M. and M. Delucchi, “A Path to Sustainable Energy by 2030," Scientific American, November 2009.

[Nero 1979] A.V. Nero, A guidebook to nuclear reactors, Berkeley: University of California Press, 1979.

[OECD 2003] OECD Nuclear Energy Agency, Nuclear Electricity Generation: What are the External Costs?, OECD technical report NEA-4372, OECD Paris, 2003.

[Sovacool 2008] Sovacool, B. K., "Valuing the Greenhouse Gas Emissions from Nuclear Power: a Critical Survey," Energy Policy 36, 2940-53, 2008.

[Storm van Leewen 2005] Storm van Leeuwen, J. W.,Smith, P. Nuclear Power, The Energy Balance, 2005. Revised 2007. available: http://www.stormsmith.nl/, webpage accessed January 30, 2010.

[USAEC 1974] US Atomic Energy Commission, Environmental survey of the uranium fuel cycle, technical report WASH-1248 (1974).

[WEC 2004] World Energy Council, "Comparison of Energy Systems Using Life Cycle Assessment," ISBN $0946121168,2004$.

[WNA 2009] World Nuclear Association, "Energy Analysis of Power Systems," WNA Information Brief 11, 2009. Available: http://www.world-nuclear.org/info/inf11.html, webpage accessed May 15, 2010. 


\section{URANIUM MINING, MILLING AND REFINING}

This section addresses the energy consumption, carbon footprint, and land and water usage of uranium mining, milling and refining. Projections related to the environmental footprint of uranium extraction and processing are complicated by the site-specific and time-evolving nature of the extraction technologies as well as the uniqueness of each ore body. Forecasts of energy consumption associated with uranium extraction from lower grade ores are hindered by a lack of industrial experience and data.

Estimates of the contemporary carbon footprint of the uranium mining, milling and refining step vary widely (Figure 3.1). Each estimate shown in the figure incorporates its author's assumptions regarding energy consumption associated with average ore grade, waste rock to ore ratio, extraction approach breakdown, and apportionment of emissions arising outside of the mine/mill gates (e.g. from production of inputs such as sulfuric acid and diesel fuel as well as embodied energy associated with equipment and facilities).

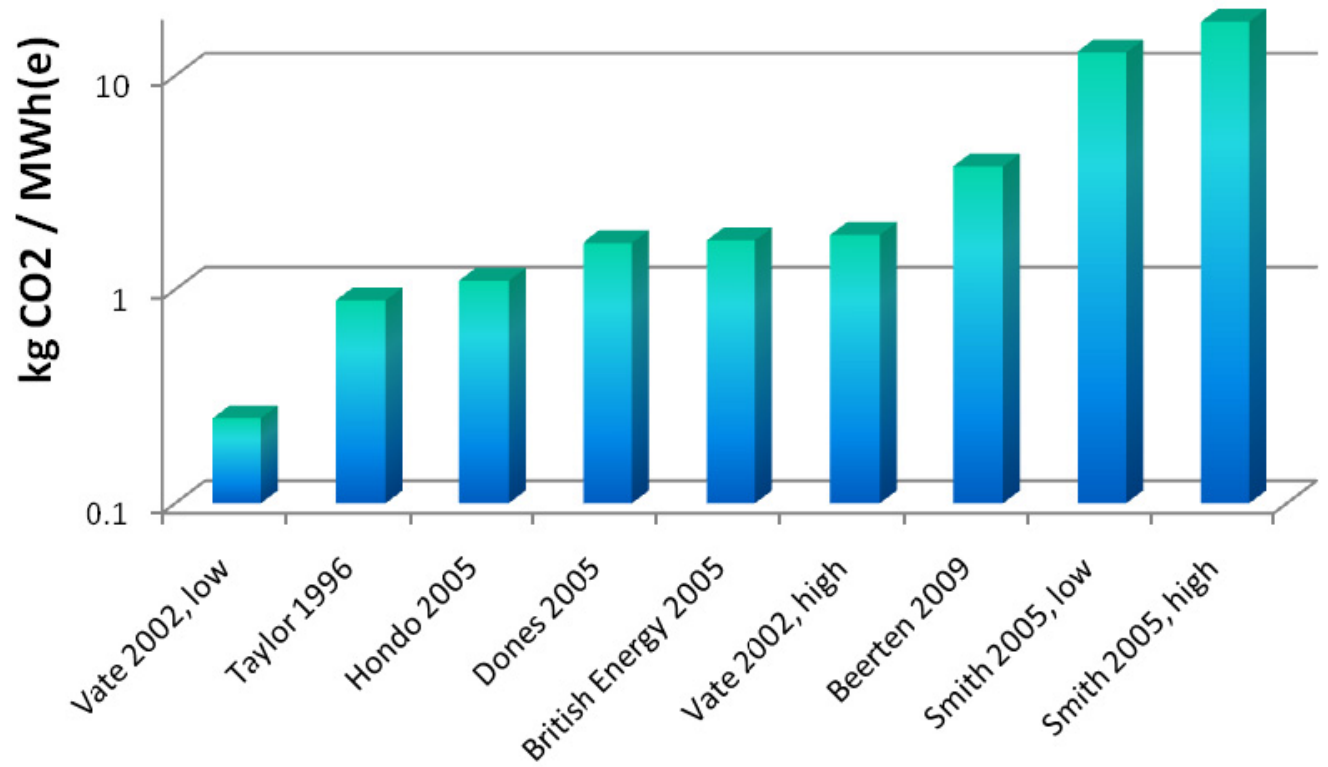

Figure 3.1. Estimates of the carbon footprint of uranium mining, milling and refining.

This study pursues a top-down approach to the problem of modeling the uranium energy balance. The bottom-up or "model mine" approach creates system mechanistic models of each technology component and process step in a mining and milling operation. It can give highly accurate forecasts in the near-term, and it excels when business models of a single mine are desired. Yet for long-term forecasting as well as depiction of the averaged characteristics of a large number of mines, a top-down approach is preferable: the mechanics of future mines and the morphology of future deposits are unknown, and unique characteristics of each mine remain important in the sense that they affect industry-average performance.

Top-down models are not intended to provide a detailed, system mechanistic depiction of individual process components. Instead, beyond a basic formulation of the most important drivers in the overall process, a top-down model treats the details of the process as if they occur within a black box. This approach is used when the process is very complex, and typical behavior is to be captured in the face of a host of local parameters that cause individual data points to deviate from the trends that the top-down model can accommodate. 
In a top-down approach, a mathematical expression is formulated that contains the most fundamental quantities upon which the normalized energy consumption $[\mathrm{GJ} / \mathrm{kgU}]$ is expected to depend. In the case of uranium extraction, these quantities are ore grade $\left[\% \mathrm{U}_{3} \mathrm{O}_{8}\right]$, mill and/or leaching process yield, and mass of waste rock relative to mass of ore.

A literature review assembles these items of data for a representative set of mines over several years of operation. A multivariate linear least-squares regression analysis is subsequently performed to obtain curve fit parameters that maximize the ability of the model to explain the per-annum energy consumption for members of the data set. If the model insufficiently reproduces the energy consumption data, the mathematical formulation is refined and/or additional data is collected. Rejection criteria for the regression model include a non-maximized coefficient of determination or the presence of a regression coefficient that does not pass the null hypothesis as quantified by the Student T-test.

Sections 3.1 through 3.5 of this chapter address the energy balance, carbon footprint, water consumption, land use, and occupational and public health impacts of uranium mining, milling and refining. Each may be expected to evolve with time as mining activities shift to newly-discovered or lower-grade deposits. Section 3.6 discusses the time evolution in the context of energy intensity, but the approach taken in this section applies to carbon, land and water impacts as well. Two appendices attach to this chapter: Appendix B lists the data collected for this study, and Appendix C reviews other published methodologies for forecasting the uranium ore grade-energy consumption relationship.

\subsection{Energy Intensity}

Figure 3.2 is a schematic diagram of the mass flows associated with uranium mining, milling and refining via conventional (open-pit or underground) techniques. There are energy inputs to each step. It is reasonable to assume that the energy consumption of each process is proportional to the mass flow through that process; this assumption is verified below through statistical analyses of mine data. The dominant energy carriers are liquid fuels for the mining/haulage process and electricity for the milling and refining steps for conventional mines.

Figure 3.2. Mass flows in uranium mining and beneficiation. After [Prasser 2008] 
Mines employing In-situ leaching (ISL) currently supply about $28 \%$ of world primary uranium [OECD 2008]. In the ISL process, the initial mining and a portion of the milling steps of Figure 3.1 are replaced by direct leaching of the underground ore body via leach liquor injection and pumping. Therefore, the energy consumption of ISL mines is driven by electricity requirements associated with pumping.

For both conventional and ISL mining, the energy intensity of uranium production is coupled to the grade of the ore being extracted. Lower-grade ores are presumed to lead to increased mining and milling energy requirements, measured on a per unit of product basis.

The association between ore grade and energy consumption in uranium production was first studied by Chapman [Chapman 1975]. Using 1970s data on mine energy consumption, Chapman estimated that energy consumption for mining, milling, and refining uranium would increase with decreasing ore grade, with energy consumption of these processes equaling the nuclear-generated electricity output for ore grades lower than $\sim 0.002 \% \mathrm{U}_{3} \mathrm{O}_{8}(20 \mathrm{ppm} \mathrm{U}$; the average abundance of uranium in the Earth's crust is $2.8 \mathrm{ppm})^{\mathrm{b}}$. It is important to note that, despite 60 years of uranium mining, the average ore grade has remained near $0.1 \% \mathrm{U}_{3} \mathrm{O}_{8}$ (Figure 3.3$)^{\mathrm{c}}$.

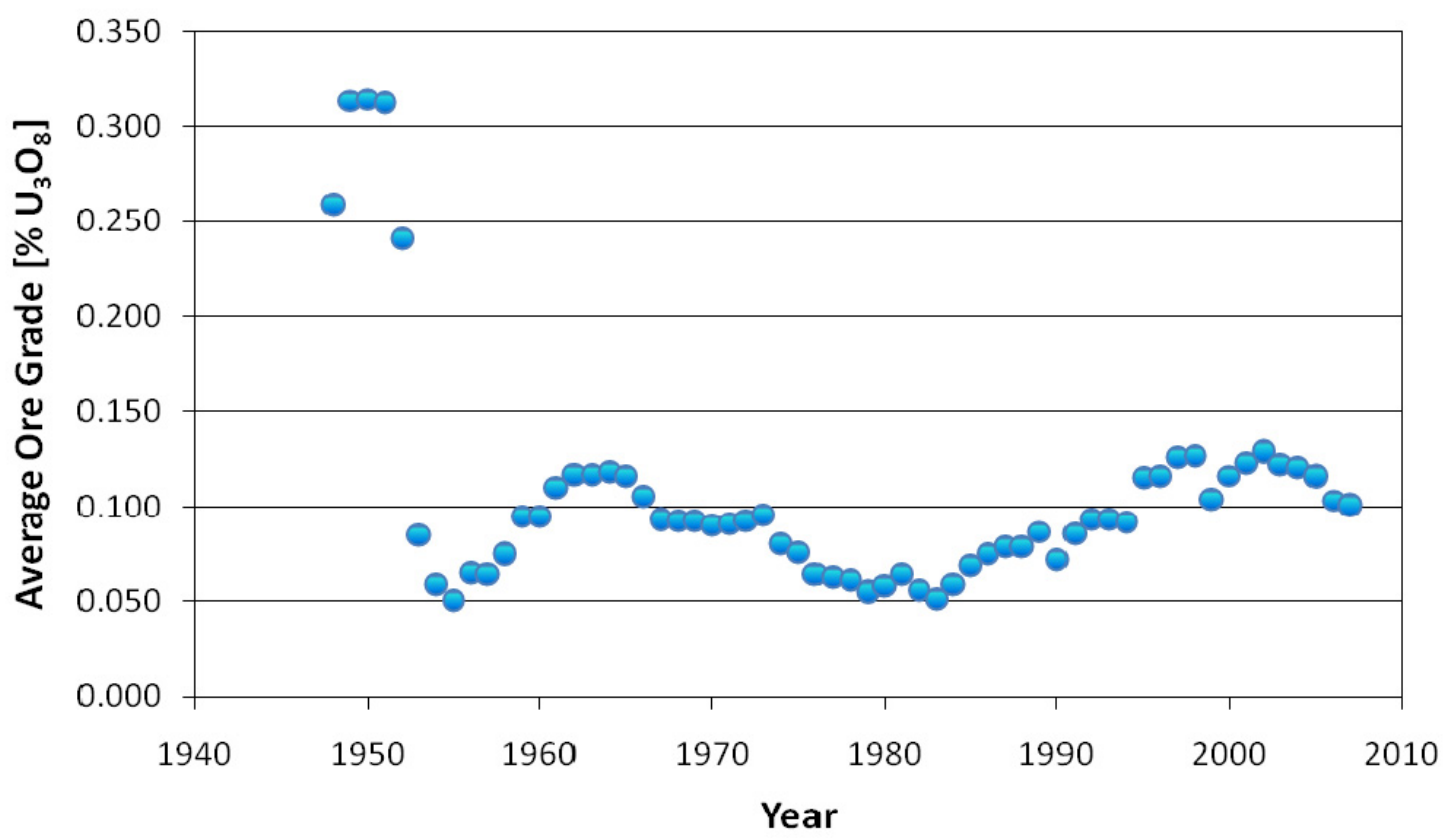

Figure 3.3. Historical trend of mass-weighted average ore grade of mined uranium. Data source: [Mudd 2008c]

b. A note regarding units: ore grades are customarily expressed in weight percent of metal in the ore or weight parts per million. The notation used here (where as an example $1.0 \mathrm{w} / \mathrm{o} \mathrm{U}$ as $\mathrm{U} 3 \mathrm{O} 8=10,000$ weight parts per million $\mathrm{U}$ are simply written as $1.0 \% \mathrm{U} 3 \mathrm{O} 8$ and 10,000 ppmU, respectively) is conventional in the literature. In the remainder of this document, weight percent "w/o" and weight parts per million U "wppm U" should be construed as implicit in the more common designations $\%$ and ppm.

c. Certain trends are noteworthy in Figure 3.3: the average ore grade declined somewhat in the 1970s and early 1980s, a period of heavy production. It increased in the late 1980s and 1990s as production declined and marginal mines - those operating at lower ore grades - shut down. 
Three studies addressed the energy consumption of the steps in the production chain over a wide range of ore grades [Chapman 1975][Storm van Leewen 2005][Prasser 2008]. The studies defined masses of overburden $\left(\mathrm{m}_{\mathrm{ob}}\right)$ and ore $\left(\mathrm{m}_{\mathrm{ore}}\right)$ associated with the production of $\mathrm{m}_{\mathrm{u}}$ tonnes of uranium in $\mathrm{U}_{3} \mathrm{O}_{8}$ and introduced energy consumption coefficients [MJ/tonne] for the steps associated with each mass. Collecting data from one or more mines, the investigators performed statistical analyses to estimate the energy consumption coefficients.

Models of this type are amenable to forecasting the energy consumption of uranium production over a wide range of ore grades. One caveat is that the overburden-to-ore mass ratio is unique to individual ore bodies and varies with mining technique. This ratio, defined as the stripping ratio $\mathrm{S}, \mathrm{S}=\mathrm{m}_{\mathrm{ob}} / \mathrm{m}_{\text {ore }}$, has varied from near zero to forty, with higher values being typical of open pit mines. The value of $\mathrm{S}$ has important ramifications for the energy balance. Available mine data indicate that $\mathrm{S}$ is generally smaller for contemporary mines extracting lower grade ore, because these deposits would not otherwise be economically competitive. For instance, $\mathrm{S}=1.15$ at the Rossing mine in Namibia where ores of grade $0.02 \% \mathrm{U}_{3} \mathrm{O}_{8}$ are being mined by the open-pit technique. At the Australian Ranger mine $\left(0.3 \% \mathrm{U}_{3} \mathrm{O}_{8}\right)$ where the ore is more than a factor of ten richer than Rossing, S averaged 3.5 between 1999 and 2006.

Another important parameter at lower ore grades is the yield associated with the leaching step. Ore leaching efficiencies are known to depend on ore grade and leach liquor residence time. Leaching efficiency declines with ore grade if residence time is held fixed. As a consequence, for low-grade ores a substantial fraction of the uranium may pass into the mill tailings rather than the product stream. Storm van Leewen has collected mill yield data and derived a functional dependence of the yield $\mathrm{Y}[\mathrm{kg} \mathrm{U}$ in mill product / $\mathrm{kg} \mathrm{U}$ in ore] for ores of grade lower than $\mathrm{G}=1 \% \mathrm{U}_{3} \mathrm{O}_{8}$ :

$\mathrm{Y}=0.98-0.0723(\log \mathrm{G})^{2}$

This function, depicted in Figure 3.4, is utilized in the current study to predict the yield-to-grade ratio when mine-specific yield data is not available. The data points shown in Figure 3.4 were taken from milling operational reports and studies addressing recovery from ores of lower grade. All data was published between 1971 and 1980 [Storm van Leewen 2005]. There remains insufficient published data to update this projection for grades lower than those presently being commercially refined. 


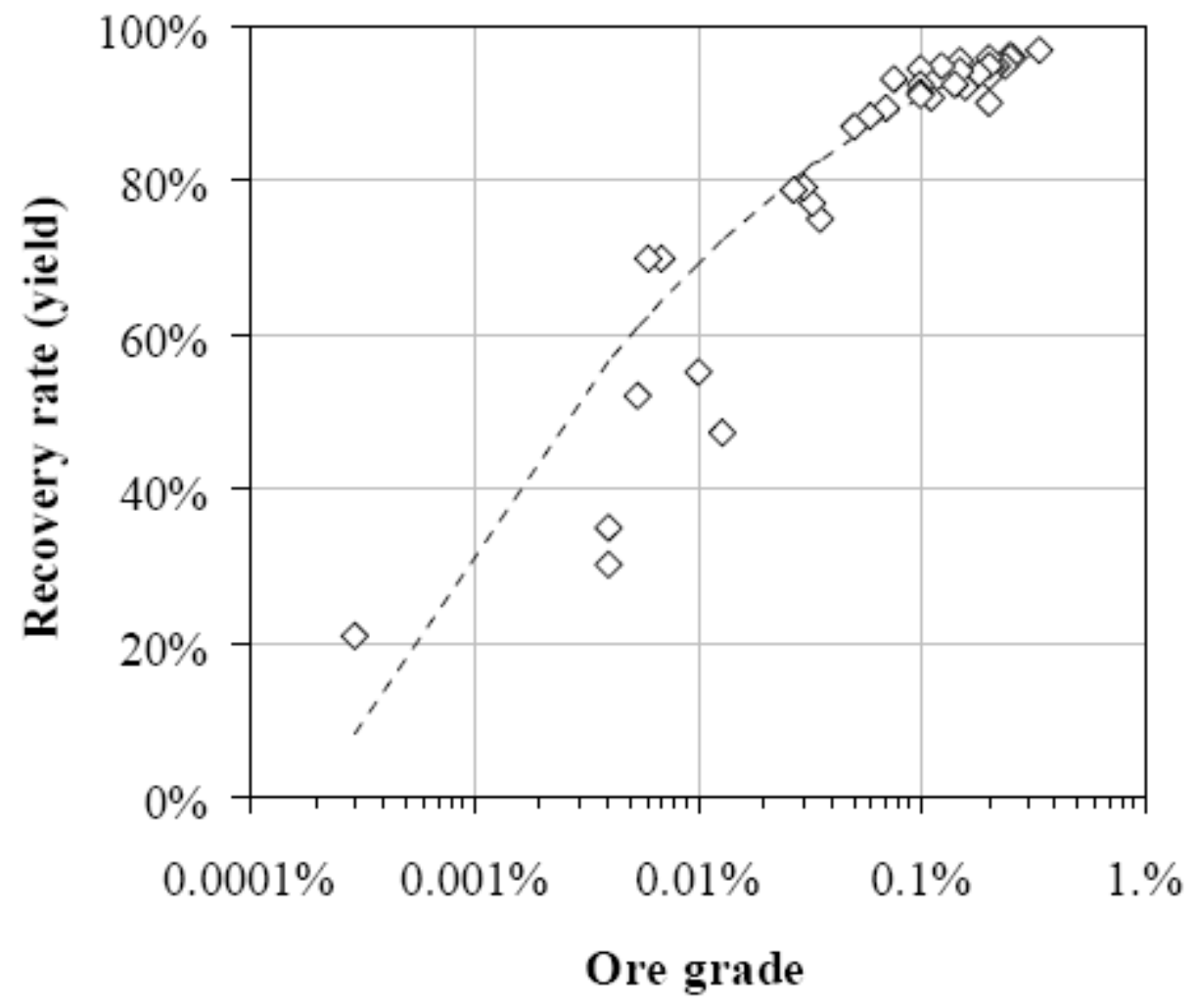

Figure 3.4. Milling yield $\mathrm{Y}$ [here shown in percent] correlated to ore grade $\left[\% \mathrm{U}_{3} \mathrm{O}_{8}\right]$. Figure: [Lenzen 2008]

Following Chapman's mine mass flow model [Chapman 1975], Storm van Leewen and Smith (SLS) and Prasser postulate an inverse relationship between ore grade and energy consumption. Prasser refines the SLS model by including a grade-independent component in the energy consumption. Neither Prasser nor SLS differentiate between the mining techniques when formulating their models. While SLS do not correlate stripping ratio to energy consumption, they argue that ore hardness is an important driver in the excavation, crushing and grinding steps of the mining and milling process. Uranium-bearing minerals presently being extracted vary in hardness from 2-3 on the Mohs scale (carnotite, tobernite, autunite) to 5-6 (uraninite, davidite, pitchblende). Appendix C presents a quantitative review of the Chapman, Prasser and SLS correlations.

It is important to define the scope of the direct energy consumption estimated by these empirical correlations and reported by mine operators. This is overwhelmingly associated with three energy carriers: electricity, fossil fuels used to propel earth-moving equipment (usually diesel fuel), and process heat (usually generated by liquid or gaseous fossil fuels). The reported consumption reflects only energy used within the plant gates. Electricity consumption is reported by the mines in units of [Joules(electric), J(e)] and onsite fossil fuel consumption in units of [Joules(thermal), J(t)]. Some mines simply report the total energy consumption in Joules, and by implication this value is a summation of the thermal and electrical energy usage.

Energy consumption estimates found in the literature do not apply a uniform standard in this regard. Some studies limit themselves to inside-the-gates consumption, while others include part of the energy consumption associated with production of fuels, mechanical equipment, chemical compounds, and other inputs. To better facilitate comparison with empirical data, this study will consider inside-the-gates consumption only. Care will be taken to notate energy consumption in units of $\mathrm{J}(\mathrm{e}), \mathrm{J}(\mathrm{t})$, or, if thermal and 
electrical energy consumption are aggregated, $\mathrm{J}(\mathrm{t}+\mathrm{e})$. This approach to specifying the often-mixed energy carriers that arise in the data follows that taken in earlier studies of the energy balance, e.g. [Storm van Leewen 2005] and [Lenzen 2008] $]^{\mathrm{d}}$.

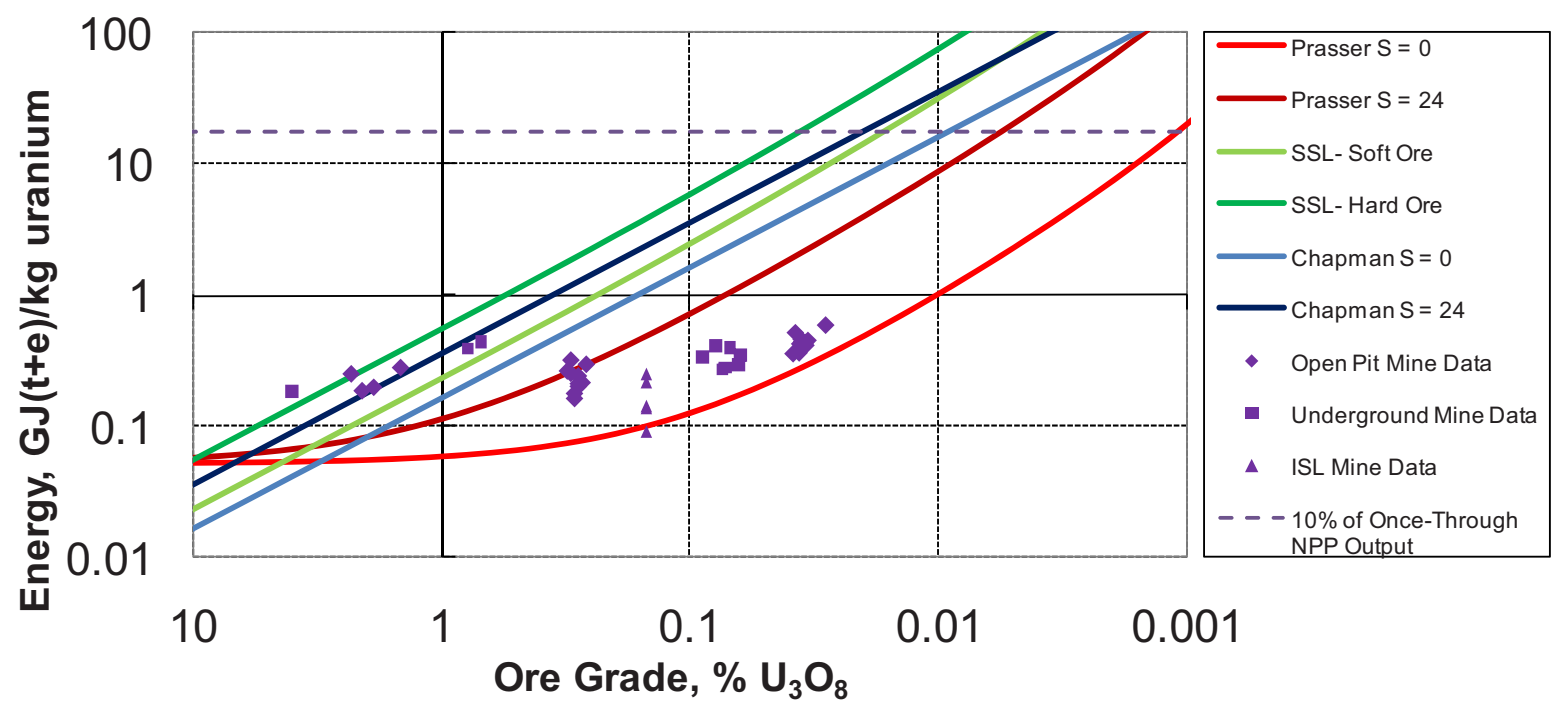

Figure 3.5. Grade-to-energy models of Chapman (blue curves), Storm van Leewen (green curves) and Prasser (red curves) and data points for individual mines (Appendix C provides mathematical depictions of the three models shown)

The three models are depicted with the data collected from the operating mines in Figure 3.5. To provide context for the energy consumption results, $10 \%$ of the electricity recovered from the uranium (contemporary PWR operating on the once-through cycle is depicted as the horizontal dotted line in Figure 3.5. This value was calculated for the reference PWR cycle (burnup $=51 \mathrm{MWd} / \mathrm{kgIHM}$ ) of the VISION nuclear fuel cycle simulation package developed at Idaho National Laboratory [INL 2007]; see Appendix A). Note that the direct thermal plus electrical energy consumption of all mines was less than $1 \%$ of the electrical output of the extracted uranium.

In the current study, data for nine facilities were collected. The data set includes open pit and underground mines operate at ore grades ranging from $0.02 \% \mathrm{U}_{3} \mathrm{O}_{8}$ (Rossing) to $19 \%$ (McArthur River). One ISL mine, Beverley (average formation ore grade of $0.18 \% \mathrm{U}_{3} \mathrm{O}_{8}$ ), is also included. Given the unique nature of each of the three mining approaches, they will each be represented by their own energy consumption vs. ore grade functional dependence.

Figure 3.6 shows the data set used in the analysis. Each point represents data for one operational year of one mine; only data from the time period 1997-2008 was included (for most mines, data was not available

d. There is strong physical justification for aggregating the $\mathrm{J}(\mathrm{t})$ and $\mathrm{J}(\mathrm{e})$ rather than converting all mine-reported data to $\mathrm{J}(\mathrm{t})$. To start, thermal-to-electric conversion efficiencies are ambiguous: the $\mathrm{J}(\mathrm{t})$ associated with some amount of $\mathrm{J}(\mathrm{e})$ changes with technology, so if an LWR with a lower thermal efficiency than say a natural gas plant, were used to power a mine, more $\mathrm{J}(\mathrm{t})$ would be needed. And if wind were used, an equivalent definition of $\mathrm{J}(\mathrm{t})$ does not exist.

There is a larger reason to retain $\mathrm{J}(\mathrm{t})$ and $\mathrm{J}(\mathrm{e})$ : a joule is a joule. To fire a boiler to make steam for low-temperature process heat, one would need to consume about as many $\mathrm{J}(\mathrm{t})$ of gas as $\mathrm{J}(\mathrm{e})$ of electricity. The thermal-to-electric conversion efficiency of the fuel that made those $\mathrm{J}(\mathrm{e})$ is not relevant; the amount of energy delivered, regardless of carrier, is. 
over the entire period). A complete listing of all input data and sources is given in Appendix B. Stripping ratio, not depicted in Figure 3.6, also plays a role in shaping the energy balance as it specifies the mass of waste rock displaced per mass of ore extracted. Stripping ratios for the underground mines in the data set, Olympic Dam, McArthur River and Rabbit Lake, are low by historical standards, with that of Olympic Dam being less than 1. Stripping ratios for the open pit mines, Rossing, Ranger, McClean Lake and Cluff Lake, vary widely, from 1.15 at Rossing to up to 35 at the high-grade mines.

Note from Figure 3.5 that the ore grade to energy consumption relationship implied by the mine data does not exhibit strictly inverse $(\sim 1 / \mathrm{G})$ behavior over all grades, contravening the fundamental assumption of previous models. It has long been understood - see [Chapman 1975], [Chapman 1983] and a recent review in [Rosa 2008] - that the inverse grade-to-energy relationship would be expected to assert itself at lower ore grades, establishing a practical lower boundary on the energetically feasible grade for any metal. Yet the available data for uranium, which spans several orders of magnitude in ore grade, clearly indicates that grade alone cannot explain the observed energy consumption trends. Evidently a substantial component of the energy consumption, especially at higher-grade mines, is not tied to the ore grade. Some of this balance-of-plant consumption is doubtless connected to the refining step, where process mass flows are proportional to the uranium product mass. Following Prasser, the models presented here will postulate that total energy consumption can be expressed as a sum of components proportional to the overburden, ore, and product masses.

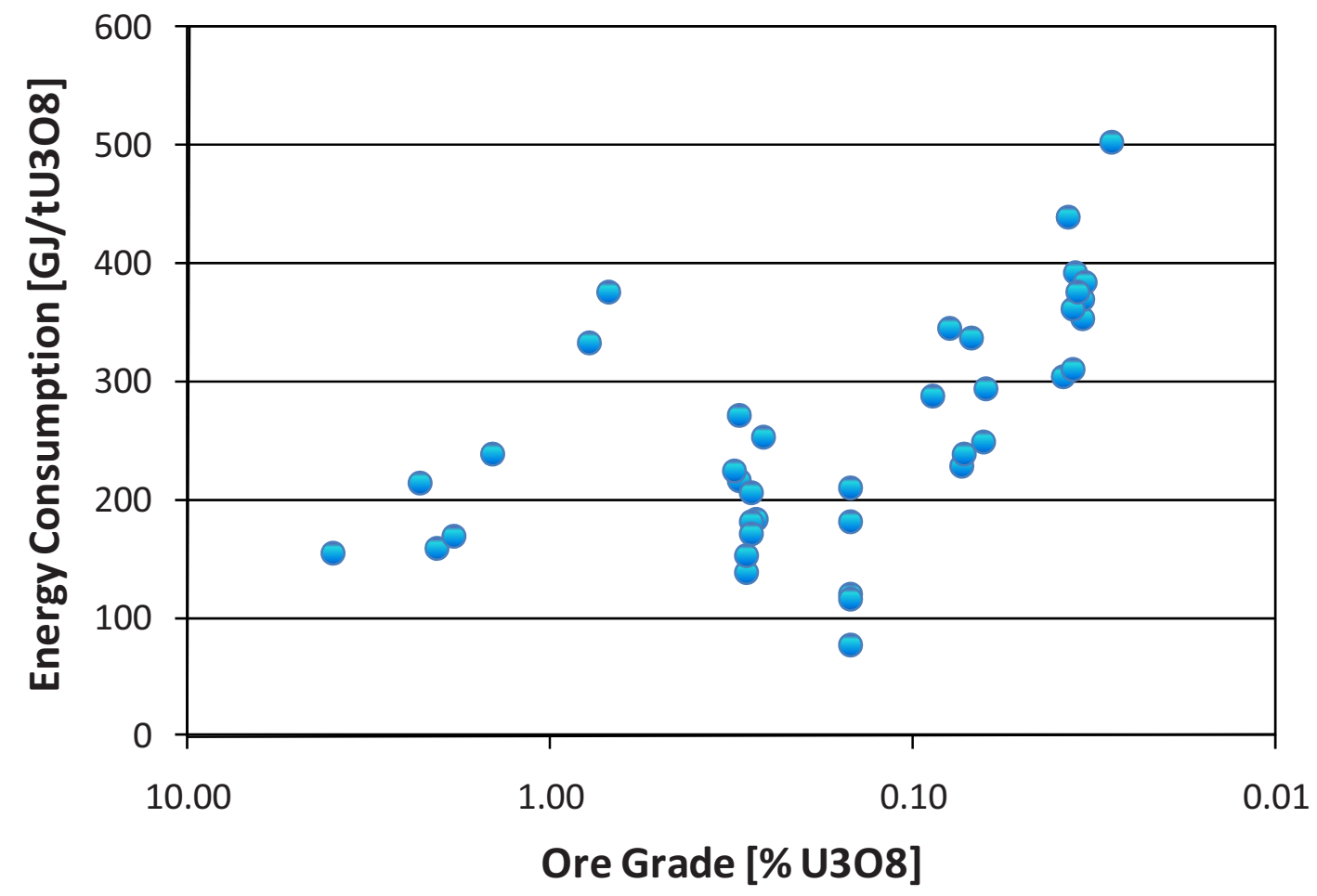

Figure 3.6. Energy Consumption versus Ore Grade, Appendix B data.

The models will seek to establish a correlation between the total (thermal plus electrical) energy consumption of a mine/mill and these three masses. Since the distribution of energy consumption between thermal and electrical carriers affects both the mine energy balances and the carbon footprints and varies between mining approaches, it is useful to review it before proceeding to the model formulation. 


\subsubsection{Consumption breakdown by energy carrier}

There is little data associated with energy consumption by process step in surface and underground uranium mining. Hence, the more extensive literature treating energy consumption for other minerals was consulted. While uranium refining does not have an exact analogue under other minerals, the extraction and milling processes are closely analogous. Two studies focusing on energy consumption associated with mining and milling of other minerals are reviewed here.

A 2005 Canadian government study [CIPEC 2005] surveyed energy consumption and carbon emissions from nine Canadian surface extraction operations. Three iron mines (grades much higher than that of uranium), four gold mines (grades much lower), and two open-pit oil sands operations (resembling conventional mineral mining) were considered. Figure 3.7 shows the average energy consumption by process step, in $\mathrm{kWh} / \mathrm{kt}$ of ore or sand, for the nine mines. Steps associated with mining total $11.76 \mathrm{kWh} / \mathrm{kt}$, those associated with milling $20.99 \mathrm{kWh} / \mathrm{kt}$. These numerical values are not precisely comparable to those associated with uranium extraction as they are strongly affected by stripping ratio, and indeed they vary by a factor of nearly three among the mines being considered, while stripping ratios for the nine surveyed mines varied from 0.04 to 6.5 . The study provided average energy intensities for mining (in GJ/t of ore plus overburden) and milling (GJ/t of ore, excluding the oil sands mines) that will later be useful for benchmarking the order of magnitude of the uranium-specific results. These were $0.0210+/-0.005 \mathrm{GJ} / \mathrm{t}$ ore + overburden and $0.0916+/-0.0316 \mathrm{GJ} / \mathrm{t}$ ore.

This study reported that steps associated with mining overwhelmingly utilized liquid fuels, predominantly diesel. This reflects the scope of the study, which was limited to open-pit mines. Processes that are typically electricity-supplied in underground mines, for instance dewatering and ventilation, are not reported.

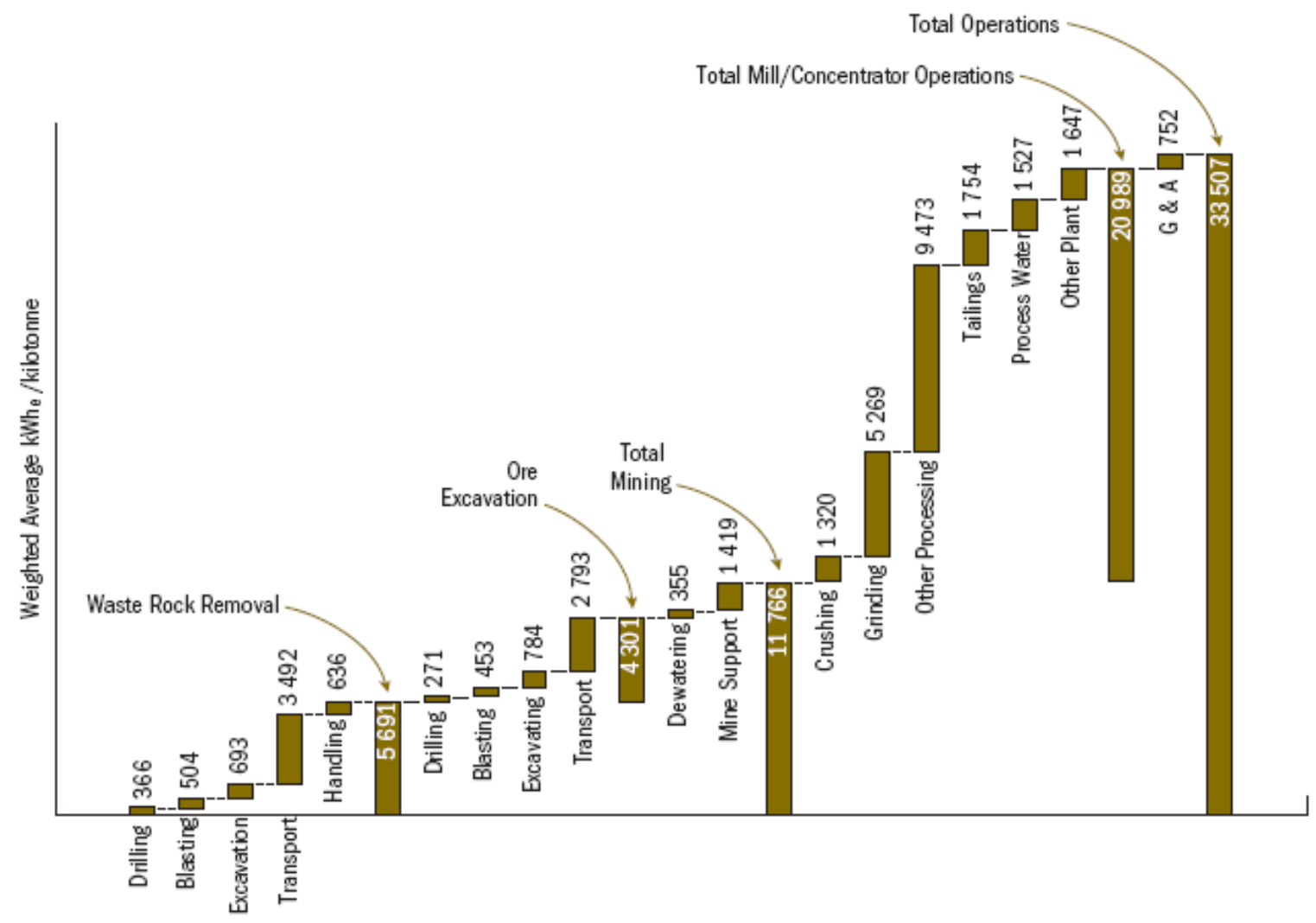

Figure 3.7. Average energy consumption by operation, nine Canadian mines. Figure: [CIPEC 2005] 
A recent US DOE study [EERE 2010] undertook a similar energy consumption survey for the US metal mining industry. Although energy commodity consumption profiles varied between metals, the energy carrier used in each step was in most cases the same. Figure 3.8 shows the energy consumption by step, averaged over all minerals. rushing, grinding and separations are associated with milling, while the other steps fall into mining. Figure 3.9 shows the energy consumption breakdown by energy carrier for the U.S. metal mining industry; again, the energy carriers used vary from metal to metal as detailed in [EERE 2010]. Some energy carriers shown in Figure 3.9 are associated with process heat generation.

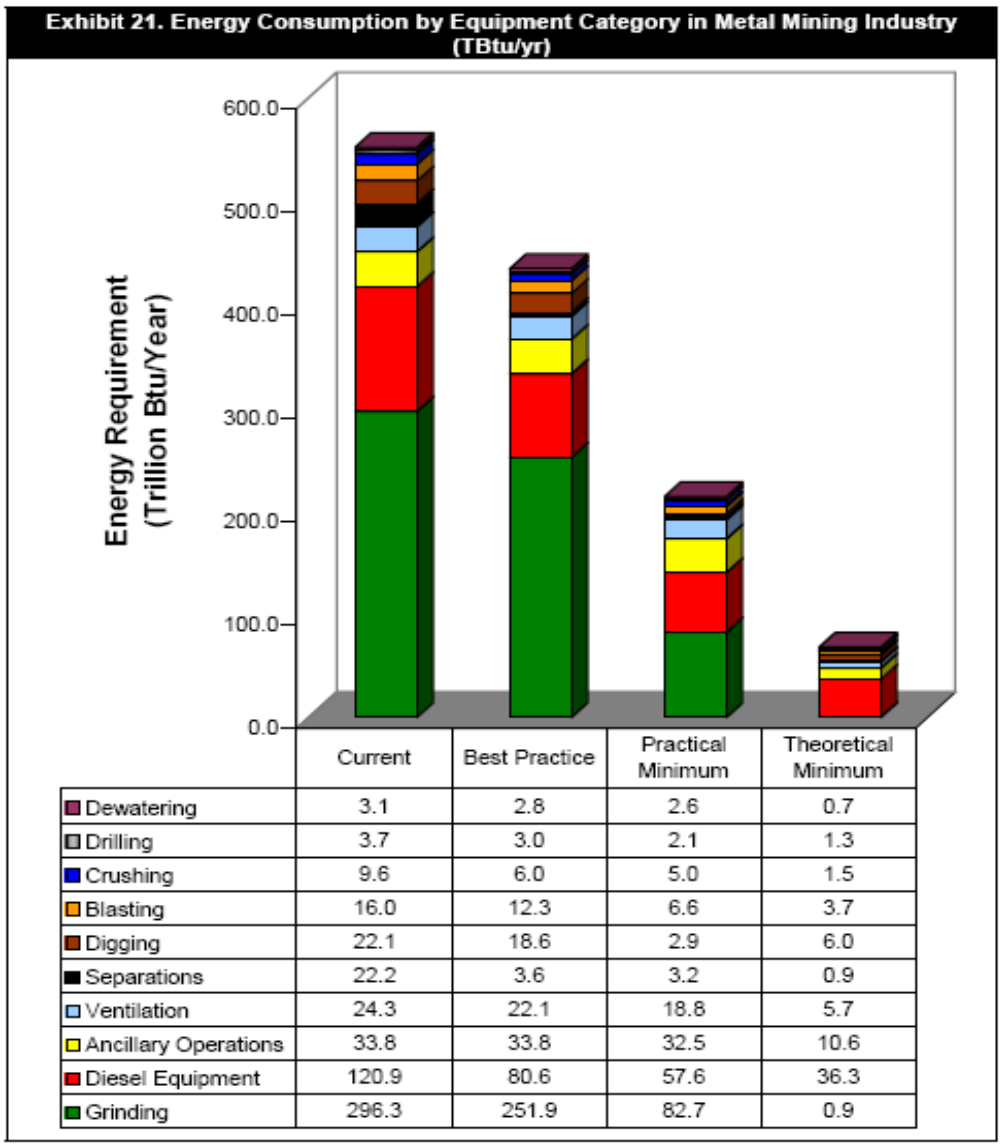

Figure 3.8. Energy consumption by mining/milling process step, US mineral mining industry. Figure: [EERE 2010]. 


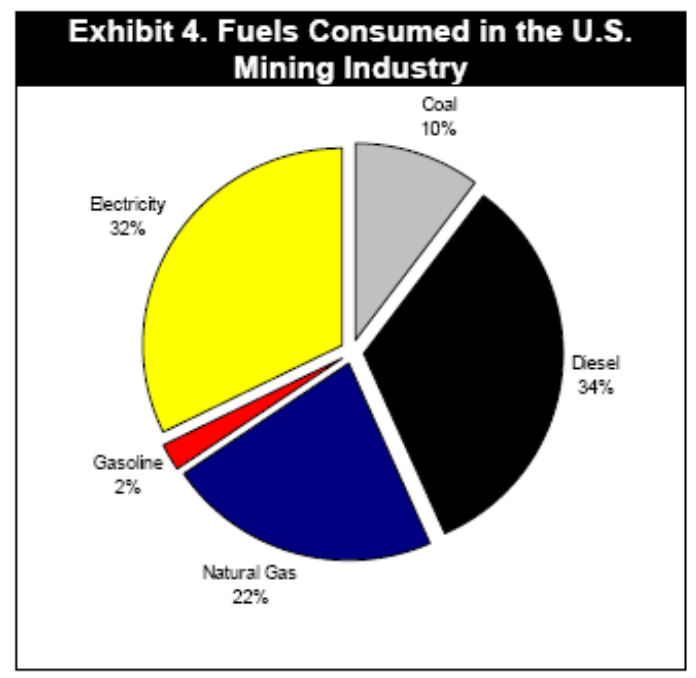

Figure 3.9. Energy consumption by energy carrier in mining/milling, US mineral mining industry. Figure: [EERE 2010].

[EERE 2010] employed the SHERPA software to create model mines for representative metals and industrial minerals. Mining was partitioned into two sets of processes, extraction (drilling, blasting, dewatering, ventilation and digging in Figure 3.9, 28\% of energy consumption if energy liberated from explosives is neglected) and materials handling ( $72 \%$ of energy consumption in the mining step).

Extraction equipment includes drills, shovels, continuous and longwall mining machines, fans and pumps. Digging and drilling, here assumed entirely diesel-powered, account for $49 \%$ of extraction energy consumption. The remaining $51 \%$, ascribed to ventilation and dewatering, would be powered by electricity. The EERE analysis showed that diesel-powered trucks, bulldozers and other earth-moving equipment accounted for $87 \%$ of the energy used in the materials handling step. The remainder, including conveyors, pumps, and hoists, is here assumed to be electricity-powered.

The above results suggest the consumption breakdown by energy carrier for the mining step shown in Table 3.1. As throughout this document, energy consumption of fossil fuels combusted on site is measured in $\mathrm{GJ}(\mathrm{t})$ while electrical is quantified in $\mathrm{GJ}(\mathrm{e})$.

Table 3.1. Mining energy consumption, GJ(t+e), by carrier imputed from [EERE 2010] model mines

\begin{tabular}{lcc}
\hline \multicolumn{1}{c}{ Energy Carrier } & Open Pit Mining & Underground Mining \\
\hline Electricity & $13 \%$ & $24 \%$ \\
{$[\mathrm{GJ}(\mathrm{e}) /(\mathrm{GJ}(\mathrm{t}+\mathrm{e}))]$} & & \\
Liquid $(100 \%$ diesel assumed $)$ & $87 \%$ & $76 \%$ \\
{$[\mathrm{GJ}(\mathrm{t}) /(\mathrm{GJ}(\mathrm{t}+\mathrm{e}))]$} & & \\
\hline
\end{tabular}

[Chapman 1975] ascribed 100\% of mining energy consumption for the four early 1960s underground mines surveyed in his source to thermal carriers. Drawing upon a 1970s study [Rotty 1975] and using the same thermal/electric accounting scheme, SLS ascribe $87 \%$ of mining energy consumption to diesel and other thermal energy producing fuels, confirming the above disaggregation. SLS do not differentiate between underground and open pit mining.

Limited uranium-specific data was recovered for the energy consumption breakdown between the uranium milling and refining steps. The steps termed milling and refining in this document both fall under the heading of milling in most other sources; the differentiation is preserved here to facilitate the disaggregation of steps proportional to the ore mass from those related to the product mass. 
Process heat usage in uranium milling varies with the leaching agent (sulfuric acid or bicarbonate), but generally the leaching circuit in which ground ore is circulated is heated to facilitate uranium dissolution. At the White Mesa mill in the US, for instance, steam injection maintains the circuit at $60-90 \mathrm{C}$ [Denison Mines 2007]. Process heat requirements arise in the drying step of uranium refining, when yellowcake slurry is baked in a high temperature furnace to reduce its water content. A typical temperature for calcining dryers is $700 \mathrm{C}$; the Rabbit Lake mill uses an oil-heated indirectly-fired dryer, which although it achieves a slightly lower product purity than a calcining dryer, consumes significantly less energy [Edwards 2000].

Based on 1970s data, SLS assign 10\% of milling energy consumption for hard ores to thermal carriers and the balance to electricity. For soft ores, on the other hand, drawing upon a separate 1970s-era study SLS ascribe $86 \%$ of consumption to thermal carriers. [Chapman 1975] ascribes direct mill energy consumption in the four early 1960s facilities his study is based upon "largely" electricity but does not provide a disaggregation. Chapman did not differentiate based on type and hardness of the ores processed by these mills.

Mine data for which thermal/electric breakdowns are available is given in Table 3.2. Most of the data in Table 3.2 does not differentiate between the mining and milling/refining processes. The exception, McArthur River/Key Lake, is a unique case: ore from McArthur river is shipped 80km to Key Lake for blending with residual ore produced by the defunct Key Lake mine and subsequent milling. Further, the crushing/grinding step is carried out underground at the McArthur River site.

Table 3.2. Mine-reported thermal and electrical energy consumption breakdowns, uranium mining, milling and refining except where noted

\begin{tabular}{lcc}
\hline & $\begin{array}{c}\text { Electricity } \\
{[\mathrm{GJ}(\mathrm{e}) /(\mathrm{GJ}(\mathrm{t}+\mathrm{e}))]}\end{array}$ & $\begin{array}{c}\text { Thermal Carriers } \\
{[\mathrm{GJ}(\mathrm{t}) /(\mathrm{GJ}(\mathrm{t}+\mathrm{e}))]}\end{array}$ \\
\hline McArthur River (mining, crushing only) & $60 \%$ & $40 \%$ \\
Key Lake (blending, milling, refining only) & $69 \%$ & $31 \%$ \\
Total, McArthur River and Key Lake, 2006 & $65 \%$ & $35 \%$ \\
McClean Lake, 2002-06 avg. & $24 \%$ & $76 \%$ \\
Rabbit Lake, 2006-07 avg. & $63 \%$ & $37 \%$ \\
Rossing, 1997-2001 avg. & $62 \%$ & $38 \%$ \\
All Canadian Mines, 1990-97 avg. ${ }^{\text {a }}$ & $36 \%$ & $64 \%$ \\
\hline a. [Nyober 2010] & & \\
\hline
\end{tabular}

Differences in the distributions shown in Table 3.2 must be ascribed to local operating conditions including ore grade and hardness, mining method, stripping ratio, and processing chemistry (acid versus alkaline). Given the energy consumption distributions reported earlier for the mining step, it appears that both of the SLS estimates represent extreme cases. The Key Lake mill will here be chosen as representative, so that the consumption distribution for the milling/refining steps used henceforth is $69 \%$ electricity, 31\% thermal. Natural gas, propane, and coal/coke use are all reported by the various mines/mills, but as natural gas is the dominant thermal energy carrier at most of the facilities in [Mudd 2007b], it will be assumed to supply all of the milling/refining thermal energy input for the carbon footprint analysis.

For ISL mining electricity is expected to be the dominant energy carrier. Data from the Beverley ISL mine wellfield operations confirm this is true [Mudd 2008a]. Natural gas fired generating stations (Caterpillar G3500s with a thermal-to-electric conversion efficiency of 41\% [Montgomery 2006]) are co-located at Beverley. Energy consumption data for that mine is reported entirely in units of GJ(t) embodied in combusted natural gas, and no distinction is made between gas utilized for process heat or 
electricity generation. Energy consumption from liquid transportation fuels e.g. for earth-moving equipment is negligible for ISL operations.

Environmental impact reports produced by the Beverley mine operator [Heathgate 2007] show that $44.9 \%$ and $41.6 \%$ of electricity consumed at the site is used to drive wellfield and mill pumps, respectively. Assuming that milling operations follow the electrical-to-thermal breakdown provided above for the Key Lake mill, the mill and refining operations would utilize $0.45 \mathrm{GJ}(\mathrm{t})$ of energy in process heat applications per GJ(e) of electricity. The imputed distribution of the energy consumption at Beverley is given in Table 3.3.

Table 3.3. Imputed natural gas consumption breakdown at Beverley

\begin{tabular}{lc}
\hline & $\begin{array}{l}\text { Energy used, process step / full } \\
\text { production chain [GJ(t) / GJ(t)] }\end{array}$ \\
\hline Electricity Generation for Wellfield Operations & $41 \%$ \\
Electricity Generation for Mill Operations & $38 \%$ \\
Process Heat for Mill Operations & $7 \%$ \\
Electricity Generation, Refining and Other Operations & $12 \%$ \\
Process Heat, Refining and Other Operations & $2 \%$ \\
\hline
\end{tabular}

This distribution is used to disaggregate the Beverley energy consumption data, given entirely in GJ(t) in [Heathgate 2007] and [Mudd 2008a], into components that are consumed as electricity and as process heat. In this manner the Beverley data set is made consistent with those reported by the other mines, for which the sum of thermal and electrical joules consumed is reported.

The energy consumption breakdowns employed in all steps of the footprint calculation for each mining technology are summarized in Table 3.4.

Table 3.4. Energy consumption disaggregation employed in this study, by extraction technology and process step.

\begin{tabular}{lccc}
\hline & $\begin{array}{c}\text { Electricity } \\
{[\mathrm{GJ}(\mathrm{e}) /(\mathrm{GJ}(\mathrm{t}+\mathrm{e})]}\end{array}$ & $\begin{array}{c}\text { Liquid (Distillate) } \\
{[\mathrm{GJ}(\mathrm{t}) /(\mathrm{GJ}(\mathrm{t}+\mathrm{e})]}\end{array}$ & $\begin{array}{c}\text { Other Thermal Carriers } \\
(\text { Natural Gas) } \\
{[\mathrm{GJ}(\mathrm{t}) /(\mathrm{GJ}(\mathrm{t}+\mathrm{e})]}\end{array}$ \\
\hline Open Pit Mining & $13 \%$ & $87 \%$ & $0 \%$ \\
Conventional Milling & $69 \%$ & $0 \%$ & $31 \%$ \\
Underground Mining & $24 \%$ & $76 \%$ & $0 \%$ \\
ISL Wellfield + Milling & $81 \%$ & $0 \%$ & $19 \%$ \\
Refining + Other & $69 \%$ & $0 \%$ & $31 \%$ \\
\hline
\end{tabular}

\subsubsection{Energy Intensity Model}

This subsection proposes models for determining the energy intensity ' $\mathrm{e}$ ' $[(\mathrm{GJ}(\mathrm{t}+\mathrm{e}) / \mathrm{tU})]$ associated with uranium mining, milling and refining. Related but distinct models are given for the three mining approaches; formulated based upon a mine mass flowchart like that depicted in Figure 3.1. Each model expresses ' $\mathrm{e}$ ' in terms of the relative size of the process mass flows in mining, milling and refining.

The basic premise of the model is that energy consumption is based upon mining method and the relative size of three characteristic mass flows (two in the case of in-situ leaching). The energy intensities of the processes associated with the three mass flows will be estimated from the mine data presented in Appendix B using linear regression analysis. The explanatory power of the models will then be discussed 
in the context of goodness of fit when applied to the individual mine data sets as well as mass-flow based energy intensity coefficients from other studies. Table 3.5 provides a listing of all symbols used in this subsection. Energy consumed from thermal and electrical carriers are aggregated within each intensity component. This aggregation is necessary because much of the data set is also aggregated in this fashion. Disaggregation according to the breakdowns derived in subsection 3.1.1 will be necessary later to estimate carbon emissions.

Table 3.5. Symbols used in energy intensity models.

\begin{tabular}{|c|c|c|}
\hline Symbol & Unit & Description \\
\hline $\mathrm{E}$ & $(\mathrm{GJ}(\mathrm{e})+\mathrm{GJ}(\mathrm{t})) / \mathrm{tU}$ & Energy required to produce 1 tonne of refined $\mathrm{U}$ (as $\mathrm{U}_{3} \mathrm{O}_{8}$ ) \\
\hline $\mathrm{e}_{\text {mine }}$ & $\begin{array}{l}(\mathrm{GJ}(\mathrm{e})+\mathrm{GJ}(\mathrm{t})) /(\mathrm{t} \text { of } \\
\text { ore }+ \text { overburden })\end{array}$ & Energy required to mine one tonne of material \\
\hline $\mathrm{e}_{\text {mill }}$ & $\begin{array}{l}(\mathrm{GJ}(\mathrm{e})+\mathrm{GJ}(\mathrm{t})) /(\mathrm{t} \text { of } \\
\text { ore })\end{array}$ & Energy required to mill one tonne of ore \\
\hline $\mathrm{e}_{\mathrm{mm}}$ & $\begin{array}{l}(\mathrm{GJ}(\mathrm{e})+\mathrm{GJ}(\mathrm{t})) /(\mathrm{t} \text { of } \\
\text { ore })\end{array}$ & $\begin{array}{l}\text { Energy required to mine and mill one tonne of ore (used in the } \\
\text { underground mine model where all available data comes from } \\
\text { mines operating at similar (low) stripping ratios }\end{array}$ \\
\hline $\mathrm{e}_{\mathrm{isl}}$ & $\begin{array}{l}(\mathrm{GJ}(\mathrm{e})+\mathrm{GJ}(\mathrm{t})) /(\mathrm{t} \text { of } \\
\text { ore })\end{array}$ & $\begin{array}{l}\text { Energy required to pump lixiviant and oxidant (leach liquor) } \\
\text { through an ore body; measured per tonne of ore in the ground }\end{array}$ \\
\hline $\mathrm{e}_{\mathrm{u}}$ & $(\mathrm{GJ}(\mathrm{e})+\mathrm{GJ}(\mathrm{t})) / \mathrm{tU}$ & $\begin{array}{l}\text { "energy required to convert beneficiated ore to required material" } \\
\text { (as [Chapman 1975]), plus other energy inputs not directly } \\
\text { proportional to the masses of mined material or ore }\end{array}$ \\
\hline G & $\% \mathrm{U}_{3} \mathrm{O}_{8}$ & Ore grade \\
\hline $\mathrm{S}$ & $\begin{array}{l}\mathrm{kg} \text { overburden } / \mathrm{kg} \\
\text { ore }\end{array}$ & Stripping ratio \\
\hline $\mathrm{Y}$ & $\begin{array}{l}\mathrm{kg} \mathrm{U} \text { in mill output / } \\
\mathrm{kg} \mathrm{U} \text { in mill input }\end{array}$ & Ore milling yield \\
\hline$Y_{\text {isl }}$ & $\begin{array}{l}\mathrm{kg} \mathrm{U} \text { in product } / \mathrm{kg} \\
\mathrm{U} \text { in ore body }\end{array}$ & ISL mining and processing yield \\
\hline
\end{tabular}

The model proposed for open pit mines is that of [Prasser 2008], informed with a considerably more extensive set of mine data spanning several orders of magnitude in ore grade and more than an order of magnitude in stripping ratio. It is written

$e=\frac{100}{G Y}\left((1+S) e_{\min e}+e_{\text {mill }}\right)+e_{u},($ open pit mining $)$

The three terms in this model each represent one step in the process depicted in Figure 3.10 below. The quantity $100(1+\mathrm{S}) / \mathrm{GY}$ is the mass of ore and overburden extracted per mass of uranium in the ore. Therefore, $100(1+\mathrm{S}) \mathrm{e}_{\mathrm{min}} / \mathrm{GY}$ is the energy required to extract ore plus overburden containing one tonne of millable uranium from the mine. Similarly, $\mathrm{e}_{\text {mill }} / \mathrm{GY}$ is the energy required to mill ore containing one tonne of uranium. 


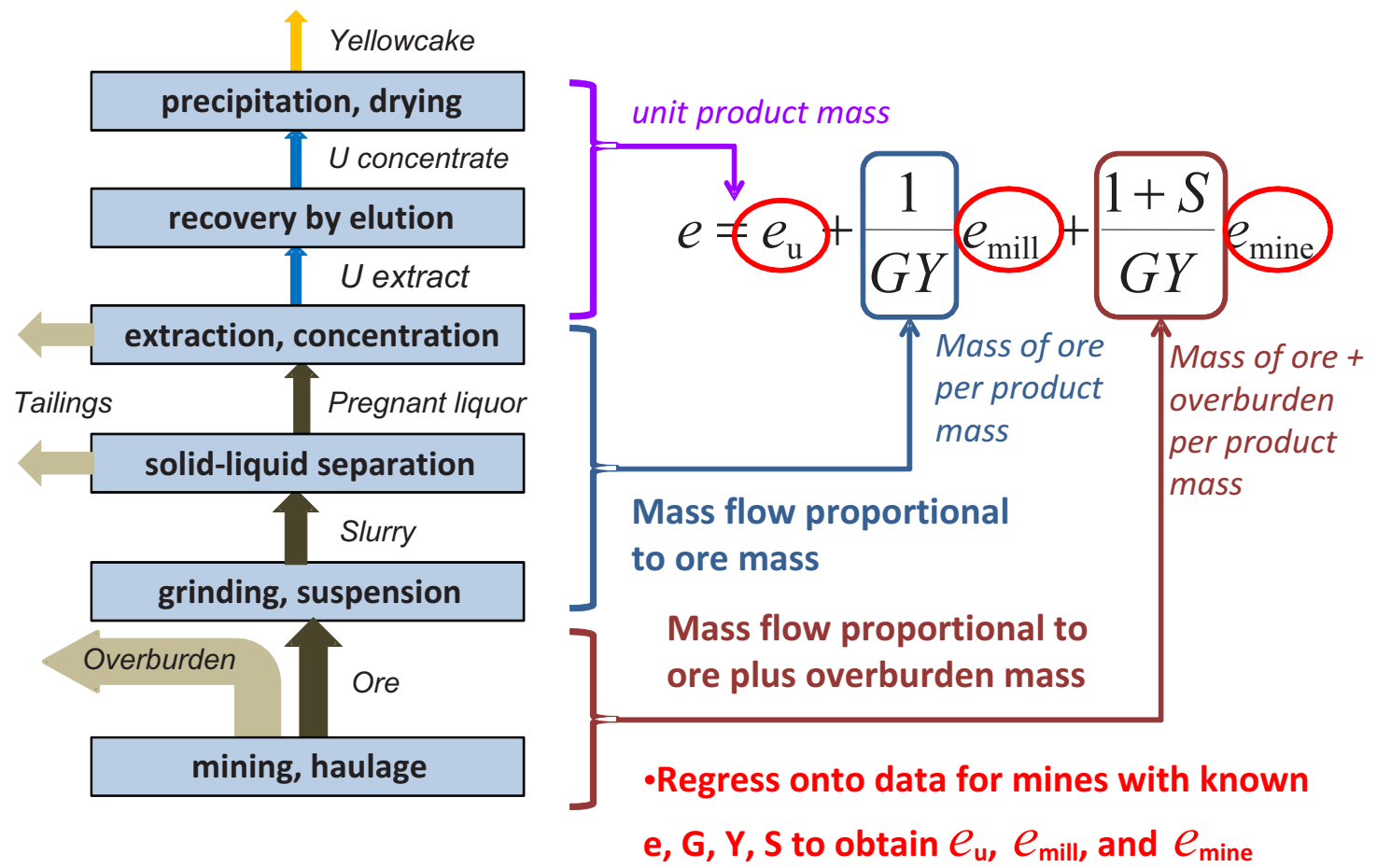

Figure 3.10. Relationship between mine and mill mass flows and top-down model terms for open pit mining

In principle, the same model, albeit with a distinct $\mathrm{e}_{\text {mine }}$ coefficient reflecting the assumedly larger energy intensity of excavation and haulage, should also describe underground mining. However all three underground mines in the data set have unique characteristics that complicate the employment of their data in the top-down model.

Flooding caused production at Rabbit Lake to be curtailed in 2007; in addition to pumping activities associated with water removal, remediation of effluent seepage into neighboring Hidden Bay may contribute to the energy consumption reported at this mine. In addition, the Rabbit Lake mill processes ore from the Eagle Point and part of the Cigar Lake mines; these activities may not be fully captured in the reported mass balance data [Wise Uranium 2008]. As mentioned earlier, McArthur river ore is crushed and ground - the first steps of the traditional milling process - underground at the mine prior to shipment to Key Lake for further milling. Uranium is a secondary product at Olympic Dam, where surface mining techniques are also used and waste rock haulage and energy consumption are reported only for the mine as a whole. [Mudd 2008a] studied the infrastructure at Olympic Dam associated with each product; he recommended that $20 \%$ of waste rock haulage and energy consumption be ascribed to uranium-related activities. This recommendation was used to create the data set for Olympic Dam shown in Appendix B, but the 20\% partition applies to mining and milling as a whole, Hence it is not useful for deriving energy co-efficients unique to these two steps. Only the McArthur River/Key Lake and Olympic Dam data sets were retained for the underground mining analysis.

The underground mines all feature similar (low) stripping ratios. The regression coefficient $\mathrm{e}_{\text {mine }}$ is multiplied by a factor $(1+\mathrm{S}) / \mathrm{GY}$, whereas $\mathrm{e}_{\text {mill }}$ is multiplied by $1 / \mathrm{GY}$. If there is little variation in $\mathrm{S}$ between members of the data set, the regression analysis cannot differentiate the energy consumption that is a consequence of mining from that of milling, leading to poor statistical confidence in one or both of the regression parameters $\mathrm{e}_{\text {mine }}$ and $\mathrm{e}_{\text {mill }}$. 
For the above reasons, mining and milling are aggregated in the top-down model for underground mining:

$$
e=\frac{100}{G Y} e_{m m}+e_{u} \cdot \text { (underground mining) }
$$

Therefore, the $\mathrm{e}_{\mathrm{mm}}$ coefficient appearing here is unique to underground mining, but the $\mathrm{e}_{\mathrm{u}}$ coefficient is the same as the one appearing in equation 3.2. The regression onto the open pit mine data - that from Rossing, Ranger and McClean Lake - onto equation 3.2 is carried out together with the regression of the underground mines onto equation 3.3, so that both data sets contribute to determining the value of $\mathrm{e}_{\mathrm{u}}$. It is critical to note that $e_{m m}$ should be interpreted as the energy $-G J(t+e)$ per tonne ore - to mill one tonne of ore plus the energy to mine the ore plus overburden by the underground technique with low stripping ratio's comparable to the mines used in the regression analysis $(\mathrm{S}<1)$. While this condition limits the scope of the underground model, the restriction is not as restrictive as it may seem. Stripping ratios in underground metal mines are generally considerably lower than in open pit mines. This is true for uranium as well [IAEA 2000].

Table 3.6 shows the coefficients obtained for open pit (OP) and underground (UG) mining by regressing the Appendix B data for the aforementioned mines onto equations 3.2 and 3.3 using the statistical analysis toolkit of Microsoft Excel. Actual mill yields derived from the data are used in the regressions: the yields are directly determined by evaluating the ratio of the uranium product to the uranium in the ore being milled. The R-squared value for the fit was 0.904 . The confidence intervals associated with the fit are small with the exception of the mining coefficient for open pit mining, $\mathrm{e}_{\text {mine. }}$. Here the regression suffers from a lack of data for open pit mines operating at high stripping ratios.

Table 3.6. Energy intensity coefficients obtained from regression analysis.

\begin{tabular}{lllcc}
\hline \multicolumn{1}{c}{ Coefficient } & Applies to & \multicolumn{1}{c}{ Value } & $\begin{array}{c}\text { Standard Error } \\
{[\mathrm{GJ}(\mathrm{t}+\mathrm{e}) / \mathrm{t}]}\end{array}$ & T Statistic \\
\hline $\mathrm{e}_{\mathrm{u}}$ & OP, $\mathrm{UG}$ & $178[\mathrm{GJ}(\mathrm{t}+\mathrm{e}) / \mathrm{tU}]$ & 12.2 & 14.6 \\
$\mathrm{e}_{\text {mill }}$ & OP & $0.0236[\mathrm{GJ}(\mathrm{t}+\mathrm{e}) /(\mathrm{t}$ of ore $)]$ & 0.0053 & 4.44 \\
$\mathrm{e}_{\text {mine }}$ & OP & $0.0125[\mathrm{GJ}(\mathrm{t}+\mathrm{e}) / \mathrm{t}($ ore + overburden $)]$ & 0.0119 & 1.04 \\
$\mathrm{e}_{\mathrm{mm}}$ & $\mathrm{UG}$ & $0.291[\mathrm{GJ}(\mathrm{t}+\mathrm{e}) /(\mathrm{t}$ of ore $)]$ & 0.0340 & 8.55 \\
\hline
\end{tabular}

For open pit mining these intensities may be compared to average data reported for the nine mines surveyed in [CIPEC 2005] (seven for the case of milling, where there is no directly analogous process in surface mining of oil sands). The [CIPEC 2005] data did not consider refining operations at the three iron mines, but it incorporated electrowinning and refining at the four gold mines within the milling process. Therefore the interpretation of the $\mathrm{e}_{\text {mill }}$ reported in [CIPEC 2005] is broader than in the present study. While an exact match is not expected as the [CIPEC 2005] data is drawn from mines and mills with widely varying products (and indeed considerable inter-mine variation is seen), the comparison can provide an order-of-magnitude check as well as illuminate the role played by the $\mathrm{e}_{\mathrm{u}}$ coefficient. To facilitate comparison with the mining and milling coefficients in Table 3.7, $\mathrm{e}_{\mathrm{u}}$ from the current model is multiplied by $\left(\mathrm{G}^{*} \mathrm{Y} / 100\right)$ with $\mathrm{G}=0.1\left[\% \mathrm{U}_{3} \mathrm{O}_{8}\right]$, an average value for current mines. The resulting quantity carries the same units as $\mathrm{e}_{\text {mill }},[\mathrm{GJ}(\mathrm{t}+\mathrm{e}) / \mathrm{t}$ ore $]$, and part of it is conceptually ascribed to mine and mill inputs that cannot be described by the $(1 / \mathrm{G})$ model.

e. Energy consumption data for Cluff Lake was not available. 
Table 3.7. Comparison of uranium energy intensity coefficients to those reported in [CIPEC 2005] for gold and iron and (mining only) oil sands.

\begin{tabular}{lcc}
\hline \multicolumn{1}{c}{ Coefficient } & $\begin{array}{c}\text { [CIPEC 2005] } \\
\text { Value (Std. Dev. })\end{array}$ & This Study \\
\hline $\mathrm{e}_{\text {mine }}[\mathrm{GJ}(\mathrm{t}+\mathrm{e}) / \mathrm{t}$ ore $+\mathrm{ob}]$ & $0.021(0.005)$ & 0.0125 \\
$\mathrm{e}_{\text {mill }}[\mathrm{GJ}(\mathrm{t}+\mathrm{e}) / \mathrm{t}$ ore $]$ & $0.092(0.031)$ & 0.0236 \\
$(\mathrm{G} / 100) * \mathrm{Y}^{*} \mathrm{e}_{\mathrm{u}}[\mathrm{GJ}(\mathrm{t}+\mathrm{e}) / \mathrm{t} \text { ore }]^{\mathrm{a}}$ & - & 0.162
\end{tabular}

a. $\mathrm{G}=0.1\left[\% \mathrm{U}_{3} \mathrm{O}_{8}\right], \mathrm{Y}=0.91$ from equation 3.1; see text above.

Table 3.7 supports the interpretation of $\mathrm{e}_{\mathrm{u}}$ suggested above, particularly for mill operations. Note that the models presented here still predict $(1 / \mathrm{G})$-governed growth in energy consumption to dominate as $\mathrm{G}$ becomes small.

A number of conditions rendering a deposit unsuitable for exploitation by conventional means may make it attractive for in-situ leaching (ISL). Deep ore bodies, especially those located below the water table, are candidates for ISL. Favorable geological conditions must exist: e.g. the deposit might reside in a permeable rock formation like sandstone, especially if proximate to a fault zone. Although overall deposit yields are lower than in conventional mining, given similar ore grade ISL can be less costly and energyintensive, making it attractive for lower-grade or unfavorably-shaped deposits [EPA 2008].

[Prasser 2008] observes that his model of the form of equation 3.2, derived for open-pit mines, provides a reasonable prediction of the energy intensity of the Beverley ISL mine if S is set to zero (see Figure 3.4). The physical reasoning behind this is that the physical distinction between the mass flows in the mining and milling processes does not apply to ISL. Since in-situ leaching eliminates haulage of ore and waste rock as well as the grinding/suspension and subsequent solid/liquor separation steps, energy requirements leading up to uranium extraction and refining are governed by the scale of the leach liquor pumping activity. Also, unlike the milling yield in conventional mining, ISL mines report an estimated overall ore body yield, defined as the fraction of the uranium residing in a deposit through which liquor is being pumped that reaches the product stream. Thus it combines the conventional milling yield defined in equation 3.1 above with the fraction of the uranium residing in the formation that is returned from the wellfield. In practice, leaching is terminated well before the ore body is fully depleted, because the uptake rate of uranium to the leach liquor is proportional to its concentration. The overall yield of the ISL process would thus be expected to decline with the ore grade, in a manner qualitatively similar to that of equation 3.1 .

The Beverley mine reports an overall yield of 0.65 [OECD 2008]; the average grade of the formation is $0.15 \% \mathrm{U}_{3} \mathrm{O}_{8}$. Equation 3.1 predicts a mill yield of 0.93 at this grade. Scaling equation 3.1 by a factor of $0.65 / 0.93=0.70$ provides a rough estimate of the practical yield for ISL, $\mathrm{Y}_{\text {isl }}$ :

$\mathrm{Y}_{\text {isl }}=0.686-0.0506(\log \mathrm{G})^{2}$.

The empirical correlation describing the energy consumption e of an ISL mine becomes:

$e=\frac{100}{G Y_{i s l}} e_{i s l}+e_{u}$, (in situ leaching) 
where $\mathrm{e}_{\text {isl }}[\mathrm{GJ}(\mathrm{t}+\mathrm{e}) / \mathrm{t}$ ore] reflects the energy required to pump leach liquor through an ore body. The expression recognizes that liquor must be pumped through 100/GY tonnes of ore to yield one tonne of $U$. Note that this approach could also be applied to heap leaching, which is usually applied to low grade ores from surface mines that are not worthwhile to mill by conventional means ${ }^{\mathrm{f}}$.

Given its broad interpretation, the $\mathrm{e}_{\mathrm{u}}$ coefficient for ISL is not restricted to take on the same value as that for open pit and underground mining. Since data was available for only one ISL mine, Beverley, it is not possible to carry out a full regression onto equation 3.5: even though several years' data for Beverley are available, regression analysis would not be able to differentiate the contributions to e from $\mathrm{e}_{\mathrm{u}}$ and $\mathrm{e}_{\mathrm{isl}}$ since $\mathrm{G}$ and $\mathrm{Y}_{\text {isl }}$ are the same for each year of data.

Therefore, the observation of Prasser that ISL is qualitatively similar to surface mining with zero stripping ratio is applied. Taking $S=0$ in equation 3.2 leads to an equation of form 3.5 with $\mathrm{e}_{\text {isl }}$ identified with $\mathrm{e}_{\operatorname{mine}}$ $+\mathrm{e}_{\text {mill }}$ of equation 3.2. Note (Figure 3.5 and Appendix B) that the energy consumption per unit product at Beverley is rather lower than that of conventional mines of similar grade. In fact, evaluating equation 3.2 with $\mathrm{S}=0, \mathrm{G}=0.15 \%$, the average grade of the Beverley deposit, and $\mathrm{Y}$ as given by equation 3.1 yields $\mathrm{e}$ $=0.202 \mathrm{GJ}(\mathrm{t}+\mathrm{e}) / \mathrm{kg} \mathrm{U}$. But taking the average thermal plus electrical energy consumption at Beverley per unit of product over 2003-07, the years for which data is available, gives $0.167 \mathrm{GJ}(\mathrm{t}+\mathrm{e}) / \mathrm{kg} \mathrm{U}$. This suggests that a first approximation to the energy intensity of ISL could be obtained by scaling the $\mathrm{e}_{\mathrm{u}}$ term of the open pit model by a factor $(0.167 / 0.202)=0.82$ and the $\left(\mathrm{e}_{\text {mine }}+\mathrm{e}_{\text {mill }}\right) / \mathrm{GY}$ term by $(0.167 / 0.202) *\left(\mathrm{Y}_{\text {isl }} / \mathrm{Y}\right)$, where $\mathrm{Y}_{\text {isl }}=0.65$ at $\mathrm{G}=0.15 \%$ (equation 3.4) and the conventional mine yield $\mathrm{Y}=$ 0.93 at the same grade (equation 3.1). This factor evaluates to 0.58 , leading to the ISL model coefficients given in Table 3.8.

Table 3.8. Coefficients for ISL energy intensity model, equation 3.5

\begin{tabular}{lc}
\multicolumn{1}{c}{ Coefficient } & Value \\
\hline $\mathrm{e}_{\text {isl }}[\mathrm{GJ}(\mathrm{t}+\mathrm{e}) / \mathrm{t}$ ore in ground $]$ & 0.021 \\
$\mathrm{e}_{\mathrm{u}}[\mathrm{GJ}(\mathrm{t}+\mathrm{e}) / \mathrm{tU}]$ & 146 \\
\hline
\end{tabular}

The open pit, underground and ISL grade-energy relations (equations 3.2, 3.3 and 3.5) are displayed with the mine data in Figure 3.11. The open pit model, equation 3.2, is plotted for two stripping ratios, 1.15 (corresponding to the average $\mathrm{S}$ at Rossing) and 35 (the highest reported $\mathrm{S}$ at the Canadian mines). Also plotted are the direct energy consumption from early 1960s US mines used by [Chapman 1975] as one data point in formulating his model, along with the direct energy consumption predicted for a hypothetical underground mining operation on low-grade Chattanooga shales [Bieneiwski 1971] that served as Chapman's second data point. A data point, reported by [Rotty 1975] and reflected the productionweighted average direct energy requirements of US mines operating in the early 1970s, is also included. The change over the past 50 years may be ascribed to the advent of ISL, the advance of technology, energy efficiency measures impelled by higher energy costs, mineralogical characteristics at most 1960s

f. Heap leaching involves two steps: grinding of ore to a sandy consistency to increase the surface-area-to-volume ratio of the ore grains, followed by continuous spray of the ore pile by an acidic or basic leach solution. The ore is placed on an impermeable pad, and the pregnant leach liquor is collected at an outflow point. Uranium extraction from the liquor then proceeds normally. This approach does not offer high product yield, but given its passive nature, it can be profitable if used on below-grade ore piles not considered suitable for conventional milling. Although not in widespread use at present, heap leaching was used on a small scale in the 1970s and 1980s and may again become more attractive if uranium prices remain high [EPA 2008]. 
and 70s US mines, and economies of scale. The facilities surveyed in the present data set range in size from $\sim 1,000-8,000 \mathrm{tU}_{3} \mathrm{O}_{8} /$ year.

The gradual decline, on a per unit product basis, in energy and other inputs that drive the extraction cost has been observed elsewhere in the mining industry. The authors of a 2008 EPA mine and mill remediation study observed that "the costs of moving the overburden and ... of processing ore at mills also influence the overall economics of underground and surface mining. These costs have steadily declined, and have lowered the ore grade that is economically feasible to extract. Thus, while an ore grade of 0.15 percent was often ignored in the early mining years, newer, more efficient ore extraction techniques have targeted ore grades as low as 0.03 percent..." [EPA 2008].

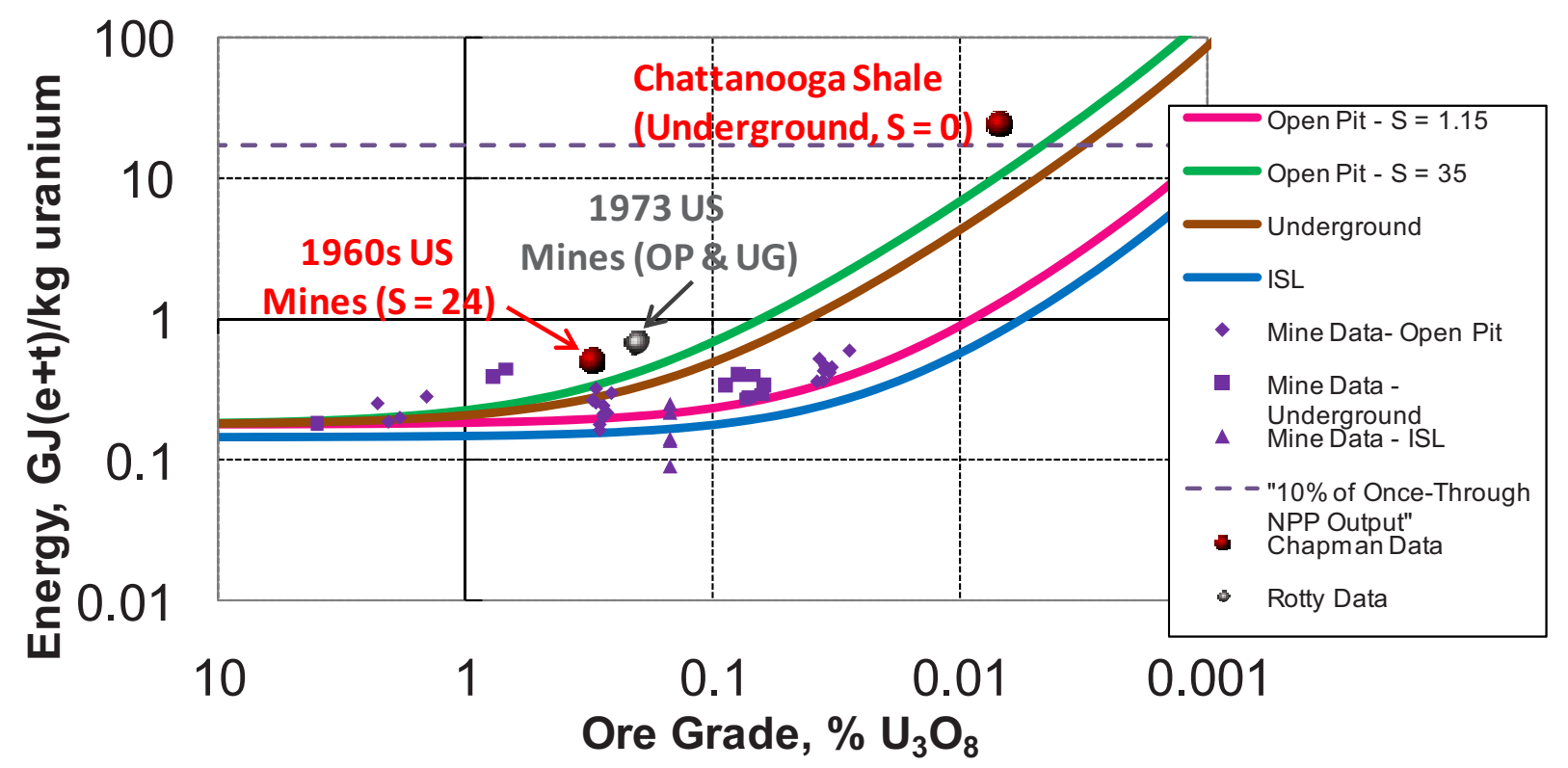

Figure 3.11. Results of current model and regression data

Comparing Figure 3.11 to Figure 3.5, it is seen that the current model significantly improves upon Prasser's predictions for ore grades of greater than $0.1 \% \mathrm{U}_{3} \mathrm{O}_{8}$ where the $\mathrm{e}_{\mathrm{u}}$ term governing uranium refining and other grade-insensitive energy inputs plays a much larger role in determining energy use. The current model agrees with Prasser at lower grades where ore milling and overburden haulage dominate the energy balance.

One of the open pit mines, Rossing, disaggregates energy consumption into the contribution from thermal and electrical energy carriers for 1999-2001. Although the available data does not associate the thermal and electrical energy consumption with steps in the mining/milling/refining process, it does provide an overall breakdown against which the model and energy carrier breakdown may be compared. Figure 3.12 shows that applying equation 3.2 with the intensity coefficients of Table 3.6 and the energy carrier breakdown provided by Table 3.4 leads to predictions that are in reasonable agreement with the split actually observed in operations at Rossing. This procedure for disaggregating of energy consumption will become important when the carbon footprint of the extraction process is estimated. 


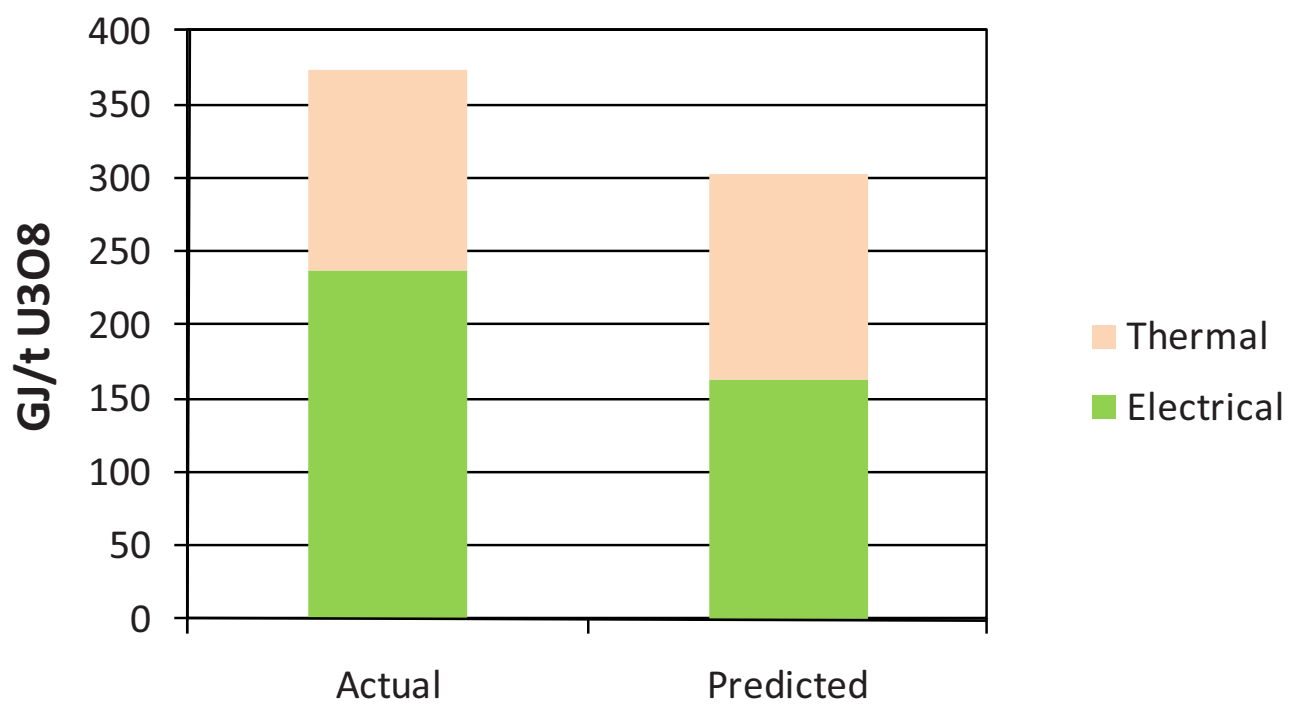

Figure 3.12. Energy consumption by energy carrier, Rossing (1999-2001 avg.)

\subsection{Carbon Footprint}

Two caveats attach to any analysis of $\mathrm{CO}_{2}$ emissions. First, the supply chain associated with end-use energy must be considered. Mines reporting $\mathrm{CO}_{2}$ emissions always do so on the basis of direct emissions associated with the energy they consume. For example, if a mine consumes diesel fuel and electricity, the emissions it reports will be those associated with the combustion of the diesel plus those arising from the combustion of the fossil fuel in the electricity generation plant. Indirect emissions such as those associated with the extraction and refining of petroleum or natural gas are not included, although mines generally obtain electricity emissions data from the relevant national agency, so standards in that area may vary.

Second, mines usually report only total energy consumption (a combination of thermal energy from liquid fuel combustion and electrical energy). Mines sometimes also report the consequent total emissions, but not the breakdown of consumption and emissions by energy carrier. Therefore it is also necessary to rely upon the estimates of energy consumption breakdown by energy carrier presented in section 3.1.1 above.

The calculations leading to the emission estimate for each mine are carried out as outlined in Table 3.9. 
Table 3.9. Emission calculation methodology

Step Open Pit

1. Compute energy intensities $[\mathrm{GJ}(\mathrm{t}+\mathrm{e}) / \mathrm{tU}]$ for each step of the mining, milling, refining process

2. Disaggregate energy intensities into electrical, liquid thermal and other thermal carriers

3. Multiply energy intensities by appropriate emission factors $\left[\mathrm{tCO}_{2} / \mathrm{GJ}\right]$

$\begin{array}{lll}\text { Equations } & \text { Equations } & \text { Equations } \\ \text { 3.1, 3.2 and } & 3.1,3.3 \text { and } & 3.4,3.5 \text { and } \\ \text { Table 3.6 } & \text { Table 3.6 } & \text { Table 3.8 }\end{array}$

Table $3.4 \quad$ See note "a" Table 3.4

Table $2.2 \quad$ Table $2.2 \quad$ Table 2.2

a. "The underground mining energy intensity model (equation 3.3) combines the mining and milling steps into a single term. To calculate the carbon footprint, the per-step mining and milling breakdowns listed in Table 3.4 must be combined; for this purpose, a 50\% (mining) / 50\% (milling) contribution is assumed. This assumption is based on Appendix B data from the McArthur River underground mine and Key Lake mill, which processes the McArthur River ore. The data show similar total energy consumption for the mining and milling steps. Taking this estimate results in the following breakdown: $46 \%$ electricity, $38 \%$ liquid thermal carrier, $16 \%$ other thermal carrier."

To validate the approach, the resultant emission estimate $\left[\mathrm{tCO}_{2} / \mathrm{tU}\right]$ is compared to mine-reported emission data when available, or independently-derived emission estimates taken from [Mudd 2008b] when not. The recommendation of [Mudd 2007b] that uranium-related activities contribute $20 \%$ to the energy consumption of the Olympic Dam mine was applied to reported emissions. Figure 3.13 shows the data against which the $\mathrm{CO}_{2}$ emission estimates will be compared, the reported emissions for each mine in the data set. Data points reflect annual intervals; therefore several points may be associated with a single mine. 


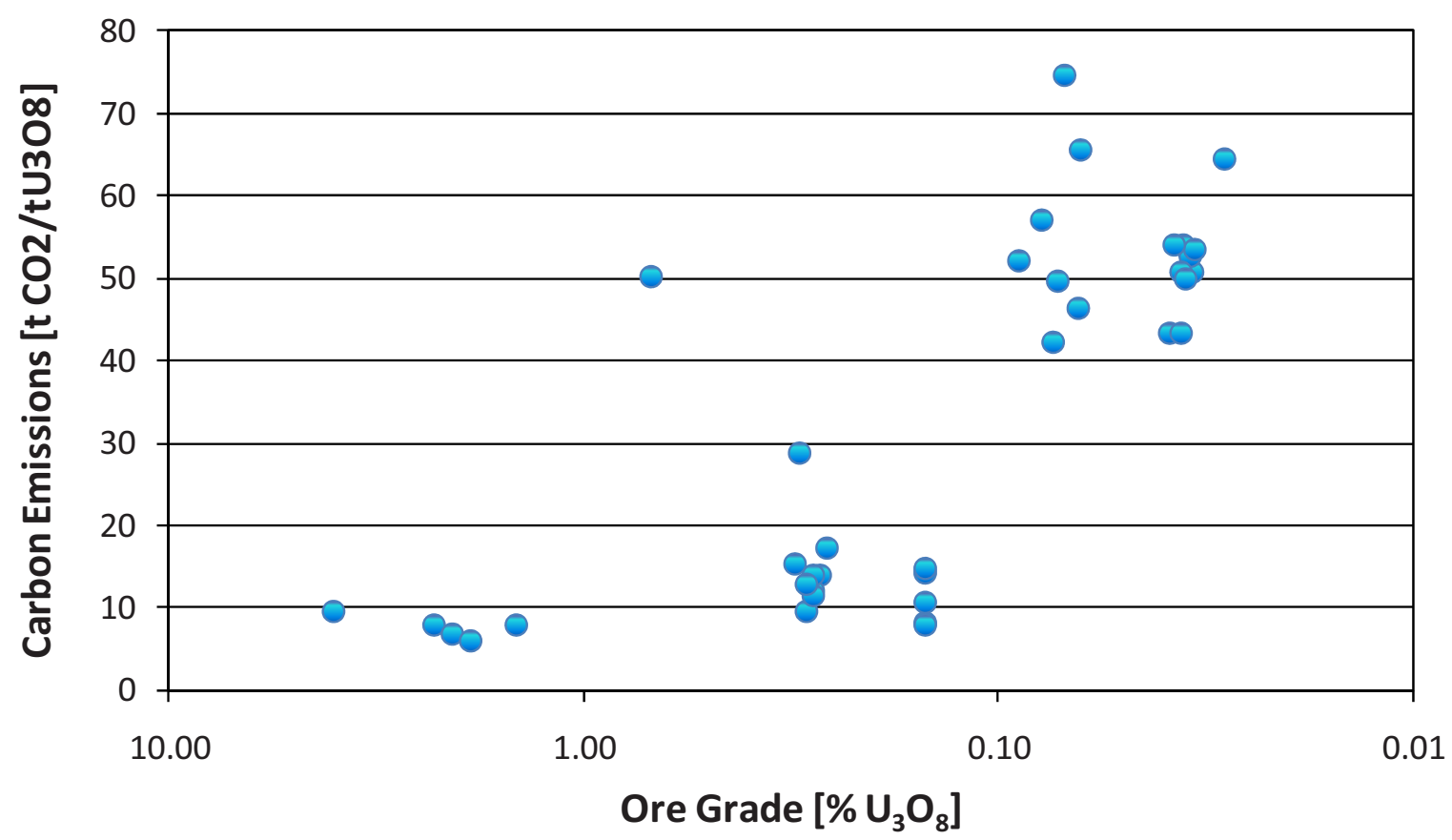

Figure 3.13. Carbon Emissions versus ore grade, all data mine-reported or independently estimated in [Mudd 2008b]

Figure 3.14 plots reported against predicted emissions, in both cases averaged over all years for which data for a given mine is available. Agreement between predicted and reported $\mathrm{CO}_{2}$ emissions is seen to be good for the reporting mines. 


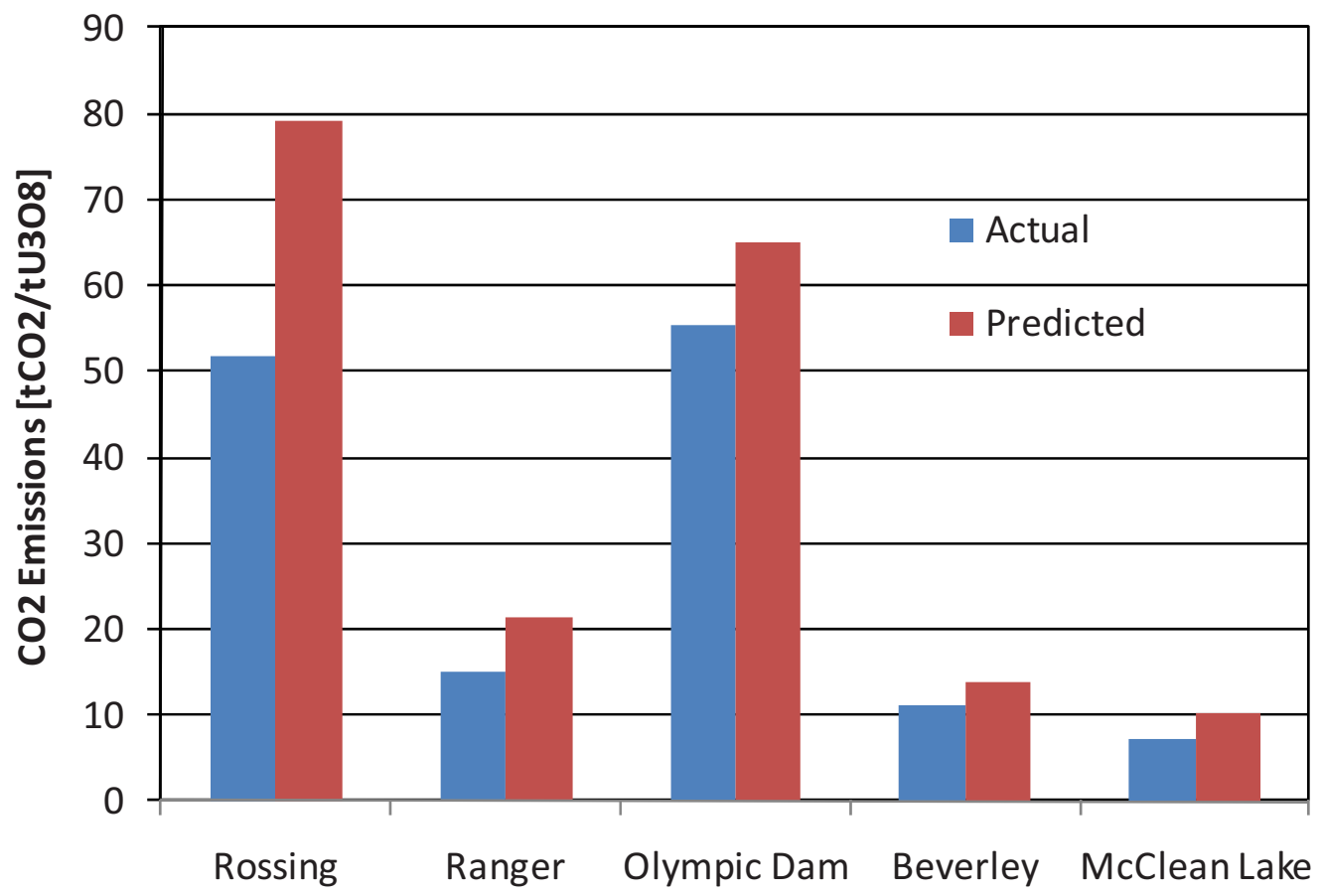

Figure 3.14. Carbon emissions, forecast versus data

As was the case for energy consumption, the approach formulated above can be employed to correlate emissions to ore grade for the industry as a whole. In 2009, world uranium production was divided as follows: $23 \%$ open pit mining, $41 \%$ underground, and $36 \%$ ISL $^{g}$ [WNA 2010]. Figure 3.15 shows the result of such a correlation under the following assumptions: production distributed as given above, an open pit stripping ratio of 4 , the average value at Ranger, electricity emissions factors at the 2009 world average, and $172 \mathrm{GJ}(\mathrm{e})(47.8 \mathrm{MWh}(\mathrm{e}))$ of nuclear electricity production per kilogram of mined uranium as derived in Appendix A. Note again that this plot reflects only emissions associated with the combustion of thermal and electrical energy carriers associated with front-end processes up through uranium refining (i.e. production of yellowcake), not the life cycle footprint. Note also that emission coefficients may be expected to decline with time as the world electricity generation mix changes and technological change and/or regulation reduce the contribution from fossil-fired capacity. This topic is addressed further in section 9.

g. Ascribing heap leaching ( $2 \%$ of the total) to open pit mining, which it usually accompanies, and assigning Olympic Dam, which was put in the category of by-product in the Redbook and elsewhere, to underground mining. 


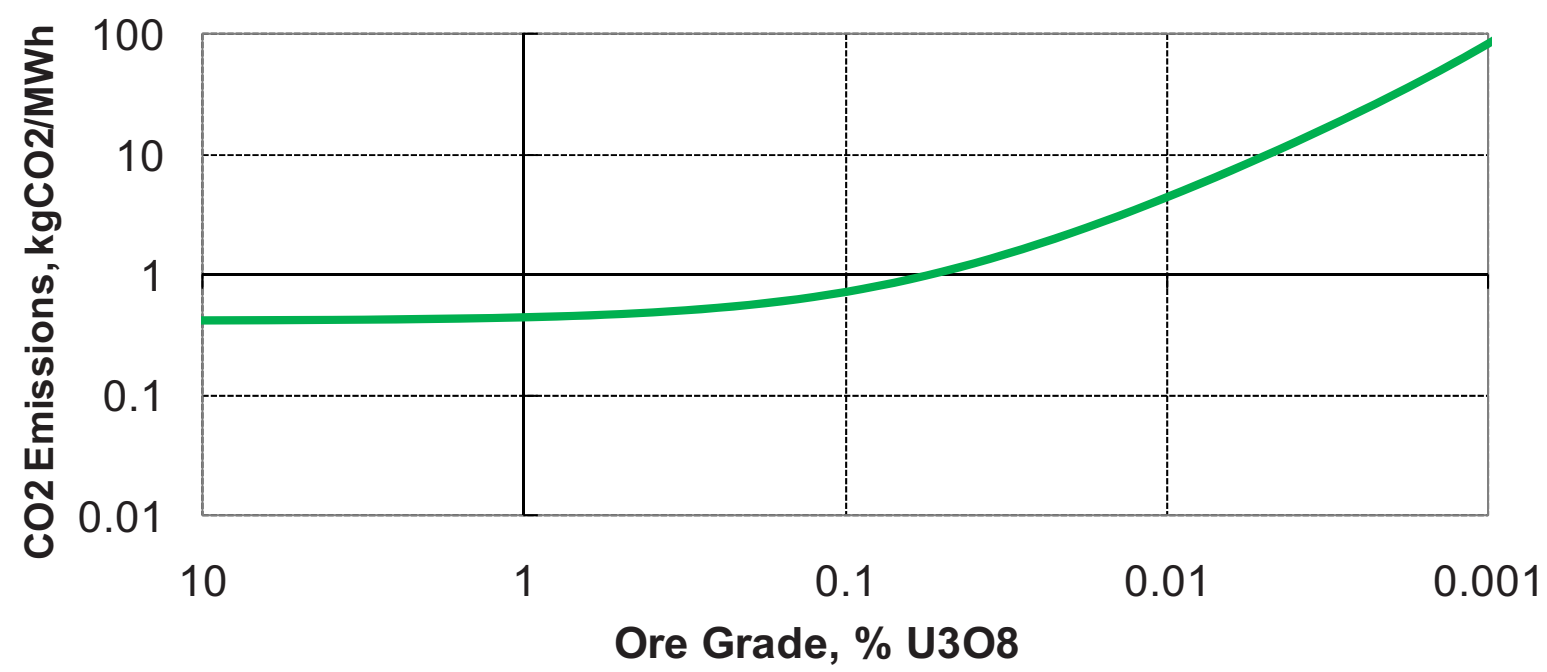

Figure 3.15. Predicted correlation between carbon emissions and ore grade, mining technology mix according to 2009 breakdown, world-average emission coefficients (see Table 2.2)

Given this correlation and a 2008 industry-average ore grade of $0.1 \% \mathrm{U}_{3} \mathrm{O}_{8}$, the contemporary direct carbon emissions associated with uranium extraction are estimated at $0.73 \mathrm{kgCO}_{2} / \mathrm{MWh}(\mathrm{e})$.

\subsection{Land Use}

Estimates of land use for generic mining/milling operations exhibit considerable variation. All of the reviewed estimates focus on conventional (open pit or underground) mining; no estimates for land use associated with ISL were found, nor were any forecasts of how land use may change as the grade of the ore being mined and milled declines.

Table 3.10 shows three reviewed estimates of land use. Each of these was specified in a different way. [Fthenakis 2009] specified disturbed land in units of $\mathrm{m}^{2}$ per $\mathrm{GWh}(\mathrm{e})$ of nuclear electricity produced. Since [Fthenakis 2009] did not give the details of the fuel cycle upon which this estimate was based (i.e., no value for the electricity production associated with $1 \mathrm{~kg}$ of extracted uranium was given), the fuel cycle of Appendix A was used to convert the result to units of $\mathrm{m}^{2} / \mathrm{tU}$ (1 $\mathrm{kg}$ of natural uranium is assumed to produce $172 \mathrm{GJ}(\mathrm{e})=0.478 \mathrm{GWh}(\mathrm{e}))$. [Finch 1997] specified mine and mill footprints associated with the operation of a $1 \mathrm{GW}(\mathrm{e})$ plant assumed to operate for 30 years and provided the uranium requirements for this plant so no assumptions were needed. [Eliasson 2003] simply gave land use directly in units of $\mathrm{m}^{2} / \mathrm{tU}$.

Table 3.10. Reviewed estimates of mining and milling/refining land use

\begin{tabular}{lccl}
\hline \multicolumn{1}{c}{ Source } & $\begin{array}{c}\text { Mining Land Use } \\
{\left[\mathrm{m}^{2} / \mathrm{tU}\right]}\end{array}$ & $\begin{array}{c}\text { Milling/Refining } \\
\text { Land Use }\left[\mathrm{m}^{2} / \mathrm{tU}\right]\end{array}$ & $\begin{array}{c}\text { Conditions (mining technology, } \\
\text { ore grade, etc.) }\end{array}$ \\
\hline [Fthenakis 2009] & 1,430 & 478 & None specified \\
[Finch 1997] & 14.9 & 58.5 & $\mathrm{G}=0.2 \%$, open pit mine \\
[Eliasson 2003] & 200 (open pit) & 100 & No grade specified \\
& 7 (underground) & & \\
\hline
\end{tabular}

The estimates of disturbed land area per unit of product are seen to vary by two orders of magnitude. Therefore, primary data from several mines was collected and a correlation was sought. The data and sources are presented in Table 3.11. 
Table 3.11. Underground and open pit mine land use data

\begin{tabular}{|c|c|c|c|c|c|c|}
\hline $\begin{array}{c}\text { Site / Data } \\
\text { Source }\end{array}$ & $\begin{array}{c}\text { Uranium } \\
\text { produced } \\
{[\mathrm{tU}]^{\mathrm{a}}}\end{array}$ & $\begin{array}{c}\text { Deposit } \\
\text { grade }[\% \\
\left.\mathrm{U}_{3} \mathrm{O}_{8}\right]\end{array}$ & $\begin{array}{l}\text { Strip } \\
\text { Ratio }\end{array}$ & $\begin{array}{l}\text { Mining } \\
\text { method }\end{array}$ & $\begin{array}{l}\text { Disturbed } \\
\text { area }\left[\mathrm{km}^{2}\right]\end{array}$ & $\begin{array}{c}\text { Disturbed } \\
\text { area/product } \\
{\left[\mathrm{m}^{2} / \mathrm{tU}\right]}\end{array}$ \\
\hline $\begin{array}{l}\text { Rum Jungle }^{\text {b }} \\
\text { [Harries 1997] }\end{array}$ & 2,970 & 0.30 & 12.1 & UG\&OP & 0.78 & 263 \\
\hline $\begin{array}{l}\text { Mary Kathleen } \\
\text { [Harries 1997] }\end{array}$ & 10,700 & 0.17 & 3.4 & OP & $\begin{array}{l}\text { Mine: } 0.89 \\
\text { Mill: } 0.60 \\
\text { Total: } 1.49\end{array}$ & $\begin{array}{c}\text { Mine: } 83 \\
\text { Mill: } 56 \\
\text { Total: } 139\end{array}$ \\
\hline $\begin{array}{l}\text { Nabarlek [Mudd } \\
\text { 2007a], [Evans } \\
\text { 2005] }\end{array}$ & 9,210 & 1.9 & 2.8 & $\mathrm{OP}$ & 1.4 & 152 \\
\hline $\begin{array}{l}\text { Ranger [Mudd } \\
\text { 2007a], [Harries } \\
\text { 1997] }\end{array}$ & 121,000 & 0.31 & 4 & $\mathrm{OP}$ & 5.0 & 41.2 \\
\hline $\begin{array}{l}\text { Pinon Ridge } \\
\text { [Energy Fuels } \\
\text { 2009] }\end{array}$ & $\begin{array}{l}15,500 \\
\text { (milled) }\end{array}$ & 0.23 & - & Mill only & Mill: 3.56 & Mill: 231 \\
\hline $\begin{array}{l}\text { Cigar Lake } \\
\text { [OECD 2008] }\end{array}$ & 94,900 & 17.4 & $\begin{array}{l}\text { Not } \\
\text { avail. }\end{array}$ & UG & 3.08 & 32.4 \\
\hline $\begin{array}{l}\text { Rossing } \\
\text { [Rossing 2010] }\end{array}$ & 117,700 & 0.03 & 1.15 & $\mathrm{OP}$ & 20.0 & 170 \\
\hline
\end{tabular}

a. Pproduction from mine opening through closure. If production is ongoing, the reserves remaining in the ground are multiplied by a yield function Y (equation 3.1).

b. Rum Jungle produced $382,000 \mathrm{t}$ of ore containing $\mathrm{Pb}, \mathrm{Cu}$ and $\mathrm{Co}$ as well as 1,111,000 $\mathrm{t}$ bearing $\mathrm{U}$ and $\mathrm{Cu}$. Therefore, the disturbed area at Rum Jungle, $1.06 \mathrm{~km} 2$, was scaled down according to the proportion of the ore that yielded uranium to $0.78 \mathrm{~km} 2$.

The primary data shows the [Fthenakis 2009] and [Finch 1997] land use estimates to be about an order of magnitude too pessimistic and optimistic, respectively. It would be expected that land disturbance at underground mines would be smaller than at open pit facilities, although the need for overburden storage acts to equalize the land requirements to an extent. Given the scarcity of underground mine data, a single analysis as follows will be carried out for the open pit mines. Land disturbance $1\left[\mathrm{~m}^{2} / \mathrm{tU}\right.$ produced] is expressed in terms of grade $\mathrm{G}$, stripping ratio $\mathrm{S}$, yield function $\mathrm{Y}$ and land use intensity coefficients $1_{\text {mine }}$ $\left[\mathrm{m}^{2} / \mathrm{t}\right.$ ore $\left.+\mathrm{ob}\right]$ and $1_{\text {mill }}\left[\mathrm{m}^{2} / \mathrm{t}\right.$ ore $]$ as follows ${ }^{\mathrm{h}}$ :

$l=\frac{100}{G Y}\left((1+S) l_{\text {mine }}+l_{\text {mill }}\right)$.

h. Land disturbance is thus postulated to increase as ore grade declines. On a per-product basis, ore body, waste rock and tailings volumes will all increase, so the area disturbed through mining and milling activities would likewise grow. It would be reasonable to suppose that the disturbed area is not linearly related to these volumes, as equation 3.8 implies, but instead grows more slowly with declining grade, say as $(1 / \mathrm{G})^{\mathrm{x}}$ where $\mathrm{x}$ is a coefficient (assumedly between 0 and 1 ) to be determined, but the data set is not large enough to support such an analysis. 
Since the five available data points do not constitute a large enough set for meaningful statistical analysis along the lines of the regressions carried out in section 3.2, rough estimates of the intensity coefficients are obtained by

- assuming the mine-to-mill land use ratio at the Mary Kathleen mine, 1.49, to be representative, impose the condition $(1+\mathrm{S}) 1_{\text {mine }} / 1_{\text {mill }}=1.49$. Then, given the stripping ratio of Mary Kathleen, $1_{\text {mine }} / 1_{\text {mill }}=0.34$

- averaging the data for the five open pit mines to arrive at a single representative value for 1 as well as the overburden-to-product mass ratio $100(1+\mathrm{S}) / \mathrm{GY}$ and ore to product ratio $100 / \mathrm{GY}$ (they evaluate to $153 \mathrm{~m}^{2} / \mathrm{tU}, 3600 \mathrm{~m}^{2} / \mathrm{t}$ ore $+\mathrm{ob}$ and $1092 \mathrm{~m}^{2} / \mathrm{t}$ ore, respectively). This is the same averaging procedure that was followed by [Chapman 1975] to obtain a single data point representing the average energy consumption of the four conventional mines for which he had data;

- $\quad$ solving for $1_{\text {mine }}$ and $1_{\text {mill. }}$.

The resulting coefficients are $1_{\text {mine }}=0.0224 \mathrm{~m}^{2} / \mathrm{t}$ ore $+\mathrm{ob}$ and $1_{\text {mill }}=0.0660 \mathrm{~m}^{2} / \mathrm{t}$ ore. To estimate contemporary conventional mine land use, equation 3.6 is evaluated using the inputs relevant to present day mines identified in section 3.2, namely the current average grade of mined ore, $\mathrm{G}=0.1 \% \mathrm{U}_{3} \mathrm{O}_{8}$, the yield function of equation 3.1 and $\mathrm{S}=4$. This results in a land use estimate for present-day conventional mining of $196 \mathrm{~m}^{2} / \mathrm{tU}$, of which $73 \mathrm{~m}^{2} / \mathrm{tU}$ is ascribed to the mill.

Land use data for four ISL mines, three in the US and Beverley, was collected. The data is given in Table 3.12. Areas given for the US facilities encompass only the disturbed area or estimates of the disturbed area made according to trends reported in [EPA 2008]; full property areas may be much larger. As was the case for open pit mining, it will be assumed that the land disturbance area is proportional to the extent of the deposit, which in turn is inversely related to its ore grade. However, given that all four facilities are operating on deposits of similar ore grades, it is not possible to use a top-down model to test the assumption that the area of disturbed land is inversely proportional to ore grade with statistical confidence.

Table 3.12. Geographical footprint of ISL facilities

\begin{tabular}{llcccc}
\hline \multicolumn{1}{c}{ Facility } & Reference & $\begin{array}{c}\text { Deposit } \\
\text { Grade [\% } \\
\left.\mathrm{U}_{3} \mathrm{O}_{8}\right]\end{array}$ & $\begin{array}{c}\text { Deposit } \\
\text { Size [tU] }\end{array}$ & $\begin{array}{c}\text { Disturbed Land } \\
\left.\text { Area [ } \mathrm{km}^{2}\right]\end{array}$ & $\begin{array}{c}\text { Land Area per } \\
\text { Product }\left[\mathrm{m}^{2} / \mathrm{tU}\right]^{\mathrm{a}}\end{array}$ \\
\hline Rosita & [EPA 2008] & 0.081 & 1,630 & $\sim 0.92$ & 916 \\
Kingsville & [EPA 2008] & 0.088 & 1,730 & $\sim 0.94$ & 875 \\
Holiday/E1 & [EPA 2008] & 0.084 & 3,750 & 1.36 & 583 \\
$\begin{array}{l}\text { Mesquite } \\
\text { Beverley }\end{array}$ & [South & 0.15 & 14,000 & 4.00 (processing & 440 \\
& Australia & & & plant 1.0, & \\
& 1998] & & wellfields 3.0) & \\
\hline a. incorporates mine and mill yields. See text. & & & \\
\hline
\end{tabular}


Then, proceeding as above for conventional mining, land disturbance $1\left[\mathrm{~m}^{2} / \mathrm{tU}\right.$ produced] is expressed in terms of grade $G$, the ISL yield function $Y_{\text {isl }}$ and a land use intensity coefficient $1_{\text {isl }}\left[\mathrm{m}^{2} / \mathrm{t}\right.$ ore $]$ as follows:

$$
l=100 \frac{l_{i s l}}{G Y_{i s l}}
$$

$\mathrm{G}$ is taken from Table 3.12 and $\mathrm{Y}_{\text {isl }}$ from equation 3.4. It is important not to neglect $\mathrm{Y}_{\text {isl }}$ as it depicts the portion of the uranium in the ore that will emerge as product. Averaging the quantity $\mathrm{GY}_{\mathrm{isl}} 1 / 100$ over the four mines provides an estimate of $1_{\text {isl }}=0.417 \mathrm{~m}^{2} / \mathrm{t}$ ore.

Applying to equation 3.7 the representative present-day grade of mined ore, $\mathrm{G}=0.1 \% \mathrm{U}_{3} \mathrm{O}_{8}$, and evaluating the ISL yield function, equation 3.4, at that grade yields an estimate of the land intensity of contemporary ISL mining and processing of $663 \mathrm{~m}^{2} / \mathrm{tU}$. Note that the intrusiveness of the land disturbance from ISL mining is qualitatively lower than that of underground or open pit extraction. Remediation practices, which focus on surface and overburden restoration for conventional mining and water table remediation for ISL, reflect thisi.

\subsection{Water Use}

Most of the mines reporting energy-related statistics also report water consumption data (Appendix B). The correct interpretation of water consumption data is generally not transparent. Some mines, for instance Rossing, pursue an active water recycling program. Others differentiate between fresh and total water usage. And yet others distinguish between water withdrawals and water consumption. Where possible, overall (fresh + other) water withdrawal data are used in this section and credit is not taken for recycling. Mines reporting water use without differentiation between fresh and total have been retained in the data set; therefore it is assumed that such data indeed reflects total consumption.

As in section 3.2 where energy consumption was addressed, it is postulated that water consumption can be disaggregated into the same three components with energy consumption coefficients replaced by water consumption coefficients.

$$
w=\frac{100}{G Y}\left((1+S) w_{\text {min } e}+w_{\text {mill }}\right)+w_{u}
$$

Here, $\mathrm{w}(\mathrm{ML} / \mathrm{tU})$ is the water consumption per unit of product, $\mathrm{w}_{\text {mine }}\left[\mathrm{ML} / \mathrm{t}\right.$ ore + overburden], $\mathrm{w}_{\text {mill }}$ $[\mathrm{ML} / \mathrm{t}$ ore $]$ and $\mathrm{w}_{\mathrm{u}}[\mathrm{ML} / \mathrm{tU}]$ are coefficients to be obtained by regressing the relationship onto the

i. Remediation practices depend on mining method and local conditions. Mill tailings piles are lined and covered to preclude both transport of dissolved solids and dust and radon release to the atmosphere. If conditions are favorable, waste can be returned to the underground or open pit works, often following the installation of a dry-cover system that acts as a barrier to water transport. For a detailed review of these practices as well as the consequences of less rigorous environmental standards that prevailed at early mines and mills, see [EPA 2008].

Remediation of ISL facilities focuses on groundwater restoration. The procedure depends on the leach liquid employed during operations. Acidic lixiviants (e.g. sulfuric acid) are becoming less-widely used as they corrode the host material of the ore body and are more likely to lead to the mobilization of chemical and radioactive toxins. Carbon dioxide oxidant / sodium bicarbonate lixiviant solutions reduce the groundwater impacts and lead to less costly remediation. In either case, groundwater to be remediated is pumped to the surface for treatment. The resulting solids, collected in lined evaporation ponds, are disposed offsite. 
available data. Figure 3.16 shows the data set; the limited data set precludes separate treatment of underground and surface mining. Note that ISL (Beverley mine) will be treated separately below.

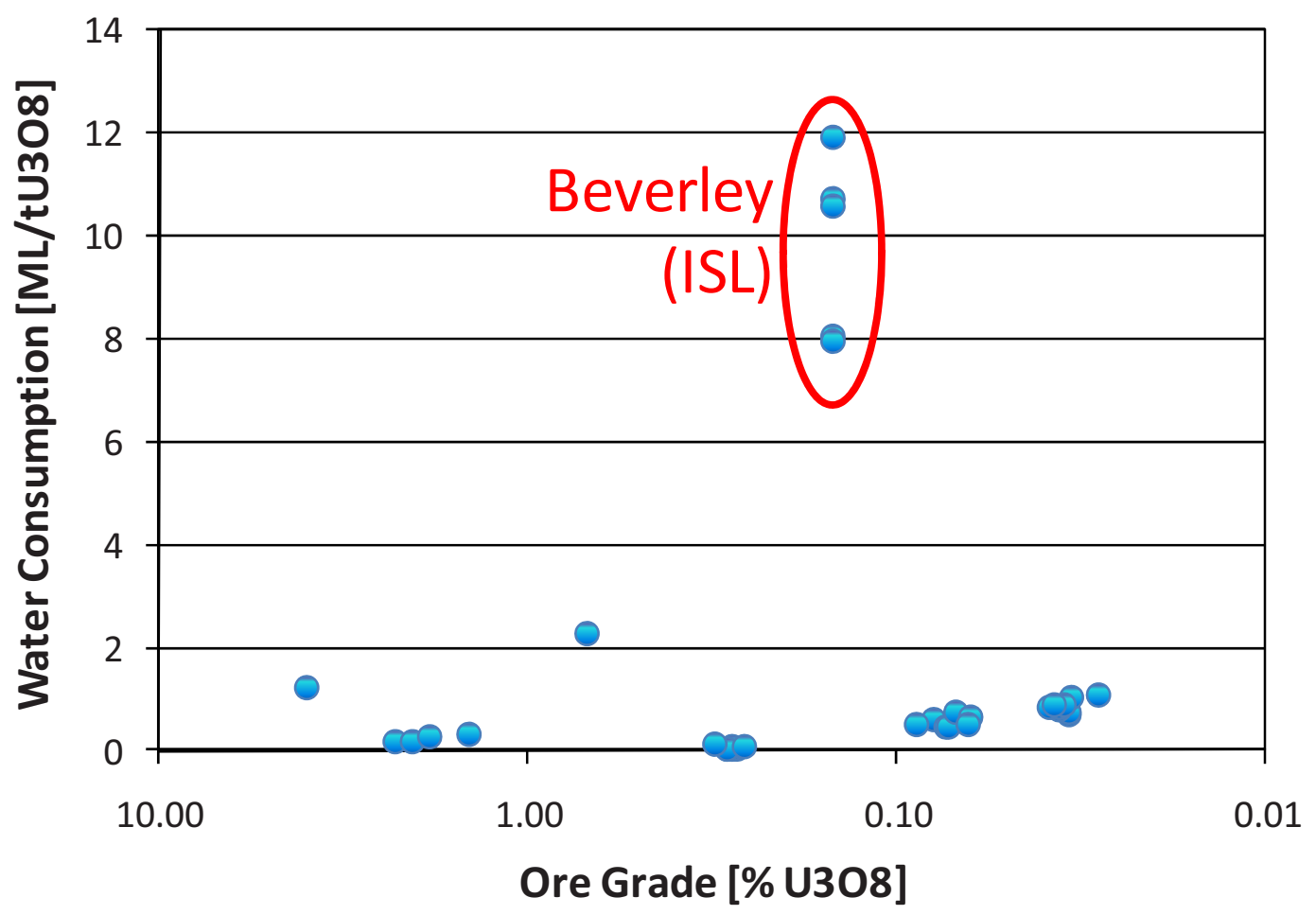

Figure 3.16. Water Consumption versus Ore Grade, all data

Upon performing the regression, it was found that the coefficient $\mathrm{w}_{\text {mill }}$ was not statistically significant even at the one standard deviation level. Following standard practice, this term, which evidently lacks explanatory power for water consumption, was discarded from the model and the regression was repeated. The coefficients thus obtained are given in Table 3.13. Note that this result does not imply that the water consumption associated with the milling step is negligible. Instead, it may imply that the water consumption in milling is more strongly determined by the uranium content of the ore, or that there is simply not enough data for this part of the statistical model to give acceptable performance.

Table 3.13. Water consumption model parameter regression results

\begin{tabular}{ccccc}
\hline Coefficient & Applies to & Value & Standard Error & T Statistic \\
\hline $\mathrm{w}_{\mathrm{u}}$ & OP, $\mathrm{UG}$ & $416,000 \mathrm{~L} / \mathrm{tU}$ & $0.130 \mathrm{ML} / \mathrm{tU}$ & 3.19 \\
$\mathrm{w}_{\text {mine }}$ & OP, $\mathrm{UG}$ & $77.2 \mathrm{~L} / \mathrm{t}$ ore $+\mathrm{ob}$ & $4.80 \times 10^{-5} \mathrm{ML} / \mathrm{t}$ ore $+\mathrm{ob}$ & 1.60 \\
\hline
\end{tabular}

The ISL process entails substantially larger water consumption per unit of product. As was the case for energy consumption, a separate model and regression were formulated for the Beverley ISL mine. The model for ISL water consumption per unit of product $\mathrm{w}[\mathrm{ML} / \mathrm{tU}]$ is:

$w=\frac{100}{G Y_{i s l}} w_{i s l}+w_{u}$ 
Regression analysis was used to estimate $\mathrm{w}_{\text {isl }}[\mathrm{ML} / \mathrm{t}$ ore]; the water consumption associated with the refining step, $\mathrm{w}_{\mathrm{u}}[\mathrm{ML} / \mathrm{tU}]$, remained as above. This correlation assumes that water consumption for steps prior to refining is inversely proportional to the grade of the ore body upon which ISL is being used, produces $\mathrm{w}_{\text {isl }}=9.88 \times 10^{-3} \mathrm{ML} / \mathrm{t}$ ore.

Figure 3.17 utilizes these results to project water consumption for each of the mines with data. As with Figure 3.14, the data and model results for each mine were averaged over the time period for which the observed data was available. Figure 3.17 does not constitute a benchmark, since the data depicted here was in fact used to derive the model coefficients. Nonetheless, observation of the variability between forecast and observations is a test of the explanatory power of the model; it is seen that the water consumption for Ranger is a low outlier when compared to the trend for the other three surface mines.

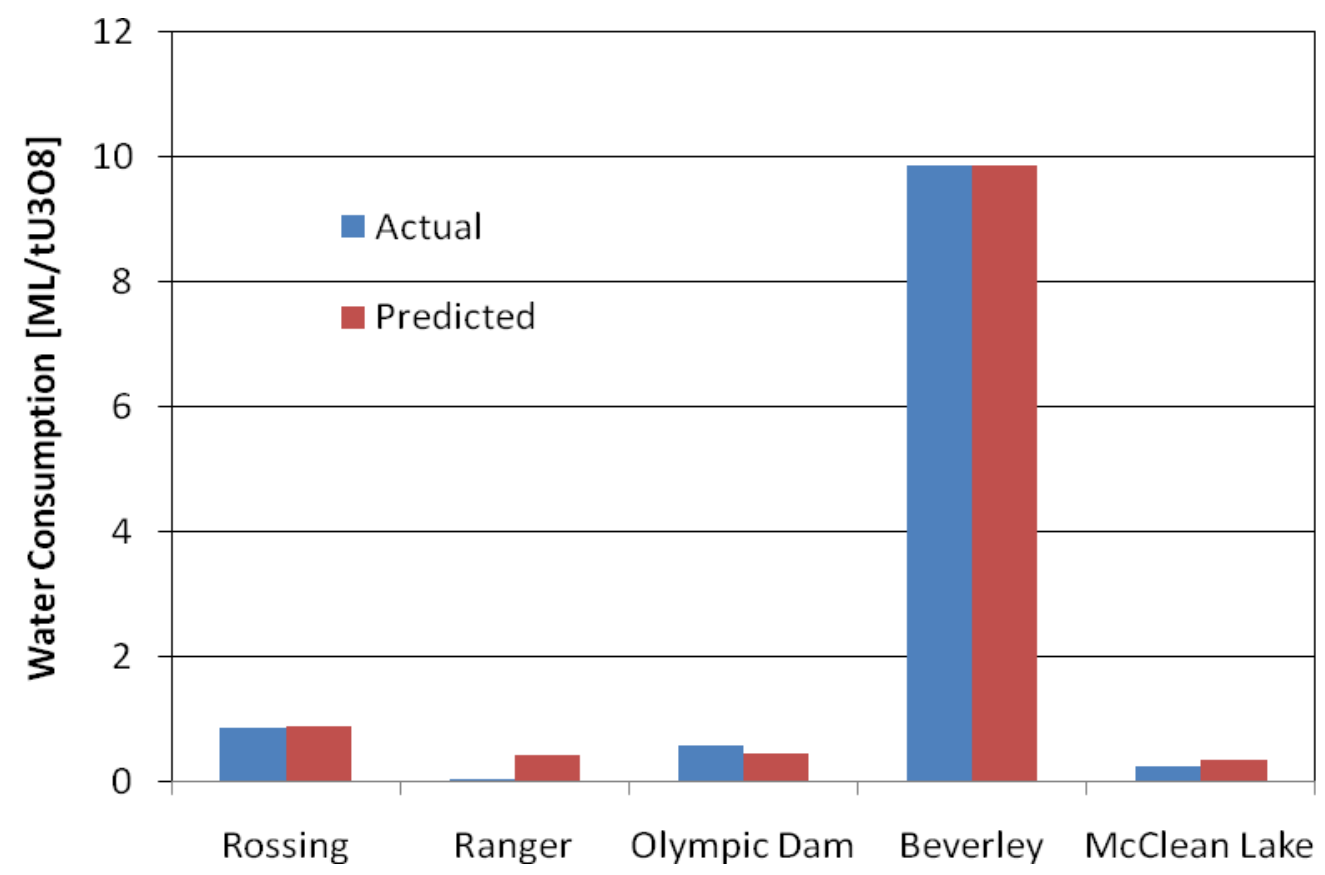

Figure 3.17. Water consumption, forecast versus data

This fact is also evident in Figure 3.18, where the water consumption forecasts are plotted versus ore grade for both ISL and conventional mining. Each member of the data set is superimposed upon this plot. With the exception of the Ranger data points which reflect unusually low water consumption, the forecast for conventional mining correlates very well using a stripping ratio of 1.15 , the lowest of the mines considered in this study. Using a higher stripping ratio in this correlation would thus be expected to conservatively overpredict water usage. Also noteworthy is the discrepancy between ISL and other mining methods. At very high ore grades, the water usage associated with both extraction strategies is dominated by uranium processing and refining. Yet the Beverley data shows that ISL can be expected to consume an order of magnitude more water per unit of product than conventional techniques at similar grades. 


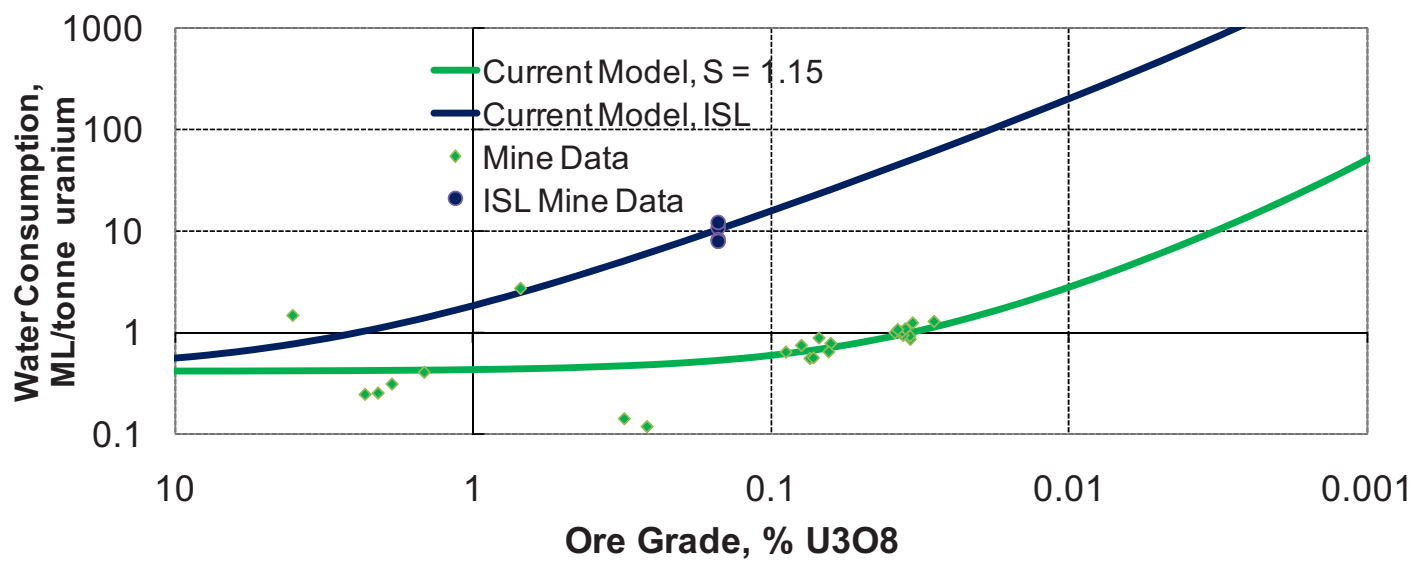

Figure 3.18. Water consumption forecast, results of current model

\subsection{Occupational and Public Health}

Radon and dust release are the major occupational and public dose delivery pathways from operating mines and mills. Occupational and public health impacts of uranium mining and milling have been extensively studied. Table 2.1 shows that mining and milling are the largest collective dose contributors to the both the public and workers of any of the front-end steps in the fuel cycle.

The reference maximum public dose results are obtained from a simplified implementation of the methods employed by the MILDOS software [ANL 1998] used by the NRC to perform mine and mill dose assessments for EISs. The implementation is available as an online software tool [Wise Uranium 2010] and its predictions will be used as the reference MEI data for this study. To confirm the results and ensure their conservatism, a short survey of public doses associated with operations at present-day sites is presented.

Table 3.14 shows the estimated dose to an individual located $5 \mathrm{~km}$ from a mine/mill complex producing $1000 \mathrm{tU} /$ year. The representative conventional mine/mill was chosen to be an open pit facility of ore grade $0.1 \% \mathrm{U}_{3} \mathrm{O}_{8}$ with $\mathrm{S}=4$, as elsewhere in this report. All other parameters were taken as the defaults recommended in the [Wise Uranium 2010] documentation. A separate analysis of an underground mine is not presented: for conventional mines, mine-specific parameters rather than mining method were seen to be much stronger drivers of the dose. Although open pit mines generally release considerably more dust per tonne of ore mined than underground mines, the dose associated with radon progeny is the dominant dose contributor from mining operations. Radon exhalation and release rates are determined by ore and host medium properties. Measured mine radon emission rates may vary by up to two orders of magnitude from mine to mine: at the Ranger mine, the average specific radon emission rate is $22 \mathrm{GBq} / \mathrm{t} \mathrm{U}_{3} \mathrm{O}_{8}$ produced, whereas the corresponding figure at the Rabbit Lake mine was $760 \mathrm{GBq} / \mathrm{t} \mathrm{U}_{3} \mathrm{O}_{8}$ [Wise Uranium 2010]. The results presented in Table 3.14 assumed a mine radon emission rate of $500 \mathrm{GBq} / \mathrm{t} \mathrm{U}_{3} \mathrm{O}_{8}$.

Dose rates would be expected to be lower for ISL extraction than conventional mining techniques, because both major pathways for dose delivery - dispersion of radionuclide-bearing dust from ore and waste rock and release of radon during ore handling and crushing - are considerably mitigated. The [Wise Uranium 2010] model forecasts this to be the case for the MEI, as ore dust release and radon exhalation rates are at or near zero. 
Table 3.14. Nearby member of the public dose estimates obtained from [Wise Uranium 2010]

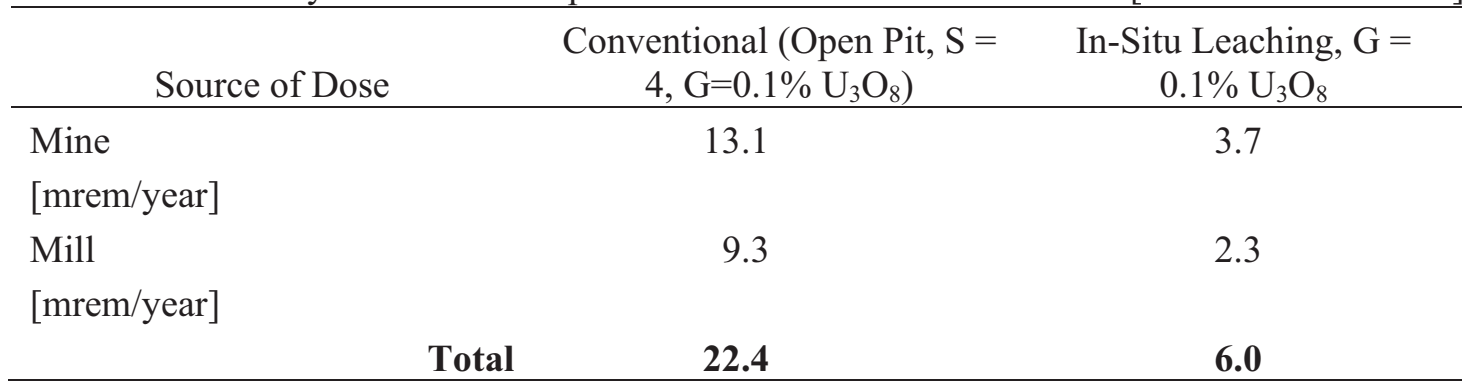

An industry-wide international survey of the occupational doses of 260,000 uranium mine workers and 18,000 mill workers over the period 1985-89 reported average individual doses of $440 \mathrm{mrem} /$ year for uranium miners and $630 \mathrm{mrem} / \mathrm{year}$ for mill workers [UNSCEAR 1993].

[EPA 2008] reports the results of an earlier NRC study of doses associated with uranium milling operations. This study estimates the annual whole body dose for the average mill worker to be $450 \mathrm{mrem} / \mathrm{year}$. The White Mesa uranium mill adheres to an ALARA goal for its workers of $1,250 \mathrm{mrem} / \mathrm{year}$ [Denison Mines 2007] and this value will be chosen as a conservative reference for milling of conventional ores.

The average dose to extraction workers at Rossing in 2009 was measured to be $540 \mathrm{mrem} / \mathrm{year}$, over ninety percent of which was external gamma dose (the rest was ascribed to alpha dose from inhalation of dust and radon) [Rossing 2010]. Dose data spanning the years 2001-07 is available for the Canadian mines and mills [CNSC 2009]. This data shows that the maximum annual dose recorded at Cigar Lake and Key Lake were less than 1,000 mrem, at Cluff Lake, McClean Lake, McArthur River between 1,000 and 1,500 mrem. At Rabbit Lake a single worker logged a dose of between 1500 and 2000 mrem in 2004; otherwise, annual doses also did not exceed 1,500 mrem. 1,500 mrem was therefore chosen as a conservative annual occupational dose rate for conventional mines.

Occupational exposure at the Beverley ISL facility is somewhat lower than at conventional mines: only a handful of annual worker doses of greater than $400 \mathrm{mrem} /$ year have been observed, and these were ascribed primarily to radon progeny and gamma dose from radionuclides in the process stream and stored product, [South Australia 1998][Heathgate 2007]. The dose to a MEI at the camp adjacent to the Beverley mine was calculated to be $2 \mathrm{mrem} /$ year [Heathgate 2007], consistent with the earlier estimate of the dose from an ISL mine to a member of the public. Hence, $400 \mathrm{mrem} / \mathrm{year}$ was considered to conservatively represent the peak worker dose for ISL mining.

The ExternE project [EC 1995] used the Lodeve mine and mill in France, which produced uranium by open pit and underground techniques from the 1970s through the 1990s, as a reference facility for collective dose assessment. The collective occupational and public doses from Lodeve were estimated at 0.42 person-rem/tU and 0.66 person-rem/tU, respectively.

\subsection{Projecting the Evolution of the Energy Balance}

The energy, carbon, water and land use models presented in Sections 3.1-3.4 are given as functions of ore grade and mining technique. To use these models to project the evolution of the environmental footprint of uranium mining, it is necessary to estimate how the average ore grade might evolve going forward in time. Present-day extraction operations, averaged over all working mines, operate at a grade of $0.1 \%$ $\mathrm{U}_{3} \mathrm{O}_{8}$ (Figure 3.3). Yet a survey of the 4.7 million tonne [Mt] Identified Resource base as defined in the Redbook [OECD 2008] indicates that the median grade of the resources remaining in the ground is just $0.06 \% \mathrm{U}_{3} \mathrm{O}_{8}$; see Figure 3.19 . 


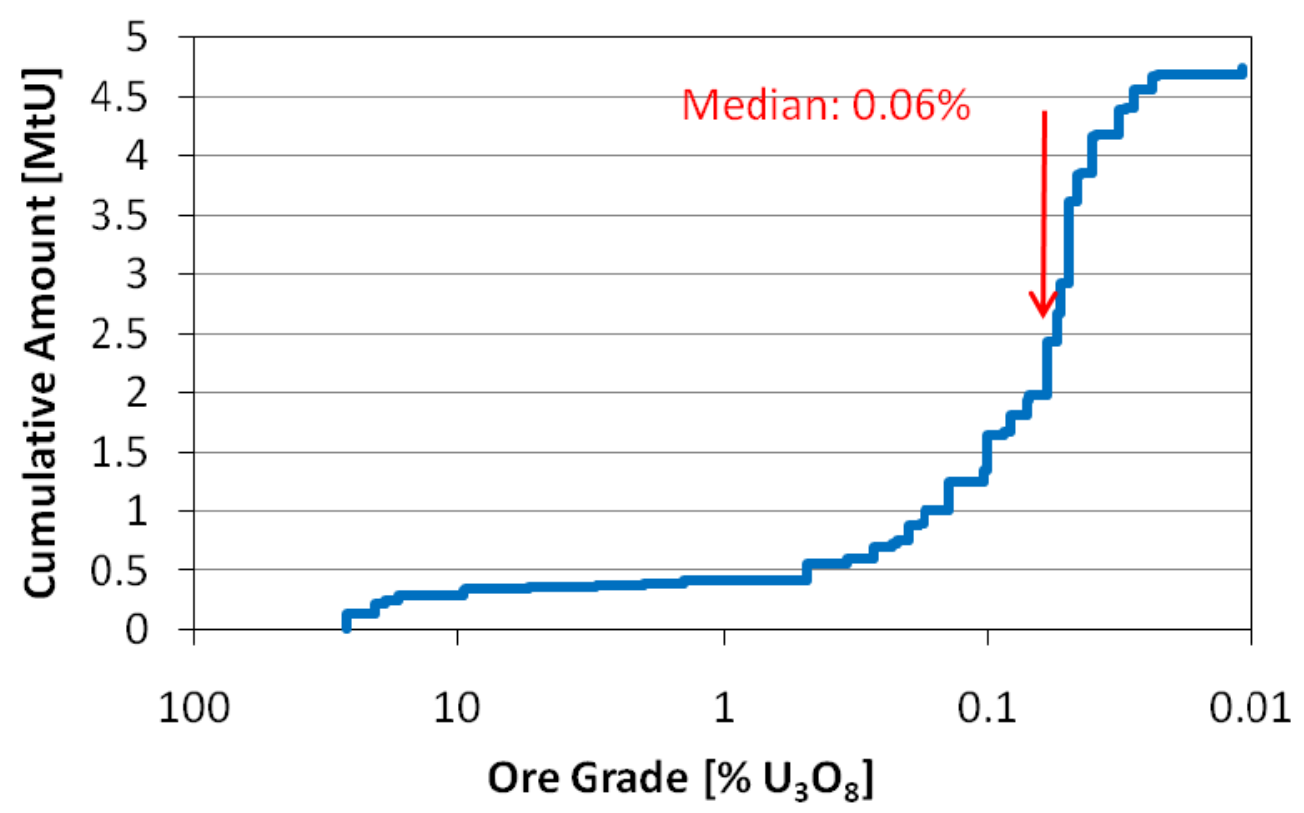

Figure 3.19. Cumulative identified $\mathrm{U}$ resources in the ground at or above the grade shown on the abscissa. Date source: [OECD 2008]

Additionally, the 2009 extraction technology breakdown - 23\% open pit mining, $41 \%$ underground, and $36 \%$ ISL - differs from the mining technology distribution of the Redbook resources. Figure 3.20 shows the Redbook-reported extraction technology breakdown of the likely/preferred technology for each deposit.

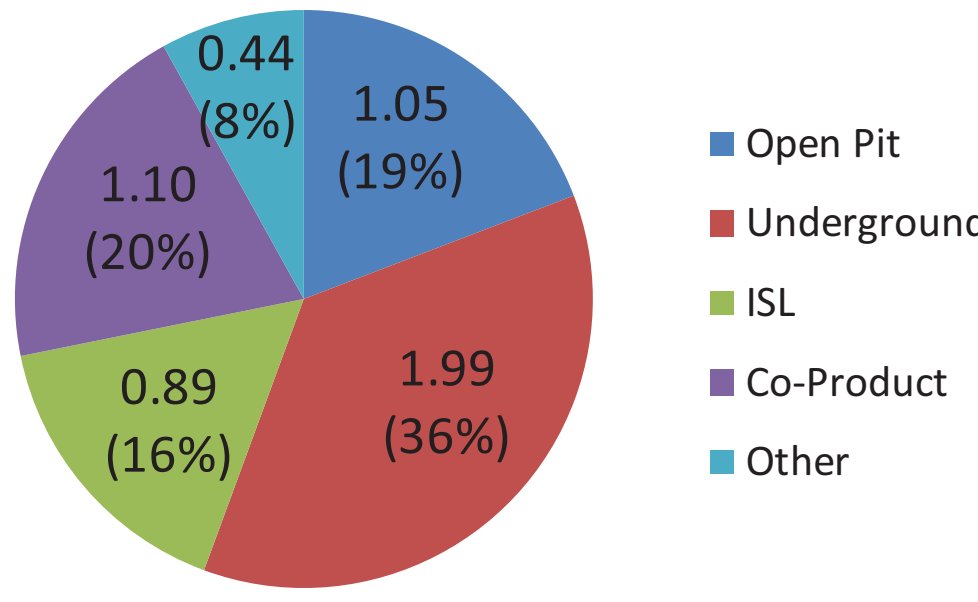

Figure 3.20. Identified uranium resources, in millions of tonnes, by extraction technology. Data source: [OECD 2008]

Assigning co-product resources, most of which reside at Olympic Dam, to underground mining and neglecting the 'other' technologies category, Figure 3.20 implies that the technology mix in the medium to long term might shift to $22 \%$ open pit mining, $59 \%$ underground, and $19 \%$ ISL. It is likely that more 
deposits are suitable for extraction via ISL because country-supplied estimates in the Redbooks may remain unchanged for decades even as technologies evolve.

To project the time evolution of the average ore grade, it will first be assumed that the resource base - call it $\mathrm{M}_{\mathrm{o}}[\mathrm{Mt}]$ - of high-grade (averaging $0.06 \% \mathrm{U}_{3} \mathrm{O}_{8}$ ) ore is fully encompassed by historical extraction plus some portion (to be parametrically studied) of presently-known deposits still in the ground. This is a coarse but very conservative approximation. Recent experience, for instance the discovery of substantial $>10 \%$ grade deposits in Canada, contravenes this assumption.

The Redbook [OECD 2008] reports multiple levels of identified and speculative resources. Ore grades associated with the speculative resources are not known, so conservative, intermediate and optimistic scenarios are formulated as follows:

Conservative Resource: The complete resource base at grades of $0.06 \% \mathrm{U}_{3} \mathrm{O}_{8}$ and up is comprised of already-extracted uranium. This case is very conservative since it is known that the median grade of identified resources still in the ground is $0.06 \%$.

Already extracted: $2.28 \mathrm{Mt}$

Total at $0.06 \% \mathrm{U}_{3} \mathrm{O}_{8}$ and up: $\mathrm{M}_{\mathrm{o}}=2.28 \mathrm{Mt}$

Intermediate Resource: Only Redbook-defined Reasonably Assured + Inferred Resources (Identified Resources, both already extracted and still in the ground) extractable only at $\$ 80 / \mathrm{kgU}$ or less reflect the complete resource base at grades of $0.06 \% \mathrm{U}_{3} \mathrm{O}_{8}$ and up. This case assumes moderate additional discovery of higher-grade deposits.

Already extracted: $2.28 \mathrm{Mt}$

Still in the ground: $4.1 \mathrm{Mt}$

Total at $0.06 \% \mathrm{U}_{3} \mathrm{O}_{8}$ and up: $\mathrm{M}_{\mathrm{o}}=6.4 \mathrm{Mt}$

Optimistic Resource: The resource at $0.06 \% \mathrm{U}_{3} \mathrm{O}_{8}$ or greater encompasses all currently identified and Redbook-reported undiscovered resources, i.e. the total resource base. The assumption here is that there is a lot of high grade uranium yet to be found.

Already extracted: $2.28 \mathrm{Mt}$

Still in the ground: $16.0 \mathrm{Mt}$

Total at $0.06 \% \mathrm{U}_{3} \mathrm{O}_{8}$ and up: $\mathrm{M}_{\mathrm{o}}=18.3 \mathrm{Mt}$

The next question to be answered is as follows: assuming that all the extractable uranium (mined and mineable) at $0.06 \% \mathrm{U}_{3} \mathrm{O}_{8}$ or greater is specified by an $\mathrm{M}_{\mathrm{o}}$ value taken from the Conservative, Intermediate or Optimistic Resource cases defined above, how much more extractable lower-grade uranium is there to be found?

Note that extractable uranium at $0.06 \% \mathrm{U}_{3} \mathrm{O}_{8}$ represents only a small portion of total crustal uranium found at concentrations of $0.06 \% \mathrm{U}_{3} \mathrm{O}_{8}$ or above. Non-extractable high-grade uranium might be located too deep in the crust, or it might be too hard to get to (e.g. under seabeds). Deffeyes and MacGregor estimated the crustal uranium distribution versus concentration [Deffeyes 1980], Figure 3.21. 


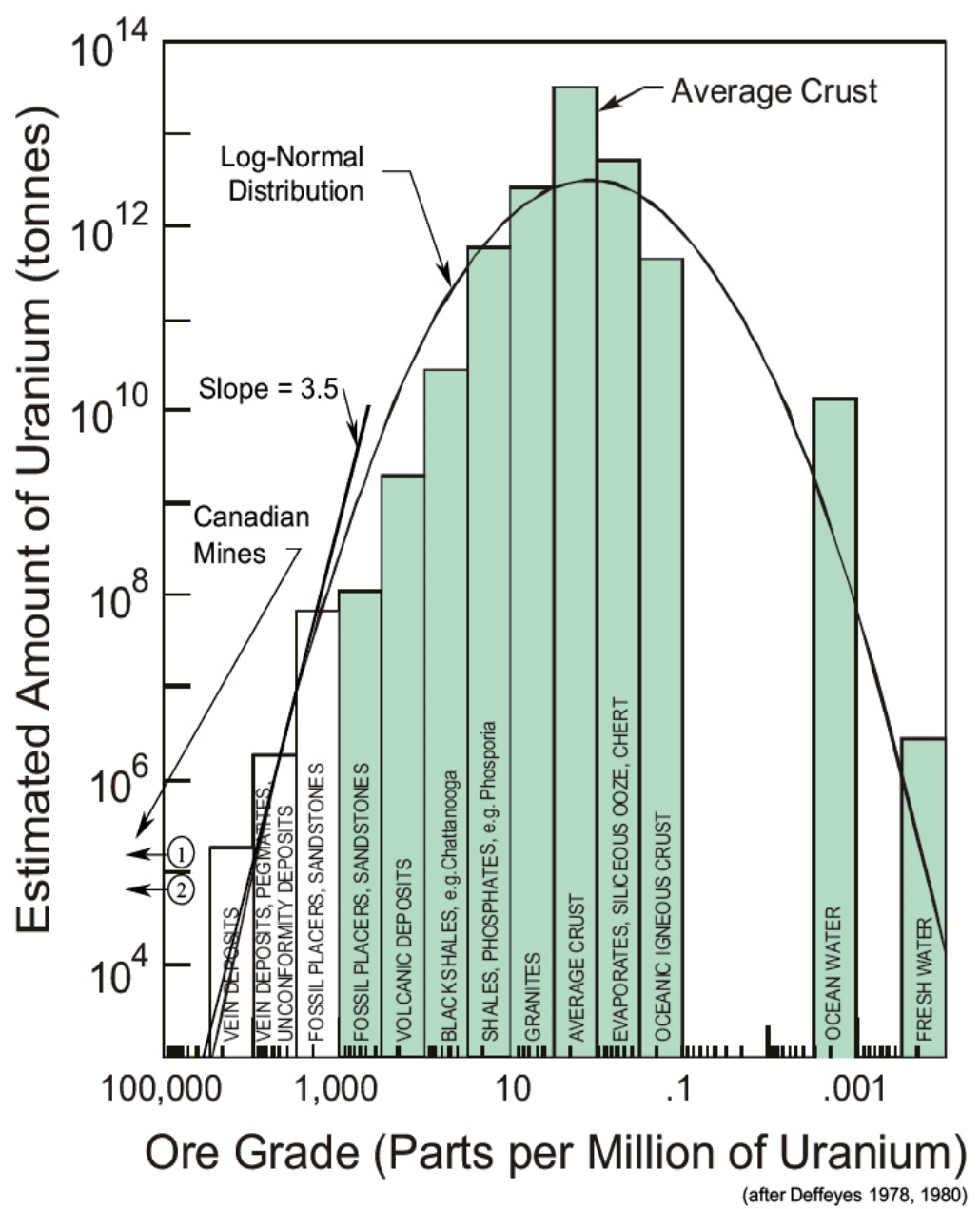

Figure 3.21. Deffeyes' projection of ore grade versus amount [Figure: Herring 2004]

Deffeyes and MacGregor estimated that the crust contains $10^{8}$ tonnes of uranium at grades of $0.06 \% \mathrm{U}_{3} \mathrm{O}_{8}$ or above (the white bars in the figure represent currently-mined deposit types). The Redbook resource base estimates plus extraction to date (viz. the conservative and optimistic resource scenarios) place the amount of economically extractable uranium at around $10^{7}$ tonnes, so only about $10 \%$ of the resource is presently considered accessible and economically viable for extraction. It will be assumed that this ratio will continue to hold true for lower-grade ores as well. On one hand, this assumption is conservative since technological advance can be expected to make additional deposits accessible over time. However, the assumption may be optimistic at low ore grades (e.g. shales and phosphates at below $0.01 \% \mathrm{U}_{3} \mathrm{O}_{8}$ ) because unfavorable conditions for mineralization may lead to a scarcity of compact ore bodies.

Given this assumption, Deffeyes' result may be used to project the amount of lower-grade uranium expected to be economically accessible. To do this, note that the crustal distribution of uranium by grade follows a log-normal distribution. This implies that if $\mathrm{Q}_{0}$ tonnes of the resource is available at grades of $\mathrm{G}_{\mathrm{o}}$ and above, the available mass $\mathrm{Q}$ of the resource at grades of $\mathrm{G}$ and above is approximately given by

$\mathrm{Q} / \mathrm{Q}_{\mathrm{o}}=\left(\mathrm{G}_{\mathrm{o}} / \mathrm{G}\right)^{\mathrm{a}-1}$,

where ' $a$ ' is the slope of the distribution in the vicinity of $\mathrm{G}_{0}$. Thus if $\mathrm{Q}_{\mathrm{o}}=10^{7}$ tonnes, $\mathrm{G}_{0}=0.06 \% \mathrm{U}_{3} \mathrm{O}_{8}$, $\mathrm{G}=0.006 \% \mathrm{U}_{3} \mathrm{O}_{8}$ and $\mathrm{a}=3.5$, the amount of uranium available at a concentration of $0.06 \% \mathrm{U}_{3} \mathrm{O}_{8}$ would be $3.2 \times 10^{9}$ tonnes, i.e. the mass of viable uranium would increase by a factor of $10^{2.5}$. This approach underpins most of the supply curve estimates shown in Figure 3.22 below. These estimates, all taken from 
previously published studies, each utilize an 'a' exponent to describe the rate at which additional discoveries can be expected. Estimates of the 'a' exponent vary; see [Schneider 2005] for a description of each of the curves in the figure. (note that additional modeling not addressed here is required to relate ore grade to extraction cost).

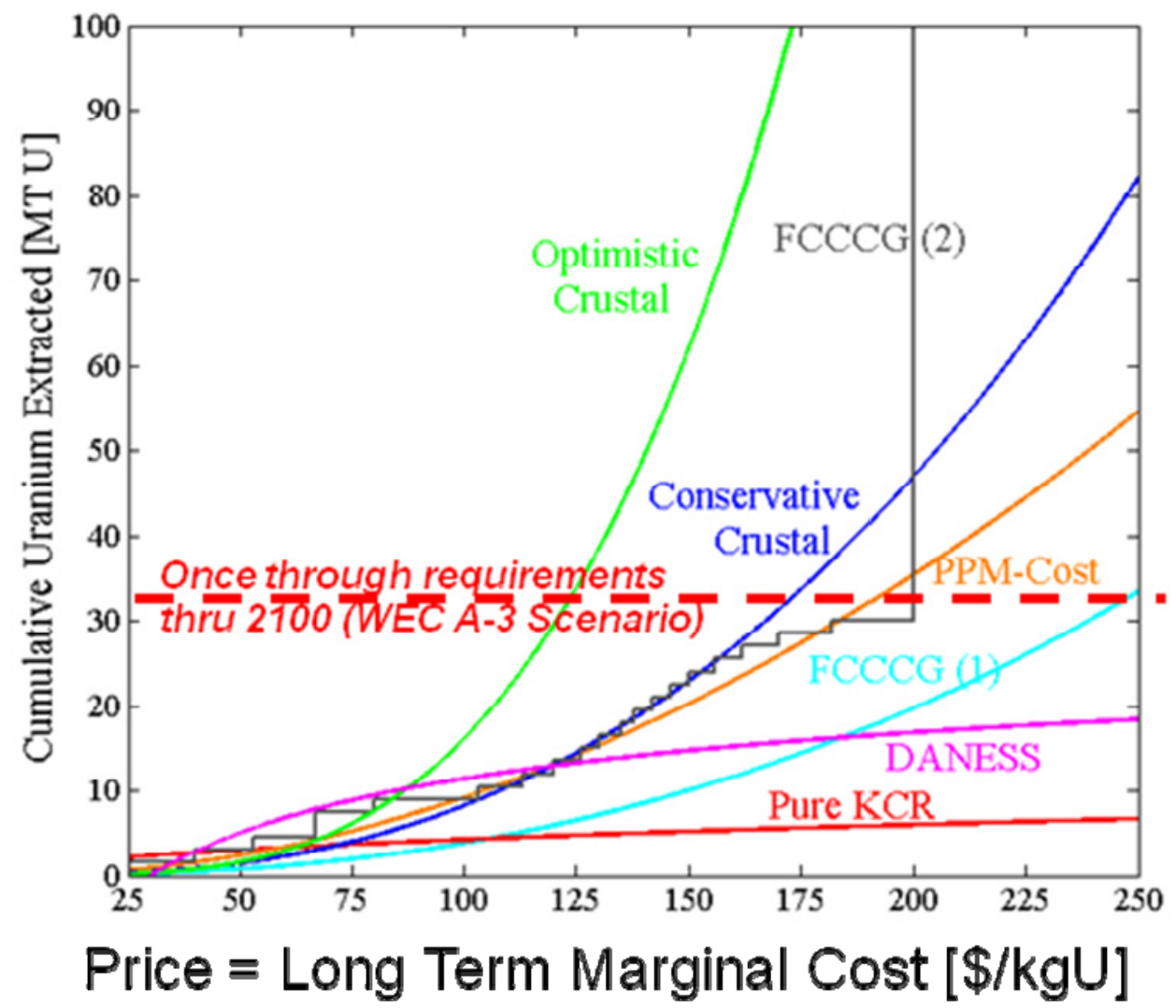

Figure 3.22 Uranium supply curve estimates, taken from the literature, relying on Deffeyes' crustal model [Schneider 2005]

The literature review that produced Figure 3.22 found exponent estimates ranging from $\mathrm{a}=2.5$ up to Deffeyes' value, $a=3.5$. Therefore, a second scenario variable is defined to reflect this range:

Conservative Crustal: $\mathbf{a}=\mathbf{2 . 5}$,

Optimistic Crustal: a $\mathbf{= 3 . 5}$.

Therefore, assuming two demand growth cases - that the annual demand for primary uranium grows at $1.8 \%$ or $3.2 \%$ per year ${ }^{j}$ from its 2009 value of $0.067 \mathrm{Mt} /$ year - one can permute the Conservative, Intermediate and Optimistic Resource scenarios with the Conservative and Optimistic Crustal scenarios to arrive at twelve forecasts of the average ore grade of extracted uranium versus time between 2010 and 2100. These are shown in Figure 3.23. Note that an additional, conservative, assumption has been made at the outset: that the average grade of mined ore will rapidly (instantly, for simplicity of modeling) drop to

j. These rates reflect moderate and aggressive nuclear fuel demand growth scenarios defined in a World Energy Council / International Institute for Applied Systems Analysis study of energy demand trends over this century [Nakicenovic 2004]. 
the Redbook average of identified resources, $0.06 \% \mathrm{U}_{3} \mathrm{O}_{8}(600 \mathrm{ppm})$, from the value of $\sim 0.1 \%$ it has held over most of the past half-century.

Note that at the $1.8 \%$ annual demand growth rate and the optimistic resource base assumption, the average grade of extracted resources would remain $0.06 \% \mathrm{U}_{3} \mathrm{O}_{8}(600 \mathrm{ppm})$ through the coming century.
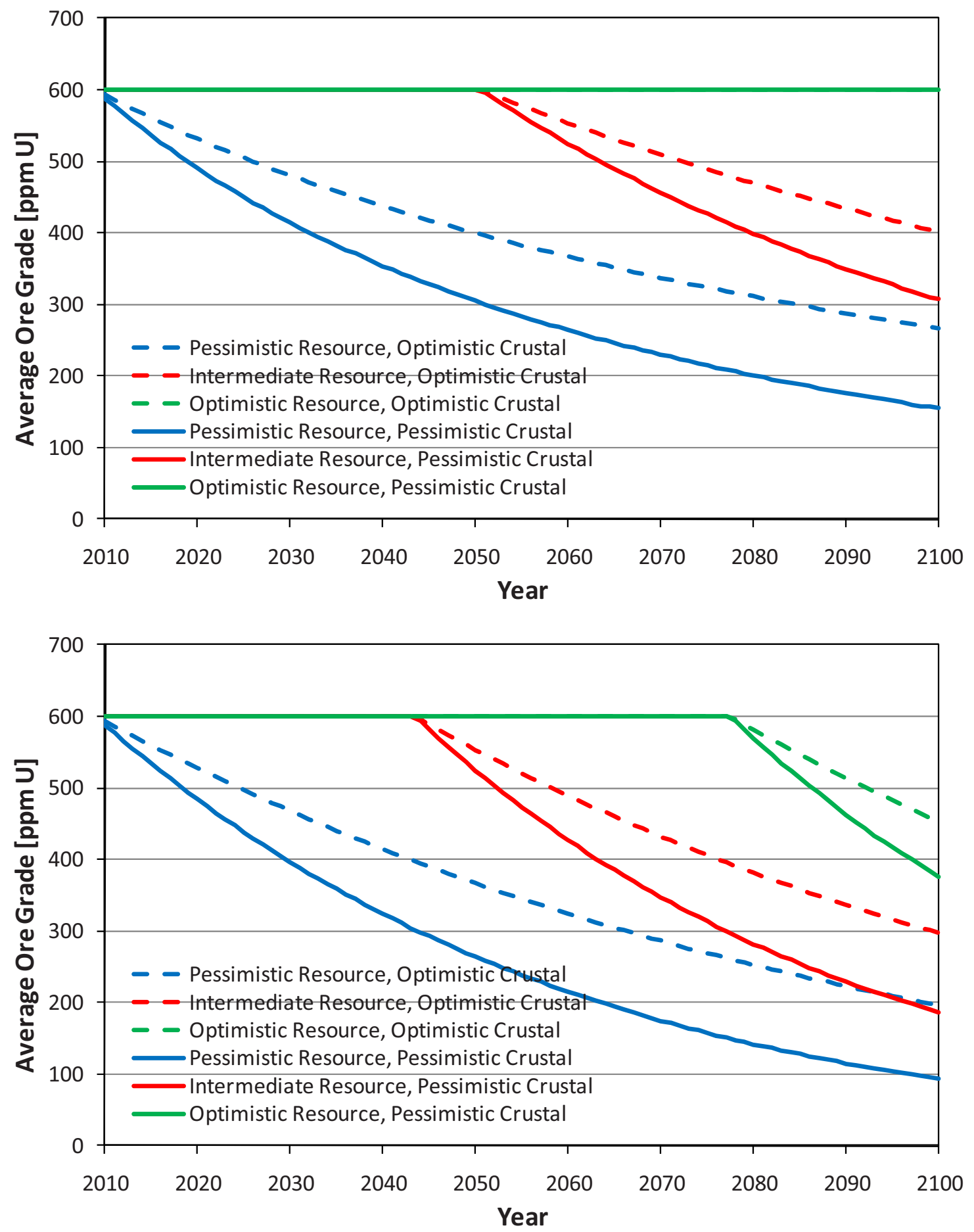

Figure 3.23. Projected average ore grade of mined uranium, 1.8\% p.a. demand growth (top) and $3.2 \%$ p.a. demand growth (bottom) 
Given these projections of mine performance, it is possible to forecast how the intensities of energy consumption will evolve for uranium mining. But first, Optimistic and Pessimistic Mining scenarios must also be considered, as they affect mine energy balance.

\section{Conservative Mining:}

- high stripping ratio deposits dominate in the future for open pit mines. $\mathrm{S} \sim 24$ (the average stripping ratio for US mines producing in the 1970s);

- the technology mix evolves toward the underground mining dominated mix depicted in Figure 3.20 (i.e. $22 \%$ open pit, $59 \%$ underground, and $19 \%$ ISL).

\section{Optimistic Mining:}

- more deposits than currently projected in the Redbook will prove amenable to ISL such that the technology mix remains at 2009 levels (i.e. $23 \%$ open pit, $41 \%$ underground, and $36 \%$ ISL);

- $\quad \mathrm{S}=4$ (the current average value for Ranger) for open pit mines.

Since the number of scenarios has grown quite large, only the bounding cases (all assumptions optimistic, all assumptions pessimistic) are labeled on the plots in Figure 3.24 below. Note that the analysis can be extended to carbon emissions simply by acting on the energy consumption with the appropriate emission coefficients, as was outlined in section 3.2. 

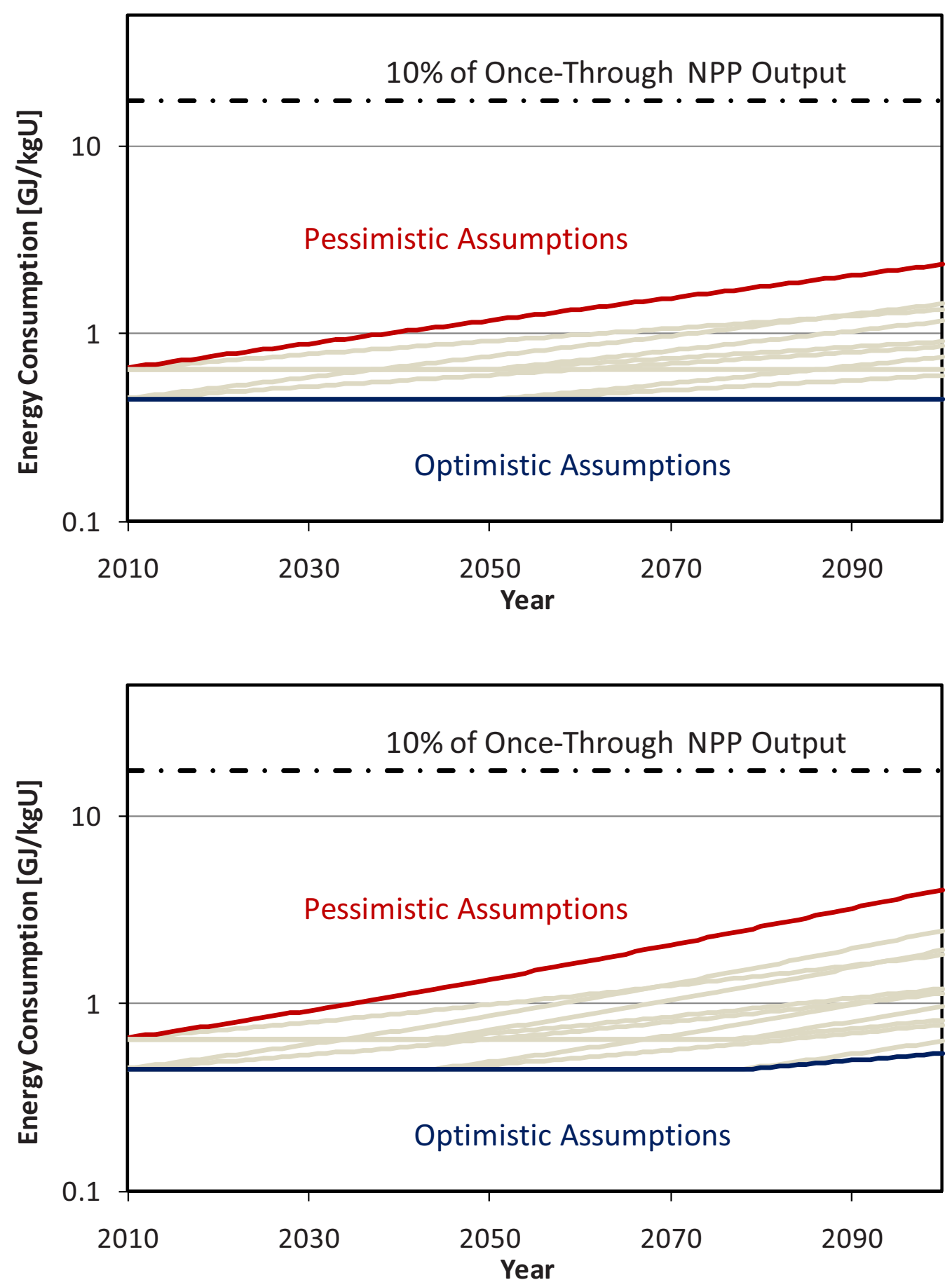

Figure 3.24. Projected specific energy consumption associated with uranium mining, $1.8 \%$ p.a. demand growth (top) and 3.2\% p.a. demand growth (bottom) 


\subsection{Summary}

Table 3.15 summarizes the environmental metric results. The table depicts the predictions of the models derived in this section for conditions approximating the current state of the industry. Therefore, the models were evaluated with the following parameters: $\mathrm{G}=0.1 \% \mathrm{U}_{3} \mathrm{O}_{8}$ for all mining methods and $\mathrm{S}=4$ for open pit mining. Note that most present-day underground mines are extracting ores of somewhat higher grade than the industry average, ISL and open pit mines slightly lower.

Table 3.15 provides contemporary impacts based on current average ore grades and mine properties. A methodology for projecting these impacts at lower-grade s was also presented along with an approach for correlating the ore grade to the cumulative amount of the resource extracted. Table 3.16 provides a roadmap to the equations and numerical data that comprise the methodology.

To enable forward projections of the environmental impacts of uranium recovery, direct energy consumption, $\mathrm{CO}_{2}$ emissions, and land and water use have been correlated to ore grade and other toplevel operating parameters. The models describing these correlations are described in the body of this section. 
Table 3.15. Summary of impacts resulting from contemporary mining, milling, and refining of one tonne natural uranium (based on ore grade, $\mathrm{G}=0.1 \%$ and Stripping Ratio, $\mathrm{S}=4$ )

\begin{tabular}{|c|c|c|c|c|c|c|c|c|c|c|}
\hline \multirow[b]{3}{*}{ Units } & \multicolumn{3}{|c|}{ Energy Consumption } & \multirow[t]{2}{*}{$\begin{array}{c}\mathrm{CO}_{2} \\
\text { Emissions }\end{array}$} & \multirow[t]{2}{*}{ Land Use } & \multirow[t]{2}{*}{ Water Use } & \multicolumn{2}{|c|}{ Maximum Dose } & \multicolumn{2}{|c|}{ Collective Dose } \\
\hline & electrical & $\begin{array}{c}\text { thermal: } \\
\text { liquid } \\
\text { carriers }\end{array}$ & $\begin{array}{c}\text { thermal: } \\
\text { other } \\
\text { carriers }\end{array}$ & & & & Worker & MEI & Workers & Public \\
\hline & $\begin{array}{l}\mathrm{GJ}(\mathrm{e}) \text { per } \\
\text { tonne } \mathrm{U}\end{array}$ & $\mathrm{GJ}(\mathrm{t}) \mathrm{p}$ & onne U & $\begin{array}{c}\mathrm{kg} \mathrm{CO} \\
\text { per tonne } \\
\mathrm{U}\end{array}$ & $\begin{array}{l}\mathrm{m}^{2} \text { per } \\
\text { tonne } U\end{array}$ & $\begin{array}{l}\text { Litres per } \\
\text { tonne U }\end{array}$ & $\mathrm{mrem} / \mathrm{yr}$ & $\mathrm{mrem} / \mathrm{yr}$ & $\begin{array}{l}\text { person-rem } \\
\text { per tonne } U\end{array}$ & $\begin{array}{c}\text { person-rem } \\
\text { per tonne } \\
\mathrm{U}\end{array}$ \\
\hline $\begin{array}{l}\text { Open pit } \\
\text { mining } \\
(\mathrm{S}=4)\end{array}$ & 150 & 60 & 63 & $3.0 \times 10^{4}$ & 196 & $8.4 \times 10^{5}$ & 1500 & 22 & 0.42 & 0.66 \\
\hline $\begin{array}{l}\text { Underground } \\
\text { mining }\end{array}$ & 270 & 122 & 106 & $5.5 \times 10^{4}$ & 196 & $8.4 \times 10^{5}$ & 1500 & 22 & 0.42 & 0.66 \\
\hline $\begin{array}{l}\text { In-Situ Leach } \\
\text { mining }\end{array}$ & 128 & 0 & 52 & $2.2 \times 10^{4}$ & 656 & $1.6 \times 10^{7}$ & 400 & 6 & NA & NA \\
\hline Composite $^{\mathrm{a}}$ & 191 & 64 & 77 & $3.8 \times 10^{4}$ & 362 & $6.3 \times 10^{6}$ & 1500 & 22 & 0.42 & 0.66 \\
\hline
\end{tabular}

Table 3.16. Roadmap to methodologies employed for estimating future impacts

\begin{tabular}{|c|c|c|c|c|c|}
\hline & \multirow{2}{*}{$\begin{array}{c}\text { Average Ore Grade vs. } \\
\text { Amount Mined }\end{array}$} & Energy Consumption & $\mathrm{CO}_{2}$ Emissions & Water Use & Land Use \\
\hline & & $\mathrm{GJ}(\mathrm{e}+\mathrm{t})$ per tonne $\mathrm{U}$ & $\mathrm{kg} \mathrm{CO}_{2}$ per tonne $\mathrm{U}$ & Litres per tonne $U$ & $\mathrm{~m}^{2}$ per tonne $\mathrm{U}$ \\
\hline Open pit mining & $\begin{array}{l}\text { Equation } 3.10 \text { (and see } \\
\text { discussion in Section 3.6) }\end{array}$ & $\begin{array}{l}\text { Equations } 3.1,3.2 \text { and } \\
\text { Table } 3.6\end{array}$ & See Table 3.9 & Equation 3.8 and Table 3.13 & Equation 3.6 \\
\hline Underground mining & $\begin{array}{l}\text { Equation } 3.10 \text { (and see } \\
\text { discussion in Section 3.6) }\end{array}$ & $\begin{array}{l}\text { Equations } 3.1,3.3 \text { and } \\
\text { Table } 3.6\end{array}$ & See Table 3.9 & Equation 3.8 and Table 3.13 & Equation 3.6 \\
\hline In-Situ Leach mining & $\begin{array}{l}\text { Equation } 3.10 \text { (and see } \\
\text { discussion in Section 3.6) }\end{array}$ & $\begin{array}{l}\text { Equations } 3.4,3.5 \text { and } \\
\text { Table } 3.8\end{array}$ & See Table 3.9 & Equation 3.9 & Equation 3.7 \\
\hline
\end{tabular}




\subsection{References}

[ANL 1998] Argonne National Laboratory, Environmental Assessment Division, "MILLDOS-AREA User's Guide," technical report, 1998.

[Beerten 2009] Beerten, J., "Greenhouse Gas Emissions in the Nuclear Life Cycle: a Balanced Appraisal,” Energy Policy, 5056-5068, 2009.

[Bieniewski 1971] Bieniewski, C. et al., "Availability of Uranium at Various Prices from Resources in the US,” US Bureau of Mines Information Circular 8501, 1971.

[British Energy 2005] "Environmental Product Declaration of Electricity from Torness Nuclear Power Station,”Technical Report, British Energy, May 2005.

[Chapman 1975] Chapman, P.F., Energy Analysis of Nuclear Power Stations, Energy Policy, pp. 285298, Dec 1975.

[Chapman 1983] Chapman, P. F. and F. Roberts, Metal Resources and Energy, London:Butterworths, 1983.

[CIPEC 2005] Canadian Industry Program for Energy Conservation, "Benchmarking the Energy Consumption of Canadian Open-Pit Mines," Resources Canada report C2005-980101-8, 2005.

[CNSC 2009] Canadian Nuclear Safety Commission, "Occupational Dose Data forMajor Canadian Nuclear Facilities 2001 07,” technical report INFO-0775, 2009.

[Deffeyes 1980] Deffeyes, K. S. and I. D. MacGregor, 1980, “World Uranium Resources,” Scientific American, 242, 66-76, January 1980.

[Denison Mines 2006] Denison. Annual Report; Denison Mines Ltd, years 2004-2006.

[Denison Mines 2007] Dension Mines Corp,. "White Mesa Uranium Mill: License Renewal Application,” February 2007.

[Dones 2005] Dones, R., "Life Cycle Inventories for the Nuclear and Natural Gas Energy Systems, and Examples of Uncertainty Analysis,"Int J Lifecycle Analysis, 10, 1, 10-23, 2005.

[EC 1995] European Commission, ExternE - Externalities of Energy, Volume 5: Nuclear, European Commission Directorate-General XII, 1995.

[Edwards 2000] Edwards, C. R. and A. J. Oliver, "Uranium Processing: a Review of Current Methods and Technology," J Minerals Metals and Materials Society, 52, 9, 12-20, September 2000.

[Eliasson 2003] Eliasson, B. and Y. Lee, eds., "Integrated Assessment of Sustainable Energy Systems in China," Kluwer Academic, Dordrecht, 2003.

[Energy Fuels 2009] Energy Fuels Resources, Inc., "Facility Operating Plan: Pinon Ridge Mill Facility," November 2009.

[EPA 2008] US Environmental Protection Agency, "Technologically Enhanced Naturally Occuring Radiactive Materials From Uranium Mining -- Volumes 1 and 2,” EPA-402-R-08-005, 2008.

[EPA 2010] Emission Facts: Average Carbon Dioxide Emissions Resulting from Gasoline and Diesel Fuel. http://www.epa.gov/oms/climate/420f05001.htm. Webpage accessed January 30, 2010.

[EERDB 2010] Energy and Environment Data Reference Bank (EEDRB), http://www.iaea.org/inisnkm/nkm/aws/eedrb/data/NA-enemcoal.html. Webpage accessed January 30, 2010 . 
[EERE 2010] DOE Office of Energy Efficiency and Renewable Energy, Energy and Environmental Profile of the U.S. Mining Industry, 2010, available: http://www1.eere.energy.gov/industry/mining/analysis.html, webpage accessed March 1, 2010.

[EIA 2006] Energy Information Administration, “Annual Energy Outlook 2006 with Projections to 2030,” Table 2. U.S. DOE Energy Information Administration. February 2006.

[EIA 2010] Energy Information Administration, “Annual Energy Outlook 2009 with Projections to 2030,” U.S. DOE Energy Information Administration. February 2009.

[ERA 2008] ERA, Annual Social and Environment Report, Energy Resources of Australia Ltd (ERA), Years 2001 to 2008, Sydney, NSW, www.energyres.com.au.

[Evans 2005] Evans, K. G. et al., eds., "eriss Research Summary," Technical Report SSR 189, Australia Department of the Environment and Heritage, 2005.

[Finch 1997] Finch, W. "Uranium, its Impact on the National and Glob al Energy Mix," US Geological Survey Circular 1141, 1997.

[Fthenakis 2009] Fthenakis, V. and H. C. Kim, "Land Use and Electricity Generation: a Life-cycle Analysis," Renewable and Sustainable Energy Reviews 13, 1465-74, 2009.

[Gerbens-Leenes 2008] Gerbens-Leenes, P. W., Hoekstra, A. Y. and T. H. van der Meer, "Water Footprint of Bio-Energy and other Primary Energy Carriers," UNESCO Value of Water Research Report \#29, March 2008.

[Harries 1997] Harries, J., Levins, D., Ring, B. and W. Zuk, "Management of Waste from Uranium Mining and Milling in Australia," Nucl. Eng. Design, 176, 15-21, 1997.

[Heathgate 2007] Heathgate Resources Pty Ltd., “Annual Environment Report - 2006,” 2007. Also earlier versions.

[Herring 2004] Herring, J.S. Uranium Resource Analysis, in Encyclopedia of Energy, Elsevier, available: http://www1.elsevier.com/homepage/sai/encycofenergy/aut.htm, 2004.

[Hondo 2005] Hondo, H. "Life cycle GHG emission analysis of power generation systems: Japanese case," Energy, 9, 2005.

[IAEA 2000] International Atomic Energy Agency, "Methods of Exploitation of Different Types of Uranium Deposits," technical report IAEA-TECDOC-1174, 2000.

[IAEA 2009] International Atomic Energy Agency, "World Distribution of Uranium Deposits (UDEPO) with Uranium Deposit Classification," technical report IAEA-TECDOC-1629, 2009.

[INL 2007] Idaho National Laboratory, "User Guide - VISION (Verifiable Fuel Cycle Simulation) Model, v1.5 edition", technical report, 2007.

[Jacobson 2009] Jacobson, M. and Delucchi, M., “A Path to Sustainable Energy by 2030," Scientific American, 58-65, November 2009.

[Kellogg 1977] H. H. Kellogg, 'Sizing up the energy requirements for producing primary metals', Engineering and Mining Journal, 178, 4, 61-65, 1977.

[Lenzen 2008] Lenzen, M., "Life cycle energy and greenhouse gas emissions of nuclear energy: A review," Energy Conversion and Management 49, 2178-2199, 2008.

[Montgomery 2006] Montgomery, D. "High Efficiency, Low-Emissions Gas Engine Technology Implementation at Caterpillar," 3rd Annual Advanced Stationary Reciprocating Engines Meeting, June 2006. 
[Mudd 2001] Mudd, G M. Critical review of acid in situ leach uranium mining: 1. USA and Australia. Environmental Geology 41, 390-403. Springer-Verlag, 2001.

[Mudd 2007a] Mudd, G. M. Compilation of Uranium Production History and Uranium Deposit Data Across Australia; SEA-US Inc, 2007; last updated July 2007.

[Mudd 2007b] Mudd, G.M., Mark Diesendorf, Sustainability Aspects of Uranium Mining: Toward Accurate Accounting?, $2^{\text {nd }}$ International Conference on Sustainability Engineering \& Science, Auckland, New Zealand. 20- 23 February 2007.

[Mudd 2007c] Mudd, G.M, The Sustainability of Mining in Australia: Key Production Trends and Their Environmental Implications for the Future. Research Report No RR5, Department of Civil Engineering, Monash University and Mineral Policy Institute, October 2007.

[Mudd 2008a] Mudd, G.M., Mark Diesendorf. Sustainability of Uranium Mining and Milling: Toward Quantifying Resources and Eco-Efficiency. Environmental Science and Technology, 42, 2624-2630, December 2008.

[Mudd 2008b] Mudd, G M. Sustainability Reporting and Water Resources: a Preliminary Assessment of Embodied Water and Sustainable Mining. Mine Water Environ (2008) 27, 136-144. Springer-Verlag, 2008.

[Nakicenovic 2004] Nakicenovic, N., Grubler, A. and A. McDonald, eds., Global Energy Perspectives, International Institute for Applied Systems Analysis and World Energy Council report, ISBN 0521 $645697,2004$.

[Norgate 2004] Norgate, T. E. and W. Rankin, The Role of Metals in Sustainable Development, CSIRO Minerals Press, Australia, 2004.

[Nyober 2010] Nyober, K. "Development of Energy Intensity Indicators for Canadian Industry 1990 to 2008," Canadian Industrial Energy End-use Data and Analysis Centre Report, March 2010.

[OECD 2008] OECD-NEA \& IAEA, var., Uranium 2007: Resources, Production and Demand, Nuclear Energy Agency, Organization for Economic Co-operation and Development (OECD-NEA) and International Atomic Energy Agency (IAEA), Paris, France, www.nea.fr, 2008.

[Prasser 2008] Prasser, M H, S A Bayard, and R Dones. Sustainability of Uranium Sources. International Conference on the Physics of Reactors " Nuclear Power: A Sustainable Resource." Casino-Kursaal Conference Center, Interlaken Switzerland, September 14-19, 2008.

[Rossing 2010] Rössing, var., Annual Report to Stakeholders, Rössing Uranium Ltd, Years 1999 to 2009, Swakopmund, Namibia, www.rossing.com, webpage accessed January 2010.

[Rosa 2008] Rosa, R. and D. R. Rosa, "Exergy Cost of Mineral Resources,” Int. J. Exergy, 5, 5/6, 532-55, 2008.

[Rotty 1975] Rotty, R. M., Perry, A. M. and D. B. Reister, "Net Energy from Nuclear Power," technical report, ORAU-IEA-75-3, Oak Ridge National Laboratory, 1975.

[Schneeweiss 2001] Schneeweiss, R. and S. Muller, "Conservation of Scarce Water Resources at the Rossing Uranium Mine," Technical Report, 2001, available: http://www.iied.org/pubs/pdfs/G02461.pdf.

[Schneider 2005] Schneider, E. A., "A Survey of Uranium Supply Curve Estimates," in Trans. Am. Nucl. Soc., 92, San Diego, CA, June 2005.

[South Australia 1998] Ministry for Primary Industries, Natural Resources and Regional Development, South Australia, "Assessment Report on the Environmental Impact Statement for the Proposed Beverley Uranium Mine,” ISBN 073084992 9, 1998. 
[Sovacool 2008] Sovacool, B. K., "Valuing the Greenhouse Gas Emissions from Nuclear Power: a Critical Survey," Energy Policy 36, 2940-53, 2008.

[Storm van Leewen 2005] Storm van Leeuwen, J. W.,Smith, P. Nuclear Power, The Energy Balance, 2005. Revised 2007. available: http://www.stormsmith.nl/, webpage accessed January 30, 2010.

[Taylor 1996] Taylor, M. "Greenhouse gases and the nuclear fuel cycle? What emissions?" IAEA Bulletin 39, 2, 12-19, 1996.

[UNSCEAR 1993] United Nations Scientific Committee on the Effects of Atomic Radiation, Sources and Effects of Ionizing Radiation, United Nations, New York, 1993.

[Vate 2002] Vate, J. F., Full-energy-chain greenhouse-gas emissions: a comparison between nuclear power, hydropower, solar power, and wind power. Int. J. Risk Assessment and Management, 3, 1, 74$75,2002$.

[WEC 2004] World Energy Council, "Comparison of Energy Systems Using Life Cycle Assessment," ISBN $0946121168,2004$.

[White 2000] White, S. and G. L. Kulcinski, "Birth to death analysis of the energy

payback ratio and $\mathrm{CO}_{2}$ gas emission rates from coal, fission, wind, and DT-fusion electrical power plants," Fusion Eng. Des., 48, 248, 473-81, 2000.

[Wise Uranium 2008] Wise Uranium Project, "Issues at Operating Uranium Mines and Mills - Canada", available: http://www.wise-uranium.org/umopcdn.html\#RABBITL, webpage accessed May 29, 2010.

[Wise Uranium 2010] Wise Uranium Project, "Uranium Mine and Mill Resident Individual Dose Calculator," available: http://www.wise-uranium.org/rdcmrh.html, webpage accessed June 20, 2010.

[WNA 2010] WNA, Energy Analysis of Power Systems, World Nuclear Association (WNA), London, UK, available: http://www.world-nuclear.org/info/inf11.htm. Webpage accessed January 30, 2010. 


\section{CONVERSION OF $\mathrm{U}_{3} \mathrm{O}_{8} \mathrm{TO}^{\mathrm{U}} \mathrm{UF}_{6}$}

Yellowcake is converted to uranium hexafluoride $\left(\mathrm{UF}_{6}\right)$ for use in enrichment operations. Enrichment specifications require the purity of this converted product to be at least $99.99 \%$. The major suppliers of conversion capability are BNFL (United Kingdom), Cameco (Canada), AREVA subsidiary Comurhex (France), ConverDyn (U.S.), and Minatom (Russia).

In France, the Comurhex Malvesi plant converts yellowcake to $\mathrm{UF}_{4}$ by the wet hydrofluorination process described in Chapter 2. The $\mathrm{UF}_{4}$ is shipped to AREVA's Tricastin facilities, where additional fluorination results in $\mathrm{UF}_{6}$; the largest chemical input in both steps of the process is hydrofluoric acid. All large plants, except in the US, follow this two facility model, so that transportation of $\mathrm{UF}_{4}$ is required. The domestic facility, Honeywell's Metropolis Works (MTW), located in Metropolis, Illinois, is the only large conversion facility that uses the dry conversion process [Price 2009]. At its time of construction, the facility had a capacity of 5,000 tonnes of uranium as $\mathrm{UF}_{6}$ per year $(\mathrm{tU} / \mathrm{yr})$; it has since been expanded several times to its 2010 capacity of 14,000 tU/yr [Shropshire 2008] and operations are underway to increase its production to $18,000 \mathrm{tU} / \mathrm{yr}$ by 2012. [ConverDyn 2007] The most comprehensive study of the environmental impacts of the conversion process [Rotty 1975] was carried out for the MTW, when nameplate capacity was 9,000 t U/ year, actual throughput was 6,060 tU/year, and operations were planned to continue for 30 years.

\subsection{Energy Intensity}

Energy use in conversion facility operations arises in the form of process heat and electricity. Both the wet and dry processes operate using similar hydrofluorination processes. The two reactions involved hydrofluorination to $\mathrm{UF}_{4}$ and further fluorination to $\mathrm{UF}_{6}-$ are shown below. The enthalpies of reaction are given below for standard temperature and pressure conditions. The reactions, though carried out at $500-600 \mathrm{C}$, remain endothermic, making this step a substantial energy consumer among the front end processes.

$\mathrm{UO}_{2}+4 \mathrm{HF} \rightarrow \mathrm{UF}_{4}+2 \mathrm{H}_{2} \mathrm{O}, \quad \Delta \mathrm{H}^{\circ}=-229 \mathrm{~kJ} / \mathrm{mol}$,

$U F_{4}+F_{2} \rightarrow U F_{6}, \quad \Delta H^{o}=-233 \mathrm{~kJ} / \mathrm{mol}$,

In addition, the fluorine gas used in the second fluorination step is typically fabricated onsite from hydrofluoric acid via electrolysis [AREVA 2010] in the presence of the conductor $\mathrm{KHF}_{2}$. Although not carried out at high temperatures, this step is also a substantial electrical energy consumer. Figure 4.1 displays the major chemical and energetic inputs to the wet and dry processes. Since the processes both utilize the fundamental reactions described by equation 4.1, no substantial difference in energy consumption is expected between them ${ }^{\mathrm{k}}$. Literature review confirms this expectation.

k. The dissolution and solvent extraction steps of the wet process produce a very high purity product; the first steps of the wet process are therefore used to prepare high-purity $\mathrm{UO}_{2}$ for natural uranium fueled reactors. Purification in the dry process takes place in a distillation step following fluorination. 


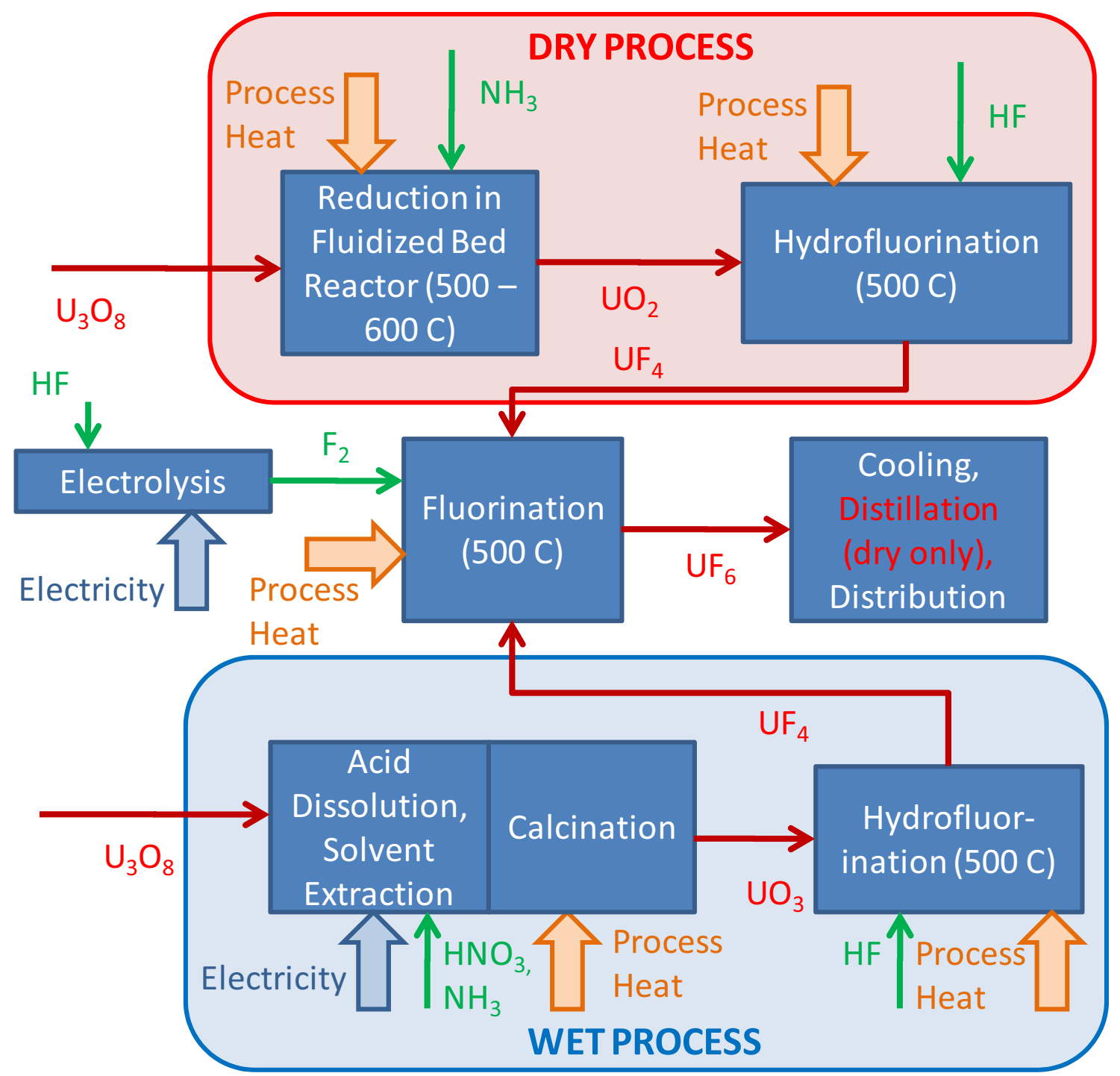

Figure 4.1. Schematic representation of dry and wet processes for $\mathrm{UF}_{6}$ production.

Operational energy use for this mature and well-established technology is documented in the literature, with estimates having been based on analyses of both the wet and dry processes. Figure 4.2 shows strong concurrence between the works reviewed for this study. Among the reported studies, the electrical and thermal energy consumption averaged $54 \mathrm{GJ}(\mathrm{e}) / \mathrm{tU}$ and $1202 \mathrm{GJ}(\mathrm{t}) / \mathrm{tU}$. This agreement arises even though the reviewed studies follow varying standards for accounting for embodied energy of fuels, materials and chemical inputs, implying that on-site energy consumption is dominant. Notably, the 1970s era study [Rotty 1975] agrees with the more modern efforts. [Rotty 1975] also confirms that direct energy consumption dominates the conversion process: by his estimate, including the embodied energy of chemicals and materials adds around 9\% to the operational energy consumption. Further review of the literature did not reveal any plant-reported energy consumption data suitable for use in an independent 
consumption estimate. Therefore, the average values taken from the literature review $(54 \mathrm{GJ}(\mathrm{e}) / \mathrm{tU}$ and $1202 \mathrm{GJ}(\mathrm{t}) / \mathrm{tU})$ will be used in this study ${ }^{1}$.

Only one of these studies assessed energy inputs to plant construction [Rotty 1975]. Distributing the direct energy consumption associated with construction over the throughput during the 30-year operational lifetime assumed in that study, it was found to be small: $0.02 \mathrm{GJ}(\mathrm{e}) / \mathrm{tU}$ and $1.45 \mathrm{GJ}(\mathrm{t}) / \mathrm{tU}$. Although embodied energy in the construction materials is likely to be substantially larger than direct consumption in the construction stage, energy associated with the construction phase is evidently small relative to conversion process operations.

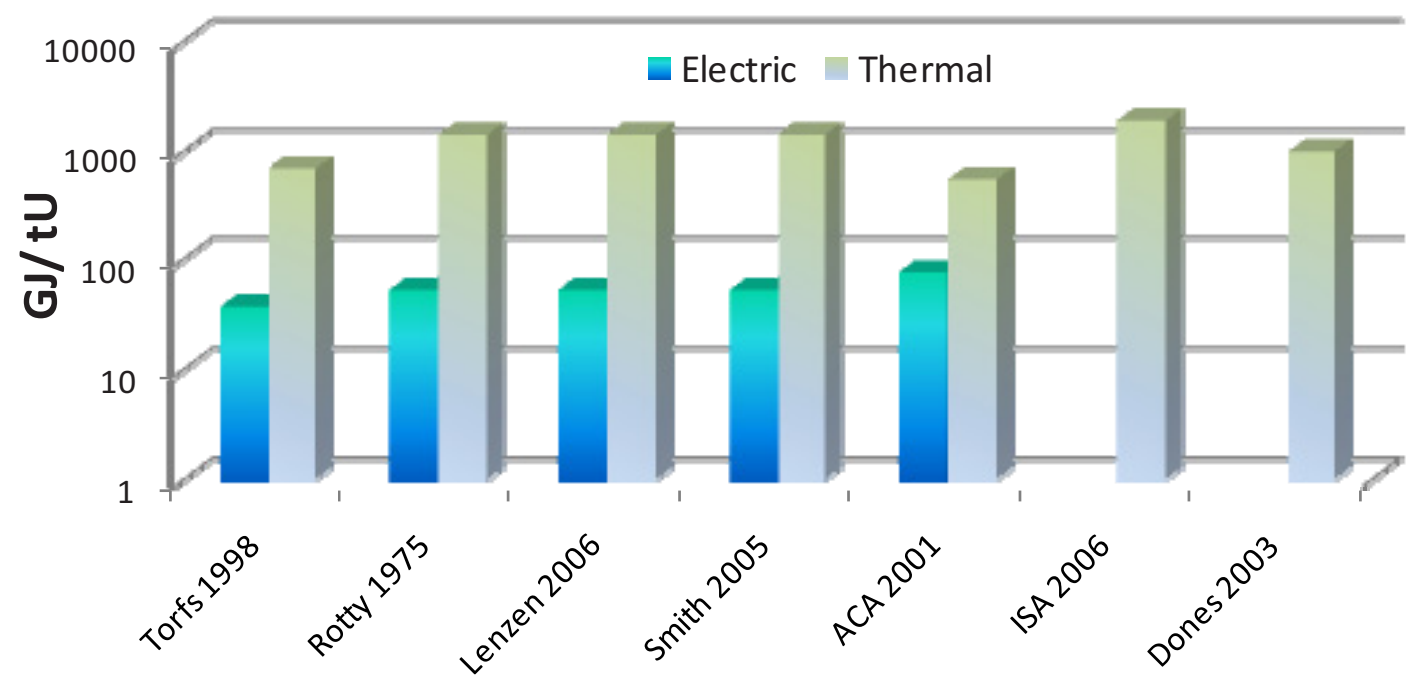

Figure 4.2. Literature review of energy consumed from electrical (blue) thermal (grey) carriers per tonne $\mathrm{U}_{\text {as }} \mathrm{UF}_{6}$ in conversion operations

\subsection{Carbon Footprint}

Virtually all ([Rotty 1975] assumes 100\%) of the thermal energy consumed in the two-step conversion process is applied as process heat to drive the fluorination reactions. For purposes of computing the carbon footprint, thermal energy is assumed to be from combustion of natural gas, as is the case at MTW. Employing the US grid average and natural gas emission factors of Table 2.2 to the average of surveys described in section 4.1, $\mathrm{CO}_{2}$ emissions estimates were calculated per tonne $\mathrm{U}$ converted to $\mathrm{UF}_{6}($ see Table 4.2). In section 9, these estimates are also summarized in terms of $\mathrm{CO}_{2}$ emissions per $\mathrm{MWh}(\mathrm{e})$ based on the once-through LWR fuel cycle described in Appendix A.

Carbon dioxide emissions associated with conversion facility operations are also well documented within the literature (Figure 4.3). Note that some authors derived emission estimates from their own values for energy intensities (viz. Figure 4.2), while others simply applied emission factors to an earlier energy intensity study. The average of the estimates presented in Figure 4.3 is $1.29 \mathrm{~kg} \mathrm{CO}_{2} / \mathrm{MWh}(\mathrm{e})^{\mathrm{m}}$.

1. Note that [ISA 2006] and [Dones 2003] do not separately report electricity consumption.

m. Smith and Storm van Leewen [Storm van Leewen 2005] present one of the two high outliers depicted in the figure, 2.42 $\mathrm{kgCO}_{2} / \mathrm{MWh}(\mathrm{e})$; this study is referenced in the other extreme estimate, [Lenzen 2006]. These outliers are noteworthy 


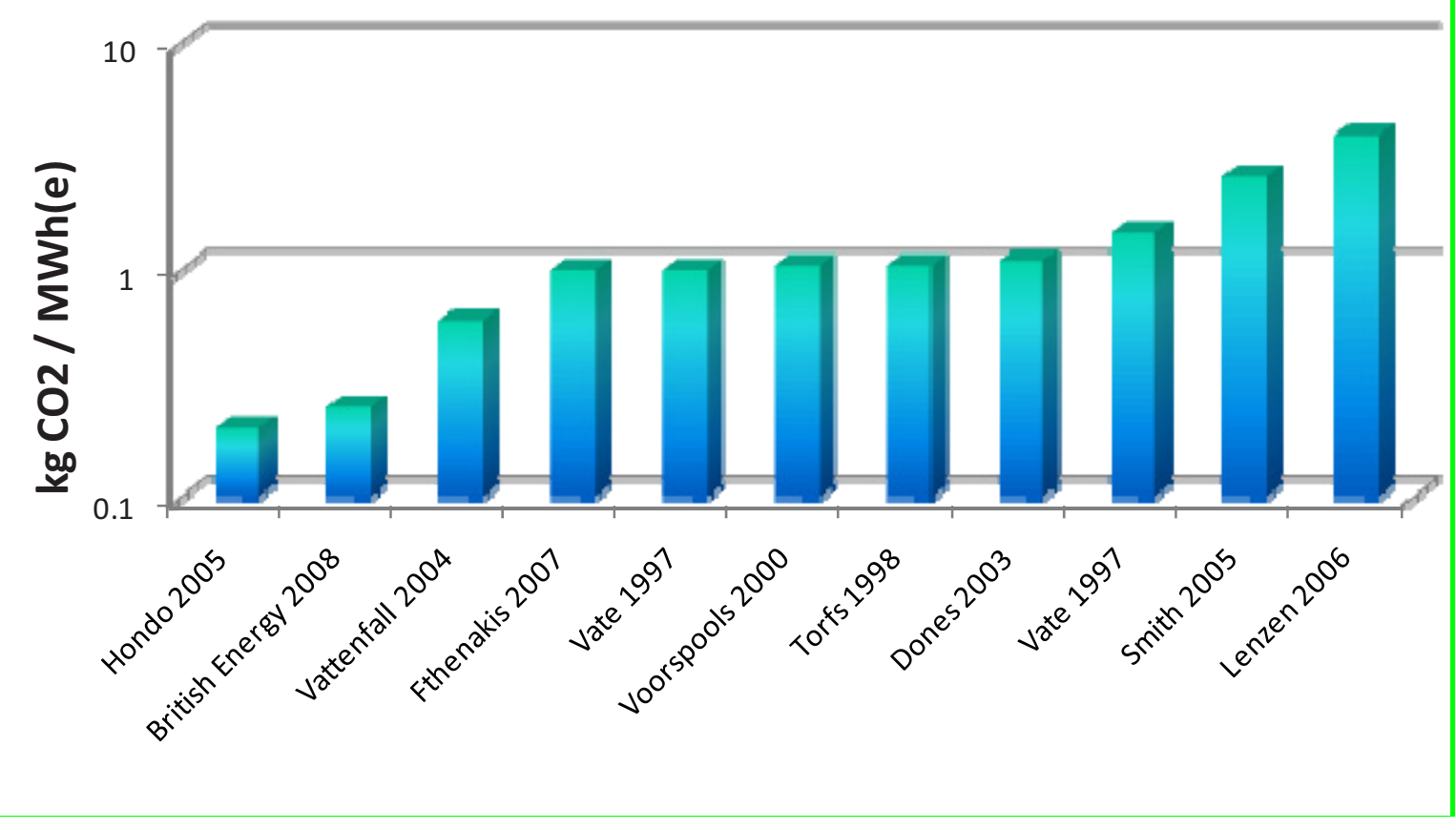

Figure 4.3. Estimates of $\mathrm{CO}_{2}$ emissions from $\mathrm{UF}_{6}$ conversion found in the literature

\subsection{Land Use}

A single independent estimate of land use was found in the literature review; this was $0.69 \mathrm{~m}^{2} / \mathrm{tU}$ by [Finch 1997]. MTW is set behind fences and covers a disturbed area of $0.24 \mathrm{~km}^{2}$ [GlobalSecurity 2010], [NRC 2006]. While two other fluorine products, $\mathrm{SF}_{6}$ and $\mathrm{IF}_{6}$, are made within this land area as well, to obtain a conservative estimate of the land footprint, all land area will be ascribed to the $\mathrm{UF}_{6}$ operations. Assuming a throughput of $14,000 \mathrm{tU} / \mathrm{yr}$ and conservatively choosing a facility lifetime of 30 years, the original licensed lifetime of MTW, land use is $0.57 \mathrm{~m}^{2} / \mathrm{tU}$ processed.

\subsection{Water Use}

The wet process for converting $\mathrm{U}_{3} \mathrm{O}_{8}$ to $\mathrm{UF}_{6}$ is water-intensive. [Gerbens 2008] specifies water use for the conversion of $\mathrm{U}_{3} \mathrm{O}_{8}$ to $\mathrm{UF}_{6}$ to be $4 \mathrm{~L} / \mathrm{GJ}(\mathrm{e})$ of nuclear electricity produced but was not sufficiently transparent to confirm its validity. Since [Gerbens 2008] does not provide this conversion, the generic conversion factor, 172,000 $\mathrm{GJ}(\mathrm{e}) / \mathrm{tU}$, derived in Appendix A was used to convert the figure from $\mathrm{L} / \mathrm{GJ}(\mathrm{e})$ to $\mathrm{L} / \mathrm{tU}$, leading to an estimate of $696,000 \mathrm{~L} / \mathrm{tU}$. Average water withdrawals for the two operating Comurhex facilities are approximately 100,000 L/tU [Areva 2010]. Both facilities are undergoing modernization; AREVA projects that the introduction of closed-loop cooling circuits should result in a reduction of withdrawals at the two facilities to just 10,000 L/tU [AREVA 2010].

because these authors' energy intensity estimates were very much in line with others'. Although not documented in [Storm van Leewen 2005], it is evident that an unfavorable emission factor was selected for reasons that are not clear. For example, if coal rather than natural gas were assumed to be used to generate the process heat, this study's estimate would rise from $1.47 \mathrm{~kg} \mathrm{CO}_{2} / \mathrm{MWh}(\mathrm{e})$ to $2.43 \mathrm{kgCO}_{2} / \mathrm{MWh}(\mathrm{e})$ - but use of coal for process heat in conversion plant operations has not been documented in this review. 
No estimates of water consumption for the dry process could be found, and the operator of the sole facility using the dry process has not published the relevant data. Hence, 100,000 L/tU was selected as the basis for estimating water usage for converting $\mathrm{U}_{3} \mathrm{O}_{8}$ to $\mathrm{UF}_{6}$.

\subsection{Occupational and Public Health}

MTW published extensive historical dose data in conjunction with a 2006 environmental assessment filing. The dose to the maximally exposed individual (MEI) at a location adjacent to the nearest residence north-northeast of the plant was reported to be 0.570 mrem per year. For the 5-year period from 2000 2004, the average annual total effective dose equivalent for MTW workers was less than $125 \mathrm{mrem}$, and almost 80 percent of the workers were exposed to an annual total effective dose equivalent of less than 500 mrem, or 10 percent of the NRC annual occupational dose limit in 10 CFR 20.1201. During this fiveyear period, just 5 of 683 workers logged annual total effective exposures of 1,000 mrem [NRC 2006].

Using Malvesi and Pierrelatte as reference facilities, the ExternE project [EC 1995] estimated collective occupational and public doses for conversion to be $8.3 \times 10^{-3}$ and $1.3 \times 10^{-4}$ person-rem per tonne of $\mathrm{U}$ converted.

\subsection{Process Chemical Inputs}

Significant chemical inputs include ammonia, nitric acid and hydrofluoric acid (Figure 4.1). The dry process practiced in the US also consumes sulfuric acid for wastewater $\mathrm{pH}$ adjustment as well as leaching activities on feed stocks containing out-of-specification levels of sodium or potassium.

AREVA reported consumption of 5,707 tonnes HF at their two conversion facilities, against $\mathrm{UF}_{6}$ production of 12,300 tonnes [AREVA 2010]. Given that $1 \mathrm{tUF}_{6}$ contains $0.68 \mathrm{tU}$, this implies that $0.69 \mathrm{t}$ HF were consumed per $\mathrm{tU}$ converted. This is close to the stoichiometrically expected value: six HF molecules are consumed per molecule of $\mathrm{UO}_{2}$ fluorinated to $\mathrm{UF}_{6}$, so the theoretical minimum HF consumption would be $0.50 \mathrm{tHF} / \mathrm{tU}$. Other process chemicals used by AREVA in uranium refining and conversion in 2008 included $\mathrm{NH}_{3}$ (4497 tonnes) and $\mathrm{HNO}_{3}$ (17,264 tonnes), or $0.54 \mathrm{t} \mathrm{NH}_{3} / \mathrm{tU}$ and $2.07 \mathrm{tHNO}_{3} / \mathrm{tU}$ (Table 4.1). Process chemical inputs for the dry process are expected to be similar, except that it does not utilize nitric acid as the dissolution/extraction steps are absent.

Table 4.1. Selected process chemical inputs for conversion of $\mathrm{U}_{3} \mathrm{O}_{8}$ to $\mathrm{UF}_{6}$

\begin{tabular}{ll}
\multicolumn{1}{c}{ Material } & \multicolumn{1}{c}{ Amount $[\mathrm{t} / \mathrm{tU}]$} \\
\hline Hydrofluoric acid, HF & 0.69 \\
Nitric Acid, $\mathrm{HNO}_{3}$ & 2.07 (wet process) \\
Ammonia, $\mathrm{NH}_{3}$ & 0.54 \\
\hline
\end{tabular}

\subsection{Summary}

The environmental footprint metrics presented in this chapter are summarized in Table 4.2. Results are applied to both the wet and dry processes unless otherwise noted. 
Table 4.2. Summary of impacts resulting from conversion of $\mathrm{U}_{3} \mathrm{O}_{8}$ to $\mathrm{UF}_{6}$

\begin{tabular}{|c|c|c|c|c|c|c|c|c|c|c|}
\hline \multirow[b]{3}{*}{ Units } & \multicolumn{3}{|c|}{ Energy Consumption } & \multirow[t]{2}{*}{$\begin{array}{c}\mathrm{CO}_{2} \\
\text { Emissions } \\
\end{array}$} & \multirow[t]{2}{*}{ Land Use } & \multirow[t]{2}{*}{ Water Use } & \multicolumn{2}{|c|}{ Maximum Dose } & \multicolumn{2}{|c|}{ Collective Dose } \\
\hline & electrical & $\begin{array}{c}\text { thermal: } \\
\text { liquid } \\
\text { carriers }\end{array}$ & $\begin{array}{c}\text { thermal: } \\
\text { other } \\
\text { carriers }\end{array}$ & & & & Worker & MEI & Workers & Public \\
\hline & $\begin{array}{l}\text { GJ(e) per } \\
\text { tonne U }\end{array}$ & $\mathrm{GJ}(\mathrm{t}) \mathrm{t}$ & tonne $\mathrm{U}$ & $\begin{array}{c}\mathrm{kg} \mathrm{CO} \mathrm{CO}_{2} \\
\text { per tonne } \\
\mathrm{U}\end{array}$ & $\begin{array}{l}\mathrm{m}^{2} \text { per } \\
\text { tonne } \mathrm{U}\end{array}$ & $\begin{array}{l}\text { Litres per } \\
\text { tonne U }\end{array}$ & $\mathrm{mrem} / \mathrm{yr}$ & $\mathrm{mrem} / \mathrm{yr}$ & $\begin{array}{l}\text { person-rem } \\
\text { per tonne U }\end{array}$ & $\begin{array}{c}\text { person-rem } \\
\text { per tonne } \\
U\end{array}$ \\
\hline Conversion & 54 & NA & $1.2 \times 10^{3}$ & $7.0 \times 10^{4}$ & 0.57 & $1.0 \times 10^{5}$ & 1,000 & 0.57 & $8.3 \times 10^{-3}$ & $1.3 \times 10^{-4}$ \\
\hline $\begin{array}{l}\text { See Document } \\
\text { Section(s) \# }\end{array}$ & 4.1 & 4.1 & 4.1 & 4.2 & 4.3 & 4.4 & 4.5 & 4.5 & 4.5 & 4.5 \\
\hline
\end{tabular}




\subsection{References}

[AREVA 2010] AREVA Corporate Website, available: http://www.AREVA.com/EN/operations757/conversion-the-fluorination-of-uranium-in-2-stages.html, web page accessed June 11, 2010.

[ACA 2001] Australian Coal Association. Electricity from a nuclear power station. Case study B16. Canberra, Australia: Australian Coal Association, 2001.

[Beerten 2009] Beerten, Jeff. Greenhouse gas emissions in the nuclear life cycle: A balanced appraisal. Energy Policy 37 (2009) 5056-5068.

[British Energy 2005] British Energy. Environmental Product Declaration of Electricity from Torness Nuclear Power Station, Technical Report, 2005.

[British Energy 2008] British Energy. Carbon Footprint of the nuclear fuel cycle, Briefing Note, 2008.

[ConverDyn 2007] CONVERDYN News Wire, available: http://www.converdyn.com/press_room/pdf/618-07.pdf, webpage accessed June 11,2010 .

[Dones 2004] Dones, R., "Life Cycle Inventories for the Nuclear and Natural Gas Energy Systems and Examples of Uncertainty Analysis," Energy Supply, 2004.

[EC 1995] European Commission, ExternE - Externalities of Energy, Volume 5: Nuclear, European Commission Directorate-General XII, 1995.

[Finch 1997] Finch, W., Uranium, Its Impact on the National and Global Energy Mix. U.S Geological Survey Circular 1141, 1997.

[Fthenakis 2007]Fthenakis, V., "Greenhouse Gas Emissions from Solar Eectric- and Nuclear Power: A Life Cycle Study," Energy Policy, 2007.

[Gerbens 2008] Gerbens-leenes et al. Water Footprint of Bio-energy and Other Primary Energy Carriers. Value of Water Research Report No. 29. UNESCO, March 2008.

[Hondo 2005] Hondo, H., "Life cycle GHG emission analysis of power generation: Japanese case," Energy, 30, pp. 2042-2056, 2005.

[GlobalSecurity 2010] GlobalSecurity.org, Honeywell Specialty Materials Metropolis Plant, available: http://www.globalsecurity.org/wmd/facility/metropolis.htm. webpage accessed June 11, 2010.

[Lenzen 2008] Lenzen, M., "Life cycle energy and greenhouse gas emissions of nuclear energy: A review," Energy Conversion and Management 49, pp. 2178-2199, 2008.

[NRC 2006] U.S. Nuclear Regulatory Commission. Environmental Assessment for Renewal of NRC License No. SUB-526 for the Honeywell Specialty Materials Metropolis Work Facility, Final Report. Docket No.40-3392, 2006.

[Price 2009] Price, Lisa. Enrichment and Conversion Technologies, Women in Nuclear Conference, 2009.

[Rotty 1975] Rotty, R M. Net Energy from Nuclear Power. IEA-75-3 1EA Report, 1975.

[Shropshire 2008] Shropshire, D. et al. Advanced Fuel Cycle Cost Basis. Idaho National Laboratory report INL/EXT-07-12107, 2008.

[Sovacool 2008] Sovacool, B., "Greenhouse Gas Emissions from Nuclear Power: A Critical Survey," Energy Policy, 2008.

[Storm van Leewen 2005] Storm van Leeuwen, J. W.,Smith, P. Nuclear Power, The Energy Balance, 2005. Revised 2007. available: http://www.stormsmith.nl/, webpage accessed January 30, 2010. 
[Vate 2002] Vate, V. , "Full-energy-chain greenhouse-gas emissions: a comparison between nuclear power,hydropower, solar power, and wind power," Int. J. Risk Assessment and Management, 3, 1, 2002.

[Vorspools 2000] Vorspools, K. R., Brouwers, E. A., and W. D. D’Haeseleer, “Energy Content and Indirect Greeenhouse Gas Emissions Embedded in 'Emission-Free' Power Plants: Results for the Low Countries," Applied Energy, 67, 307-330, 2000. 


\section{ENRICHMENT}

This section addresses enrichment of the ${ }^{235} \mathrm{U}$ content of $\mathrm{UF}_{6}$ from the naturally-occurring level to the $3 \%$ to $5 \%$ required by light water reactors. Two enrichment technologies are deployed at industrial scale in 2010: gaseous diffusion and gas centrifuge. A third technology, the Silex process being developed by GE-Hitachi, may make a commercial debut in the 2010s. Unlike the present-day technologies, which rely upon the mass difference between ${ }^{235} \mathrm{UF}_{6}$ and ${ }^{238} \mathrm{UF}_{6}$, the laser-driven Silex process takes advantage of the isotopic shift between ${ }^{235} \mathrm{UF}_{6}$ and ${ }^{238} \mathrm{UF}_{6}$ absorption bands. As diffusion plants in the US and France are being retired in favor of centrifuge technology, they are largely of historical interest and will only be treated briefly. As of 2010, technical data for Silex continues to be covered by corporate and federal (US) classification restrictions; therefore, it can only be discussed in qualitative terms.

Centrifuge technology will be the focus of this section. Reference data for centrifuge enrichment will be taken from facilities operated by Urenco, operator of plants in the United Kingdom, Germany, the Netherlands and the United States [Urenco 2008]. Additional data will be drawn from the four centrifuge complexes operated by the Russian Ministry of Atomic Energy (Minatom) [Bukharin 2004]. The Areva EURODIF Georges Besse plant in Tricastin, France will serve as the reference diffusion facility [Areva 2009].

The unit against which the environmental impacts of enrichment will be normalized is the separative work unit (SWU). SWU carries units of mass and quantifies the degree of isotopic separation achieved. It is proportional to the feed mass (of an individual enrichment unit or a collection of units acting in series and parallel, termed a 'cascade') as well as the energy requirement. See Appendix A for a quantitative discussion.

\subsection{Energy Intensity}

Gaseous diffusion technology emerged in the 1940s; large (> $10 \mathrm{MSWU} /$ year), aging plants in the US and France are slated to be phased out in the 2010 s in favor of centrifuge facilities. The process is energyintensive: electricity is expended to compress the $\mathrm{UF}_{6}$ gas entering each diffusion machine, to remove the heat of compression associated with this pumping, and to maintain a partial vacuum within each diffusion chamber. The degree of enrichment achieved by a single diffusion unit is very small, so that a ${ }^{235} \mathrm{U}$ atom would pass through at least ca. 1,000 units between entering as part of natural uranium feed and leaving as enriched product. This is a consequence of the reliance of the technology on small differences in the mean free-gas diffusion velocity of ${ }^{235} \mathrm{UF}_{6}$ and ${ }^{238} \mathrm{UF}_{6}$; as is not the case with centrifuge or laser technology, this approach to separation imposes an upper limit (and a very restrictive one) on the degree of separation that can be achieved within a single machine.

As a consequence, the energy intensity of diffusion plants has changed little since the inception of the technology. A literature review (Table 5.1) confirms this; many of the cited estimates were identified in an earlier review by [Lenzen 2008].

Table 5.1. Electricity consumption, gaseous diffusion, estimates from the literature

\begin{tabular}{lc}
\hline \multicolumn{1}{c}{ Reference } & $\begin{array}{c}\text { Consumption } \\
(\mathrm{kWh}(\mathrm{e}) / \mathrm{SWU})\end{array}$ \\
\hline [Heinloth 1997] & 2860 \\
[WNA 2010] & 2500 \\
[Chapman 1975] & $2420-2520$ \\
[Rotty 1975] & $2810-3050$ \\
[Villani 1984] & 2460 \\
\hline
\end{tabular}


Consumption associated with energy carriers other than electricity is negligible: EURODIF reported only $0.75 \mathrm{kWh}(\mathrm{t}) / \mathrm{SWU}$ of natural gas consumption in 2008 [Areva 2009]. Therefore, the reference energy intensity for gaseous diffusion will be taken to be the average of the values given in Table 5.1: 2660 $\mathrm{kWh}(\mathrm{e}) / \mathrm{SWU}$ or $9.58 \mathrm{GJ}(\mathrm{e}) / \mathrm{SWU}$.

For centrifuge enrichment, energy is required to maintain the rotation of the centrifuges, to pump the $\mathrm{UF}_{6}$ gas, and also to heat individual units to establish a convective flow pattern that facilitates gas collection. Centrifuge enrichment technology is far less energy-intensive than diffusion, and the principal reason for this is the far larger per-unit separation efficiency: a ${ }^{235} \mathrm{U}$ atom might pass through as few as ca. 20 units in a centrifuge cascade before emerging as product, as opposed to 1,000 diffusion units.

Surveyed estimates ([WNA 2010], [Heinloth 1997], [Wagner 1978], [Dones 1996], [Dones 2004], [Villani 1984] and [Bukharin 2004], red squares in Figure 5.2) disagree by a factor of up to 5. This disagreement is explained by the time at which each estimate was made. There is no physical upper limit to the degree of separation that can be achieved per unit: a unit's SWU capacity is determined by its height and linear speed of rotation ${ }^{\mathrm{n}}$. Therefore, development of stronger materials able to withstand rotation-induced stresses ${ }^{\circ}$, reduction of frictional losses, and improvement of component reliability can all improve performance and decrease per-unit and plant-wide energy intensity. These engineering-based frontiers have consistently been pushed back over the 50 years since the technology was first commercially deployed.

The dates of the estimates shown in Figure 5.2 are taken to be the year of publication unless otherwise specified in the source document, with one exception. In [Bukharin 2004], energy intensities for two MINATOM centrifuge generation designs are provided for the year in which the generation began industrial production. To ensure compatibility with the other estimates, which were taken from commercial operating data of the day, the [Bukharin 2004] estimates were each applied ten years after production of that generation began, reflecting a date when the technology would likely be the dominant one in use.

Figure 5.2 shows that centrifuge technology has followed a Moore's Law pattern of development. Moore's Law was originally formulated to describe the rate of growth of computing power, specifically the time rate of change of the number of transistors per integrated circuit. [Moore 1965] predicted that this would double every two years, a forecast that has remained astonishingly accurate through 2010. Moore's Law has since been applied to describe the evolution of other technologies ${ }^{\mathrm{p}}$ where exponential transformations are observed, although the time constant associated with the doubling varies from industry to industry.

n. Specifically, it is proportional to the fourth power of the linear speed of the rotor for earlier machines, trending toward the second power for advanced machines as the interior of each centrifuge becomes a near-vacuum at high speeds. It is directly proportional to the height of the machine and inversely proportional to the square of the temperature (diffusive effects which degrade the gas stratification are accentuated as temperature increases).

o. A force balance shows that to preserve circular motion the tensile stress $\sigma\left[\mathrm{N} / \mathrm{m}^{2}\right]$ in the cylinder wall will increase with the angular speed $\omega[\mathrm{rad} / \mathrm{s}]$ and radius a $[\mathrm{m}]$ of the centrifuge. Therefore, the angular speed is limited to $\omega_{\max }$ by the yield strength $\sigma_{\mathrm{y}}$ of the cylinder wall as:

$\omega_{\max }=(1 / \mathrm{a})\left(\sigma_{\mathrm{y}} / \rho\right)^{1 / 2}$,

where $\rho\left[\mathrm{kg} / \mathrm{m}^{3}\right]$ is the density of the wall material. Hence wall materials continue to evolve toward higher strength-todensity ratios, from aluminum alloys in the 1960 s and 70 s to maraging steel (ultra high strength low-carbon high-nickel alloys) in the 1980s to carbon fiber in the 1990s and 2000s [Glaser 2008].

p. Moore's Law has been applied to depict developments in hardware memory capacity, pixel count in digital cameras, fiber optics, magnetic disks, and nanotechnology, to name a few. 
This trend is well-known within the centrifuge enrichment industry; it was qualitatively discussed in an article in Nature in 2010 [Slakey 2010]. Figure 5.1 is Urenco's conceptual depiction. Urenco has produced a new 'generation' of centrifuges every 7-10 years, as has Minatom [Bukharin 2004].

\section{Urenco Centrifuge Development}

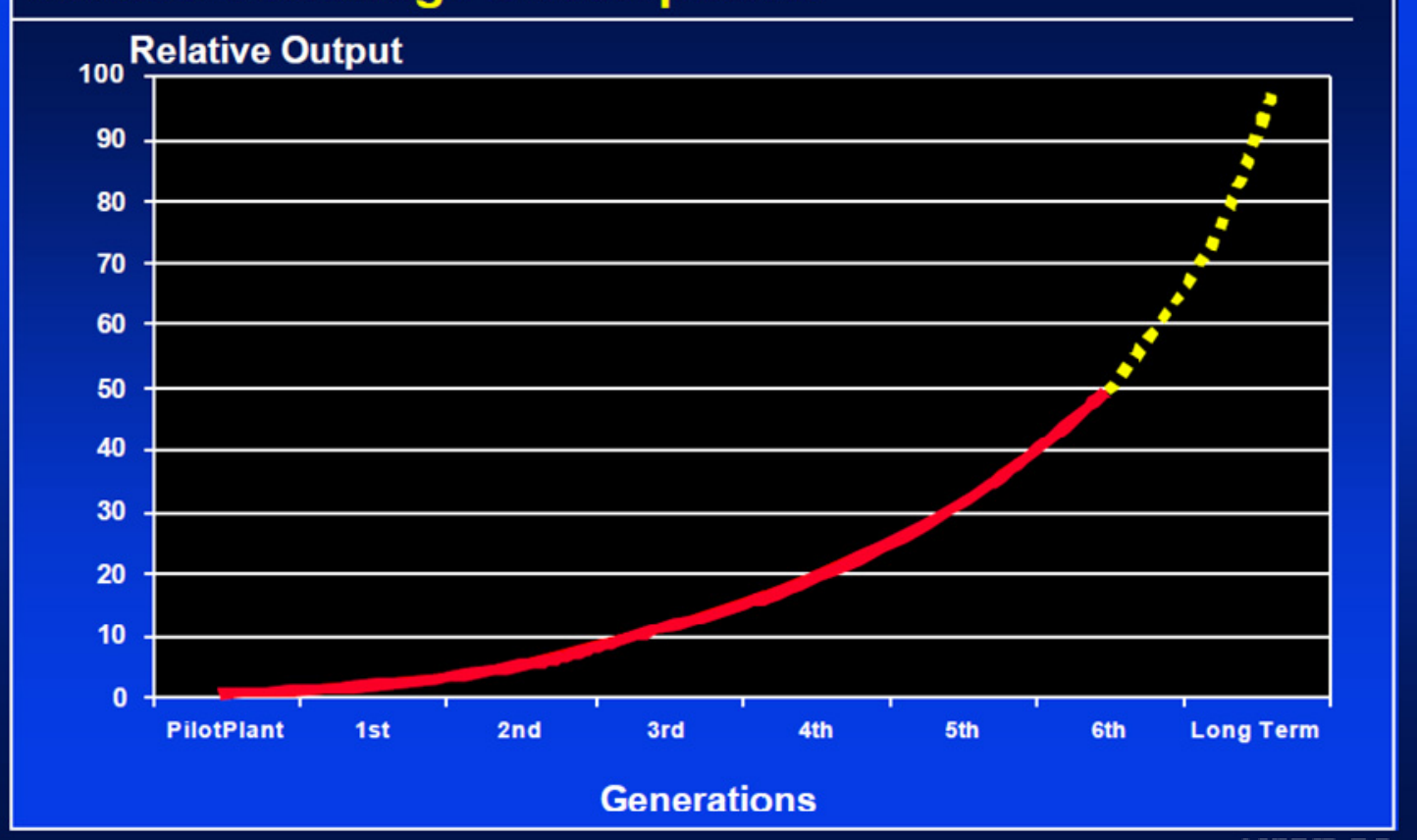

Figure 5.1. Urenco illustration of the Moore's Law behavior of enrichment technologies. Figure source: [Upson 2001]

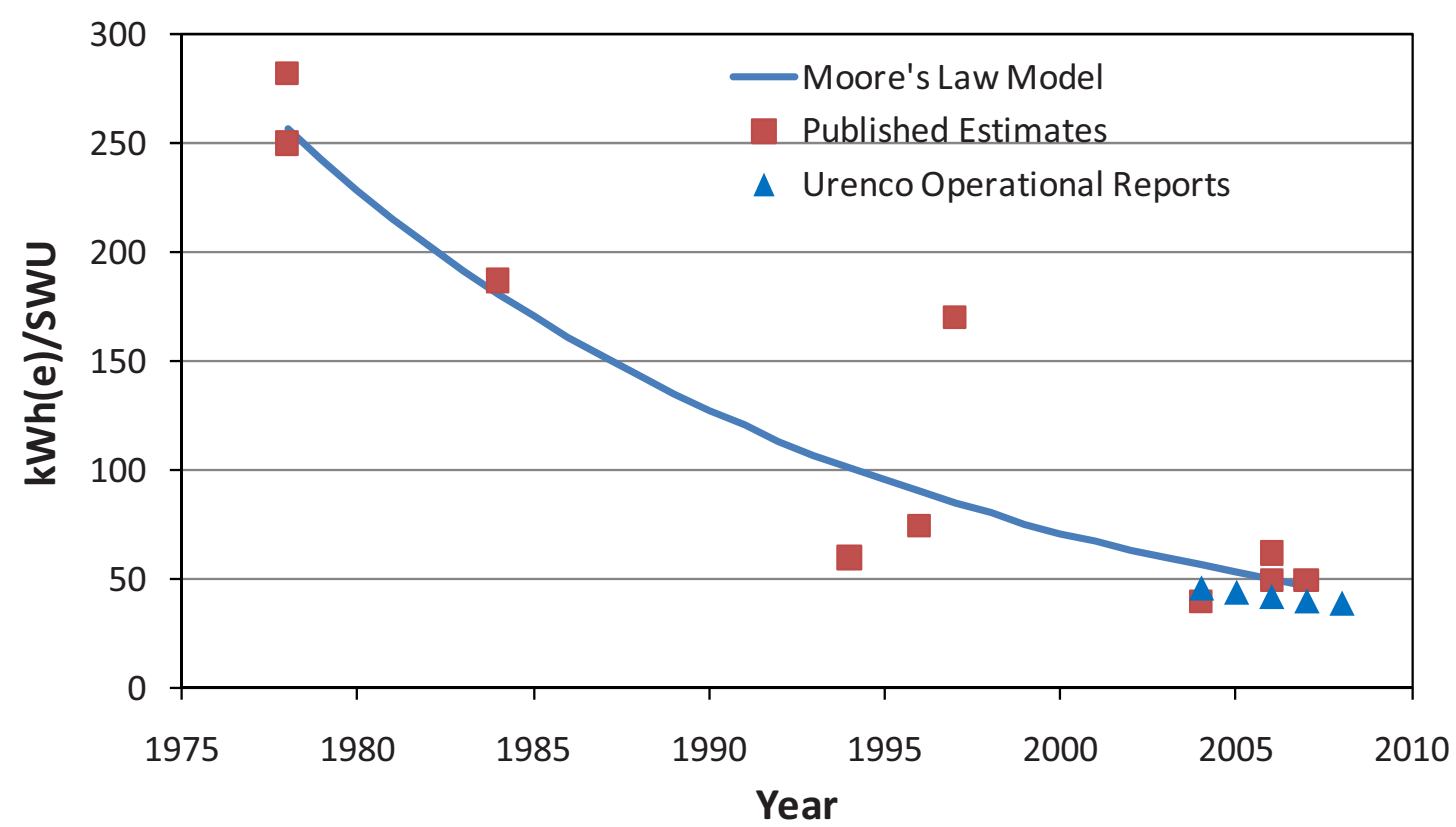

Figure 5.2. Moore's Law fit to surveyed estimates (red); comparison to Urenco operational data 2003-08 
Annual Urenco electricity consumption data was only available for the period 2003-08 [Urenco 2008]. The Urenco plants consume negligible energy from carriers other than electricity. This data is plotted on Figure 5.2 (blue triangles).

The curve depicted in Figure 5.2 was derived by fitting an exponential function of the form

$\mathrm{e}=\mathrm{K} \exp (\mathrm{m}(\mathrm{T}-2010))$

to the published estimates (red squares). Here e $[\mathrm{kWh}(\mathrm{e}) / \mathrm{SWU}]$ is the energy intensity of enrichment, $\mathrm{K}$ $[\mathrm{kWh}(\mathrm{e}) / \mathrm{SWU}]$ is a normalization constant that takes on the value of the energy intensity forecasted 2010 , $\mathrm{T}$ is the year, and $\mathrm{m}[1 /$ year] is a time constant. Regression analysis produced $\mathrm{K}=39.88 \mathrm{kWh}(\mathrm{e}) / \mathrm{SWU}$ and $\mathrm{m}=-0.0582 /$ year. The function plotted in Figure 5.2 is then

$\mathrm{e}=39.88 \exp (-0.0582(\mathrm{~T}-2010)) \mathrm{kWh}(\mathrm{e}) / \mathrm{SWU}$, or

$\mathrm{e}=0.144 \exp (-0.0582(\mathrm{~T}-2010)) \mathrm{GJ}(\mathrm{e}) / \mathrm{SWU}$.

The Moore's Law model agrees remarkably well with both the magnitude and the time rate of change of the energy intensity of the independent data series, the Urenco plant reports.

Evidence supporting Moore's Law for enrichment can also be found from the Russian centrifuge development program. [Bukharin 2004] provides performance parameters for eight generations of Minatom centrifuges spanning a development period of four decades (Table 5.2). While [Bukharin 2004] does not provide energy intensities for most of the generations, it is possible to deduce a trend from the data that is given.

Table 5.2. Russian centrifuge performance by technology generation

\begin{tabular}{lccc}
$\begin{array}{c}\text { Generation (date } \\
\text { of first production) }\end{array}$ & $\begin{array}{c}\text { Separative capacity } \\
\text { [SWU/yr/ centrifuge] }\end{array}$ & $\begin{array}{c}\text { Rotor speed } \\
{[\mathrm{m} / \mathrm{s}]}\end{array}$ & $\begin{array}{c}\text { Rotor radius * (rotor speed) })^{2} \text { per } \\
\text { SWU/yr (normalized to Gen 1 = 1.0) }\end{array}$ \\
\hline $1(1960)$ & 0.4 & 340 & 1 \\
$2(1962)$ & 0.6 & 360 & 0.90 \\
$3(1964)$ & 1.0 & 425 & 0.75 \\
$4(1964)$ & 1.4 & 475 & 0.67 \\
$5(1970)$ & 1.9 & 530 & 0.61 \\
$6(1984)$ & 2.5 & 580 & 0.56 \\
$7(1997)$ & 3.2 & 630 & 0.52 \\
$8(2003)$ & 4.2 & 690 & 0.47 \\
\hline
\end{tabular}

One might crudely assume that a significant portion of the energy consumption is associated with overcoming frictional losses. If this is the case, then the rotor kinetic energy would play a major role in determining energy consumption. All Minatom centrifuges have a radius of $6 \mathrm{~cm}$ (except Generation 1: $5 \mathrm{~cm}$ ) and length 60-70 $\mathrm{cm}$ [Bukharin 2004], so - making a number of conservative assumptions - it is possible to estimate an energy consumption trend by evaluating the product of rotor radius (proportional to its volume and hence mass) and the square of the rotor speed. Conservative assumptions made in doing this include: no variation in rotor wall thickness or density between generations, no reduction in frictional losses from one generation to the next. Even under these assumptions, the relative energy consumed per SWU for the Minatom designs would have dropped by more than $50 \%$ (last column of Table 5.2).

Energy efficiency improvements associated with technological change are evident in the other fuel cycle processes as well: see Chapters 3 and 6 for discussions of their manifestation in uranium extraction and 
fuel fabrication. Yet among the fuel cycle technologies the rate of change has been most dramatic - far exceeding the rate of decline of the energy intensity for the aggregated economy - for enrichment. One driving factor for this is the rapid capital stock turnover time within this industry. Within an enrichment plant, wear and tear requires that individual centrifuges be replaced every ten to fifteen years [Upson 2001], and these are replaced with next-generation machines. Other fuel cycle processes take place in large, one-of-a-kind facilities with components that are generally not replaced until a nextgeneration facility is built, a time scale of 40 to 60 years.

Past adherence to Moore's Law does not guarantee that it will be followed indefinitely into the future. In some cases, inviolate limits tied to the fundamental physics governing the process may be reached. This is unlikely to be the case for enrichment, as the thermodynamic minimum energy for separation is several orders of magnitude below present-day consumption ${ }^{q}$. For centrifuge enrichment, engineering constraints may someday impede this continued rate of progress: Urenco management has stated that new centrifuge generations can no longer be expected as frequently as every 7-10 years [Upson 2001]. But Moore's Law can transcend individual exemplars of technologies that achieve the same goal. Figure 5.3 shows, on a logarithmic scale, the data presented in Figure 5.2 and the Moore's Law fit. In addition, the energy consumption associated with gaseous diffusion has been plotted against the inception date of that technology.

Figure 5.3 should not be interpreted to imply that the energy intensity of enrichment has always varied (or will always vary) smoothly with time, although this has been close to the truth during the centrifuge era. The best achievable energy intensity in fact dropped precipitously when the first generation of centrifuges was introduced. It may do so again with the commercialization of the Silex process. As mentioned earlier, no technical data regarding the process has been published, so it is not yet possible to formulate a set of environmental impacts. But energy continues to represent a considerable portion of the cost of

q This limit was first examined in the context of uranium enrichment by Fuchs and Peierls in 1942 [Fuchs 1942]. The minimum energy $\Delta \mathrm{U}$ required to achieve isotopic separation (or indeed any separation process in which the internal energy and temperature of the constituents remain unchanged) may be written as

$\Delta \mathrm{U}=\mathrm{T} \Delta \mathrm{S}$,

where $\mathrm{S}$ is the entropy of the mixture; for an ideal two-component mixture with a first component mole fraction of $\mathrm{m}$. $\mathrm{S}$ is given by

$\mathrm{S}=\mathrm{n} \mathrm{R}(\mathrm{m} \ln \mathrm{m}+(1-\mathrm{m}) \ln (1-\mathrm{m}))$,

where $\mathrm{R}=8.314 \mathrm{~J} / \mathrm{K} / \mathrm{mol}$ is the ideal gas constant and $\mathrm{n}$ is the number of moles of all components of the mixture. Note that $\mathrm{S}$ approaches zero as an isotopically pure mixture is achieved (i.e. $\mathrm{m}->0$ or $\mathrm{m}->1$ ) since $\lim \mathrm{m}->0 \mathrm{~m} \ln \mathrm{m}=0$ and is strictly negative otherwise. Consider the enrichment of uranium where the entropy of three streams, feed, product and tails must be considered. Let $\mathrm{F}, \mathrm{P}$ and $\mathrm{W}$ be the number of moles in each stream and $\mathrm{m}_{\mathrm{F}}, \mathrm{m}_{\mathrm{P}}$ and $\mathrm{m}_{\mathrm{W}}$ be the mole fractions of the first component in each stream. Then by atomic balance

$\mathrm{F}=\mathrm{P}+\mathrm{W}$,

$\mathrm{Fm}_{\mathrm{F}}=\mathrm{Pm}_{\mathrm{P}}+\mathrm{Wm}_{\mathrm{W}}$

Consider the separation of one mole of uranium $(\mathrm{F}=1 \mathrm{~mol})$ with feed concentration $\mathrm{m}_{\mathrm{F}}=0.0072$ into streams with concentration $\mathrm{m}_{\mathrm{W}}=0.002$ and $\mathrm{m}_{\mathrm{P}}=.045$. Then $\mathrm{P}=0.121 \mathrm{~mol}$ and $\mathrm{W}=0.879 \mathrm{~mol}$. Then, let $\Delta \mathrm{S}=\mathrm{S}_{1}-\mathrm{S}_{0}=$ the final state entropy minus the initial state entropy. These entropies are $\mathrm{S}_{0}=-0.04270 \mathrm{~J} / \mathrm{K}$ and $\mathrm{S}_{1}=-0.03488 \mathrm{~J} / \mathrm{K}$, so that $\Delta \mathrm{S}=0.00782$ $\mathrm{J} / \mathrm{K}$.

Taking the temperature at which the separation is carried out to be $337 \mathrm{~K}$, the triple point temperature of $\mathrm{UF}_{6}$, the work $\Delta \mathrm{U}$ associated with separating one mole of feed as described is found to be $2.64 \mathrm{~J}$. If the feed is instead $1 \mathrm{~kg}$ of natural uranium (4.20 moles), the work becomes $11.07 \mathrm{~J}$.

Compare this against the energy consumed by modern Urenco centrifuges accepting $1 \mathrm{~kg}$ of natural uranium and producing $0.12 \mathrm{~kg}$ of $4.5 \%$ enriched product. This requires $0.91 \mathrm{SWU}$; at $40 \mathrm{kWh} / \mathrm{SWU}=144 \mathrm{MJ} / \mathrm{SWU}, 132 \mathrm{MJ}$ of energy are consumed, about six orders of magnitude more than the thermodynamic minimum. 
enrichment; if Moore's Law continues to hold for enrichment as it has done in the past, one may infer that for Silex to achieve commercial success one objective it must meet is to follow or beat the trend shown in Figure 5.3.

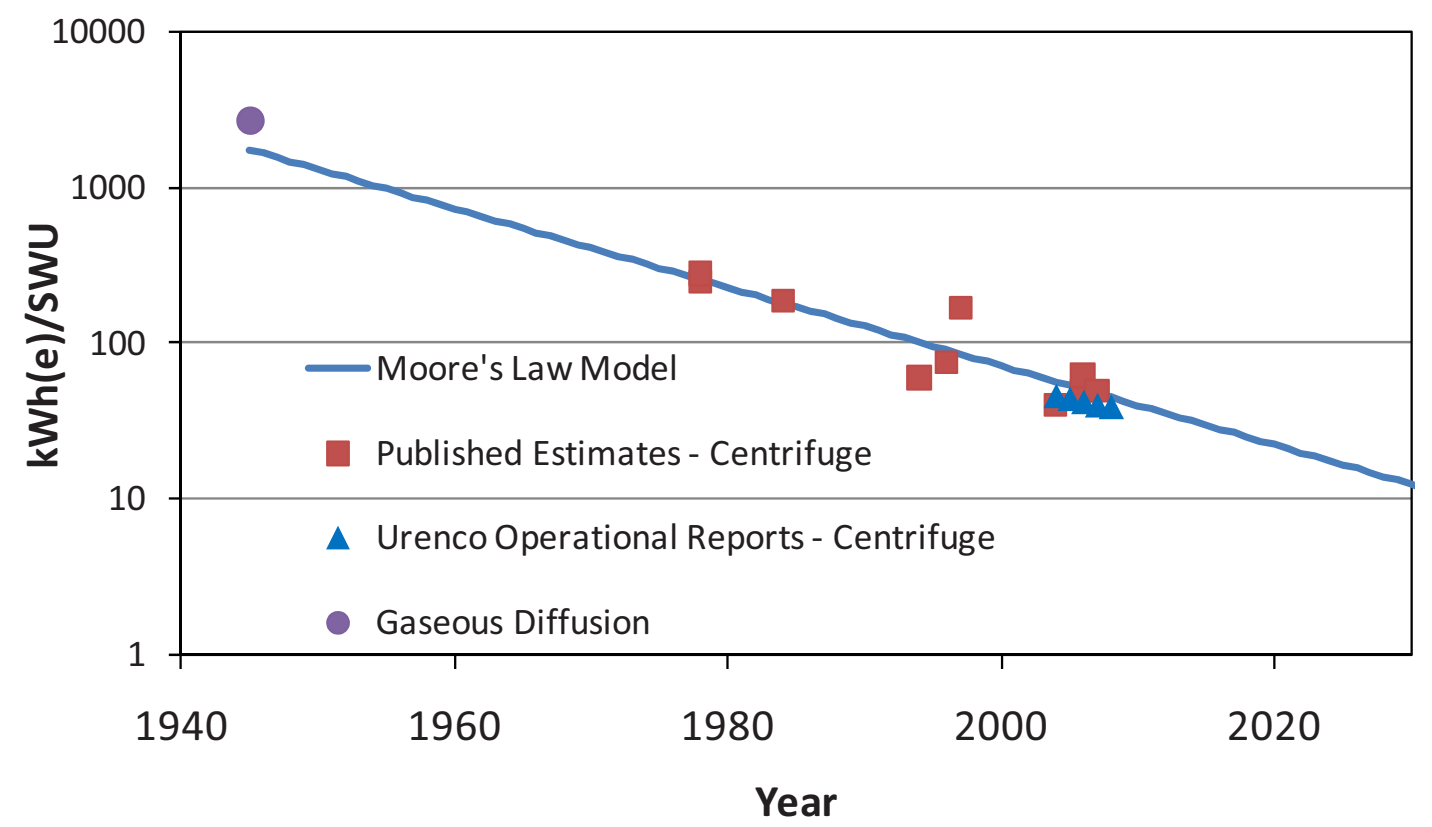

Figure 5.3. Moore's Law trend, extrapolation to the past (showing the earlier technology, diffusion) and future. Logarithmic scale.

The reference contemporary energy intensity for centrifuge enrichment will be the 2008 value reported for the Urenco plants, $39 \mathrm{kWh}(\mathrm{e}) / \mathrm{SWU}$ or $0.140 \mathrm{GJ}(\mathrm{e}) / \mathrm{SWU}$. Moore's Law forecasts of the future intensity of enrichment can be made from equation 5.2; this is assumed to reflect the evolution of centrifuge technology as well as the possible commercialization of Silex ${ }^{\mathrm{r}}$.

r. In fact, [Lyman 2005] provides just enough information to make a crude estimate regarding one portion of the energy input to the Silex process. [Lyman 2005] estimates that 9,600 $\mathrm{kWh}(\mathrm{e})$ of electrical energy would need to be supplied to the lasers to process $140 \mathrm{~kg}$ of natural uranium bearing $1 \mathrm{~kg}$ of ${ }^{235} \mathrm{U}$. [Lyman 2005] conservatively assumed that a near-pure ${ }^{235} \mathrm{U}$ stream could be obtained from a single pass, but Silex has subsequently claimed that such performance is not expected.

[SILEX 2010] provides a range of 2-20 for the stage separation factor, $\alpha$. This quantity is defined as

$\alpha=\mathrm{x}_{\mathrm{P}}\left(1-\mathrm{x}_{\mathrm{W}}\right) / \mathrm{x}_{\mathrm{W}}\left(1-\mathrm{x}_{\mathrm{P}}\right)$,

where $\mathrm{x}_{\mathrm{P}}$ and $\mathrm{x}_{\mathrm{W}}$ are the ${ }^{235} \mathrm{U}$ mole fractions of the product and tails streams and $\mathrm{x}_{\mathrm{F}}$ will be the mole fraction of the natural uranium feed. Centrifuges can achieve a stage separation factor of approximately 1.3, so even this would represent a considerable advance. Assuming that $\alpha=20$ for SILEX, and also that the system is configured as an ideal cascade so that the product-to-feed and feed-to-tails ${ }^{235} \mathrm{U}:{ }^{238} \mathrm{U}$ ratios are equal (as might be done in a commercial plant, but perhaps not a SILEX plant), a single pass would result in a product 235U enrichment of $\mathrm{x}_{\mathrm{P}}=0.0310$.

Processing $140 \mathrm{~kg}$ of natural uranium in this way would represent about $134 \mathrm{SWU}$ (though the expression for separative work presented in Appendix A and used to calculate this figure is not really applicable to processes with large stage separation factors). Therefore, the laser power would be $72 \mathrm{kWh}(\mathrm{e}) / \mathrm{SWU}$. Additional energy would be needed to maintain vacuum and provide pumping.

Lyman was assessing a small-scale setup, not one optimized for commercial operation, and the components he modeled were selected with the aim of near-complete single-pass separation, not the more realistic factor chosen here. Hence this estimate must be considered very pessimistic, but laser power requirements will certainly play a role, perhaps the dominant role (along with achievement of tight wavelength tolerances), in establishing the commercial viability of the technology. 


\subsection{Carbon Footprint}

Literature estimates of carbon dioxide emission estimates associated with enrichment (Figure 5.4) vary by more than two orders of magnitude. This is explained by the large difference in energy intensity between the two commercial enrichment technologies, but also by the time evolution of centrifuge intensity. Estimates where both technologies had a share of the market are shown in blue in Figure 5.4; the centrifuge (C) / diffusion (D) breakdown by SWU capacity, if it was given, is provided.

$\mathrm{CO}_{2}$ emissions estimates were calculated by multiplying the electricity emissions factors of Table 2.2 by the energy intensities and the SWU required to produce $1 \mathrm{kgIHM}$ of enriched $\mathrm{U}$ reactor fuel (see Table 5.3). In order to facilitate summing impacts across each step in the front end of the nuclear fuel cycle, these were then normalized per tonne U based on the once-through LWR fuel cycle described in Appendix A (see table 5.4).

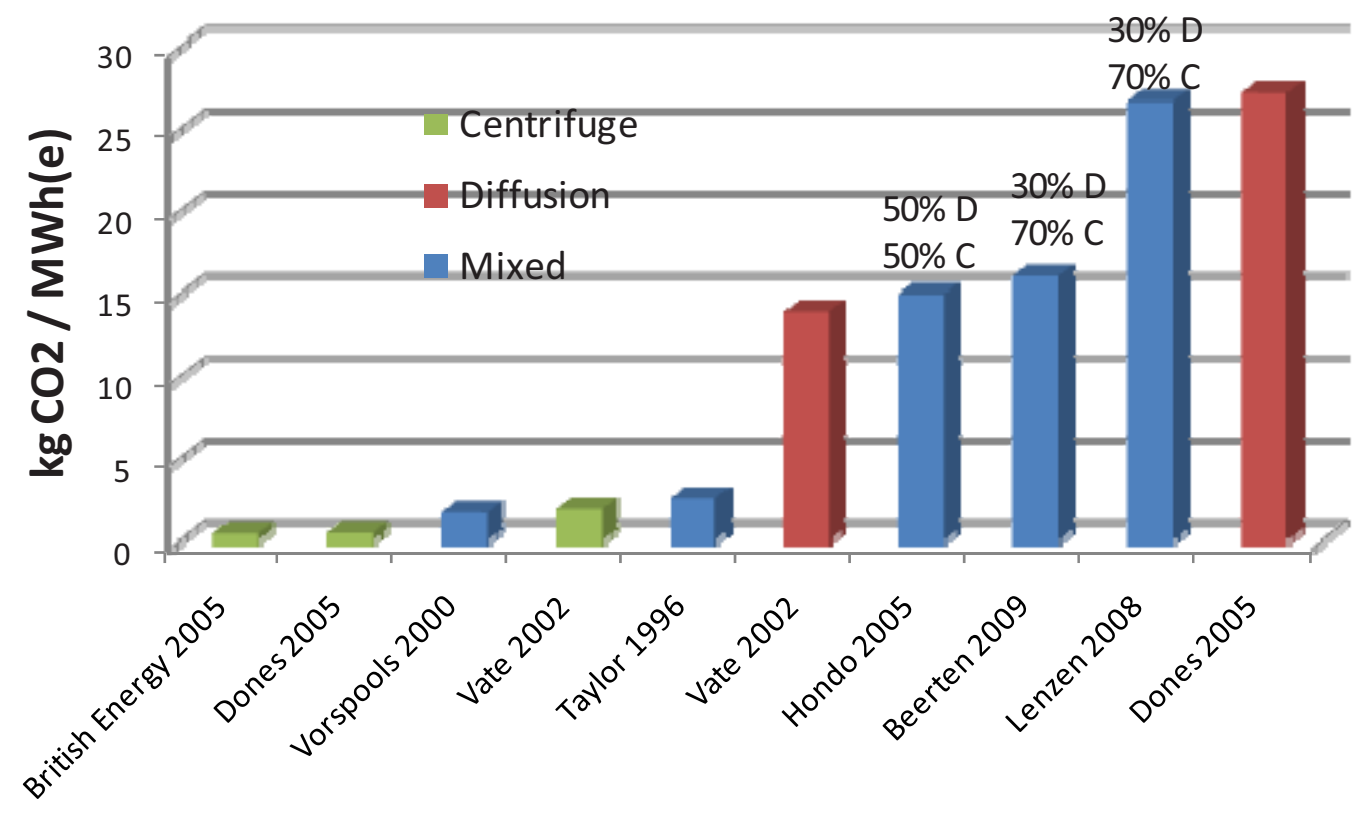

Figure 5.4. Estimates of $\mathrm{CO}_{2}$ emissions from enrichment found in the literature

\subsection{Land Use}

Minimal direct land disturbance is associated with enrichment facilities. Land use associated with enrichment is much more strongly affected by the strategy for handling the depleted $\mathrm{UF}_{6}$ tails (Section 7).

Within a 3,425 acre federal site, the USEC Paducah gaseous diffusion plant occupies 750 acre footprint. Although licensed to produce 11.3 MSWU/year, the facility has never produced at this level and in fact the installed equipment is not capable of producing more than $8 \mathrm{MSWU} / \mathrm{year}$ [USEC 2009]. Reported production in 2008 was $6.5 \mathrm{MSWU} /$ year; applying this production rate to a 40 year lifetime gives a land use of $1.17 \times 10^{-2} \mathrm{~m}^{2} / \mathrm{SWU}$.

The Urenco / Louisiana Energy Services National Enrichment Facility occupies a 139 ha plot of which 81 ha will be disturbed [NRC 2005]. The original site license allows production of 3 MSWU/year; although capacity expansions are planned, a conservative estimate will be made by assuming $3 \mathrm{MSWU}$ of production per year for a 40 year period. This gives rise to a land use intensity of $6.75 \times 10^{-3} \mathrm{~m}^{2} / \mathrm{SWU}$. 


\subsection{Water Use}

Most water withdrawn by enrichment plants goes toward removal of heat generated in the process of compressing and pumping $\mathrm{UF}_{6}$ gas, so the diffusion process, where many more compression stages are required per SWU, is more water intensive. [Gerbens 2008] specifies operational water use for fuel fabrication to be $12 \mathrm{~L}$ per GJ(e) of nuclear electricity for diffusion and $2 \mathrm{~L}$ per GJ(e) for centrifuges. As for the other technology steps, a conversion factor for the electricity produced from one tonne initial heavy metal, $1.450 \mathrm{GJ}(\mathrm{e}) / \mathrm{kgIHM}$, derived in Appendix A was used along with the SWU consumption per mass of IHM fabricated, 7.69 SWU/kgIHM, to convert the figures from L/GJ(e) to L/SWU. Gerbens' estimate is therefore $2260 \mathrm{~L} / \mathrm{SWU}$ for diffusion and $380 \mathrm{~L} / \mathrm{SWU}$ for centrifuge enrichment.

Operational water withdrawal data is available for the Areva EURODIF diffusion facility [Areva 2009]. It withdraws 12,300 ML of water per year against a throughput of $10.4 \mathrm{MSWU} / \mathrm{year}$, for a specific consumption of $1180 \mathrm{~L} / \mathrm{SWU}$ [Westinghouse 2004]. The average water withdrawal at three Urenco centrifuge facilities over 2006-08 was $34 \mathrm{~L} / \mathrm{SWU}$ [Urenco 2008]. These figures will be used as the reference data.

\subsection{Occupational and Public Health}

The maximum recorded annual occupational dose at Urenco Capenhurst over 1998-2002 was 310 mrem. Over the same time period, the maximum worker dose at the USEC Paducah facility did not exceed $500 \mathrm{mrem} / \mathrm{year}$ [NRC 2005]. Occupational doses at Paducah remained at this level in 2008 [NRC 2009]. Cylinder handlers generally receive the highest doses, about a factor of three higher than maintenance staff. Given that the chemical form of the radioactive material as well as the dose pathways are similar for centrifuge and diffusion facilities, the highest reported value for either type of facility - $500 \mathrm{mrem} / \mathrm{year}-$ will be used as the reference datum.

The estimated MEI dose at the Cameco/LES National Enrichment Facility was determined by assessing the dose by the airborne pathway to a worker at the public facility nearest the plant. This was $1.9 \times 10^{-3}$ mrem/year [NRC 2005].

The ExternE project [EC 1995] arrived at collective occupational and public doses for enrichment of 8.33E-6 and 2.68E-5 person-Sv per TWh(e) which (see Figure 2.1), when renormalized to the units employed in this document ${ }^{\mathrm{s}}$, become $4.5 \times 10^{-8}$ and $1.5 \times 10^{-7}$ person-rem per SWU.

The EURODIF Georges Besse plant was the reference facility. Thus only the impacts for a gaseous diffusion plant were assessed, but the dose pathways remain the same for centrifuge plants. Therefore it is not unreasonable to apply these results to enrichment facilities generically.

\subsection{Summary}

Table 5.3 summarizes the environmental footprint results reported in this section. For projections of the future energy intensity of enrichment, refer to equation 5.2 and the associated discussion.

s. Table 1.1 of [EC 1995] indicates that 6.2 tonnes of enriched UF6 are required per TWh(e); this corresponds to 4.2 tonnes LEU/TWh(e). The enrichment of the fuel in the [EC 1995] base case was 3.3\%. Assuming that enrichment tails are at $0.25 \%$, a standard value in the mid-1990s, 4,410 SWU are needed to produce 1 tonne of this LEU. Therefore, there are $4410 * 4.2=18,500 \mathrm{SWU} / \mathrm{TWh}(\mathrm{e})$. On a per-SWU basis, after converting sievert to rem, the collective public dose becomes $2.68 \mathrm{E}-3 / 18500=4.50 \mathrm{E}-8$ person-rem/SWU. The occupational dose is calculated similarly. 
For enrichment, it is more natural to normalize the impacts against Separative Work Units (SWU), which carry units of mass. The amount of SWU required per unit of enriched product is directly proportional to the number of enrichment units in the cascade multiplied by the mass processed by each unit. Since the operational energy consumption of an enrichment cascade is in turn proportional to this integrated mass throughput, energy consumption and other environmental measures of enrichment are most naturally expressed in terms of SWU consumption. 
Table 5.3. Summary of impacts resulting from enrichment

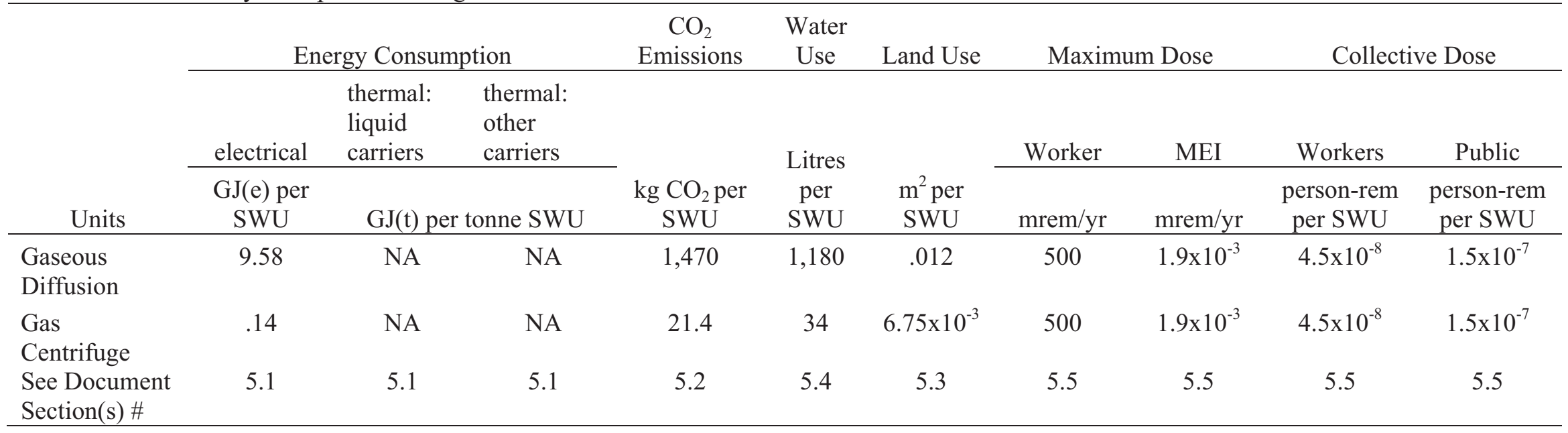

Noting that, as shown in Appendix A, 914 SWU (1000*7.69/8.41) are needed to enrich one tonne U for our reference fuel cycle (4.5\% enriched LWR fuel), the above table can be translated to impacts per tonne natural uranium as shown in Table 5.4.

Table 5.4. Summary of enrichment impacts per tonne $\mathrm{U}$ for the reference fuel cycle

\begin{tabular}{|c|c|c|c|c|c|c|c|c|c|c|}
\hline \multirow[b]{3}{*}{ Units } & \multicolumn{3}{|c|}{ Energy Consumption } & \multirow{3}{*}{$\begin{array}{c}\mathrm{CO}_{2} \\
\text { Emissions } \\
\\
\\
\mathrm{kg} \mathrm{CO} \text { per } \\
\text { tonne } \mathrm{U}\end{array}$} & \multirow{3}{*}{$\begin{array}{l}\text { Water Use } \\
\\
\text { Litres per } \\
\text { tonne U }\end{array}$} & \multirow{3}{*}{$\begin{array}{l}\text { Land } \\
\text { Use } \\
\\
\\
\text { m per }^{2} \text { tonne } \\
\text { U }\end{array}$} & \multicolumn{2}{|c|}{ Maximum Dose } & \multicolumn{2}{|c|}{ Collective Dose } \\
\hline & electrical & $\begin{array}{l}\text { thermal: } \\
\text { liquid } \\
\text { carriers }\end{array}$ & $\begin{array}{l}\text { thermal: } \\
\text { other } \\
\text { carriers }\end{array}$ & & & & Worker & MEI & Workers & Public \\
\hline & $\begin{array}{l}\mathrm{GJ}(\mathrm{e}) \text { per } \\
\text { tonne } \mathrm{U}\end{array}$ & \multicolumn{2}{|c|}{$\mathrm{GJ}(\mathrm{t})$ per tonne $\mathrm{U}$} & & & & $\mathrm{mrem} / \mathrm{yr}$ & $\mathrm{mrem} / \mathrm{yr}$ & $\begin{array}{l}\text { Person-rem } \\
\text { per tonne U }\end{array}$ & $\begin{array}{l}\text { Person-rem } \\
\text { per tonne U }\end{array}$ \\
\hline $\begin{array}{l}\text { Gaseous } \\
\text { Diffusion }\end{array}$ & 8,760 & NA & NA & $1.3 \times 10^{6}$ & $1.1 \times 10^{6}$ & 10.7 & 500 & $1.9 \times 10^{-3}$ & $4.1 \times 10^{-5}$ & $1.3 \times 10^{-4}$ \\
\hline $\begin{array}{l}\text { Gas } \\
\text { Centrifuge }\end{array}$ & 128 & NA & NA & $2.0 \times 10^{4}$ & $3.1 \times 10^{4}$ & 6.17 & 500 & $1.9 \times 10^{-3}$ & $4.1 \times 10^{-5}$ & $1.3 \times 10^{-4}$ \\
\hline
\end{tabular}




\subsection{References}

[Areva 2009] Areva NC, Rapport de sûreté nucléaire et de radioprotection 2008: Tricastin, 2009.

[Beerten 2009] Beerten, J. Greenhouse gas emissions in the nuclear life cycle: A balanced appraisal. Energy Policy 37 (2009) 5056-5068.

[British Energy 2005] British Energy, Environmental Product Declaration of Electricity from Torness Nuclear Power Station, Technical Report, 2005.

[Bukharin 2004] Bukharin, O. Russia's Gaseous Centrifuge Technology and Uranium Enrichment Complex, Technical Report, Woodrow Wilson School of Public Affairs, Princeton University, January 2004.

[Chapman 1975] Chapman, P.F., Energy Analysis of Nuclear Power Stations, Energy Policy, pp. 285298, December 1975.

[Dones 1996] Dones, R., Gantner, U., Hirschberg, S., Doka, G., and I. Knoepfel, Environmental inventories for future electricity supply systems for Switzerland, Paul Scherrer Institut report 96-07, 1996.

[Dones 2004] Dones, R., "Life Cycle Inventories for the Nuclear and Natural Gas Energy Systems and Examples of Uncertainty Analysis," Energy Supply, 2004.

[Dones 2005] Dones, R., "Life Cycle Inventories for the Nuclear and Natural Gas Energy Systems, and Examples of Uncertainty Analysis,"Int J Lifecycle Analysis, 10, 1, 10-23, 2005.

[EC 1995] European Commission, ExternE - Externalities of Energy, Volume 5: Nuclear, European Commission Directorate-General XII, 1995.

[Fthenakis 2007] Fthenakis, V. Greenhouse Gas Emissions from Solar Electric and Nuclear Power: A Life Cycle Study, Energy Policy, 2007.

[Fuchs 1942] Fuchs, K. and R. Peierls, "Separation of Isotopes,” DTA [Directorate of Tube Alloys] Report MS12A, 1942; declassified 1947.

[Gerbens 2008] D. Gerbens-leenes et al. Water Footprint of Bio-energy and Other Primary Energy Carriers. Value of Water Research Report No. 29. UNESCO, March 2008.

[Glaser 2008] Glaser, A. "Characteristics of the Gas Centrifuge for Uranium Enrichment and Their Relevance for Nuclear Weapon Proliferation," Science and Global Security 16, pp. 1-25, 2008.

[Heinloth 1997] Heinloth, K., The energy question. Braunschweig, Germany: Vieweg, 1997.

[Hondo 2005] Hondo, H., "Life cycle GHG emission analysis of power generation: Japanese case," Energy 30, pp. 2042-2056, 2005.

[Lenzen 2008] Lenzen, M. "Life cycle energy and greenhouse gas emissions of nuclear energy: A review," Energy Conversion and Management, 49 , 2178-2199, 2008.

[Lyman 2005] Lyman, J., 2005, "Enrichment Separative Capacity for SILEX," Los Alamos National Laboratory report LA-UR-05-3786, 2005.

[Moore 1965] Moore, G., "Cramming more components onto integrated circuits," Electronics, 38, 8, April 1965.

[NRC 2005] US Nuclear Regulatory Commission, Environmental Impact Statement for the Proposed National Enrichment Facility in Lea County, New Mexico, NUREG-1790, 2005. 
[NRC 2009] US Nuclear Regulatory Commission, Occupational Radiation Exposure at Commercial Nuclear Power Reactors and Other Facilities 2008, NUREG-0713, 2009.

[Rotty 1975] Rotty, R M. Net Energy from Nuclear Power, IEA Report IEA-75-3, 1975.

[SILEX 2010] SILEX Systems Ltd., "Investor Presentation Update - May 2010," available: http://www.silex.com.au/public/uploads/investor/Investor\%20presentation \%20May\%2010.pdf, webpage accessed June 25, 2010.

[Slakey 2010] Slakey, F. and L. Cohen, "Stop Laser Uranium Enrichment,” Nature 464, pp. 32-33, March 2010.

[Taylor 1996] Taylor, M. "Greenhouse gases and the nuclear fuel cycle? What emissions?” IAEA Bulletin 39, 2, 12-19, 1996.

[Upson 2001] Upson, P., "Centrifuge Technology: the Future of Enrichment," Proceedings of the 2001 World Nuclear Association Annual Meeting, London, September 2001.

[Urenco 2008] Urenco Limited, Urenco Sustainability Report 2008.

[USEC 2009] United States Enrichment Corporation, Energy Security Delivered by USEC: 2008 Annual Report, available: http://216.139.227.101/interactive/usu2008/, webpage accessed June 26, 2010.

[Vate 2002] Vate, V. Full-energy-chain greenhouse-gas emissions: a comparison between nuclear power, hydropower, solar power, and wind power,Int. J. Risk Assessment and Management, 3, 1. 2002.

[Vorspools 2000] Vorspools, K. R., Brouwers, E. A., and W. D. D’Haeseleer, "Energy Content and Indirect Greeenhouse Gas Emissions Embedded in 'Emission-Free' Power Plants: Results for the Low Countries," Applied Energy, 67, 307-330, 2000.

[Villani 1984] Villani, S., "Progress in uranium enrichment," Naturwissenschaften, 71, 3, pp. 115-23, 1984.

[Wagner 1978] 34. Wagner, H-J., The energy cost of building and operating selected energy supply system technologies, Angewandte Systemanalyse, 10 , 1978.

[WNA 2010] World Nuclear Association, "Uranium enrichment: Information paper 28," available: http://www.world-nuclear.org/info/inf28.htm, May 2010. Webpage accessed June 1, 2010. 


\section{FUEL FABRICATION}

This section addresses fabrication of uranium oxide (UOX) and mixed oxide (MOX) fuel assemblies for light water reactors (LWRs). The fuel fabrication process incorporates chemical processing in which enriched $\mathrm{UF}_{6}$ is converted into uranium oxide $\left(\mathrm{UO}_{2}\right)$ powder. Physical operations follow: formation of the $\mathrm{UO}_{2}$ powder into pellets, compaction and sintering, and loading into fuel rods and assemblies. Mixed oxide (MOX) fuel fabrication operates along the same general principles. However, an additional chemical polishing step may be employed to remove decay products and other impurities from the plutonium. Given the radiotoxicity of plutonium, a dedicated fabrication facility is necessary to support remote and glovebox operations [Shropshire 2008].

Reference data for UOX fabrication are taken from the Westinghouse UOX fabrication facility in Columbia, SC, which has operated since 1969 and has an annual throughput of $1150 \mathrm{tIHM}^{\mathrm{t}}$ [Westinghouse 2004], the Areva/FBFC Romans establishment in France with a fabrication capacity of $1400 \mathrm{tIHM} /$ year [FBFC 2009], the SIEMENS Lingen plant in Germany, with an annual throughput of 400 tIHM [IAEA 2002], and the Japanese fuel fabrication complex (as reported in [IAEA 2002]). The reference facilites for MOX fabrication are the $\sim 100$ tIHM/year Shaw Areva MOX Services LLC MOX fabrication plant at the Savannah River Site in South Carolina [NRC 2005] and the 195 tIHM/year Areva MELOX plant [AREVA 2009]. Assessments by [Rotty 1975] are compared against data for both UOX and MOX fabrication.

Figure 6.1 shows a flow diagram of the fabrication process. The uranium input is in the form of $\mathrm{UF}_{6}$; the $\mathrm{UF}_{6}$-to- $\mathrm{UO}_{2}$ defluorination process is here considered together with the fuel fabrication step, although it is sometimes (e.g. in France and Japan) carried out in a separate facility, giving rise to an intervening shipping step. Two defluorination processes are employed at the industrial scale; the wet process depicted in equation 6.1 is used at the Westinghouse plant in the US. The first step in this process is exothermic and yields ammonium uranyl carbonate, $\left(\mathrm{NH}_{4}\right)_{4} \mathrm{UO}_{2}\left(\mathrm{CO}_{3}\right)_{3}$. This compound is heated to around $500 \mathrm{C}$ in a fluidized bed and reduced to form uranium oxide powder.

$$
\begin{aligned}
& \mathrm{UF}_{6}+3 \mathrm{CO}_{2}+10 \mathrm{NH}_{3}+5 \mathrm{H}_{2} \mathrm{O} \rightarrow\left(\mathrm{NH}_{4}\right)_{4} \mathrm{UO}_{2}\left(\mathrm{CO}_{3}\right)_{3}+6 \mathrm{NH}_{4} \mathrm{~F} \\
& \mathrm{H}_{2}+\left(\mathrm{NH}_{4}\right)_{4} \mathrm{UO}_{2}\left(\mathrm{CO}_{3}\right)_{3} \rightarrow \mathrm{UO}_{2}+4 \mathrm{NH}_{4}+3 \mathrm{CO}_{2}+3 \mathrm{H}_{2} \mathrm{O}
\end{aligned}
$$

The dry process, used for UOX fuel in France and elsewhere, involves hydrolysis and reduction and gives rise to no liquid wastes but leads to a coarser product powder. The reactions are:

$$
\begin{aligned}
& U_{6}+\mathrm{H}_{2} \mathrm{O} \rightarrow \mathrm{UO}_{2} \mathrm{~F}_{2}+4 \mathrm{HF} \\
& \mathrm{UO}_{2} \mathrm{~F}_{2}+\mathrm{H}_{2} \rightarrow \mathrm{UO}_{2}+2 \mathrm{HF}
\end{aligned}
$$

If MOX is to be fabricated, the coarser powder produced by the dry process does not lead to an acceptably homogenous fuel. Further discussion of the wet and dry defluorination processes may be found in Section 7, where the construction of dedicated facilities for $\mathrm{DUF}_{6}$ defluorniation and stabilization is discussed.

t. The basis product unit in this section is the tonne initial heavy metal (tIHM) of actinides (uranium and/or plutonium) in fabricated fuel assemblies. 
Plutonium enters $\mathrm{MOX}$ fabrication as $\mathrm{PuO}_{2}$; an aqueous polishing step may be needed prior to fabrication to remove impurities ${ }^{\mathrm{u}}$. The $\mathrm{UO}_{2}$ or $\mathrm{UO}_{2} / \mathrm{PuO}_{2}$ powders are blended, pressed, and sintered at high temperature in a hydrogen environment. Hydrogen is generally produced on-site and the energy balances given herein incorporate the energy input to hydrogen production [IAEA 2002].

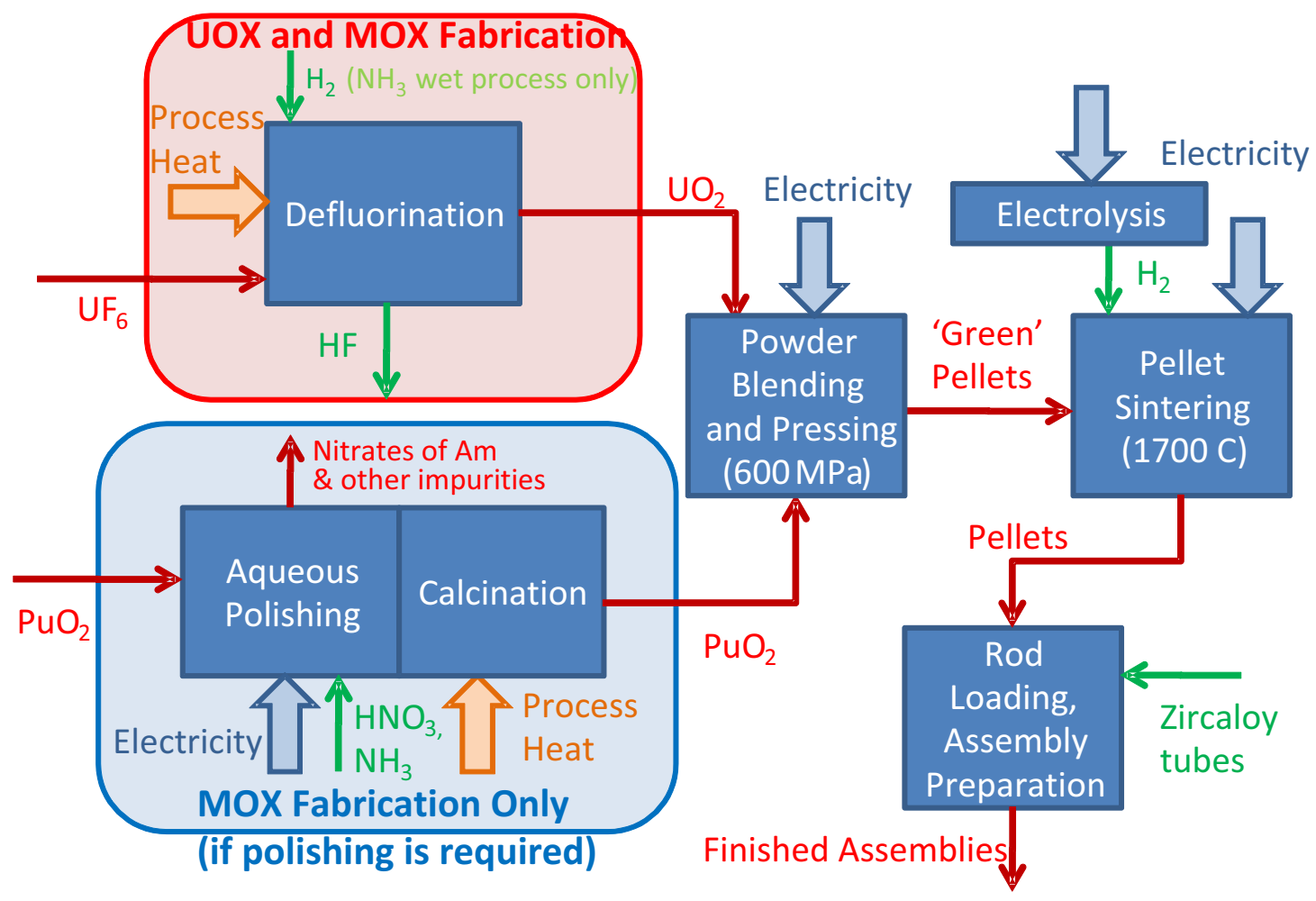

Figure 6.1. Flow diagram of fuel fabrication process, showing points of energetic input and other major inputs/outputs

\subsection{Energy Intensity}

\subsubsection{UOX Fuel Fabrication}

[Rotty 1975] drew upon an earlier, partially unpublished, process analysis of operational energy use at a $600 \mathrm{tIHM} /$ year, $\mathrm{UF}_{6}$-to- $\mathrm{UO}_{2}$ conversion and fuel fabrication facility conducted by the Bechtel Corporation and found, on a per unit product basis, direct electricity consumption of $357 \mathrm{GJ}(\mathrm{e}) / \mathrm{tIHM}$ and thermal consumption of $228 \mathrm{GJ}(\mathrm{t}) / \mathrm{tIHM}$. Most of the thermal energy, obtained from combustion of natural gas in [Rotty 1975], is used to provide heat input for chemical reactions as well as high temperature sintering operations; see section 6.5. Dividing the direct energy use for plant construction reported [Rotty 1975] by the throughput over a 30 year operational lifetime, 18,000 tIHM, would add $<1 \mathrm{GJ}(\mathrm{e}) / \mathrm{tIHM}$ and 9 $\mathrm{GJ}(\mathrm{t}) / \mathrm{tIHM}$ to the totals. A later estimate for an unspecified facility [Eliasson 2003] provided much lower figures: $80 \mathrm{GJ}(\mathrm{e}) / \mathrm{tIHM}$ and $101 \mathrm{GJ}(\mathrm{t}) / \mathrm{tIHM}$. In this estimate, the thermal energy carrier was specified as distillate fuel (diesel). A second estimate of energy intensity for a facility of moderate capacity (400 tIHM/year) was provided in [IAEA 2002]: $90 \mathrm{GJ}(\mathrm{e}) / \mathrm{tIHM}$ and $34 \mathrm{GJ}(\mathrm{t}) / \mathrm{tIHM}$. This estimate was

u. The primary decay product, $241 \mathrm{Am}$, builds in from the decay of $241 \mathrm{Pu}\left(\mathrm{h}_{21} \mathrm{f}\right.$ life of $\left.14.4 \mathrm{yr}\right)$. If not removed, its chemical volatility and radiotoxicity would complicate the fabrication process. 
evidently inferred from data reported by the Lingen facility in Germany, but it may (see the annex to [IAEA 2002]) only incorporate the dry $\mathrm{UF}_{6}$-to- $\mathrm{UO}_{2}$ process step used at Lingen, not pellet preparation or assembly fabrication. Hence there is considerable disagreement and ambiguity between the early assessment of Rotty and the two later estimates and operational data from industrial facilities was collected.

The Japanese UOX fuel fabrication industry consists of four complexes. Japan Nuclear Fuel Conversion (JCO) provides $\mathrm{UF}_{6}$-to- $\mathrm{UO}_{2}$ services; Mitsubishi Nuclear Fuel Ltd. (MNF) provides $\mathrm{UF}_{6}$-to- $\mathrm{UO}_{2}$ and fuel assembly fabrication for PWRs; Nuclear Fuel Industries Tokai Works (NFI T) and Japan Nuclear Fuel Ltd (JNF) provide fabrication services only for BWRs, while Nuclear Fuel Industries Kumatori Works (NFI K) provides fabrication services only for PWRs. The average energy consumption for these five facilities for 1995-98 from [IAEA 2002] is given in Table 6.1.

Table 6.1. Direct energy consumption, Japanese fuel fabrication complex, 1995-98 average

\begin{tabular}{lccc}
\hline \multicolumn{1}{c}{ Facility } & $\begin{array}{c}\mathrm{UF}_{6} \text {-to-UO } \\
(\mathrm{GJ} / \mathrm{tIHM})\end{array}$ & $\begin{array}{c}\text { Fabrication } \\
(\mathrm{GJ} / \text { tIHM })\end{array}$ & Total \\
\hline JCO & 58 & - & - \\
MNF (PWR) & & & 209 \\
NFI T (BWR) & $58^{\mathrm{a}}$ & 195 & 253 \\
JNF (BWR) & $58^{\mathrm{a}}$ & 149 & 207 \\
NFI K (PWR) & $58^{\mathrm{a}}$ & 245 & 303
\end{tabular}

a. The NFIT, JNF, and NFIK fabrication facilities include $58 \mathrm{GJ} / \mathrm{tIHM}$ for conversion of UF6-to-UO2, based on the JCO facility.

Taking the average of four data points, MNF as well as the sum of JCO and each of the other three facilities, provides an estimate of the energy intensity both steps of the fabrication process, $\mathrm{UF}_{6}$-to- $\mathrm{UO}_{2}$ and assembly fabrication. The value obtained is $243 \mathrm{GJ} / \mathrm{tIHM}$; it is conservatively assumed that this is electrical energy alone, as the data source specifies only 'energy use' and does not differentiate between electrical and thermal carriers. Data for the Romans establishment, a $\mathrm{UF}_{6}$-to- $\mathrm{UO}_{2}$ conversion and $\mathrm{UOX}$ fabrication facility operated by the Areva subsidiary FBFC, was obtained for 2005-08 [FBFC 2009]. During this period, Romans fabricated an average of $524 \mathrm{tIHM} /$ year of UOX fuel, against a licensed pelletizing and assembly capacity of $820 \mathrm{tIHM} /$ year. Energy consumption and other process parameters will be normalized against actual throughput; it is unclear whether this distinction was made in [Rotty 1975]. On this basis, the average direct energy consumption at Romans was $212 \mathrm{GJ}(\mathrm{e}) / \mathrm{tIHM}$ and $73 \mathrm{GJ}(\mathrm{t}) / \mathrm{tIHM}$. The sole thermal energy carrier identified was natural gas for generation of steam as a process energy carrier for the $\mathrm{UF}_{6}$ to $\mathrm{UO}_{2}$ conversion chemistry.

The primary data from Romans will be chosen as the reference datum for this study. It is in good agreement with the Japanese data and utilizes the same set of processes as the plant studied in [Rotty 1975], but direct energy consumption reported at Romans is lower by approximately 50\%. Reductions in specific energy consumption may be ascribed to process technological improvements over the more than thirty-five year interval between the data points and are consistent with the historical rate of 
energy intensity decline across the industrial sector of the economy ${ }^{\mathrm{v}}$. Operational energy consumption for the Westinghouse facility was not reported.

\subsubsection{MOX Fuel Fabrication}

For a facility fabricating 150 tIHM/year of MOX fuel with 4\% Pu content, [Rotty 1975] estimates direct energy consumption of $430 \mathrm{GJ}(\mathrm{e}) / \mathrm{tIHM}$ and $274 \mathrm{GJ}(\mathrm{t}) / \mathrm{tIHM}$. These figures simply represent a $20 \%$ increase over the energy intensity of UOX fabrication, on a per IHM mass basis, evidently following the assumptions of the unpublished Bechtel study cited in [Rotty 1975].

The EIS for the Shaw Areva MOX Services LLC MOX fabrication plant [NRC 2005] provides an estimate of the energy consumption associated with fabrication of $\sim 100 \mathrm{tIHM} / \mathrm{year}^{\mathrm{w}}$ of MOX fuel from excess weapon grade plutonium. A plutonium pit disassembly facility is also associated with this complex, and where possible, environmental impacts associated with pit disassembly are removed from the reported totals. Often (as is the case for energy consumption) only the aggregated sum is reported. The figures given here must be considered conservative for two reasons: one, a conventional MOX fabrication plant would not include a pit handling facility; two, this plant is designed for a specific, ten-year mission, not for large-scale production of MOX in an environment of market competition. [NRC 2005] reports anticipated direct electricity consumption of $6700 \mathrm{GJ}(\mathrm{e}) / \mathrm{tIHM}$ and negligible thermal energy usage. Since the facility will use electricity to fire its boilers for process steam generation, thermal energy consumption comes only in the form of fuel oil (kerosene) for backup electricity generation. MOX fabrication in Japan took place on an even smaller scale: the Japanese Nuclear Cycle Institute Tokai Works fabricated approximately $5 \mathrm{tIHM} / \mathrm{year}$ of MOX fuel for the JOYO reactor [IAEA 2002]. Specific energy consumption was reported as $12,100 \mathrm{GJ} / \mathrm{tIHM}$ of MOX with $32 \% \mathrm{Pu}$ content (far higher than in conventional LWR MOX). Given the small scale of operations and specialized fuel assembly design for JOYO, this value is probably not representative of industrial scale MOX fabrication.

The Areva MELOX MOX fabrication plant has been in operation since 1995; its current licensed capacity is $195 \mathrm{tIHM}$ /year, but production over 2006-08 averaged $132 \mathrm{tIHM} /$ year. During this period the average energy intensity of the MELOX plant was $1037 \mathrm{GJ}(\mathrm{e}) / \mathrm{tIHM}$ and $153 \mathrm{GJ}(\mathrm{t}) / \mathrm{tIHM}$ [Areva 2009]. Thermal energy consumption came in the form of liquid fuels (kerosene and diesel) for climate control and machinery operation. MELOX is a commercial facility, but the MELOX and MOX Services plants differ in one additional important respect. Designed to process aged stockpiled plutonium, the MOX Services facility incorporates an aqueous polishing step to remove decay products and other impurities from the plutonium prior to oxidation and blending with $\mathrm{UO}_{2}$ powder. If fabrication of $\mathrm{MOX}$ follows quickly after reprocessing, as is the usually case for the MELOX plant, this polishing step is not necessary; if it is needed, the French Areva La Hague facility provides the service.

The data show that the [Rotty 1975] estimate of a 20\% increase in energy intensity for MOX fabrication is unjustifiably optimistic. While the MELOX facility reports the lowest per-product direct energy consumption of the three surveyed facilities, it is the sole plant in commercial operation reporting data and will be used as the reference. Its energy intensity exceeds that estimated by Rotty by a factor of around two.

v. This has averaged around 1\% per year since the early 1970s: US DOE data over the 19 year period from 1985 (the first year for which a consistent data set is available) to 2004 indicates a decline of $19 \%$ in the energy intensity of the US industrial sector, on a per unit value basis [DOE 2008].

w. The facility is planned to fabricate MOX fuel bearing 3.4 tonnes of plutonium per year for 10 years. Since the isotopic content of the plutonium is variable, its content in the fabricated MOX fuel will range from $2.3-4.8$ weight percent. Taking the midpoint of this range, $3.5 \%$, gives rise to an estimate of $97(\sim 100)$ tIHM/year of fabricated MOX. 
In closing, special mention must be made of the importance of embodied energy in the fuel fabrication process. [Rotty 1975] estimates that embodied energy consumption is a factor of more than five greater than direct. Rotty ascribed this to the energy embodied in the zirconium constituent of the fuel cladding. Quantification of the energy intensity of zircaloy production is warranted in the context of a life cycle embodied energy analysis of the fuel cycle.

\subsection{Carbon Footprint}

Carbon dioxide emission estimates associated with UOX fuel fabrication plant operations are well documented within the literature and values are summarized in Figure 6.2. The average value found from the literature is $0.4 \mathrm{~kg} \mathrm{CO}_{2}$ per $\mathrm{MWh}(\mathrm{e})$ of nuclear electricity produced; the median is 0.19 . Most of the surveyed estimates were ambiguous regarding whether $\mathrm{UF}_{6}$-to- $\mathrm{UO}_{2}$ conversion was counted as part of the fuel fabrication process, but the higher forecasts [Storm van Leeuwen 2005][Lenzen 2006], citing [Rotty 1975], incorporated the estimated embodied energy in the cladding material described in the preceding subsection in their emission calculations.

Reference $\mathrm{CO}_{2}$ emissions associated with direct energy consumption are obtained by multiplying the emissions factors of Table 2.2 by the direct energy intensities of the reference facilities - Areva-Romans for UOX, Areva-MELOX for MOX. These emissions are normalized per tonne U and per MWh(e) in table 6.5 and section 9 , respectively.

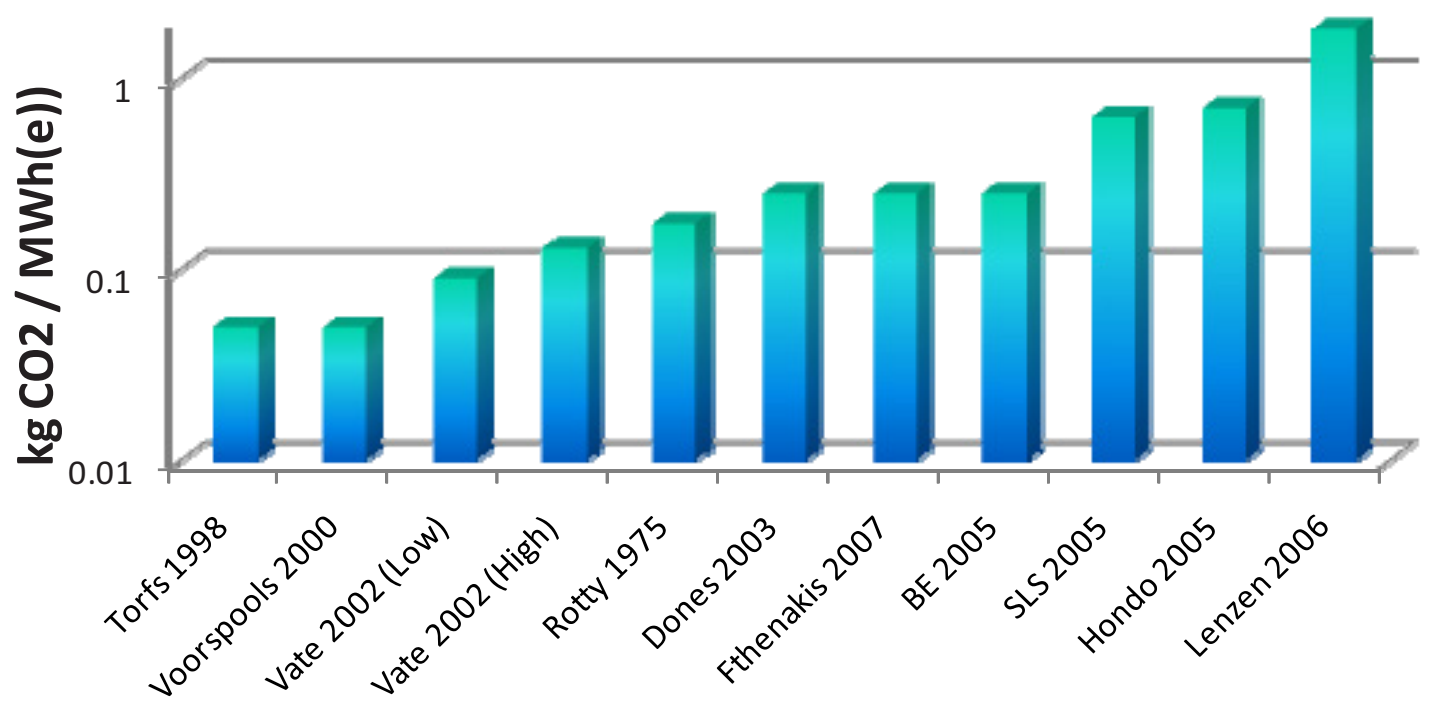

Figure 6.2. Estimates of $\mathrm{CO}_{2}$ emissions from $\mathrm{UOX}$ fuel fabrication found in the literature ${ }^{\mathrm{x}}$

\subsection{Land Use}

The direct land transformation tied to fuel fabrication is expected to be small, as mass throughput and waste volumes are not large in comparison with processes such as mining and enrichment. Neither of the studies that estimate land use associated with other front end processes provides a useful starting point for the land footprint of fuel fabrication: [Fthenakis 2009] claims only that land transformation associated

x. BE $2005=$ [British Energy 2005], SLS $2005=$ [Storm van Leeuwen 2005]. 
with fabrication is negligible, while fabrication is the only technology for which [Finch 1997] provides no value at all.

An estimate is formulated from the disturbed land footprint for several facilities plus two assumptions: first, the present-day licensed capacity is applied over the full lifetime of each facility, and second, that the operational lifetime is 40 years or the duration of the plant operating license, whichever is more conservative. On a property of 1150 acres, the Westinghouse Columbia UOX fuel fabrication plant occupies 60 acres of disturbed land ${ }^{\mathrm{y}}$. Given a throughput of 1,150 t IHM/yr and a facility lifetime of 40 years, land use for the plant is $5.3 \mathrm{~m}^{2} / \mathrm{tIHM}$ [Westinghouse 2010]. The Springfields fabrication plant in the United Kingdom has a throughput of $330 \mathrm{tIHM} /$ year for LWR fabrication but also fabricates metallic magnesium alloy-clad uranium fuel for Magnox reactors with a licensed throughput of $1300 \mathrm{tIHM} / \mathrm{year}$ [IAEA 2002]; assuming a plant lifetime of 40 years and normalizing against the sum of both throughputs, the plant's land use is $12.9 \mathrm{~m}^{2} / \mathrm{t} \mathrm{HM}$ [IAEA 2002]. Disturbed land footprints for the other UOX fabrication facilities were not available.

Land use for the Savannah River MOX plant is considered for a throughput of 100 tIHM/year and the licensed plant lifetime of 20 years [NRC 2005]. The footprint of the facility itself is 16 hectares (ha) but the total area disturbed by the plant will be $50 \mathrm{ha}$ ); normalized against this basis, the footprint would be $250 \mathrm{~m}^{2} / \mathrm{tIHM}$. Note that since land occupation is given only for the plant as a whole, this footprint includes the pit disassembly facility. The Areva MELOX facility occupies 14 ha of land [Bailly 2009]; with a capacity of $195 \mathrm{tIHM} /$ year and 40 year lifetime, land use would be $17.9 \mathrm{~m}^{2} / \mathrm{tIHM}$. The Westinghouse and Areva data will be chosen as references for UOX and MOX respectively.

\subsection{Water Use}

[Gerbens 2008] specifies operational water use for fuel fabrication to be $1 \mathrm{~L}$ per GJ(e) of nuclear electricity produced. As for the other technology steps, a conversion factor for the electricity produced from one tonne initial heavy metal, $1.45 \times 10^{6} \mathrm{GJ}(\mathrm{e}) / \mathrm{tIHM}$, derived in Appendix A was used to convert the figure from $\mathrm{L} / \mathrm{GJ}(\mathrm{e})$ to $\mathrm{L} / \mathrm{tIHM}$. Gerbens' estimate is therefore $1.45 \times 10^{6} \mathrm{~L} / \mathrm{tIHM}(1.45 \mathrm{ML} / \mathrm{tIHM})$.

Operational water withdrawal data for several facilities is given in Table 6.2. Gerbens' estimate is seen to be about an order of magnitude larger than reported data from UOX fabrication facilities. Regarding MOX fabrication, water consumption would be expected to be higher at Savannah River than MELOX since plutonium at that facility is subjected to an initial aqueous polishing step, although mass throughputs associated with that step are small.

Table 6.2. Water withdrawals at operating and planned fabrication facilities

\begin{tabular}{llc}
\multicolumn{1}{c}{ Facility } & \multicolumn{1}{c}{ Reference } & Water Withdrawal [L/tIHM] \\
\hline Westinghouse (UOX) & [Westinghouse 2004] & 56,000 \\
AREVA Romans (UOX) & [FBFC 2009] & 141,000 \\
Savannah River (MOX) & [NRC 2005] & 760,000 \\
AREVA MELOX (MOX) & [AREVA 2009] & 578,000 \\
\hline
\end{tabular}

The Areva facility figures will be used as reference data for both UOX and MOX fabrication.

\footnotetext{
${ }^{\mathrm{y}}$ As is the case for the other technologies, only disturbed land will be counted toward the land use metric.
} 


\subsection{Occupational and Public Health}

[Stoetzel 1982] reported a typical early 1980s average annual dose to workers at UOX fabrication plants to be $500 \mathrm{mrem} /$ year, but doses have declined as ALARA practices have become rigorously enforced. For the Springfield plant in the 1990s [British Energy 2005], the average worker dose was $220 \mathrm{mrem} /$ year; the corresponding figure at Romans for 2005-08 is $15 \mathrm{mrem} / \mathrm{year}$ [FBFC 2009].

The reviewed facilities report maximum annual worker doses; many also estimate MEI doses to a member of the public. These are summarized in Table 6.3.

Table 6.3. Maximum annual worker doses and MEI public doses

\begin{tabular}{llcc}
\multicolumn{1}{c}{ Facility } & \multicolumn{1}{c}{ Data source } & $\begin{array}{c}\text { Maximum worker } \\
\text { dose [mrem/year] }\end{array}$ & $\begin{array}{c}\text { MEI public dose } \\
\text { [mrem/year] }\end{array}$ \\
\hline Romans (UOX) & [FBFC 2009] & 285 & - \\
Westinghouse (UOX) & [NRC 2009] & 1,000 & 0.4 \\
Springfields (UOX) & [Westinghouse 2004] & & - \\
Savannah River & [NRC 2005] & 500 & 0.18 \\
(MOX) (forecast) & & 1,700 & - \\
MELOX (MOX) & [Areva 2009] & 1,000 & - \\
\hline
\end{tabular}

For conservatism, the maximum worker dose for each fuel type is selected to represent the dose for all facilities of that type. MEI public dose for both fuel types is chosen to be the largest of the reported values for either fuel type ${ }^{\mathrm{z}}$.

The ExternE assessment of the French fuel cycle collective dose did not extend to MOX fuel. For UOX fabrication, [EC 1995] arrived at a collective occupational dose of $1.9 \times 10^{-1}$ person-rem/tIHM and public dose of $2.4 \times 10^{-4}$ person-rem/tIHM.

\subsection{Summary}

Tables 6.4 and 6.5 summarize the impacts identified for fabrication of UOX and MOX fuels. The UOX intensities presented in the table incorporate deconversion of $\mathrm{UF}_{6}$, but the MOX intensities do not include aqueous polishing. See section 6.1 for discussion.

As outlined in Appendix A, in the reference fuel cycle (4.5\% enriched LWR fuel) one tonne U yields $118.9 \mathrm{kgIHM}$ of LEU fuel. Hence for UOX fabrication Table 6.4 can be translated to the impacts per tonne natural uranium given in Table 6.5. Since the reference cycle covers only the once-through front end, no analogous conversion is made for MOX fuel.

z. One reason the maximally exposed member of the public dose at the Savannah River facility is small is because the nearby individual is several miles distant: the MOX plant will be located within the 310 sq. mi. Savannah River Site. 
Table 6.4. Summary of impacts resulting from UOX and MOX fuel fabrication.

\begin{tabular}{|c|c|c|c|c|c|c|c|c|c|c|}
\hline \multirow[b]{3}{*}{ Units } & \multicolumn{3}{|c|}{ Energy Consumption } & $\begin{array}{c}\mathrm{CO}_{2} \\
\text { Emissions } \\
\end{array}$ & $\begin{array}{l}\text { Water } \\
\text { Use }\end{array}$ & Land Use & \multicolumn{2}{|c|}{ Maximum Dose } & \multicolumn{2}{|c|}{ Collective Dose } \\
\hline & electrical & $\begin{array}{l}\text { thermal: } \\
\text { liquid } \\
\text { carriers }\end{array}$ & $\begin{array}{l}\text { thermal: } \\
\text { other } \\
\text { carriers }\end{array}$ & \multirow[b]{2}{*}{$\begin{array}{l}\mathrm{kg} \mathrm{CO}_{2} \\
\text { per tonne } \\
\text { IHM }\end{array}$} & \multirow[b]{2}{*}{$\begin{array}{l}\text { Litres per } \\
\text { tonne } \\
\text { IHM }\end{array}$} & \multirow[b]{2}{*}{$\begin{array}{l}\mathrm{m}^{2} \text { per } \\
\text { tonne } \\
\text { IHM }\end{array}$} & Worker & MEI & Workers & Public \\
\hline & $\begin{array}{l}\text { GJ(e) per } \\
\text { tonne } \\
\text { IHM }\end{array}$ & $\mathrm{GJ}(\mathrm{t})$ per & onne IHM & & & & $\mathrm{mrem} / \mathrm{yr}$ & $\mathrm{mrem} / \mathrm{yr}$ & $\begin{array}{l}\text { person-rem } \\
\text { per tonne } \\
\text { IHM }\end{array}$ & $\begin{array}{l}\text { person-rem } \\
\text { per tonne } \\
\text { IHM }\end{array}$ \\
\hline $\begin{array}{l}\text { MOX Fuel } \\
\text { Fabrication }\end{array}$ & 1,037 & NA & 153 & 166,500 & 578,000 & 17.9 & 1,700 & 0.4 & Not Avail. & Not Avail. \\
\hline $\begin{array}{l}\text { See Document } \\
\text { Section(s) \# }\end{array}$ & 6.1 & 6.1 & 6.1 & 6.2 & 6.4 & 6.3 & 6.5 & 6.5 & 6.5 & 6.5 \\
\hline
\end{tabular}

Table 6.5. Summary of UOX fuel fabrication impacts per tonne $U$ for the reference fuel cycle

\begin{tabular}{|c|c|c|c|c|c|c|c|c|c|c|}
\hline \multirow[b]{3}{*}{ Units } & \multicolumn{3}{|c|}{ Energy Consumption } & $\begin{array}{c}\mathrm{CO}_{2} \\
\text { Emissions }\end{array}$ & $\begin{array}{l}\text { Water } \\
\text { Use }\end{array}$ & Land Use & \multicolumn{2}{|c|}{ Maximum Dose } & \multicolumn{2}{|c|}{ Collective Dose } \\
\hline & electrical & $\begin{array}{l}\text { thermal: } \\
\text { liquid } \\
\text { carriers }\end{array}$ & $\begin{array}{c}\text { thermal: } \\
\text { other } \\
\text { carriers }\end{array}$ & \multirow{2}{*}{$\begin{array}{c}\mathrm{kg} \mathrm{CO} \\
\text { per tonne } \\
\mathrm{U}\end{array}$} & \multirow[b]{2}{*}{$\begin{array}{l}\text { Litres per } \\
\text { tonne } U\end{array}$} & \multirow[b]{2}{*}{$\begin{array}{l}\mathrm{m}^{2} \text { per } \\
\text { tonne } \mathrm{U}\end{array}$} & Worker & MEI & Workers & Public \\
\hline & $\begin{array}{l}\text { GJ }(\mathrm{e}) \text { per } \\
\text { tonne U }\end{array}$ & $\mathrm{GJ}(\mathrm{t}) \mathrm{p}$ & tonne U & & & & $\mathrm{mrem} / \mathrm{yr}$ & $\mathrm{mrem} / \mathrm{yr}$ & $\begin{array}{l}\text { Person-rem } \\
\text { per tonne U }\end{array}$ & $\begin{array}{l}\text { Person-rem } \\
\text { per tonne U }\end{array}$ \\
\hline $\begin{array}{l}\text { UOX Fuel } \\
\text { Fabrication }^{\mathrm{a}}\end{array}$ & 25.2 & NA & 8.7 & 4,300 & 16,800 & .63 & 1,000 & 0.4 & $2.3 \times 10^{-2}$ & $2.9 \times 10^{-5}$ \\
\hline
\end{tabular}




\subsection{References}

[Areva 2009] Areva Etablissement de MELOX, Rapport environnemental, social, societal, de surete nucleaire et de radioprotection 2008, 2009.

[Australian Coal Association 2001] Australian Coal Association. Electricity from a nuclear power station. Case study B16. Canberra, Australia: Australian Coal Association, 2001.

[Bailly 2009] Bailly, F. “French Operational Experience in Recycling Used Nuclear Fuel," Proceedings of FCIX Conference, Rockville, MD, June 2009.

[Beerten 2009] Beerten, J., "Greenhouse gas emissions in the nuclear life cycle: A balanced appraisal," Energy Policy 37, pp. 5056-5068, 2009.

[British Energy 2005] British Energy, Environmental Product Declaration of Electricity from Torness Nuclear Power Station, Technical Report, 2005.

[British Energy 2008] British Energy, Carbon Footprint of the nuclear fuel cycle, Briefing Note, 2008.

[DOE 2008] US Department of Energy, Office of Energy Efficiency and Renewable Energy, "Energy Intensity Indicators in the US," 2008. Available:

http://www1.eere.energy.gov/ba/pba/intensityindicators/index.html, webpage accessed June 20, 2010.

[Dones 2004] Dones, R. , "Life Cycle Inventories for the Nuclear and Natural Gas Energy Systems and Examples of Uncertainty Analysis," Energy Supply, 2004.

[EC 1995] European Commission, ExternE - Externalities of Energy, Volume 5: Nuclear, European Commission Directorate-General XII, 1995.

[Eliasson 2003] Eliasson, B. and Y. Lee, eds., "Integrated Assessment of Sustainable Energy Systems in China," Kluwer Academic, Dordrecht, 2003.

[FBFC 2009] FBFC Etablissement de Romans, Rapport environnemental, social, societal, de surete nucleaire et de radioprotection 2008, 2009.

[Fthenakis 2007] Fthenakis, V. Greenhouse Gas Emissions from Solar Electric-and Nuclear Power: A Life Cycle Study. Energy Policy, 2007.

[Gerbens 2008] D. Gerbens-leenes et al. Water Footprint of Bio-energy and Other Primary Energy Carriers. Value of Water Research Report No. 29. UNESCO, March 2008.

[Hondo 2005] Hondo, H., "Life cycle GHG emission analysis of power generation: Japanese case," Energy, 30, pp. 2042-2056, 2005.

[IAEA 2002] International Atomic Energy Agency, Environmental aspects based on operational performance of nuclear fuel fabrication facilities. IAEA-TECDOC-1306, July 2002.

[Lenzen 2008] Lenzen, M., "Life cycle energy and greenhouse gas emissions of nuclear energy: A review," Energy Conversion and Management, 49, pp. 2178-2199, 2008.

[NRC 2005] US Nuclear Regulatory Commission, Environmental Impact Statement on the Construcation and Operation of a Proposed Mixed Oxide Fuel Fabrication Facility at the Savannah River Site, South Carolina, NUREG-1767, 2005.

[NRC 2009] US Nuclear Regulatory Commission, Occupational Radiation Exposure at Commercial Nuclear Power Reactors and Other Facilities 2008, NUREG-0713, 2005.

[Rotty 1975] Rotty, R M. Net Energy from Nuclear Power. IEA-75-3 1EA Report, 1975. 
[Shropshire 2008]Shropshire, D. et al. Advanced Fuel Cycle Cost Basis. Idaho National Laboratory report INL/EXT-07-12107, 2008.

[Sovacool 2008] Sovacool, B., "Greenhouse Gas Emissions from Nuclear Power: A Critical Survey," Energy Policy, 2008.

[Stoetzel 1982] Stoetzel, G.A. et al. Radiological Health Aspects of Commercial Uranium Conversion, Enrichment, and Fuel Fabrication, technical report PNL-4428 USUR-03, 1982.

[Storm van Leeuwen 2005] Storm van Leeuwen, J.W and P. Smith, Nuclear power - the energy balance, 2005. Available: http://www.stormsmith.nl. Webpage accessed June 25, 2010.

[Vate 2002] Vate, V. , "Full-energy-chain greenhouse-gas emissions: a comparison between nuclear power,hydropower, solar power, and wind power," Int. J. Risk Assessment and Management, 3, 1, 2002.

[Vorspools 2000] Vorspools, K. R., Brouwers, E. A., and W. D. D’Haeseleer, "Energy Content and Indirect Greeenhouse Gas Emissions Embedded in 'Emission-Free' Power Plants: Results for the Low Countries," Applied Energy, 67, 307-330, 2000.

[Westinghouse 2004] Westinghouse Electric Co., Environmental Report SNM 1007/70-1151, Columbia, SC, 2004.

[Westinghouse 2010] Westinghouse Electric Co., Overview of Columbia Fuel Fabrication Facility, 2010. Available: http://www.erh.noaa.gov/cae/Hazmat2008/Steve\%20Carver\%20-\%20Westinghouse.pdf, Webpage accessed June 14, 2010. 


\section{DEPLETED URANIUM STORAGE AND MANAGEMENT}

Over the last seven decades, large quantities of uranium have been enriched in the United States using gaseous diffusion. Depleted uranium hexafluoride $\left(\mathrm{DUF}_{6}\right)$ is a by-product of enrichment and the United States has stored its $\mathrm{DUF}_{6}$ at the three gaseous diffusion enrichment sites located at Paducah, Kentucky; Portsmouth, Ohio; and the East Tennessee Technology Park (ETTP—formerly known as the K-25 Site) in Oak Ridge, Tennessee. In 2007 ETTP's inventory was successfully shipped to Portsmouth. [Shropshire 2008] UF6 is a solid at room temperature, but converts to a gas at about $56 \mathrm{C} / 132 \mathrm{~F}$. Exposed to the atmosphere, it readily reacts with moisture in the air to form toxic hydrogen fluoride and a soluble uranium compound, uranium oxyfluoride. Consequently, the states claim it is a hazardous waste under the Resource Conservation and Recovery Act (RCRA), [Hartman 2004] and in 2005 the DOE declared it as low-level waste (LLW) [Wise Uranium 2010].

At present, there are approximately 700,000 MT of $\mathrm{DUF}_{6}$ (250,517 at Portsmouth, 436,369 at Paducah) in over 60,000 cylinder containers stored at the Paducah and Portsmouth sites. Going forward there are a number of options leading to permanent disposal or stabilized long-term storage of this enrichment byproduct. [Shropshire 2008] The Department of Energy continues to look at two options for managing depleted uranium hexafluoride. The two options are based on leaving the material as $\mathrm{DUF}_{6}$ or converting it to $\mathrm{DU}_{3} \mathrm{O}_{8}$ (Figure 7.1). Only the storage and disposal strategies are assessed here.

Depleted uranium in the past has been stored generally as $\mathrm{UF}_{6}$ in cylinders, often in storage facilities in the open air. However, $\mathrm{DUF}_{6}$ is very reactive and this way of storage requires ongoing cylinder refurbishment, in view of deteriorating and leaking vessels and increasing chances for accidents. DUF 6 could continue to be stored. This would require transferring the material to fresh containers every 40 years as cylinders corrode from the environmental and chemical processes. [Quapp 2000] Stored DUF 6 remains available for future re-enrichment if needed.

The other option is deconversion of $\mathrm{DUF}_{6}$ to a uranium oxide. As of June 2010, a deconversion facility at Paducah has been completed; energy, water and land use results included in its environmental impact statement are used here to characterize this approach. [Walker 2010] It is assumed that the inventory contained at Portsmouth would be shipped to the Paducah site (hereafter referred to as the reference site). Conversion plants would typically be capable of receiving depleted DUF $_{6}$ cylinders on trucks temporarily storing a small inventory of full cylinders, processing the depleted $\mathrm{DUF}_{6}$ to an oxide, and temporarily storing the converted uranium product and any other products until shipment off site. [Hartman 2004] The converted $\mathrm{U}_{3} \mathrm{O}_{8}$ could then be 1) stored permanently at a disposal site in the same cylinders as the DUF6 was stored, or 2) mixed with concrete to form DUCRETE and committed to shallow land burial [Hartman 2004]. DUCRETE has other potential uses such as a shielding material for interim storage for spent nuclear fuel and high-level waste. It has also been suggested that the reconverted uranium oxide be used as fast reactor matrix or blanket fuel. [Hertzler 1994] 


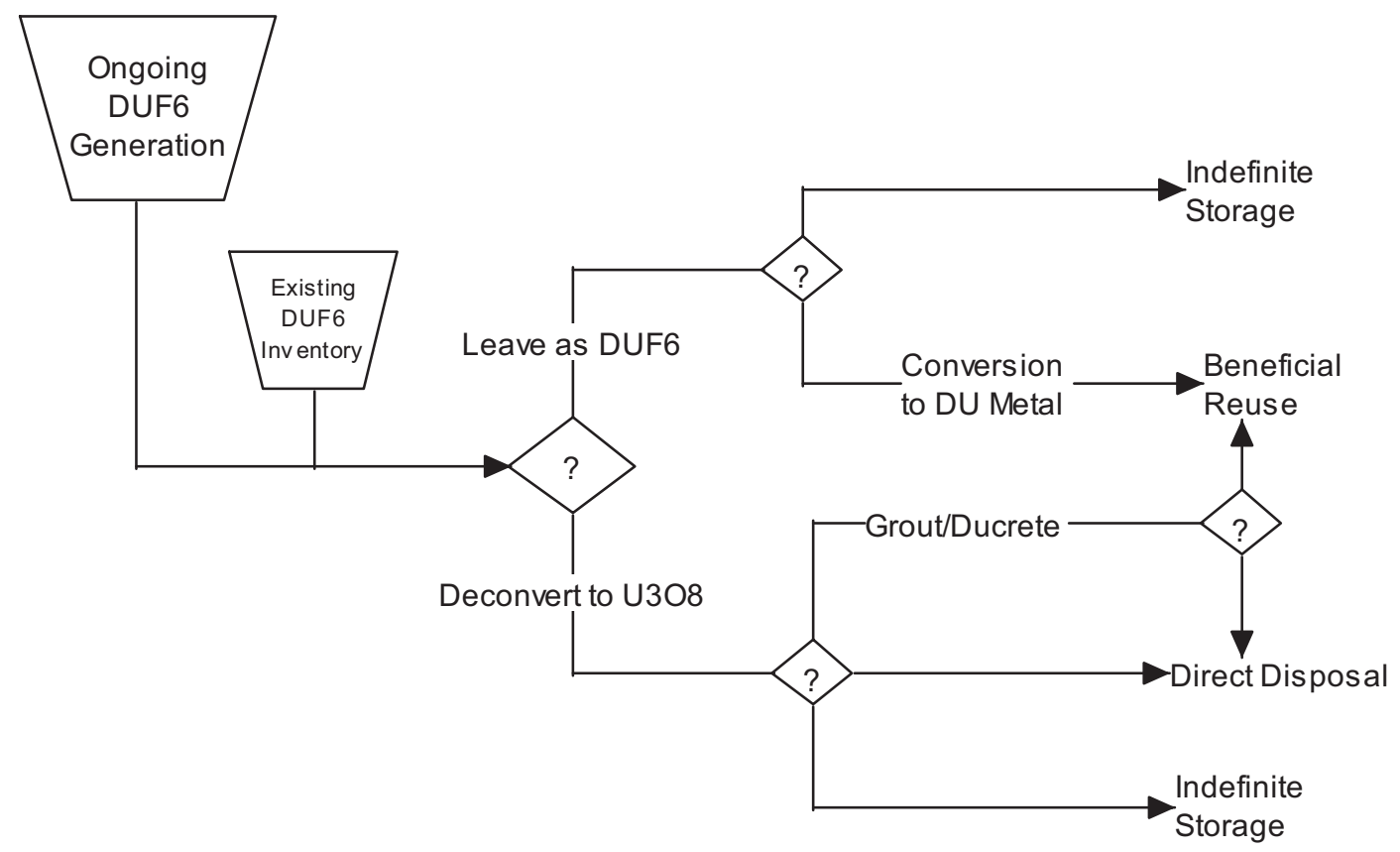

Figure 7.1. $\quad$ DUF $_{6}$ options tree

\subsection{Continued Storage of DUF 6}

The first option to be considered is to make sustainable the approach that domestic gaseous diffusion plants have followed since the 1950s. This option therefore entails continued storage of the DUF 6 cylinders at enrichment sites or a centralized storage facility, with the DUF 6 transferred to new or refurbished cylinders every 40 years to ensure continued cylinder integrity. A study conducted by DOE [Hartmann 1999] addressed 40-year (1999-2039) cylinder storage on the ETTP site prior to cylinder relocation to Portsmouth. About $10 \%$ of the inventory was considered for this alternative: 4,683 cylinders, or 65,562 tonnes of $\mathrm{DUF}_{6}(44,330 \mathrm{t} \mathrm{DU})$. The identified impacts assume construction of a new storage yard construction, routine inspections of cylinders, repair and/or removal of any cylinders that might be breached during storage period. A cylinder is considered breached if it has a hole of any size. On the basis of these assumptions, the number of breaches that were assumed to occur in the 40 year time period analyzed in the cited study was 11 per year or 444 total. This breach estimate is based on the historical corrosion rate determined when the cylinders were stored under poor conditions. The sites would continue to be monitored and maintained by DOE. [Hartman 2004]

Given that many of the cylinders will already have been storing $\mathrm{DUF}_{6}$ for several decades, it is conservative to assume a complete turnover of the cylinder stock every 40 years to ensure that this strategy is to be viable going forward. This would require the construction of a transfer facility capable of receiving cylinders, storing a small number of cylinders, and transferring the contents to new cylinders. Transfer operations would entail using autoclaves to heat the contents of the cylinder to $\mathrm{DUF}_{6}$ gas, which then can be piped to a new cylinder. For a cylinder transfer facility accompanying the reference storage yard, the construction is assumed to take two years and operations, based on a 320 cylinder/year throughput, are considered 15 years for the 4,683 cylinders that will need to be transferred [Hartmann 1999]. 


\subsubsection{Energy Intensity}

Energy use arises in the form of diesel fuel and gasoline for construction equipment and transportation vehicles, and continued operation and maintenance of the cylinder yards. Energy consumption associated with construction of a new cylinder yard and for continued storage of 65,562 tonnes of DUF 6 as well as breach repair of 11 cylinders/year over a 40 year period of storage is taken from [Hartmann 1999] and given in Table 7.1. Energy consumption for the construction and operation of the cylinder transfer facility is also taken from [Hartmann 1999] and scaled up to reflect transfer of the complete $\mathrm{UF}_{6}$ inventory to new cylinders: see Table 7.2. The accompanying $\mathrm{CO}_{2}$ emissions for the facilities are calculated employing the emission factors from Table 2.2.

\subsubsection{Land Use}

Land use is associated with the footprint of the storage yard. The requirement for the necessary cylinder yard reconstruction is an additional $27,000 \mathrm{~m}^{2}$ (6.7 acres). Because a DUF 6 storage yard would likely be located in an area already dedicated to similar use, immediate access to infrastructure and utility support would be possible with only minor disturbances to existing land [Hartmann 1999]. [Hartmann 1999] also gives impacts to land use from the construction and operation of a cylinder transfer facility. The land disturbed by the transfer facility would be small, about $49,000 \mathrm{~m}^{2}$.

\subsubsection{Water Use}

In the ETTP study, water use for construction was estimated to be 3.06 million liters. Operational water use was estimated to range from 94,000 to 121,000 liters/yr. [Hartmann 1999] Water resources would be retrieved from nearby rivers. For complete cylinder transfer, water use associated with construction, normalized against the amount of uranium transferred, is 7,683 L/t $\mathrm{U}$ [Hartmann 1999].

Environmental impacts associated with the storage yard are given in Table 7.1; those associated with the cylinder transfer facility are listed in Table 7.2. The overall footprint of the $\mathrm{UF}_{6}$ storage and transfer strategy listed in the summary table at the end of this section is the sum of these two impact sets.

Table 7.1. Resource consumption over 40-year lifetime of a $\mathrm{DUF}_{6}$ storage yard for 4,683 cylinders (44330tDU).

\begin{tabular}{llcc}
\hline \multicolumn{1}{c}{ Resource } & Consumption & Consumption/tDU \\
\hline \multirow{5}{*}{ Operations } & & & \\
& Gasoline (GJ (t)) & 160 & 0.004 \\
& Diesel fuel (GJ(t)) & 990 & 0.022 \\
& Water (L) & $3.06 \times 10^{6}$ & 69.0 \\
& Gasoline (GJ (t)) & 3940 & \\
& Diesel fuel (GJ(t)) & 11,000 & 0.09 \\
& Water (L) & $4.3 \times 10^{6}$ & 0.25 \\
\hline
\end{tabular}


Table 7.2. Resource consumption for transfer of 4,683 cylinders (44,330 tDU) every 40 years

\begin{tabular}{llll}
\hline \multirow{2}{*}{ Construction } & Resource & Consumption & Consumption/ tDU \\
\cline { 2 - 3 } & & & \\
& Electricity (GJ(e)) & 90,000 & 2.0 \\
& Diesel fuel (GJ(t)) & 162,600 & 3.7 \\
& Water (L) & $4.92 \times 10^{7}$ & 1,110 \\
& & & \\
& Electricity(GJ(e)) & 383,400 & 8.65 \\
& Natural Gas(GJ(t)) & 421,980 & 9.52 \\
& Water $(\mathrm{L})$ & $3.41 \times 10^{7}$ & 769 \\
\hline
\end{tabular}

\subsubsection{Occupational and Public Health}

Potential environmental and health effects were considered over the forty year operational period of the storage facility. [Hartmann 1999] The impacts during normal operations would be limited to workers directly involved in handling cylinders. The radiation exposure of involved workers (cylinder yard workers) is estimated to be well within public health standards (10 CFR Part 835). The maximum annual dose to individual involved workers was conservatively estimated at about $740 \mathrm{mrem} / \mathrm{yr}$. The estimated doses do not account for standard ALARA practices that would be used to keep the actual doses as low as practicable. In fact, in 2001, the measured doses to cylinder yard workers ranged from about 170 to 427 $\mathrm{mrem} / \mathrm{yr}$, with an average of $254 \mathrm{mrem} / \mathrm{yr}$. The maximum radiation dose to the general public (all persons within $50 \mathrm{mi}[80 \mathrm{~km}]$ ) would be less than $0.1 \mathrm{mrem} / \mathrm{yr}$ [Hartman 1999].

For the transfer facility, the dose to involved workers will average at $.022 \mathrm{mrem} / \mathrm{yr}$. The average individual dose to involved workers would be less than $660 \mathrm{mrem} / \mathrm{yr}$. The radiation doses to the off-site public MEI from normal operations of the cylinder transfer facility were estimated to be less than $4.4 \times$ $10^{-5} \mathrm{mrem} / \mathrm{yr}$.

\subsection{Conversion to $\mathrm{DU}_{3} \mathrm{O}_{8}$}

A second option for depleted uranium hexafluoride disposition is to convert it, using a dry process, to a more stable oxide form; yellowcake $\left(\mathrm{U}_{3} \mathrm{O}_{8}\right)$ is considered here. The $\mathrm{U}_{3} \mathrm{O}_{8}$ could be either put back into the cylinders previously used for $\mathrm{DUF}_{6}$ for long-term storage, or mixed with concrete to form DUCRETE for subsequent use or disposal. Once the depleted uranium has been converted from DUF 6 to the oxide form, the risk associated with handling at a disposal facility is greatly decreased because the corrosive fluorine component has been removed and the oxide form is not reactive [ANL 2000]. A typical converted $\mathrm{U}_{3} \mathrm{O}_{8}$ storage cylinder is shown in Figure 7.2. [Weiner 2010] The conversion reaction [Hartman 2004] to make $\mathrm{U}_{3} \mathrm{O}_{8}$ is:

$$
\begin{aligned}
& U F_{6}+\mathrm{H}_{2} \mathrm{O} \rightarrow \mathrm{UO}_{2} \mathrm{~F}_{2}+4 \mathrm{HF} \\
& 3 \mathrm{UO}_{2} \mathrm{~F}_{2}+\mathrm{H}_{2}+2 \mathrm{H}_{2} \mathrm{O} \rightarrow \mathrm{U}_{3} \mathrm{O}_{8}+6 H F
\end{aligned}
$$

One or more deconversion facilities would be constructed, preferably co-located with an enrichment site to avoid transportation impacts. Environmental impact results presented here are taken from the EIS for the deconversion facility being constructed at the Paducah site [Hartman 2004]. An EIS is also available for Portsmouth, but the numbers are the same for both studies. This study assumes a two year construction time, 25 year operational lifetime, and a total facility throughput of 450,000 tonnes $\mathrm{DUF}_{6}$ $(\sim 304,000 \mathrm{t} \mathrm{U})$. Table 7.3 summarizes the operational specifications of this facility; the energy, $\mathrm{CO}_{2}$, land 
use, water, occupational and public safety considerations associated with building and operating the deconversion facility.

Table 7.3. $\quad$ DUF $_{6}$ deconversion facility operational parameters. Data from [Hartman 2004]

\begin{tabular}{lc}
\multicolumn{1}{c}{ Parameter } & Amount \\
\hline Construction time & $2 \mathrm{yrs}$ \\
Operational period & $25 \mathrm{yrs}$ \\
Facility Land Use & $0.18 \mathrm{~km}^{2}$ \\
Facility throughput & $18,000 \mathrm{t} \mathrm{DUF}_{6} / \mathrm{yr}^{(12,170 \mathrm{tU} / \mathrm{yr})}$ \\
Total Facility throughput & $450,000 \mathrm{t} \mathrm{DUF}_{6}(304,000 \mathrm{t} \mathrm{U})$ \\
\hline
\end{tabular}

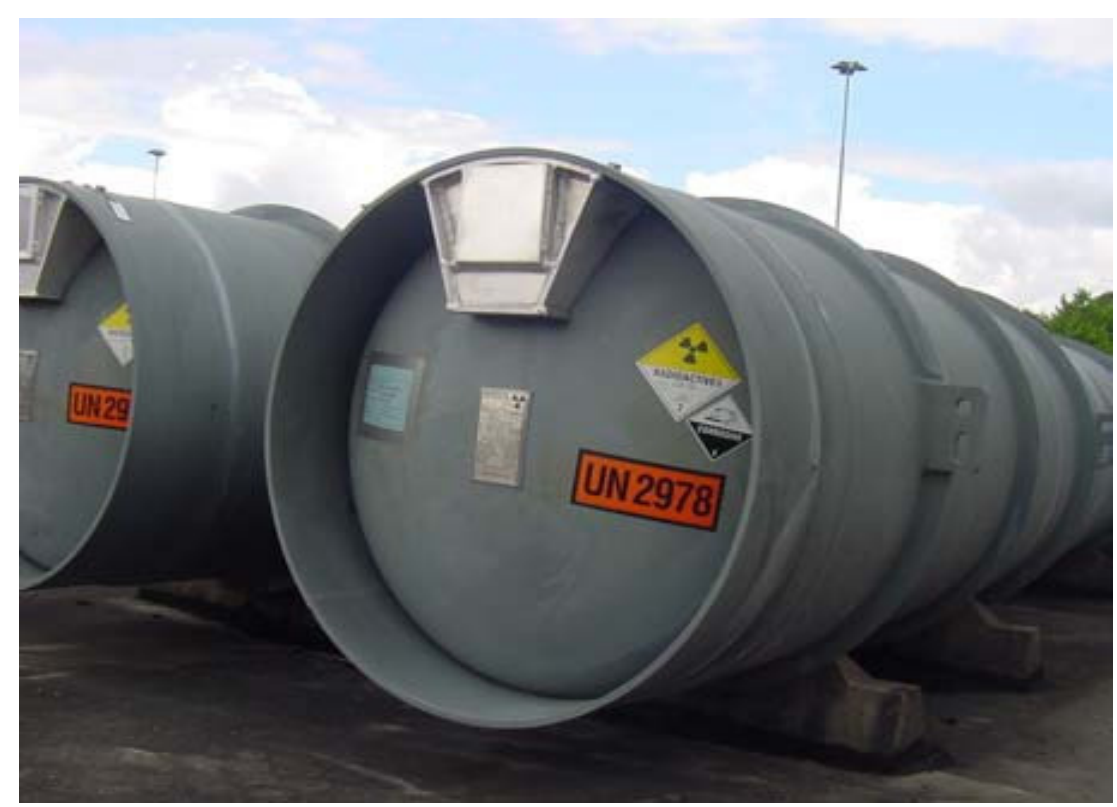

Figure 7.2. Cylinder storage.

\subsubsection{Energy Intensity}

A literature review yielded only two sets of estimates of the carbon intensity of deconversion of $\mathrm{DUF}_{6}$ and disposal of the resultant $\mathrm{DU}_{3} \mathrm{O}_{8}$; this fuel cycle process is evidently often neglected in energy and carbon balance analyses. The estimates varied by two orders of magnitude, with the highest value being $19.21 \mathrm{~kg} \mathrm{CO}_{2} / \mathrm{t} \mathrm{U}$ and the lowest $0.46 \mathrm{~kg} \mathrm{CO}_{2} / \mathrm{t} \mathrm{U}$. The results are shown in $\mathrm{kg} \mathrm{CO}_{2} / \mathrm{MWh}$ in Figure 7.3. 


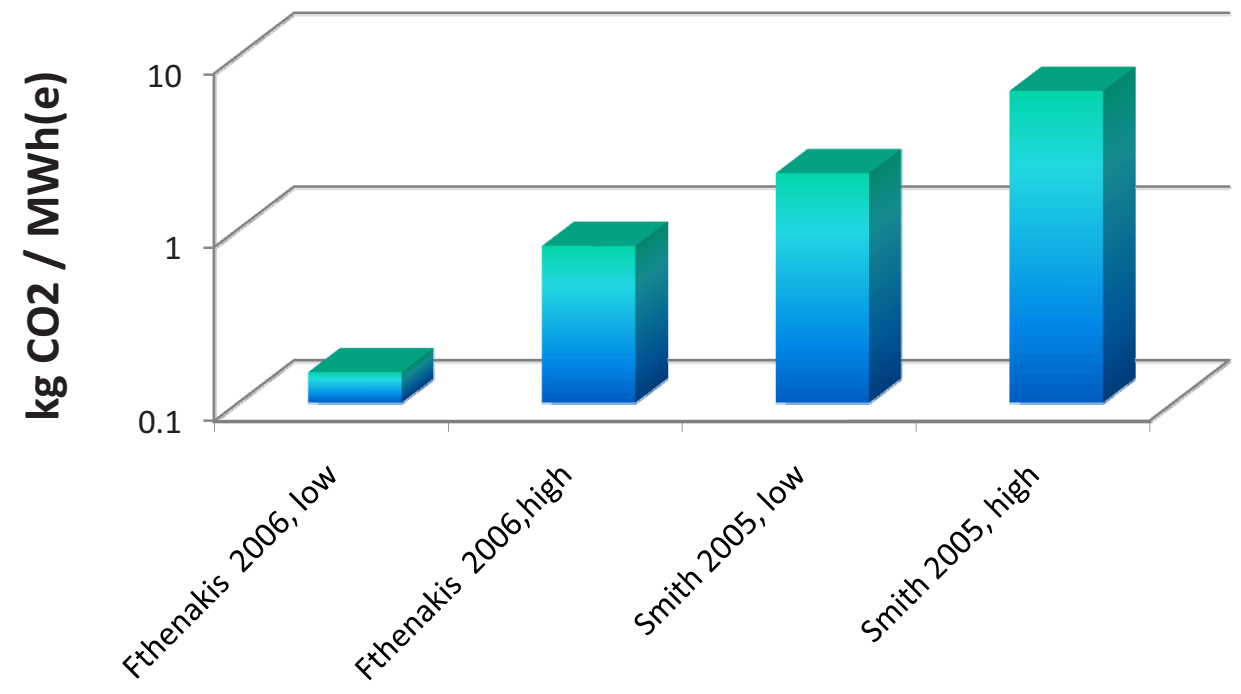

Figure 7.3. Carbon footprint of $\mathrm{DUF}_{6}$ deconversion and management - estimates from the literature

Electrical and liquid (diesel) energy consumption associated with the construction of the deconversion facility were reported in the EIS [Hartman 2004]. Energy also would be expended in the form of diesel fuel for cylinder transport, equipment and transportation vehicles. Carbon dioxide emissions are estimated by employing the emission factors given in Table 2.2. Energy use and $\mathrm{CO}_{2}$ emissions for construction and operation can be found in Table 7.4.

\subsubsection{Land Use}

It was estimated that the reference facility would occupy approximately $40,000 \mathrm{~m}^{2}$ (10 acres). When completed, the total area of construction-related disturbance, however, would be approximately 180,000 $\mathrm{m}^{2}$ (45 acres), because land will be occupied during construction, including temporary lay-down areas, support buildings, parking, and utility access. The total area of disturbance is considered here.

\subsubsection{Water Use}

Water withdrawals for construction and operation of the reference facility were taken from [Hartman 2004]. They are given in Table 7.4." 
Table 7.4. Resource consumption for construction and operation of conversion facility with lifetime throughput of 304,000 t DU (25 years)

\begin{tabular}{|c|c|c|c|}
\hline & Resource & Consumption & per tDU \\
\hline \multirow[t]{5}{*}{ Construction } & & $\begin{array}{l}\text { Over } 2 \text { years } \\
\text { Construction }\end{array}$ & \\
\hline & Electricity(GJ(e)) & $5.40 \times 10^{3}$ & $1.77 \times 10^{-2}$ \\
\hline & $\begin{array}{l}\text { Diesel fuel } \\
(\mathrm{GJ}(\mathrm{t}))\end{array}$ & $9.89 \times 10^{3}$ & $3.25 \times 10^{-2}$ \\
\hline & Water (L) & $1.51 \times 10^{7}$ & $4.98 \times 10^{1}$ \\
\hline & & $\begin{array}{c}\text { Over } 25 \text { year } \\
\text { operational period }\end{array}$ & \\
\hline \multicolumn{4}{|l|}{ Operations } \\
\hline & Electricity $(\mathrm{GJ}(\mathrm{e}))$ & $3.35 \times 10^{6}$ & 11.0 \\
\hline & $\begin{array}{l}\text { Diesel fuel } \\
(G J(t))\end{array}$ & $1.36 \times 10^{4}$ & $4.45 \times 10^{-2}$ \\
\hline & $\begin{array}{l}\text { Natural } \\
\text { Gas }(G J(t))\end{array}$ & $1.20 \times 10^{6}$ & 3.94 \\
\hline & Water (L) & $3.79 \times 10^{9}$ & $1.24 \times 10^{4}$ \\
\hline
\end{tabular}

\subsubsection{Occupational and Public Health}

The estimated external radiation exposure to workers involved in the construction of the conversion facility is $35 \mathrm{mrem} / \mathrm{yr}$ for a hypothetical worker at 1,000 hours per year (4 hours per day and 250 days per year) at the spot of the highest radiation level. The dose was estimated to average around $75 \mathrm{mrem} / \mathrm{year}$ for workers in the conversion facility and to range up to $690 \mathrm{mrem} / \mathrm{year}$ for those working in the cylinder yards. Because of the small airborne release rates of depleted uranium during normal operations, potential radiation exposures of the noninvolved workers would be small. Radiation exposures of the off-site public (people living within fifty miles of the site) also would be small. The dose to the MEI among the public was estimated to be less than $3.9 \times 10^{-5} \mathrm{mrem} / \mathrm{yr}$. Doses are summarized in Table 7.5 [Hartman 2004].

Table 7.5. Doses to Population

\begin{tabular}{ll}
\hline & \multicolumn{1}{c}{ Dose $(\mathrm{mrem} / \mathrm{yr})$} \\
Involved Worker & \\
Construction & 35 (average) \\
Operation & 75 (average)-690 (maximum) \\
Public & $3.9 \times 10^{-5}$ \\
\hline
\end{tabular}

\subsubsection{Other Process Inputs and Outputs}

Several chemicals are associated with the inputs and outputs of the conversion process. The hydrofluoric acid (HF) by-product has value because it can be sold. Numbers are given in Table 7.6 for chemical inputs and outputs as well as on a per tonne uranium basis. 
Table 7.6. Data for Paducah Conversion Facility processing 450,000 tDUF 6 (304,000 tDU)

\begin{tabular}{lrl}
\hline \multicolumn{1}{c}{ Parameter } & tonnes & t $/ \mathbf{t ~ D U}$ \\
\hline \multicolumn{1}{c}{ Conversion Inputs } & & \\
Ammonia & 16,750 & $5.50 \times 10^{-2}$ \\
Potassium hydroxide & 200 & $6.57 \times 10^{-4}$ \\
Nitrogen & 250,000 & 0.822 \\
& & \\
$\quad$ Conversion Outputs & & \\
$\mathrm{CaF}_{2}$ & 600 & 0.002 \\
$70 \% \mathrm{HF}$ acid & 82,500 & 0.271 \\
$49 \% \mathrm{HF}$ acid & 192,500 & 0.633 \\
\hline
\end{tabular}

\subsection{Disposal of $\mathrm{DU}_{3} \mathrm{O}_{8}$}

Long-term immobilization of $\mathrm{DU}_{3} \mathrm{O}_{8}$ within a cement matrix (DUCRETE) is presently the reference option for DOE. DUCRETE has value in shielding applications because it allows for higher decay heat dissipation than conventional concrete casks, superior moderation of fast neutrons, and greater resistance to impact [Emirchev 2006]. If DUCRETE is used in such a manner, the environmental impacts of its disposal would need to be assessed in the context of the disposal of the material being shielded. Therefore, in this study only the environmental aspects of the stand-alone disposal process, shallow land burial of DUCRETE, will be considered.

\subsubsection{Energy Intensity}

A mass ratio of 1:1.5:14 (cement: sand: $\mathrm{U}_{3} \mathrm{O}_{8}$ aggregate) gives rise to the highest recommended uranium oxide loading for large casting structures of concrete. [Lessing 1995] Almost all the energy input for concrete is in the production of cement: production of one tonne of cement consumes approximately 4.6 GJ(e) [NACI 2007] to $5 \mathrm{GJ}(\mathrm{e}) / \mathrm{t}$ [Concrete Assoc 2008], so that $0.39 \mathrm{GJ}(\mathrm{e}) / \mathrm{DU}$ would be consumed through DUCRETE production. For consistency reasons, this energy consumption will not be included in the system energy balance as it is embodied in the cement.

A study [Hightower 2000] evaluating the disposal of converted DUF $_{6}$ products considered two forms of $\mathrm{DU}_{3} \mathrm{O}_{8}$ product, ungrouted and grouted. The study was done for the reference Paducah site, with the same inventory of 450,000 t UF 6 ( 304,000 t DU) over 25 years. Ungrouted waste refers to $\mathrm{DU}_{3} \mathrm{O}_{8}$ in powder or pellet form to be disposed of in cylinders. DUCRETE (i.e., grouted $\mathrm{DU}_{3} \mathrm{O}_{8}$ ) waste refers to the solid obtained by mixing $\mathrm{DU}_{3} \mathrm{O}_{8}$ with cement, which would be repackaged in the washed out cylinders for disposal. DUCRETE is intended to increase structural strength and stability of the waste. However, because cement would be added to the uranium oxide, grouting would increase the total volume that requires disposal. Fabrication of DUCRETE from waste was assumed to occur at the disposal facility.

Assuming an average DUCRETE density of $6.5 \mathrm{~g} / \mathrm{cm}^{3}$ [Lessing 1995] and the mixing ratio defined above, $1 \mathrm{~m}^{3}$ of DUCRETE would contain 4.81 tonnes of DU (as $\mathrm{DU}_{3} \mathrm{O}_{8}$ ). At-site energy inputs for disposal would include excavation of the disposal trench and haulage of the displaced soil, at $1.25 \mathrm{~m}^{3}$ of soil per $\mathrm{m}^{3}$ of DUCRETE when space for overpack is included, as well as fabrication of the DUCRETE from the cement and aggregate. Table 7.7 provides energy intensities for these processes. 
Table 7.7. At site inputs to DUCRETE disposal

\begin{tabular}{llc}
\multicolumn{1}{c}{ Activity } & \multicolumn{1}{c}{$\begin{array}{c}\text { Consumption (Data source: } \\
{[\text { IPCC 1996]) }}\end{array}$} & Consumption per DU \\
\hline Concrete mixing and pouring & Energy: $0.11 \mathrm{GJ}(\mathrm{t}) / \mathrm{m}^{3}$ concrete & $0.023 \mathrm{GJ}(\mathrm{t}) / \mathrm{DU}$ \\
& Water: $1100 \mathrm{~L} \mathrm{H} \mathrm{H}_{2} \mathrm{O} / \mathrm{m}^{3}$ concrete & $230 \mathrm{~L} \mathrm{H}_{2} \mathrm{O} / \mathrm{DU}$ \\
$\begin{array}{l}\text { Soil excavation and haulage } \\
\text { (assumed } 1 \mathrm{~km})\end{array}$ & Energy: $0.0015 \mathrm{GJ}(\mathrm{t}) / \mathrm{m}^{3}$ soil & $3.1 \times 10^{-4} \mathrm{GJ}(\mathrm{t}) / \mathrm{DU}$ \\
\hline
\end{tabular}

\subsubsection{Land Use}

Under the NRC classification system, depleted uranium oxides are Class A low-level radioactive wastes eligible for near-surface disposal. [Hertzler 1994b] Shallow land burial, the most commonly used form of low-level waste disposal, will be the option considered here. These burial structures would be excavated to a depth of about $8 \mathrm{~m}$, with the length and width determined by site conditions and the annual volume of waste to be disposed. Disposal would consist of placing waste on a stable structural pad with barrier walls constructed of compacted clay. Any open space between containers would be filled with earth, sand, or gravel as each layer of cylinders are emplaced. After the structure was filled, a 2 m thick cap composed of engineered fill dirt and clay would be placed on top and compacted.

Disposal of the $\sim 304,000 \mathrm{t}$ DU as ungrouted waste or DUCRETE $\mathrm{U}_{3} \mathrm{O}_{8}$ was estimated in [Hightower 2000 ] to require about $243,000 \mathrm{~m}^{2}$ (60 acres) and 445,000 $\mathrm{m}^{2}$ (110 acres), respectively. [Hertzler 1994b] identified the Low-Level Waste Management Unit (LLWMU) at the Area 5 Radioactive Waste Management Site at the Nevada Test Site, as a candidate disposal site. Through 1990, the LLWMU, on a footprint of 92 acres $\left(372,000 \mathrm{~m}^{2}\right)$, disposed of 5.3 million cubic feet of LLW. This volume is similar to the estimated 6.9 million cubic feet necessary to dispose of the concretized DU and associated waste in Hightower's estimate. So the LLWMU footprint serves as another data point that supports the estimate. There would certainly be an exclusion zone around the disposal site; in the case of the LLWMU it is Area 5 at the NTS. The total footprint of Area 5 is 2,960,000 $\mathrm{m}^{2}$ (732 acres). Other waste is stored at Area 5, but to obtain a conservative land use estimate the total Area 5 footprint will be used to estimate the land use for disposal of DUCRETE.

\subsubsection{Water Use}

Direct water consumption in DUCRETE disposal consists of the water input to concrete mixing. This was estimated (see Table 7.7 and preceding discussion) at $230 \mathrm{~L} \mathrm{H}_{2} \mathrm{O}$ per tonne of DU.

\subsubsection{Occupational and Public Health}

A 1999 DOE programmatic environmental impact statement [DOE 1999] included an assessment of the radiological impacts of the shallow land burial disposal strategy for $\mathrm{DU}_{3} \mathrm{O}_{8}$. The study indicated that occupational doses during emplacement would reach $290 \mathrm{mrem} / \mathrm{year}$ for involved workers. The maximally exposed member of the public was estimated to receive a dose of $0.016 \mathrm{mrem} / \mathrm{year}^{\mathrm{aa}}$.

aa. DOE estimated that maximum occupational doses would increase from 290 to $550 \mathrm{mrem} / \mathrm{year}$ if the DU were to be disposed in ungrouted form, but the collective occupational dose would decrease by around $40 \%$. Due to its lower density and larger overall volume, disposing grouted $\mathrm{DU}_{3} \mathrm{O}_{8}$ involves the movement and handling of more individual packages, albeit with lower per-package radionuclide loadings. DOE also estimated that the MEI public member dose would increase by $60 \%$ from the quoted value if the disposal facility were situated in a wet environment with enhanced waterborne dose pathway. 


\subsection{Other options for $\mathrm{DUF}_{6}$}

A further option for DU management is conversion to DU metal. The use of DU metal as a nonstructural shielding component in a SNF container is technically feasible. DU metal has been used in the past for gamma shielding in transportation casks and is acceptable to the U.S. Nuclear Regulatory Commission, but a more probable application of conversion to metal is as a precursor step to utilization of the DU in metallic reactor fuel.

DU metal can be converted from $\mathrm{DUF}_{6}$ via the Ames process. The DUF 6 is converted to $\mathrm{DUF}_{4}$ using a hydrogen reduction and then the $\mathrm{DUF}_{4}$ is converted to uranium metal using a batch thermite reduction

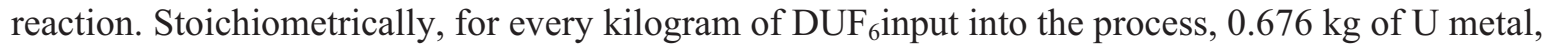
$0.114 \mathrm{~kg}$ of $\mathrm{HF}$, and $0.354 \mathrm{~kg}$ of $\mathrm{MgF}_{2}$ will be produced. Assuming the total inventory of 740,000 MT of $\mathrm{DUF}_{6}$ is fed to the conversion process, the resulting quantities of uranium metal, $\mathrm{HF}$, and secondary waste would be 500,240 MT, 84,360 MT, and 261,960 MT, respectively. [Hertzler 1994]

Other potential uses for DU metal include [Brown 1997]:

- as a blanket or matrix material in a thermal or fast spectrum reactor

- for down-blending high-enriched uranium (HEU);

- in munitions. This demand is decreasing as environmental regulations become more stringent.

- In biological shielding: DU metal has a high density, which makes it suitable for shielding from xrays or gamma rays for radiation protection.

- In counterweights and flywheels. Because of its high density, DU has been used to make highcapacity flywheels for such applications as the aircraft industry

\subsection{Summary}

Two options are presented, continued storage of DU as $\mathrm{DUF}_{6}$ and conversion to $\mathrm{DU}_{3} \mathrm{O}_{8}$ with subsequent shallow land burial as DUCRETE. Note that if the storage as DUF $_{6}$ option is pursued, the environmental price would need to be paid every 40 years to reflect storage cylinder refurbishment and replacement.

The environmental footprint metrics for DU management presented in this chapter are summarized in Table 7.8. It does not include an estimate of the collective dose because no source data were found for developing an estimate (data for DU management were not computed in the ExternE analysis of the French fuel cycle). Table 7.9 provides the impacts normalized to a unit of natural uranium based on a DU/U ration of $.88(7.41 \mathrm{~kg} / 8.41 \mathrm{~kg})$ as provided in Appendix A. 
Table 7.8. Summary of impacts resulting from management of DU.

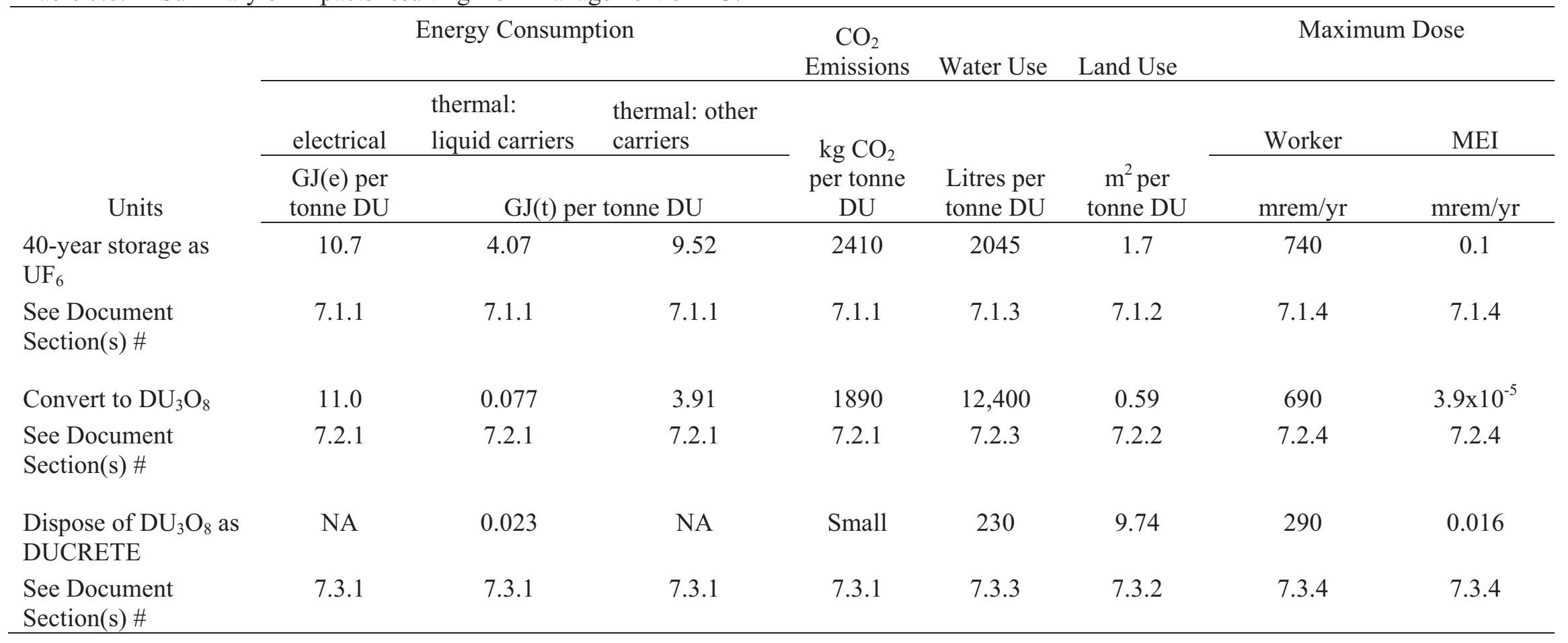


Table 7.9. Summary of DU management impacts per tonne $U$ for the reference fuel cycle

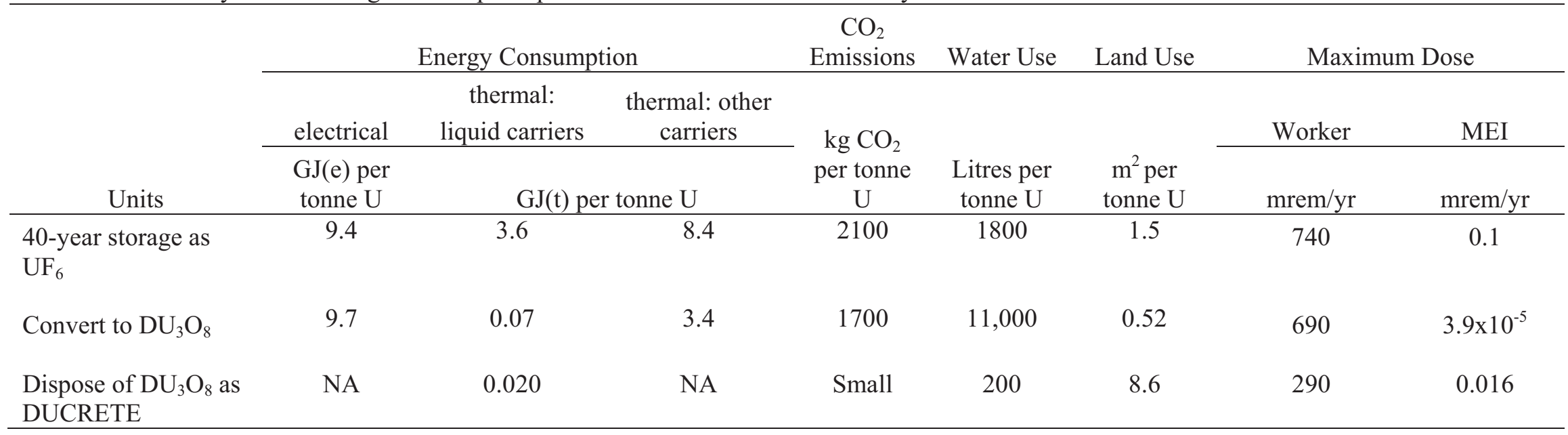




\subsection{References}

[ANL 2000] Argonne National Laboratory, Disposal of Depleted Uranium, June 2000, available: http://web.ead.anl.gov/uranium/guide/health/disposal/index.cfm. Webpage accessed June 2, 2010.

[Bulko 1999] Bulko, J. and D. Schlier, Recovery of High Value Fluorine Products from Uranium Hexafluoride Conversion, Proc. Waste Management '99, 1999.

[Brown 1997] Brown, C. Beneficial Uses of Depleted Uranium. Oak Ridge National Laboratory technical report, 1997.

[Concrete Assoc 2008] National Ready Mixed Concrete Association, Concrete $\mathrm{CO}_{2}$ factsheet, 2008.

[DOE 1999] UD Department of Energy, Final Programmatic Environmental Impact Statement for Alternative Strategies for the Long-term Management and Use of Depleted Uranium Hexafluoride," DOE Office of Nuclear Energy, Science and Technology Report DOE/EIS-0269, 1999.

[Ermichev 2006] Ermichev, S.G et al., "High-Density Concrete with Ceramic Aggregate Based on Depleted Uranium Dioxide," Proc. IHLRWM 2006, pp. 880-884, 2006.

[Fthenakis 2007] Fthenakis, V., "Greenhouse Gas Emissions from Solar Eectric- and Nuclear Power: A Life Cycle Study,” Energy Policy, 2007.

[Hartman 2004] Hartman, G. Final Environmental Impact Statement for Construction and Operation of a Depleted Uranium Hexafluoride Conversion Facility at the Paducah, Kentucky, Site (DOE/EIS0359), Volume 1: Main Text and Appendixes A-H, Department of Energy, 2004, available: http://web.ead.anl.gov/uranium/documents/paddeis/index.cfm. Webpage accessed June 2, 2010.

[Hartmann 1999] Hartmann, H. Depleted Uranium Hexafluoride Management Program: Data Compilation for the K-25 Site in Support of Site-Specific NEPA Requirements for Continued Cylinder Storage and Cylinder Preparation Activities, ANL/EAD/TM-107, Argonne National Laboratory, Argonne, Ill., Aug. 1999.

[Hertzler 1994] Hertzler, T.J, D.D. Nishimoto. Depleted Uranium Management, Idaho National Engineering Laboratory, Idaho Falls, ID. EGG-MS-11416, 1994.

[Hertzler 1994b] Hertzler, T.J, D.D. Nishimoto, M.D. Otis. Depleted Uranium Disposal Options Evaluation. Waste Management Techonology Division, Idaho Falls, ID. EGG-MS-11297 1994.

[Hightower 2000] Hightower, J.R., and J.R. Trabalka. Depleted Uranium Storage and Disposal Trade Study: Summary Report, Oak Ridge National Laboratory, 2000.

[IPCC 1996] Intergovernmental Panel on Climate Change, Greenhouse Gas Inventory Reference Manual, Vol. 3, 1996, available: http:/www.ipcc-nggip.iges.or.jp/public/gl/invs6.html, Webpage accessed August 3, 2010.

[Lessing 1995] Lessing, P., Development of DUCRETE. Idaho National Engineering Laboratory report, March 1995.

[NACI 2007] North American Cement Industry, Annual Yearbook 2007, 2007.

[Quapp 2000]Quapp, W. J. et al., DUCRETE:A Cost Effective Radiation Shielding Material, 2000.

[Shropshire 2008] Shropshire, D. et al., Advanced Fuel Cycle Cost Basis, Idaho National Laboratory report INL/EXT-07-12107, 2008.

[Sovacool, 2008] Sovacool, B. "Greenhouse Gas Emissions from Nuclear Power: A Critical Survey," Energy Policy, 2008. 
[Storm van Leeuwen 2005] Storm van Leeuwen, J., and P. Smith, Nuclear power - the energy balance, 2005, available: http://www.stormsmith.nl/. Webpage accessed June 10, 2010.

[Walker 2010] Walker, M., "EnergySolutions Hails Milestone on DOE Start-Up Conversion Plant at Piketon," Available: http://www.marketwatch.com/story/energysolutions-hails-milestone-on-doestart-up-of-conversion-plant-at-piketon-2010-06-03?reflink=MW news stm. Webpage accessed June 4, 2010.

[Weiner 2010] Weiner, R. et al., Generic Systems Analysis for Transportation Needs and Impacts for Fuel Cycle Based on a 800-Tonne Separations Plant, technical report FCR\&D-SYSA-PMO-MI-DV -2009000216, US Department of Energy, 2010.

[Wise Uranium 2010] Current Issues: Waste Management of Depleted Uranium, available: http://www.wise-uranium.org/ediss.html. Webpage accessed June 20, 2010. 


\section{TRANSPORTATION}

There are six junctures in the front end of the fuel cycle at which long-distance transportation of nuclear materials is required (Figure 8.1):

- $\mathrm{U}_{3} \mathrm{O}_{8}$ from mill to conversion facility,

- $\mathrm{UF}_{6}$ from conversion to enrichment,

- $\mathrm{UF}_{6}$ from enrichment to fuel fabrication,

- $\mathrm{UF}_{6}$ from enrichment to storage or defluorination,

- depleted $\mathrm{U}_{3} \mathrm{O}_{8}$ to disposal or storage,

- $\mathrm{UO}_{2}$ from fuel fabrication to a reactor.

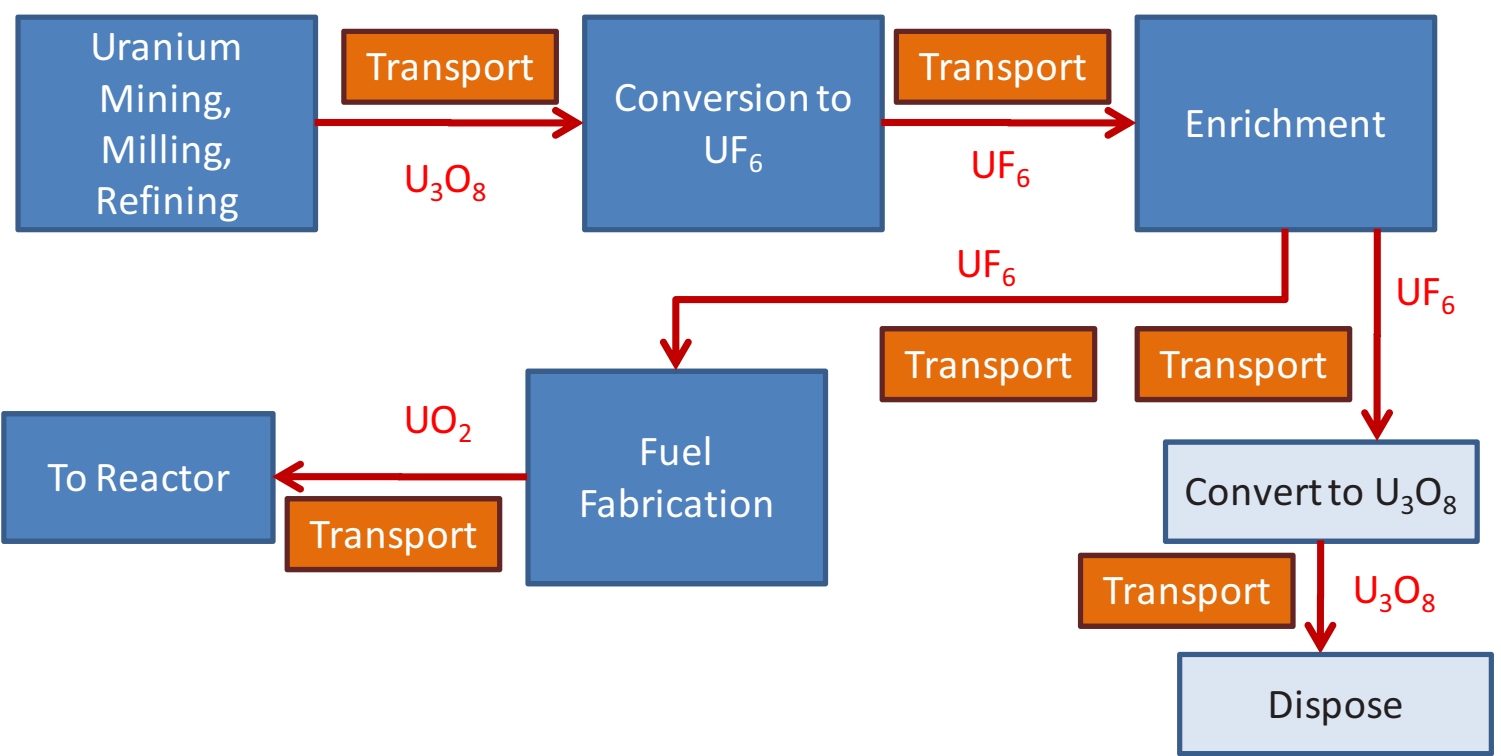

Figure 8.1. Transportation processes considered in this study

A system-level study of transportation needs for contemporary and advanced fuel cycles [Weiner 2010] was issued in early 2010 by the Fuel Cycle Research \& Development program. The purpose of this section is to summarize the transportation impacts reported in [Weiner 2010] that are relevant to the frontend environmental footprint. The impacts will include energy intensities - normalized per kilometer of travel per tonne of actinide mass - and the carbon emissions derived from them.

\subsection{Energy Intensity and Carbon Footprint}

The focus in this section is on the energy required to transport one tonne of actinides a distance of one kilometer by diesel-powered train or truck. Energy intensities for cargo transport are usually specified in units of GJ(t)/tonne of cargo-km [EIA 2010]; however, depending on container and overpack specifications the actinide mass may contribute only a small share of the cargo mass transported. Additionally, in some cases regulatory limitations on radionuclide transport limit the per-shipment inventories. Therefore, [Weiner 2010] computes transportation requirements on the basis of the actinide mass transported per vehicle (combination truck trailer or train car). To obtain the energy requirements associated with transportation, energy intensities per vehicle-km are derived from mode-averaged data reported in the DOE Transportation Energy Data Book [Davis 2008]. The average fuel efficiency of 
combination trucks engaged in long-haul cargo transport in 2007 was reported as $5.1 \mathrm{mpg}(2.2 \mathrm{~km} / \mathrm{L})$. Given the energy content of diesel fuel, $36.4 \mathrm{MJ} / \mathrm{L}$, this translates to $0.0168 \mathrm{GJ} / \mathrm{km}$ per vehicle. For train transportation, [Davis 2008] reports 2007 energy consumption of 566.9 trillion BTU against 38,186 million car-miles of freight transported, or $0.00973 \mathrm{GJ} /$ rail car-km. The emission factor for diesel fuel given in Table $2.2,70 \mathrm{~kg} / \mathrm{GJ}(\mathrm{t})$, was applied to the intensities to obtain the normalized factors $[\mathrm{kg}$ $\mathrm{CO}_{2} /$ carrier (truck or rail car)-km] shown in Table 8.1.

Table 8.1. Energy and $\mathrm{CO}_{2}$ per tonne per kilometer traveled

\begin{tabular}{lll} 
& \multicolumn{1}{c}{$\mathrm{GJ}(\mathrm{t}) /$ carrier-km } & \multicolumn{1}{c}{$\mathrm{kg} \mathrm{CO} /$ carrier-km } \\
\cline { 2 - 3 } Train & 0.00973 & 0.681 \\
Truck & 0.0168 & 1.176 \\
\hline
\end{tabular}

\subsection{1 $\mathrm{U}_{3} \mathrm{O}_{8}$ to Conversion or Disposal}

$\mathrm{U}_{3} \mathrm{O}_{8}$ is shipped from a uranium mill to a conversion facility or from a deconversion facility to storage/disposal by truck in Type 7A stainless steel drums. The content is considered low specific activity (LSA) and therefore unlimited amounts can be transported (10 CFR 21.73) [Weiner 2010]. The number of drums that can be transported by truck is in this case only limited by weight and volume $\left(450 \mathrm{~kg} \mathrm{U}_{3} \mathrm{O}_{8}\right.$ or $381 \mathrm{~kg} \mathrm{U}$ ), so that a typical truck can carry 42 drums of $\mathrm{U}_{3} \mathrm{O}_{8}$ at a time [Weiner 2010]. Table 8.2 summarizes $\mathrm{U}_{3} \mathrm{O}_{8}$ transportation data, energy use, and carbon emissions for one full truck shipment of $\mathrm{U}_{3} \mathrm{O}_{8}$. The per-vehicle intensity data in Table 8.1 was utilized to calculate the energy intensity in GJ per tonne $\mathrm{U}$ per $\mathrm{km}$.

Table 8.2. $\mathrm{U}_{3} \mathrm{O}_{8}$ transportation data, energy use, and carbon emissions

\begin{tabular}{ll}
\hline \multicolumn{1}{c}{ Container } & \multicolumn{1}{c}{ Stainless Steel Drum (7A) } \\
\hline Payload/ container & $0.382 \mathrm{tU}$ \\
Containers/ truck & 42 \\
Payload/ truck & $16.0 \mathrm{tU}$ \\
Energy intensity & $1.05 \times 10^{-3} \mathrm{GJ}(\mathrm{t}) / \mathrm{tU}-\mathrm{km}$ \\
$\mathrm{CO}_{2}$ emission intensity & $7.33 \times 10^{-2} \mathrm{~kg} \mathrm{CO}_{2} / \mathrm{tU}-\mathrm{km}$ \\
\hline
\end{tabular}

\subsubsection{Natural or Depleted $\mathrm{UF}_{6}$}

After $\mathrm{U}_{3} \mathrm{O}_{8}$ has been converted to gaseous $\mathrm{UF}_{6}$ (natural uranium hexafluoride) it may be transported by truck or rail to an enrichment facility. Following enrichment, depleted uranium may also be transported as DUF $_{6}$ (depleted uranium hexafluoride) to a storage or fuel fabrication facility. In both cases the product is packed in 48X type B thick walled cylinders [Weiner 2010]. These cylinders can hold $9540 \mathrm{~kg} \mathrm{UF}_{6}$ or $6450 \mathrm{kgU}$. Energy data, along with carbon emissions using emission factors for distillate fuel, are given in Table 8.3 per tonne of uranium in $\mathrm{UF}_{6}$. 
Table 8.3. $\mathrm{DUF}_{6}$ and $\mathrm{UF}_{6}$ transportation data, energy use, and carbon emissions

\begin{tabular}{lll}
\hline & \multicolumn{1}{c}{ Truck } & \multicolumn{1}{c}{ Train } \\
\hline Container & $48 \mathrm{X} \mathrm{Cylinder} \mathrm{(Type} \mathrm{B)}$ & $48 \mathrm{X}$ Cylinder (Type B) \\
Payload/ container & $6.45 \mathrm{tU}$ & $6.45 \mathrm{tU}$ \\
Containers/ truck or car & 1 & 1 \\
Payload/ truck or car & $6.45 \mathrm{tU}$ & $6.45 \mathrm{tU}$ \\
Energy intensity & $2.60 \times 10^{-3} \mathrm{GJ}(\mathrm{t}) / \mathrm{tU}-\mathrm{km}$ & $1.51 \times 10^{-3} \mathrm{GJ}(\mathrm{t}) / \mathrm{tU}-\mathrm{km}$ \\
$\mathrm{CO}_{2}$ emission intensity & $1.82 \times 10^{-1} \mathrm{~kg} \mathrm{CO} / \mathrm{tU}-\mathrm{km}$ & $1.06 \times 10^{-1} \mathrm{~kg} \mathrm{CO}_{2} / \mathrm{tU}-\mathrm{km}$ \\
\hline
\end{tabular}

\subsubsection{Low Enriched $\mathrm{UF}_{6}$}

Two streams result from enrichment. The stream from which reactor fuel is fabricated is low-enriched $\mathrm{UF}_{6}\left(\mathrm{LEUF}_{6}\right)$, the other is depleted $\mathrm{UF}_{6}$. DUF 6 transportation is addressed above in Table 8.3 for $\mathrm{UF}_{6}$. The other stream, $\mathrm{LEUF}_{6}$, continues to a deconversion/fuel fabrication plant and is transported in $30 \mathrm{~B}$ cylinders that can accommodate $2280 \mathrm{~kg} \mathrm{LEUF}_{6}$ or $1541 \mathrm{~kg} \mathrm{U}$ [Weiner 2010]. The energy and carbon intensities for $\mathrm{LEUF}_{6}$ shipment are given in Table 8.4.

Table 8.4. LEUF $_{6}$ transportation data, energy use, and carbon emissions

\begin{tabular}{lll}
\hline & \multicolumn{1}{c}{ Truck } & \multicolumn{1}{c}{ Train } \\
\hline Container & $30 \mathrm{~B} \mathrm{Cylinder}$ (Type B) & $30 \mathrm{~B}$ Cylinder (Type B) \\
Payload/ container & $1.54 \mathrm{tU}$ & $1.54 \mathrm{tU}$ \\
Containers/ truck or car & 2 & 2 \\
Payload/ truck or car & $3.08 \mathrm{tU}$ & $3.08 \mathrm{tU}$ \\
Energy intensity & $5.45 \times 10^{-3} \mathrm{GJ}(\mathrm{t}) / \mathrm{tU}-\mathrm{km}$ & $3.16 \times 10^{-3} \mathrm{GJ}(\mathrm{t}) / \mathrm{tU}-\mathrm{km}$ \\
$\mathrm{CO}_{2}$ emission intensity & $3.81 \times 10^{-1} \mathrm{~kg} \mathrm{CO} / \mathrm{tU}-\mathrm{km}$ & $2.21 \times 10^{-1} \mathrm{~kg} \mathrm{CO}_{2} / \mathrm{tU}-\mathrm{km}$ \\
\hline
\end{tabular}

\subsection{4 $\mathrm{UO}_{2}$ Fuel Assemblies}

Fabricated fuel assemblies are shipped by truck to reactors in type A(F) fissile material packagings; packing density is limited by criticality constraints and different packagings are used to transport PWR and BWR fuel. The 50132-2 packaging holds 2 PWR assemblies while the ANF-10 packaging holds 2 BWR assemblies. [Weiner 2010] takes each PWR assembly to have a heavy metal (uranium) content of 0.436 tIHM and each BWR assembly 0.173 tIHM. The energy and carbon intensities for PWR and BWR fuel assembly shipment are given in Table 8.5.

Table 8.5. $\quad \mathrm{UO}_{2}$ fuel assembly transportation data, energy use, and carbon emissions

\begin{tabular}{lll}
\hline & \multicolumn{1}{c}{ Truck (PWR) } & \multicolumn{1}{c}{ Truck (BWR) } \\
\hline Container & $51032-2($ Type A(F)) & ANF-10 \\
Payload/ container & $0.872 \mathrm{tIHM}$ & $0.346 \mathrm{tIHM}$ \\
Containers/ truck & 1 & 6 \\
Payload/ truck & $0.872 \mathrm{tIHM}$ & $2.08 \mathrm{tIHM}$ \\
Energy intensity & $1.93 \times 10^{-2} \mathrm{GJ}(\mathrm{t}) / \mathrm{tIHM}-\mathrm{km}$ & $8.09 \times 10^{-3} \mathrm{GJ}(\mathrm{t}) / \mathrm{tIHM}-\mathrm{km}$ \\
$\mathrm{CO}_{2}$ emission intensity & $1.35 \mathrm{~kg} \mathrm{CO}_{2} / \mathrm{tIHM}-\mathrm{km}$ & $0.566 \mathrm{~kg} \mathrm{CO}_{2} / \mathrm{tIHM}-\mathrm{km}$ \\
\hline
\end{tabular}




\subsection{Occupational and Public Health}

Dose estimation for front-end processes not associated with fuel recycle fell outside of the scope of [Weiner 2010], so a brief review was conducted. A survey of dose received by Japanese, German and British drivers and handlers was published in 2006 by the World Nuclear Transport Institute [Wilkinson 2006]. The survey covered transportation of $U$ oxides (as powder and fabricated fuel) and $\mathrm{UF}_{6}$, as well as used fuel and high level waste transportation (outside of the scope of this study). Truck drivers were observed to receive average doses of 10 to $20 \mathrm{mrem} / \mathrm{year}$, with the largest dose, $70 \mathrm{mrem} /$ year, having been recorded in the UK. MEI member of the public doses associated with truck transport were estimated not to exceed $0.4 \mathrm{mrem} / \mathrm{year}$. For transport by train, [Wilkinson 2006] reported data from French rail workers involved with $\mathrm{U}_{3} \mathrm{O}_{8}$ and enriched $\mathrm{UF}_{6}$ transportation. The highest occupational dose rates recorded among this population were $30 \mathrm{mrem} /$ year and $7.5 \mathrm{mrem} / \mathrm{year}$, respectively, and the MEI public dose rate was estimated at $0.1 \mathrm{mrem} /$ year.

MEI public dose estimates associated with transportation of several commodities associated with the front end were presented on a per-shipment in the EIS for the Savannah River MOX fuel fabrication plant [NRC 2005]. The dose to the MEI, 30 meters from a passing shipment, per $\mathrm{UO}_{2}$ shipment to the site was $3.7 \times 10^{-5}$ mrem, per $\mathrm{UF}_{6}$ shipment $2.3 \times 10^{-5} \mathrm{mrem}$. Given that $11 \mathrm{UF}_{6}$ and $6 \mathrm{UO}_{2}$ shipments to the facility are planned per year, these remain negligibly small on a per-annum basis. Per-trip doses to transportation crew were estimated not to exceed 6 mrem for the $\mathrm{UO}_{2}$ shipments and 4 mrem for the $\mathrm{UF}_{6}$ shipments.

The primary data from [Wilkinson 2006] will be taken as the reference; since the data of [Wilkinson 2006] as well as the model projections in [NRC 2005] indicate little difference between dose rates associated with workers involved in oxide and hexafluoride shipments, the most conservative reported dose rate will be applied to all transportation processes.

Only truck transportation was assessed in the ExternE collective dose study of the French fuel cycle [EC 1995]. The doses presented in that study are provided in the summary table at the end of this section. In [EC 1995] doses were computed on a per-trip basis, so the per-trip results were divided by the average trip distances given in [EC 1995] to obtain the numbers shown in Table 8.6.

\subsection{Summary}

The environmental footprint for the transport of a shipment of $\mathrm{U}_{3} \mathrm{O}_{8}, \mathrm{UF}_{6} / \mathrm{DUF}_{6}, \mathrm{LEUF}_{6}$ and $\mathrm{UO}_{2}$ fuel assemblies by truck and (where available) train are summarized in Table 8.6 on a per kilometer traveled, per unit mass of heavy metal transported (always uranium in the cases studied) basis. Also in Table 8.6 are maximum doses to transportation workers and the MEI member of the public.

Estimation, on a per MWh(e) basis, of the contribution of front-end transportation to the carbon balance of nuclear power would require knowledge of the travel distances involved with each type of shipment. To permit an illustrative estimate, truck transport will be assumed and the practice in [Lenzen 2008] will be followed so that each shipment will be assumed to take place over a distance of $1,000 \mathrm{~km}$. It will also be assumed that depleted $\mathrm{UF}_{6}$ is deconverted to $\mathrm{U}_{3} \mathrm{O}_{8}$ at a site co-located with the enrichment facility, the $\mathrm{U}_{3} \mathrm{O}_{8}$ is subsequently transported for disposal, and the reactor is a PWR. Then, using the mass balance and per-mass nuclear energy production presented in Appendix A with Table 8.6, the transportation carbon emissions associated with all transportation events leading to the delivery of $1 \mathrm{tIHM}$ of fuel to the reactor are found to be $4,420 \mathrm{~kg} \mathrm{CO}$ : 


$$
\begin{aligned}
& 1000[\mathrm{~km}]^{*} \quad\left(8.41\left[\mathrm{tU} \text { in } \mathrm{U}_{3} \mathrm{O}_{8}\right]^{*} 7.33 \times 10^{-2}\left[\mathrm{~kg} \mathrm{CO}_{2} / \mathrm{km} / \mathrm{tU} \text { in } \mathrm{U}_{3} \mathrm{O}_{8}\right]+\right. \\
& 8.41\left[\mathrm{tU}^{\text {in }} \mathrm{UF}_{6}\right]^{*} 1.82 \times 10^{-1}\left[\mathrm{~kg} \mathrm{CO}_{2} / \mathrm{km} / \mathrm{tU} \text { in } \mathrm{UF}_{6}\right]+ \\
& 7.41\left[\mathrm{tDU} \text { in } \mathrm{U}_{3} \mathrm{O}_{8}\right]^{*} 7.33 \times 10^{-2}\left[\mathrm{~kg} \mathrm{CO}_{2} / \mathrm{km} / \mathrm{tDU} \text { in } \mathrm{U}_{3} \mathrm{O}_{8}\right]+ \\
& \left.1.00 \text { [tLEU in } \mathrm{UF}_{6}\right]^{*} 3.81 \times 10^{-1}\left[\mathrm{~kg} \mathrm{CO}_{2} / \mathrm{km} / \mathrm{tLEU} \text { in } \mathrm{UF}_{6}\right]+ \\
& 1.00 \text { [tLEU in IHM]* } 1.35\left[\mathrm{~kg} \mathrm{CO}_{2} / \mathrm{km} / \mathrm{tLEU} \text { in IHM]) }=4,420 \mathrm{~kg} \mathrm{CO}_{2}\right. \text {. }
\end{aligned}
$$

Set against 403,000 MWh(e) of electricity production per tIHM of fuel, the carbon emissions associated with transportation are found to be small: $\sim 0.01 \mathrm{kgCO}_{2} / \mathrm{MWh}(\mathrm{e})$. This calculation is meant to be illustrative only; many parameters, especially transportation distances, are scenario-specific.

Table 8.7 shows the impacts normalized against 1 tonne of extracted $U$ for the reference fuel cycle mass balance of Appendix A. All transportation is assumed to take place by truck, and the total transportation impact, summed over all five processes depicted in Figure 8.1, is provided. 
Table 8.6. Summary of transportation impacts

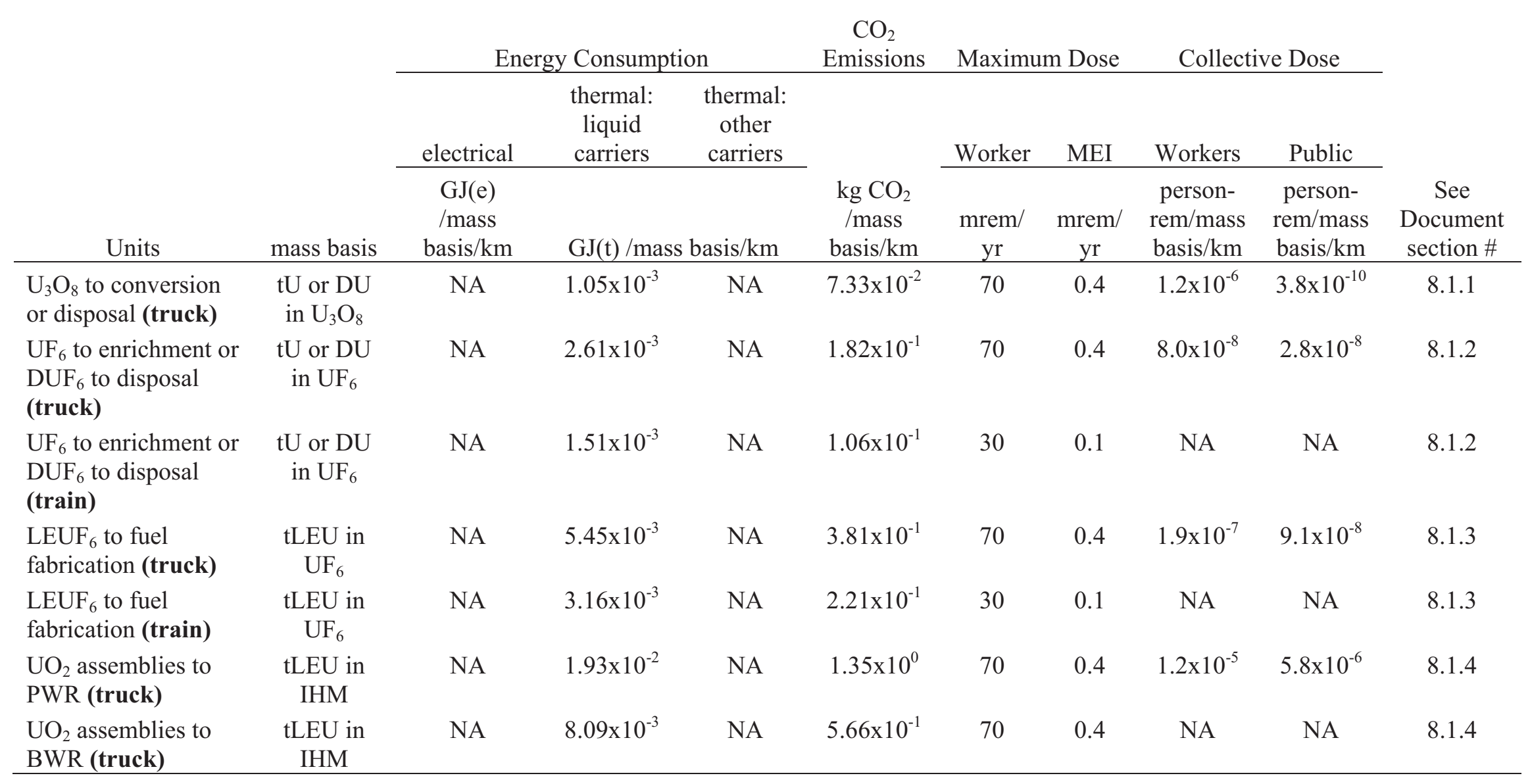


Table 8.7. impacts per tonne $\mathrm{U}$ for the reference fuel cycle

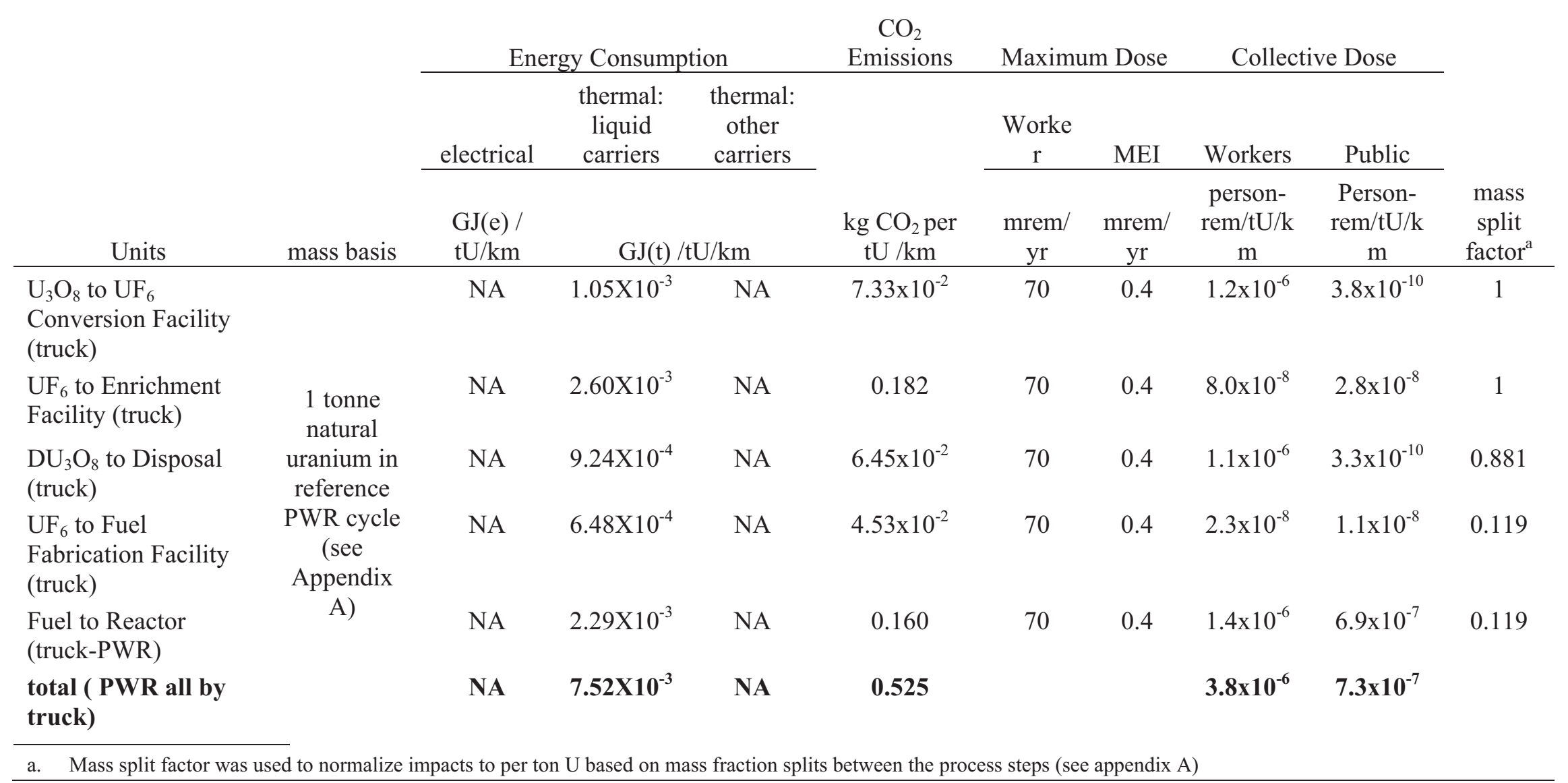




\subsection{References}

[Davis 2008] Davis, S., Diegel, S. and R. Boundy, “Transportation Energy Data Book Edition 28," Oak Ridge National Laboratory Report ORNL-6984, 2008.

[EC 1995] European Commission, ExternE - Externalities of Energy, Volume 5: Nuclear, European Commission Directorate-General XII, 1995.

[EIA 2010] US Energy Information Administration, Transportation Sector. http://www.eia.doe.gov/emeu/efficiency/ee_ch5.htm. Webpage last accessed June 25, 2010.

[Weiner 2010] R. Weiner et al., Generic Systems Analysis for Transportation Needs and Impacts for Fuel Cycle Based on an 800-Tonne Separations Plant, Technical report FCR\&D-SYSA-PMO-MI-DV 2009-000216, US Department of Energy, 2010.

[Greene 2003] Green, D. and A. Schafer. Reducing Greenhouse Gasses From U.S. Transportation. ORNL, 2003.

[Lenzen 2008] Lenzen, M., "Life cycle energy and greenhouse gas emissions of nuclear energy: A review," Energy Conversion and Management 49, 2178-2199, 2008.

[NRC 2005] US Nuclear Regulatory Commission, Environmental Impact Statement on the Construction and Operation of a Proposed Mixed Oxide Fuel Fabrication Facility at the Savannah River Site, South Carolina, NUREG-1767, 2005.

[Wilkinson 2006] Wilkinson, W., Radiation Dose Assessment for the Transport of Nuclear Fuel Cycle Materials, World Nuclear Transport Institute Review Series no. 2, 2006. 


\section{CONCLUSIONS}

This study has inventoried the direct energy consumption and associated carbon emissions, water withdrawals, land transformation, and occupational and public health impacts associated with the front end processes of the once-through fuel cycle. Metrics were developed to allow quantification of each of these impacts across the full set of front end processes. In nearly all cases, recent data from primary sources - operating facilities that provide the fuel cycle services - was utilized to assemble the estimates. Table 9.1 summarizes the environmental impacts identified in Sections 3 thru 8.

Table 9.1. Environmental footprint measures normalized to 1 tonne of extracted U.

\begin{tabular}{|c|c|c|c|c|c|c|c|c|}
\hline & \multicolumn{3}{|c|}{ Energy Consumption } & \multirow[b]{2}{*}{$\begin{array}{c}\mathrm{CO}_{2} \\
\text { Emissions } \\
\mathrm{kg} \mathrm{CO}_{2} / \\
\mathrm{tU}\end{array}$} & \multirow[b]{2}{*}{$\begin{array}{c}\text { Water } \\
\text { Use } \\
\mathrm{L} / \\
\mathrm{tU} \\
\end{array}$} & \multirow[b]{2}{*}{$\begin{array}{l}\text { Land } \\
\text { Use } \\
\mathrm{m}^{2} / \\
\mathrm{tU}\end{array}$} & \multicolumn{2}{|c|}{ Cumulative Dose } \\
\hline & $\begin{array}{c}\text { Electrical } \\
\mathrm{GJ}(\mathrm{e}) / \\
\mathrm{tU}\end{array}$ & $\begin{array}{c}\text { Thermal: } \\
\text { liquid } \\
\text { carriers } \\
\text { GJ }(\mathrm{t}) / \\
\mathrm{tU}\end{array}$ & $\begin{array}{c}\text { Thermal: } \\
\text { other } \\
\text { carriers } \\
\text { GJ }(\mathrm{t}) / \\
\mathrm{tU}\end{array}$ & & & & $\begin{array}{l}\text { Workers } \\
\text { person- } \\
\text { rem/tU }\end{array}$ & $\begin{array}{l}\text { Public } \\
\text { person- } \\
\text { rem/tU }\end{array}$ \\
\hline $\begin{array}{l}\text { Uranium } \\
\text { extraction }\end{array}$ & 191 & 64 & 77 & $3.8 \times 10^{4}$ & $6.3 \times 10^{6}$ & 362 & $4.2 \times 10^{-1}$ & $6.6 \times 10^{-1}$ \\
\hline Conversion & 54 & NA & 1200 & $7.0 \times 10^{4}$ & $1.0 \times 10^{5}$ & 0.57 & $8.3 \times 10^{-3}$ & $1.3 \times 10^{-4}$ \\
\hline $\begin{array}{l}\text { Enrichment } \\
\text { (centrifuge) }\end{array}$ & 128 & NA & NA & $2.0 \times 10^{4}$ & $3.1 \times 10^{4}$ & 6.17 & $4.1 \times 10^{-5}$ & $1.3 \times 10^{-4}$ \\
\hline $\begin{array}{l}\text { Fuel Fab. } \\
\text { (UOX) }\end{array}$ & 25.2 & NA & 8.7 & 4,300 & $1.68 \times 10^{4}$ & 0.63 & $2.3 \times 10^{-2}$ & $2.9 \times 10^{-5}$ \\
\hline $\begin{array}{l}\text { DU Man- } \\
\text { agement }^{\text {b }}\end{array}$ & 9.7 & 0.09 & 3.4 & 1,700 & $1.1 \times 10^{4}$ & 9.1 & \multicolumn{2}{|c|}{ Not Avail. } \\
\hline $\begin{array}{l}\text { Transport- } \\
\text { ation }^{\mathrm{c}}\end{array}$ & NA & 7.52 & NA & 525 & NA & NA & $3.8 \times 10^{-3}$ & $7.3 \times 10^{-4}$ \\
\hline Totals & 408 & 71 & $1.29 \times 10^{3}$ & $1.33 \times 10^{5}$ & $6.44 \times 10^{6}$ & 378 & $4.5 \times 10^{-1}$ & $6.6 \times 10^{-1}$ \\
\hline
\end{tabular}

The above data represent an estimate of the present-day (2010) values of each of the metrics, but these have not been time-independent, nor are they expected to be in the future. For most technologies, energy intensity is expected to evolve along the lines of the intensity of the broader industrial sector. Two exceptions were identified: uranium extraction, where the energy intensity is expected to eventually increase with time as the most attractive deposits are depleted; and enrichment, where the rate of energy intensity decrease has been, and will probably continue to be, much larger than that of the broader industry. For both of these processes, models were formulated to project temporal changes in the energy intensity.

The uranium extraction forecast used a simple mine mass flow model, informed by historical data for nine operating mines, to project the relation between energy intensity, ore grade, and mining technology. Coupled with forecasts of resource availability at lower grades derived from well-known predictions of the crustal distribution of uranium, the model projected that the energy intensity of uranium recovery 
might increase by an order of magnitude or more by the latter part of the century. The time evolution of ancillary impacts associated with uranium extraction, water use and land use, were also projected.

The historical energy intensity of enrichment was observed to follow Moore's Law (exponential decrease). Because existing centrifuge technology continues to evolve and new technologies may be on the horizon, it was postulated that the Moore's Law behavior would continue into the future. Therefore, the historical data was analyzed to estimate a time constant for continued exponential decrease.

Tables 9.2 through 9.5 summarize the results of the current study, normalized to $1 \mathrm{MWh}(\mathrm{e})$ of nuclear electricity produced by the reference PWR cycle described in Appendix A. Table 9.3 additionally provides a comparison to the maximum and minimum emissions reported in seventeen other studies surveyed by [Sovacool 2008] along with combustion emissions associated with current production of fossil-fueled electricity. Discrepancies between the carbon footprint estimates arise primarily from three sources: energy accounting practices, assumptions regarding the individual process technologies (in particular whether diffusion or centrifuge enrichment is used), and the material balance of the fuel cycle. A cycle representative of current PWR operations was chosen as the reference fuel cycle for this study: both burnup (51 MWd(t)/kgIHM) and uranium enrichment (4.5\%) values were higher than those assumed in the studies surveyed by [Sovacool 2008]. The net effect of higher burnup is to reduce emissions per energy produced.

The water and land use estimates provided in Table 9.4 are compared to those found in the literature for nuclear and two fossil electrical technologies; the literature estimates are taken from [Gerbens 2008] and [Fthenakis 2009] for water and land use, respectively. The increase in estimated water use relative to the reviewed study is a result of increased use of in-situ leach mining. As explained in section 2, the reported water use represents total water withdrawals rather than net water use. Hence, water recycling programs substantially reduce the net impact of these withdrawals.

Table 9.5 summarizes the radiological dose estimates to workers and the public resulting from the processes of the front-end of the nuclear fuel cycle.

Table 9.2. Energy consumption per unit electricity produced

\begin{tabular}{lcccc}
\hline \multicolumn{1}{c}{ Process } & Electrical & $\begin{array}{c}\text { Thermal: liquid } \\
\text { carriers }\end{array}$ & $\begin{array}{c}\text { Thermal: other } \\
\text { carriers }\end{array}$ & $\begin{array}{c}\text { Total Energy } \\
\text { Consumption }\end{array}$ \\
\hline & {$[\mathrm{GJ}(\mathrm{e}) / \mathrm{MWh}(\mathrm{e})]$} & $\mathrm{GJ}(\mathrm{t}) / \mathrm{MWh}(\mathrm{e})]$ & $\begin{array}{c}\mathrm{GJ}(\mathrm{t}) / \mathrm{MWh}(\mathrm{e})] \\
{[\mathrm{GJ}(\mathrm{t}+\mathrm{e}) / \mathrm{MWh}(\mathrm{e})]}\end{array}$ \\
Uranium extraction & $4.0 \times 10^{-3}$ & $1.3 \times 10^{-3}$ & $1.6 \times 10^{-3}$ & $6.9 \times 10^{-3}$ \\
${\text { Conversion to } \mathrm{UF}_{6}}$ & $1.1 \times 10^{-3}$ & $\mathrm{NA}$ & $2.5 \times 10^{-2}$ & $2.6 \times 10^{-3}$ \\
Centrifuge enrichment & $2.7 \times 10^{-3}$ & $\mathrm{NA}$ & $\mathrm{NA}$ & $2.7 \times 10^{-3}$ \\
Fuel fabrication (UOX) & $5.2 \times 10^{-4}$ & $\mathrm{NA}$ & $1.8 \times 10^{-4}$ & $7.1 \times 10^{-4}$ \\
DU Management & $2.0 \times 10^{-4}$ & $1.8 \times 10^{-6}$ & $7.2 \times 10^{-5}$ & $2.8 \times 10^{-4}$ \\
Transportation & $\mathrm{NA}$ & $1.6 \times 10^{-4}$ & $\mathrm{NA}$ & $1.6 \times 10^{-4}$ \\
Total & $\sim \mathbf{8 . 5 \times 1 0 ^ { - 3 }}$ & $\sim \mathbf{1 . 5 \times 1 0 ^ { - 3 }}$ & $\mathbf{2 . 7} \times \mathbf{x 1 0}^{-\mathbf{2}}$ & $\mathbf{3 . 7 \times 1 0}$ \\
\hline
\end{tabular}

Based on 1970s technologies, Rotty (see Table 2.5) estimated indirect energy associated embodied energy, construction, and decommissioning of FEFC processes to be $4.1 \times 10^{-2} \mathrm{GJ}((\mathrm{t}+\mathrm{e}) / \mathrm{MWh}(\mathrm{e})$. Assuming this to be a reasonable upper bound and comparing it to the direct energy consumption estimated by this study, one concludes that inclusion of indirect energy could increase the FEFC energy consumption estimate by a factor of up to $\sim 2$. 
Table 9.3. Emissions per unit electricity produced

\begin{tabular}{lc}
\hline \multicolumn{1}{c}{ Process } & $\begin{array}{c}\text { Emissions } \\
{\left[\mathrm{kgCO}_{2} / \mathrm{MWh}(\mathrm{e})\right]}\end{array}$ \\
\hline Uranium extraction & 0.78 \\
${\text { Conversion to } \mathrm{UF}_{6}}$ & 1.45 \\
Centrifuge enrichment & 0.41 \\
Fuel fabrication & 0.09 \\
DU Management & 0.035 \\
Transportation & 0.011 \\
Total & $\sim 2.8$ \\
17 other studies [Sovacool 2008] & $0.68-118$ \\
Coal-fired Electricity (US average) & 979 \\
Natural Gas-fired Electricity (US average) & 410 \\
\hline
\end{tabular}

Table 9.4. Water and land use per unit electricity produced

\begin{tabular}{lcc}
\hline \multicolumn{1}{c}{ Process } & Water Use [L/MWh(e)] & Land Use $\left[\mathrm{m}^{2} / \mathrm{MWh}(\mathrm{e})\right]$ \\
\hline Uranium extraction & 130 & $7.5 \times 10^{-3}$ \\
Conversion to UF 6 & 2.1 & $1.2 \times 10^{-5}$ \\
Centrifuge enrichment & 0.65 & $1.3 \times 10^{-4}$ \\
Fuel fabrication & 0.35 & $1.3 \times 10^{-5}$ \\
DU Management & 0.23 & $1.9 \times 10^{-4}$ \\
Transportation & $\mathrm{NA}$ & $\mathrm{NA}$ \\
Total, this study & $\sim 130$ & $\sim 0.008$ \\
Total, reviewed study & 30 & 0.04 \\
Coal-fired Electricity Front End & $\mathrm{a}$ \\
Natural Gas Electricity Front End & & 0.30 \\
& 51 & 0.26 \\
a. Average of underground and surface mining. & 6.3 & \\
b. Extraction, pipeline transmission, storage. & & \\
\hline
\end{tabular}


Table 9.5. Cumulative dose per unit electricity produced

\begin{tabular}{lcc}
\multicolumn{1}{c}{ Process } & $\begin{array}{c}\text { Workers } \\
\text { [person-rem/MWh(e)] }\end{array}$ & $\begin{array}{c}\text { Public } \\
\text { [person-rem/MWh(e)] }\end{array}$ \\
\hline Uranium extraction & $8.7 \times 10^{-6}$ & $1.4 \times 10^{-5}$ \\
Conversion to UF 6 & $1.7 \times 10^{-7}$ & $2.7 \times 10^{-9}$ \\
Centrifuge enrichment & $8.6 \times 10^{-10}$ & $2.8 \times 10^{-9}$ \\
Fuel fabrication & $4.7 \times 10^{-7}$ & $5.9 \times 10^{-10}$ \\
DU Management & $\mathrm{NA}$ & $\mathrm{NA}$ \\
Transportation & $\mathbf{7 . 9 \times 1 0 ^ { - 8 }}$ & $1.5 \times 10^{-8}$ \\
Total & $\sim \mathbf{9 . 5 \times 1 0 ^ { - 6 }}$ & $\sim \mathbf{1 . 4 \times 1 0 ^ { - 5 }}$ \\
\hline
\end{tabular}

\subsection{Time Evolution of the Footprint}

The environmental footprint of the front end technologies will evolve as innovations occur within the fuel cycle technologies themselves and the broader energy sector. Changes within the energy sector are manifested by a declining carbon intensity of end-use energy. The electricity emission factors depicted in Table 2.2 reflect the contemporary generation mix. Economists and technologists have collaborated to develop forecasts of the time evolution of these factors.

Table 9.6 shows the emission factors for 2050 for two extreme-case scenarios described in the UN Intergovernmental Panel on Climate Change Special Report on Emissions Scenarios [IPCC 2000]. Historical 1990 values are provided for comparison. The A2 scenario is relatively pessimistic: this 'heterogeneous-world' scenario features high population growth, relatively slow economic growth, and minimal technological innovation. It gives rise to a pessimistic assessment of carbon intensities at midcentury. The B1 scenario postulates convergence of economic conditions between the developed and developing worlds and rapid technological change. Midcentury emissions under the B1 scenario are roughly half those of $\mathrm{A} 2$, with much of the improvement having come from accelerating rates of decrease in the energy intensity of GDP and the carbon intensity of electricity production. Electricity generation by midcentury in the B1 scenario is dominated by nuclear and renewable, with much of the remaining fossil based generation incorporating carbon capture and sequestration.

Table 9.6. Energy consumption, emissions and emission factors for IPCC scenarios

\begin{tabular}{lcccccc}
\hline & $\begin{array}{c}\text { Final } \\
\text { Energy } \\
\text { Electricity }\end{array}$ & $\begin{array}{c}\text { Final } \\
\text { Energy } \\
\text { Other }\end{array}$ & $\begin{array}{c}\mathrm{CO}_{2} \\
\text { Emissions }- \\
\text { Electricity }\end{array}$ & $\begin{array}{c}\mathrm{CO}_{2} \\
\text { Emissions } \\
\text { Other }\end{array}$ & $\begin{array}{c}\text { Emission } \\
\text { Factor }- \\
\text { Electricity }\end{array}$ & $\begin{array}{c}\text { Emission } \\
\text { Factor }- \\
\text { Other }\end{array}$ \\
\hline & {$[\mathrm{EJ}(\mathrm{e})]$} & {$[\mathrm{EJ}(\mathrm{t})]$} & {$\left[\mathrm{Mt} \mathrm{CO}_{2}\right]$} & {$\left[\mathrm{Mt} \mathrm{CO}_{2}\right]$} & {$\left[\mathrm{tCO}_{2} / \mathrm{GJ}(\mathrm{e})\right]$} & {$\left[\mathrm{tCO}_{2} / \mathrm{GJ}(\mathrm{t})\right]$} \\
1990 & 35 & 240 & 1,773 & 5,539 & 0.186 & 0.085 \\
$\begin{array}{l}2050-\mathrm{A} 2 \\
\text { Scenario }\end{array}$ & 184 & 566 & 4,875 & 10,169 & 0.097 & 0.066 \\
$\begin{array}{l}2050-\mathrm{B} 1 \\
\text { Scenario }\end{array}$ & 172 & 432 & 763 & 7,604 & 0.016 & 0.065 \\
\hline
\end{tabular}


Note that the contemporary world average electricity emission factor given in Table 2.2, $0.153 \mathrm{tCO}_{2} / \mathrm{GJ}(\mathrm{e})$, has declined from its 1990 value and is forecast by the IPCC to continue declining through 2050, even under the pessimistic A2 scenario. The 'other' category in Table 9.6 aggregates numerous types of nonelectric end-use energy consumption but is dominated by industrial and transportation applications.

In this study the time evolution of two of the front-end processes was addressed: uranium mining and milling with declining ore grades, and enrichment in the context of a continuation of the Moore's Law behavior. Technological change will lead to declining energy intensities for all surveyed processes, but a simple, conservative estimate of the front end footprint at 2050 may be made by considering changes in the mining/milling and enrichment processes and the electricity emission factor only.

Table 9.7 shows the assumptions input to the 2050 emissions scenario estimates. Low and high forecasts are developed using the emission optimistic and pessimistic electricity emission factors of Table 9.6; the thermal energy emission factors are unchanged from the values of Table 2.2. This assumption is conservative because, as Table 9.6 shows, nonelectric industrial and transportation emission factors are forecast to decline somewhat by midcentury as well.

The uranium mining and grade versus quantity extracted estimates for the 2050 low and high cases are formulated according to the most optimistic and pessimistic of the assumption sets presented in Section 3.6. Uranium requirements were assumed to grow at $3.2 \%$ per year. For the 2050 high case, the enrichment energy intensity was forecast to remain at 2010 levels; to develop the low case, the Moore's Law model presented in Section 5.1 was utilized. All other process energy intensities are assumed to remain unchanged.

Table 9.7. $\quad \mathrm{CO}_{2}$ emission time dependencies, 2050 emissions scenario

\begin{tabular}{|c|c|c|c|}
\hline & \multicolumn{3}{|c|}{ Values Used in Estimates } \\
\hline & Current & 2050 low & 2050 high \\
\hline Electrical grid $\mathrm{CO}_{2}$ emissions, $\mathrm{kg} \mathrm{CO}_{2} / \mathrm{MWh}(\mathrm{e})$ & 0.153 & 0.016 & 0.097 \\
\hline Mining technique: & - & - & - \\
\hline$\%$ Open pit & 23 & 23 & 22 \\
\hline$\%$ Underground & 41 & 41 & 59 \\
\hline$\%$ ISL & 36 & 36 & 19 \\
\hline Open pit mining stripping ratio ${ }^{a}$ & 4 & 4 & 24 \\
\hline $\mathrm{U}$ reserves with grade $>0.06 \%, \mathrm{Mt}$ & NA & 0 & 16 \\
\hline Exponent for Deffeyes crustal model $^{\mathrm{b}}$ & NA & 2.5 & 3.5 \\
\hline Uranium usage, annual \% growth & NA & 1.8 & 3.2 \\
\hline Uranium extraction energy consumption, $\mathrm{GJ}(\mathrm{t}+\mathrm{e}) / \mathrm{tU}$ & 332 & 447 & 1351 \\
\hline Enrichment energy consumption, GJ(e)/SWU & 0.144 & 0.014 & 0.144 \\
\hline \multicolumn{4}{|c|}{$\begin{array}{l}\text { a. Stripping ratio is defined as the mass of overburden divided by the mass of ore. } \\
\text { b. See section } 3.6 \text { for an explanation of Deffeyes crustal model and its use for estimating relative abundance of uranium at a } \\
\text { given ore grade. }\end{array}$} \\
\hline
\end{tabular}

These assumptions give rise to the midcentury emissions scenarios depicted in Tables 9.8 (normalized against electricity production) and 9.9 (normalized against natural uranium). While the carbon footprint associated with uranium extraction nearly triples in the pessimistic scenario, the overall carbon impact remains small relative to alternative large-scale energy technologies. 
Table 9.8. $\quad \mathrm{CO}_{2}$ emissions, 2050 scenarios

\begin{tabular}{lrcc}
\hline & \multicolumn{3}{c}{$\mathrm{kg} \mathrm{CO}_{2} / \mathrm{MWh}(\mathrm{e})$} \\
\cline { 2 - 4 } Mining, milling, and refining & Current & $2050 \mathrm{Low}$ & $2050 \mathrm{High}$ \\
\cline { 2 - 4 } Conversion & 0.78 & 0.35 & 2.17 \\
Enrichment (centrifuge) & 1.45 & 1.30 & 1.39 \\
Fuel Fab (UOX) & 0.41 & 0.01 & 0.26 \\
DU Management & 0.09 & 0.02 & 0.06 \\
Transportation & 0.04 & 0.01 & 0.02 \\
Total & 0.01 & 0.01 & 0.01 \\
& $\mathbf{2 . 8}$ & $\sim \mathbf{1 . 7}$ & $\sim \mathbf{3 . 9}$ \\
\hline
\end{tabular}

Table 9.9. Emissions, 2050 scenarios, normalized to 1 tonne of extracted U

\begin{tabular}{lrrr}
\hline & \multicolumn{3}{c}{$\mathrm{kg} \mathrm{CO}_{2} / \mathrm{tU}$} \\
\cline { 2 - 4 } & \multicolumn{1}{c}{ Current } & $2050 \mathrm{Low}$ & $2050 \mathrm{High}$ \\
\cline { 2 - 4 } Mining, milling, and refining & 38,000 & 16,800 & 104,000 \\
Conversion & 70,000 & 62,300 & 66,700 \\
Enrichment (centrifuge) & 20,000 & 500 & 12,500 \\
Fuel Fab (UOX) & 4,300 & 1,000 & 2,900 \\
DU Management & 1,700 & 500 & 1,000 \\
Transportation & 525 & 500 & 500 \\
Totals & $\mathbf{1 3 0 , 0 0 0}$ & $\sim \mathbf{8 0 , 0 0 0}$ & $\sim \mathbf{1 9 0 , 0 0 0}$ \\
\hline
\end{tabular}

In closing, it is important to reemphasize that several important components of a full life cycle analysis of environmental impacts were outside the scope of this study. While inventories of chemical and other material inputs to the processes were surveyed, only the most significant inputs (in the authors' judgment) were discussed. A complete life cycle analysis would include all process, construction and decommissioning inputs. The energy embodied in these ancillary inputs would also be considered. A full accounting of embodied energy would also extend to land and water use as well as emissions embodied by the process inputs. To avoid omissions and double-counting and to provide a valid basis for comparison with alternative technologies, such an analysis should be carried out within the framework of a model comprehending the full energy sector at the least.

\subsection{References}

[Fthenakis 2009] Fthenakis, V. and H. C. Kim, "Land Use and Electricity Generation: a Life-cycle Analysis," Renewable and Sustainable Energy Reviews 13, 1465-74, 2009.

[Gerbens 2008] D. Gerbens-leenes et al., Water Footprint of Bio-energy and Other Primary Energy Carriers. Value of Water Research Report No. 29. UNESCO, March 2008.

[IPCC 2000] Nakicenovic, N. and R. Swart, Eds., Special Report on Emissions Scenarios, UN Intergovernmental Panel on Climate Change Report, 2000. Available:

http://www.ipcc.ch/ipccreports/sres/emission/index.php?idp=0, webpage accessed August 16, 2010.

[Sovacool 2008] Sovacool, B. K., "Valuing the Greenhouse Gas Emissions from Nuclear Power: a Critical Survey," Energy Policy 36, 2940-53, 2008. 


\section{Appendix A}

\section{Reference Fuel Cycle Mass Balance}




\section{Appendix A}

\section{Reference Fuel Cycle Mass Balance}

In this report, emission factors for the fuel cycle processes are derived per unit of throughput. To normalize them instead against electricity production, conversion factors carrying units of [MWh(e) per throughput unit] must be derived. This in turn requires a mass balance relating the throughput for each front end process to the electricity produced by a reactor. It is important to note that emission results, when expressed as $\left[\mathrm{g} \mathrm{CO}_{2} / \mathrm{MWh}(\mathrm{e})\right]$, are tied to the fuel cycle mass balance. Alteration of parameters that shape the mass balance such as the fuel burnup or enrichment will thus change the front end carbon footprint.

The mass balance employed in this study was built from the reference PWR cycle of the VISION nuclear fuel cycle simulation package developed at Idaho National Laboratory [INL 2007]. This cycle assumes fuel fabrication and reactor operating parameters consistent with contemporary PWRs in the US. Table A.1 lists parameters describing the cycle.

Table A.1 Parameters of the reference fuel cycle

\begin{tabular}{lll}
\multicolumn{1}{c}{ Parameter } & \multicolumn{1}{c}{ Symbol } & \multicolumn{1}{c}{ Value } \\
\hline${ }^{235} \mathrm{U}$ Weight Fraction of Fuel & $\mathrm{x}_{\mathrm{P}}$ & $0.045\left(4.5\right.$ weight percent $\left.{ }^{235} \mathrm{U}\right)$ \\
${ }^{235} \mathrm{U}$ Weight Fraction of Depleted Uranium Tails & $\mathrm{x}_{\mathrm{W}}$ & $0.002\left(0.2\right.$ weight percent $\left.{ }^{235} \mathrm{U}\right)$ \\
Thermal-to-electric efficiency & $\eta$ & $0.33 \mathrm{MWd}(\mathrm{e}) / \mathrm{MWd}(\mathrm{t})$ \\
Fuel burnup & $\mathrm{B}$ & $51 \mathrm{MWd}(\mathrm{t}) / \mathrm{kgIHM}^{\mathrm{bb}}$ \\
\hline
\end{tabular}

Given these parameters, a series of calculations relate mass throughputs for each process to electricity production. Figure A.1 depicts the throughputs normalized against a unit mass of $4.5 \%$ enriched LEU fuel. The calculations leading to this figure are summarized below.

bb. A 'kilogram of initial heavy metal' $[\mathrm{kgIHM}]$ is the standard unit of normalization for burnup. The mass of initial heavy metal is defined as the mass of elements having $Z=90$ or more protons in nuclear fuel at the time it is charged to a reactor. In typical LWR fuel considered here, the IHM is composed solely of U-235 and U-238. In Section 6, where mixed oxide (MOX) fuel is considered, IHM consists also of $\mathrm{Pu}$. 


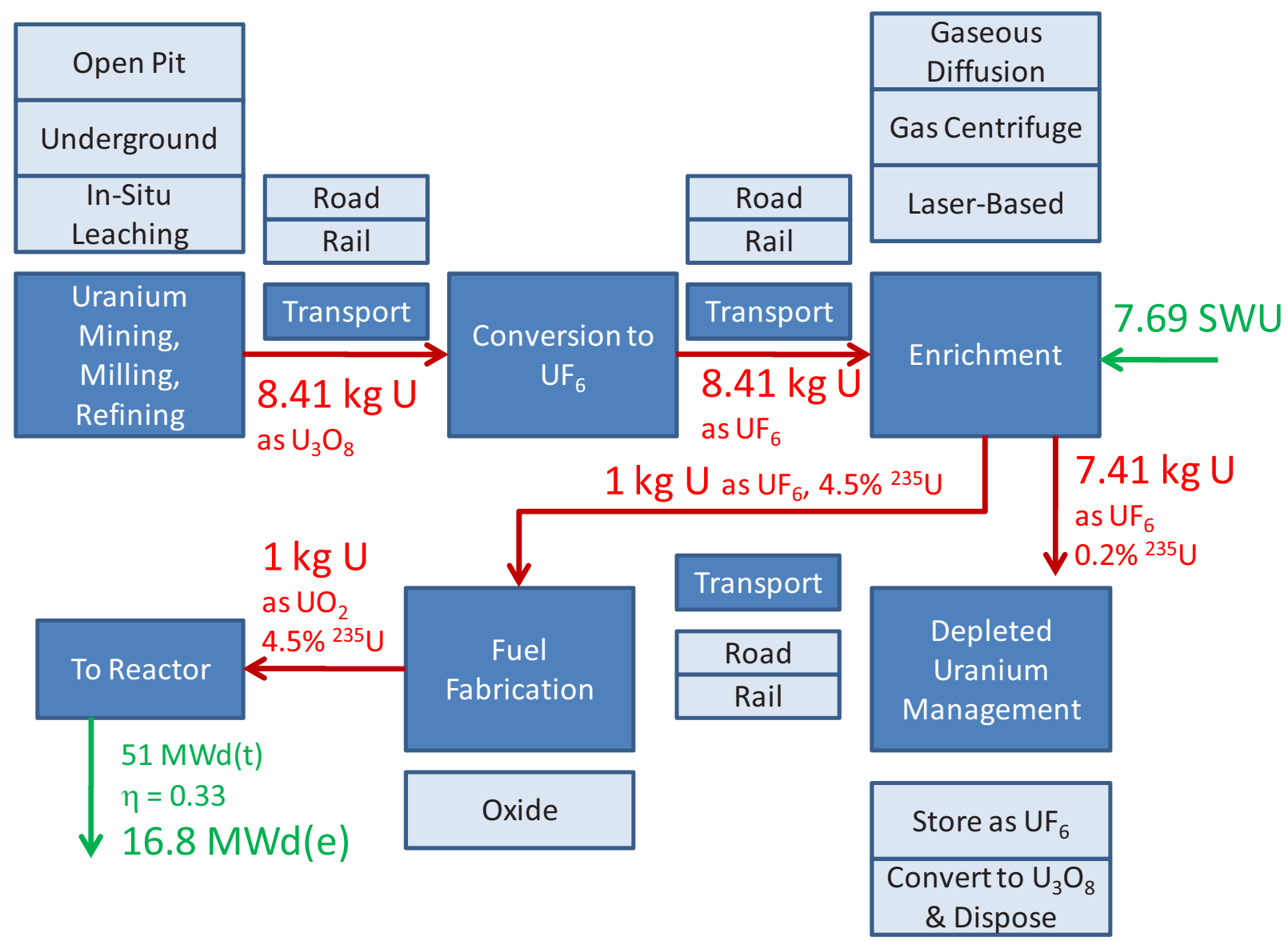

Figure A.1. Mass flows in the front end of the reference fuel cycle

The ${ }^{235} \mathrm{U}$ weight fraction in natural uranium is $\mathrm{x}_{\mathrm{F}}=0.00711$. Define $\mathrm{M}_{\mathrm{F}}, \mathrm{M}_{\mathrm{P}}$ and $\mathrm{M}_{\mathrm{W}}$ as the masses $[\mathrm{kg} \mathrm{U}$ ] of natural uranium feed, enriched uranium product and depleted uranium tails, respectively, at enrichment. Then mass balances on the ${ }^{235} U$ and ${ }^{238} U$ entering and leaving enrichment result in the relationship

$$
M_{F}=M_{P} \frac{x_{P}-x_{W}}{x_{F}-x_{W}} .
$$

Given a product mass $M_{P}=1 \mathrm{~kg} \mathrm{U}$ and the mass fractions in Table A.1, the feed mass of natural uranium is $\mathrm{M}_{\mathrm{F}}=8.41 \mathrm{~kg} \mathrm{U}$. Since $\mathrm{M}_{\mathrm{F}}=\mathrm{M}_{\mathrm{P}}+\mathrm{M}_{\mathrm{W}}, \mathrm{M}_{\mathrm{W}}=7.41 \mathrm{~kg} \mathrm{U}$. The separative work, $\mathrm{M}_{\mathrm{SWU}}$, required to perform this enrichment is given by the relationship [Lamarsh 2001]

$M_{S W U}=M_{F} V_{F}-M_{P} V_{P}-M_{W} V_{W}$

where each value function $\mathrm{V}_{\mathrm{i}}(\mathrm{i}=\mathrm{F}, \mathrm{P}, \mathrm{W})$ is given in terms of the weight fraction $\mathrm{x}_{\mathrm{i}}$ by

$V_{i}=\left(1-2 x_{i}\right) \ln \left(\frac{1-x_{i}}{x_{i}}\right)$.

Evaluating these expressions for the reference cycle, $\mathrm{M}_{\mathrm{SWU}}=7.69 \mathrm{SWU}$ is found. 


\section{A-1. ELECTRICAL OUTPUT PER UNIT MASS OF URANIUM MINED}

In Chapter 3, it is found useful to also express the electrical energy production in units of GJ(e). One kgIHM produces electrical energy eт $_{\mathrm{OT}}[\mathrm{GJ}(\mathrm{e}) / \mathrm{kgIHM}]$ :

$$
e_{O T}=\frac{51 M W d(t)}{k g I H M} \bullet \frac{0.33 J(e)}{J(t)} \bullet \frac{86400 s}{d} \bullet \frac{G J}{10^{3} M J}=1450 \frac{G J(e)}{k g I H M} \text {. }
$$

But $8.41 \mathrm{~kg} \mathrm{U}$ must be mined to produce $1 \mathrm{kgIHM}$ of fuel. So the electrical energy yield per $\mathrm{kg}$ of natural $\mathrm{U}(\mathrm{U})$ mined is $1450 / 8.41=172 \mathrm{GJ}(\mathrm{e}) / \mathrm{kgU}$. In Chapter 3, ten percent of this electrical yield, i.e., 17.2 $\mathrm{GJ}(\mathrm{e}) / \mathrm{kgU}$, is plotted against mine/mill energy consumption data to provide a point of reference.

Several advanced fuel cycles under development have the potential to substantially improve the uranium utilization. For example, under a fully closed breeding cycle every atom of mined uranium is ultimately fissioned (minus minor losses neglected here). Full burnup of a kilogram of $U$ yields about $940 \mathrm{MWd}$ of thermal energy [Lamarsh 2001], so in this case assuming a thermal efficiency of 0.4 - typical of a sodium-cooled fast reactor - the electrical energy $\mathrm{e}_{\text {closed }}$ produced by $1 \mathrm{~kg} \mathrm{U}$ would be

$$
e_{\text {closed }}=\frac{940 \mathrm{MWd}(t)}{\mathrm{kgNU}} \bullet \frac{0.4 J(e)}{J(t)} \bullet \frac{86400 \mathrm{~s}}{d} \cdot \frac{\mathrm{GJ}}{10^{3} \mathrm{MJ}}=32,500 \frac{\mathrm{GJ}(e)}{\mathrm{kgNU}} \text {. }
$$

Hence the fully closed cycle produces over two orders of magnitude more energy per kilogram of mined uranium than the reference once-through cycle: $32,500 \mathrm{GJ}(\mathrm{e}) / \mathrm{kg} \mathrm{U}$ versus $172 \mathrm{GJ}(\mathrm{e}) / \mathrm{kg} \mathrm{U}$.

\section{A-2. REFERENCES}

[INL 2007] Idaho National Laboratory, "User Guide - VISION (Verifiable Fuel Cycle Simulation) Model, v1.5 edition", technical report, 2007.

[Lamarsh 2001] Lamarsh, J. and A. Baratta, Introduction to Nuclear Engineering, ${ }^{\text {rd }}$ Ed., Prentice \& Hall, 2001. 


\section{Appendix B}

\section{Complete Listing of Uranium Mine and Mill Data}




\section{Appendix B}

\section{Complete Listing of Uranium Mine and Mill Data}

Table B.1. Data for Rossing (Open Pit)

\begin{tabular}{|c|c|c|c|c|c|c|c|}
\hline Year & U308 (t) & Ore Milled (kt) & $\begin{array}{c}\text { Ore Grade } \\
(\mathrm{ppm} U)\end{array}$ & $\begin{array}{c}\text { Overburden } \\
\text { (kt) }\end{array}$ & \begin{tabular}{|c|} 
Energy Consumed \\
$(\mathrm{TJ}(\mathrm{t}+\mathrm{e}))$
\end{tabular} & $\begin{array}{c}\text { CO2 Emissions } \\
(\mathrm{kt} \mathrm{CO} 2)\end{array}$ & $\begin{array}{c}\text { Water consumption } \\
(\mathrm{ML})\end{array}$ \\
\hline 1999 & 3171 & 10463 & 357 & 15607 & 1248 & 171.6 & 2779 \\
\hline 2000 & 3200 & 11039 & 341 & 9787 & 1133 & 162.9 & 2312 \\
\hline 2001 & 2643 & 9084 & 342 & 12033 & 979 & 139.7 & 2053 \\
\hline 2002 & 2752 & 8969 & 361 & 13015 & 999 & 139.9 & 2175 \\
\hline 2003 & 2374 & 8347 & 335 & 10434 & 915 & 127.5 & 2486 \\
\hline 2004 & 3582 & 10972 & 384 & 8139 & 1096 & 155.7 & 3003 \\
\hline 2005 & 3711 & 12027 & 363 & 7483 & 1152 & 161 & 3170 \\
\hline 2006 & 3617 & 12008 & 354 & 16835 & 1366 & 181.2 & 3315 \\
\hline 2007 & 3046 & 12613 & 284 & 21396 & 1534 & 197 & 3300 \\
\hline 2008 & 4108 & 12858 & 376 & 33899 & 1812 & 222.6 & 3700 \\
\hline
\end{tabular}

Source:

Annual Report to Stakeholders, Rössing Uranium Ltd, Years 1999 to 2009, Swakopmund, Namibia, available: www.rossing.com, webpage accessed January 5, 2010.

Table B.2. Data for Ranger (Open Pit)

\begin{tabular}{|c|c|c|c|c|c|c|c|}
\hline Year & $\mathrm{U} 308(\mathrm{t})$ & Ore Milled (kt) & $\begin{array}{l}\text { Ore Grade } \\
\text { (ppm U) }\end{array}$ & $\begin{array}{c}\text { Overburden } \\
\text { (kt) }\end{array}$ & $\begin{array}{c}\text { Energy Consumed } \\
(\mathrm{TJ}(\mathrm{t}+\mathrm{e}))\end{array}$ & $\begin{array}{c}\mathrm{CO} 2 \text { Emissions } \\
(\mathrm{kt} \mathrm{CO} 2)\end{array}$ & $\begin{array}{c}\text { Water consumption } \\
(\mathrm{ML})\end{array}$ \\
\hline 1997 & 4162 & & & 5871 & 749 & & \\
\hline 1998 & & & & 5343 & 906 & & 210 \\
\hline 1999 & 4375 & 1827 & 2700 & 4524 & 808 & 62.1 & 219 \\
\hline 2000 & 4244 & 1550 & 3000 & 5835 & 922 & & \\
\hline 2001 & 6564 & 1510 & 2900 & 3485 & 916 & 63.0 & 191 \\
\hline 2002 & 4470 & 1784 & 2800 & 2819 & 810 & 55.0 & 227 \\
\hline 2003 & 5065 & 2068 & 2800 & 4249 & 873 & 59.3 & 149 \\
\hline 2004 & 5137 & 2086 & 2800 & 8500 & 1064 & 72.4 & 430 \\
\hline 2005 & 5910 & 2293 & 2900 & 14910 & 902 & 77.4 & 181 \\
\hline 2006 & 4748 & 2072 & 2600 & 9900 & 1205 & 82.1 & 477 \\
\hline 2007 & 5412 & 2900 & 3100 & & 1223 & 83.3 & 650 \\
\hline 2008 & 5339 & 3500 & 3000 & & 1457 & 154.8 & \\
\hline
\end{tabular}

Sources:

Mudd, G.M., The Sustainability of Mining in Australia: Key Production Trends and Their Environmental Implications for the Future, Research Report No RR5, Department of Civil Engineering, Monash University and Mineral Policy Institute, October 2007.

Annual Social and Environment Report, Energy Resources of Australia Ltd (ERA), Years 2001 to 2008, Sydney, NSW, available: www.energyres.com.au, webpage accessed January 2, 2010. 
Table B.3. Data for Olympic Dam (Underground)

\begin{tabular}{|c|c|c|c|c|c|c|c|}
\hline Year & U3O8 (t) & Ore Milled $(\mathrm{kt})$ & $\begin{array}{c}\text { Ore Grade } \\
(\mathrm{ppm} U)\end{array}$ & $\begin{array}{c}\text { Overburden } \\
(\mathrm{kt})\end{array}$ & $\begin{array}{c}\text { Energy Consumed } \\
(\mathrm{TJ}(\mathrm{t}+\mathrm{e}))\end{array}$ & $\begin{array}{c}\text { CO2 Emissions } \\
(\mathrm{kt} \mathrm{CO2})\end{array}$ & $\begin{array}{c}\text { Water consumption } \\
(\mathrm{ML})\end{array}$ \\
\hline 1998 & 1740 & 681 & 790 & 54 & 604 & 99 & 1094 \\
\hline 1999 & 3198 & 1349 & 890 & 108 & 924 & 167 & 1732 \\
\hline 2000 & 4500 & 1780 & 740 & 142 & 1037 & 190 & 2112 \\
\hline 2001 & 4355 & 1867 & 720 & 149 & 1043 & 217 & 2070 \\
\hline 2002 & 2881 & 1775 & 690 & 142 & 976 & 215 & 2146 \\
\hline 2003 & 3176 & 1677 & 630 & 134 & 933 & 209 & 2094 \\
\hline 2004 & 4370 & 1777 & 640 & 142 & 1089 & 204 & 2380 \\
\hline 2005 & 4362 & 1929 & 620 & 154 & & & \\
\hline 2006 & & 1817 & 570 & 145 & & & \\
\hline
\end{tabular}

Source:

Mudd, G.M., The Sustainability of Mining in Australia: Key Production Trends and Their Environmental Implications for the Future, Research Report No RR5, Department of Civil Engineering, Monash University and Mineral Policy Institute, October 2007.

Table B.4. Data for Beverley (ISL)

\begin{tabular}{|c|c|c|c|c|c|c|c|}
\hline Year & U308 (t) & Ore Milled (kt) & $\begin{array}{l}\text { Ore Grade } \\
(\mathrm{ppm} \mathrm{U})^{* *}\end{array}$ & $\begin{array}{c}\text { Overburden } \\
\text { (kt) }\end{array}$ & $\begin{array}{c}\text { Energy Consumed } \\
(\mathrm{TJ}(\mathrm{t}+\mathrm{e}))\end{array}$ & $\begin{array}{c}\text { CO2 Emissions } \\
(\mathrm{kt} \mathrm{CO} 2)\end{array}$ & $\begin{array}{c}\text { Water consumption } \\
(\mathrm{ML})\end{array}$ \\
\hline 1999 & & N/A & 1500 & N/A & & & 3661 \\
\hline 2000 & & N/A & 1500 & N/A & & & 5726 \\
\hline 2001 & 546 & N/A & 1500 & N/A & & & 5878 \\
\hline 2002 & 746 & N/A & 1500 & N/A & & & 7904 \\
\hline 2003 & 717 & N/A & 1500 & N/A & 86 & 5.9 & 8581 \\
\hline 2004 & 1084 & N/A & 1500 & N/A & 84 & 8.7 & 8733 \\
\hline 2005 & 977 & N/A & 1500 & N/A & 114 & 10.6 & 7776 \\
\hline 2006 & 825 & N/A & 1500 & N/A & 151 & 11.8 & \\
\hline 2007 & 748 & N/A & 1500 & N/A & 157 & 11.2 & \\
\hline
\end{tabular}

** average ore grade of the formation.

Source:

Mudd, G.M., M. Diesendorf, "Sustainability Aspects of Uranium Mining: Toward Accurate Accounting?" 2nd International Conference on Sustainability Engineering \& Science, Auckland, New Zealand, 20- 23 February 2007. 
Table B.5. Data for McLean Lake (Open Pit)

\begin{tabular}{|c|c|c|c|c|c|c|c|}
\hline Year & U3O8 $(\mathrm{t})$ & Ore Milled (kt) & $\begin{array}{c}\text { Ore Grade } \\
(\mathrm{ppm} \mathrm{U})\end{array}$ & $\begin{array}{c}\text { Overburden } \\
(\mathrm{kt})\end{array}$ & $\begin{array}{c}\text { Energy Consumed } \\
(\mathrm{TJ}(\mathrm{t}+\mathrm{e}))\end{array}$ & $\begin{array}{c}\text { CO2 Emissions } \\
(\mathrm{kt} \mathrm{CO} 2)\end{array}$ & $\begin{array}{c}\text { Water consumption } \\
(\mathrm{ML})\end{array}$ \\
\hline 2002 & $\mathbf{2 7 6 1}$ & $\mathbf{1 2 2}$ & $\mathbf{2 2 9 0 0}$ & $\mathbf{2 4 4 0}$ & $\mathbf{5 9 4}$ & $\mathbf{2 2 . 1}$ & $\mathbf{5 7 5}$ \\
\hline 2003 & $\mathbf{2 7 3 3}$ & 132 & $\mathbf{2 0 7 0 0}$ & $\mathbf{2 6 4 9}$ & $\mathbf{4 3 7}$ & $\mathbf{1 9 . 1}$ & $\mathbf{5 8 5}$ \\
\hline 2004 & $\mathbf{2 6 8 1}$ & 148 & $\mathbf{1 8 6 0 0}$ & $\mathbf{2 9 5 6}$ & $\mathbf{4 5 6}$ & $\mathbf{1 6 . 1}$ & $\mathbf{7 0 5}$ \\
\hline 2005 & $\mathbf{2 4 5 1}$ & 173 & $\mathbf{1 4 5 0 0}$ & $\mathbf{3 4 6 7}$ & $\mathbf{5 8 8}$ & $\mathbf{1 9 . 6}$ & $\mathbf{8 4 0}$ \\
\hline 2006 & $\mathbf{8 1 4}$ & 131 & $\mathbf{6 8 0 0}$ & $\mathbf{2 6 1 0}$ & & & \\
\hline 2007 & $\mathbf{8 6 4}$ & 170 & $\mathbf{5 3 0 0}$ & $\mathbf{3 4 0 2}$ & & & \\
\hline
\end{tabular}

Source:

Mudd, G.M., M. Diesendorf, "Sustainability Aspects of Uranium Mining: Toward Accurate Accounting?" 2nd International Conference on Sustainability Engineering \& Science, Auckland, New Zealand, 20- 23 February 2007.

Table B.6. Data for other mines

\begin{tabular}{|c|c|c|c|c|c|c|c|}
\hline Year & $\mathrm{U} 308(\mathrm{t})$ & Ore Milled (kt) & $\begin{array}{l}\text { Ore Grade } \\
\text { (ppm U) }\end{array}$ & $\begin{array}{c}\text { Overburden } \\
\text { (kt) }\end{array}$ & $\begin{array}{c}\text { Energy Consumed } \\
(\mathrm{TJ}(\mathrm{t}+\mathrm{e}))\end{array}$ & $\begin{array}{c}\text { CO2 Emissions } \\
(\mathrm{kt} \mathrm{CO} 2)\end{array}$ & $\begin{array}{c}\text { Water consumption } \\
\text { (ML) }\end{array}$ \\
\hline \multicolumn{8}{|c|}{ McArthur River (Mining Only) (Underground) } \\
\hline 2007 & & 44 & 190000 & 51 & 586 & 81.9 & 123 \\
\hline \multicolumn{8}{|c|}{ Key Lake (Milling and Refining Only) } \\
\hline 2006 & 8462 & 219 & 39100 & & & & \\
\hline 2007 & 8483 & 212 & 40700 & & 734 & 89 & 10469 \\
\hline \multicolumn{8}{|c|}{ Rabbit Lake / Eagle Point (Underground) } \\
\hline 2006 & 2359 & 313 & 7800 & 360 & 787 & 105 & \\
\hline 2007 & 1825 & 273 & 6900 & 314 & 686 & 92 & 4172 \\
\hline \multicolumn{8}{|c|}{ Cluff Lake (Open Pit) } \\
\hline 2002 & 1917 & 72 & 27000 & & & 23 & 700 \\
\hline
\end{tabular}

Source:

Mudd, G.M., M. Diesendorf, "Sustainability Aspects of Uranium Mining: Toward Accurate Accounting?" 2nd International Conference on Sustainability Engineering \& Science, Auckland, New Zealand, 20- 23 February 2007. 


\section{Appendix C}

\section{Review of Energy Intensity Models for Uranium Mining, Milling and Refining}




\section{Appendix C}

\section{Review of Energy Intensity Models for Uranium Mining, Milling and Refining}

Most of the energy intensity and carbon footprint estimates for uranium extraction reviewed in Section 3 are point estimates that focus only upon contemporary mining practices. Only a handful of investigators have undertaken to relate significant mine and mill operational parameters like ore grade and stripping ratio to energy consumption in a general way. This appendix reviews their findings.

The first effort to correlate grade and other top-level deposit and mill characteristics to energy consumption was undertaken by Chapman in 1975 [Chapman 1975]. Following a practice that had been applied to model energy consumption associated with production of other metals, Chapman's formulation of the energy required to produce a ton of refined product incorporated contributions from the mining, milling and product refining steps.

It is useful to here include a table (Table C.1) of all symbols that will be used in presenting the energy intensity models reviewed in this appendix.

Table C.1. Quantities used in models reviewed in this appendix

\begin{tabular}{|c|c|c|}
\hline Symbol & Unit & Description \\
\hline $\mathrm{e}$ & $(\mathrm{GJ}(\mathrm{e})+\mathrm{GJ}(\mathrm{t})) / \mathrm{tU}$ & Energy required to produce 1 tonne of refined $\mathrm{U}\left(\right.$ as $\mathrm{U}_{3} \mathrm{O}_{8}$ ) \\
\hline $\mathrm{e}_{\operatorname{mine}}$ & $\begin{array}{l}(\mathrm{GJ}(\mathrm{e})+\mathrm{GJ}(\mathrm{t})) /(\text { tonne of } \\
\text { ore }+ \text { overburden })\end{array}$ & Energy required to mine one tonne of material \\
\hline $\mathrm{e}_{\text {mill }}$ & $\begin{array}{l}(\mathrm{GJ}(\mathrm{e})+\mathrm{GJ}(\mathrm{t})) /(\text { tonne of } \\
\text { ore })\end{array}$ & Energy required to mill one tonne of ore \\
\hline $\mathrm{e}_{\text {refine }}$ & $(\mathrm{GJ}(\mathrm{e})+\mathrm{GJ}(\mathrm{t})) / \mathrm{tU}$ & $\begin{array}{l}\text { [Chapman 1975] interpretation: "energy required to convert } \\
\text { beneficiated ore to required material" }\end{array}$ \\
\hline$e_{u}$ & $(\mathrm{GJ}(\mathrm{e})+\mathrm{GJ}(\mathrm{t})) / \mathrm{tU}$ & $\begin{array}{l}\text { [Prasser 2008] and current document interpretation: As } \\
\text { [Chapman 1975] above, plus other energy inputs not directly } \\
\text { proportional to the masses of mined material or ore }\end{array}$ \\
\hline G & $\% \mathrm{U}_{3} \mathrm{O}_{8}$ & Ore grade \\
\hline S & $\mathrm{kg}$ overburden/kg ore & Stripping ratio \\
\hline Y & $\begin{array}{l}\mathrm{kg} \mathrm{U} \text { in mill output / } \mathrm{kg} \mathrm{U} \\
\text { in mill input }\end{array}$ & Ore milling yield \\
\hline
\end{tabular}

Chapman's formulation was as follows:

$$
e=\frac{100}{0.848 G}\left(e_{\text {mill }}+(1+S) e_{\text {mine }}\right) \text {. }
$$

The three terms in this model each represent one step in the process depicted in Figure 3.1. The quantity $(1+\mathrm{S}) / \mathrm{G}$ is the mass of ore and overburden extracted per mass of uranium in the ore. Therefore, $(1+\mathrm{S}) \mathrm{e}_{\min } / \mathrm{G}$ is the energy required to extract ore plus overburden containing one tonne of millable 
uranium from the mine. Similarly, $\mathrm{e}_{\text {mill }} / \mathrm{G}$ is the energy required to mill ore containing one tonne of uranium. The factor 0.848 converts tonne $\mathrm{U}_{3} \mathrm{O}_{8}$ to tonne $\mathrm{U}$.

In his 1975 paper, Chapman also included a term $\mathrm{e}_{\text {refine, }}$, representing the energy needed to produce and purify yellowcake from milling product containing 1 tonne of uranium, but he did not estimate its value nor did he include it in his final formulation of the energy intensity of uranium production. In view of Equation C.1, then, Chapman is assuming that the energy cost of uranium production always exhibits a strictly inverse relationship with the ore grade.

Chapman used two data points to calibrate his model and obtain values for the coefficients $\mathrm{e}_{\text {mill }}$ and $\mathrm{e}_{\text {mine. }}$. The first was a compilation of energy consumed by four mines operating in Wyoming in the early 1960s [Everett 1963]. These mines featured an average ore grade of $0.31 \% \mathrm{U}_{3} \mathrm{O}_{8}$ and stripping ratio of 24; Chapman weighted them according to the estimated reserves embodied by each mine to arrive at his data point: $1210 \mathrm{MJ}(\mathrm{t})$ per tonne of ore for mining and $99 \mathrm{MJ}(\mathrm{e})+828 \mathrm{MJ}(\mathrm{t})$ per tonne of ore for milling. Following [Everett 1963], Chapman included embodied energy from some of the constituents used in the mining and milling processes: chemical and water consumption as well as machinery and plant establishment are mentioned.

The second data point was taken from a 1971 study of the energy required to extract uranium from Chattanooga shale grading $0.007 \% \mathrm{U}_{3} \mathrm{O}_{8}$ [Bieniewski 1971] using underground mining. Assuming a stripping ratio of zero as the ore body was the entire shale formation, Chapman found that the energy inputs to mining from this formation were $32,700 \mathrm{MJ}(\mathrm{e})$ and $36,100 \mathrm{MJ}(\mathrm{t})$ per tonne of ore for mining (with no overburden) and 77,500 $\mathrm{MJ}(\mathrm{e})$ and 219,500 $\mathrm{MJ}(\mathrm{t})$ per tonne of ore for milling. $20 \%$ of the thermal energy input to milling was embodied energy, mostly attributed to sulfuric acid and sodium carbonate. Embodied energy accounted for $37 \%$ of the energy consumed in underground mining, mostly in the form of machine parts and explosives.

Setting a precedent for a practice that has been followed by subsequent investigators, Chapman aggregated the electrical and thermal energy consumed to derive his model coefficients. There is some physical justification for this. The thermal-to-electric conversion efficiencies of the facilities that generated the electricity are impossible to identify, and a degree of energy carrier switching (i.e. from electric to thermal) may occur for many processes between mines or (over time) within a mine. The effect of such switching on aggregate energy consumption would have nothing to do with the conversion efficiency of the plant that generated the electricity.

Then he evidently allowed himself a bit of license: although the energy intensities given above, taken from his paper, lead to aggregated extraction energy intensities of $0.81 \mathrm{TJ}(\mathrm{t}+\mathrm{e}) / \mathrm{tU}$ for the four US mines with $\mathrm{S}=24$ and $30.2 \mathrm{TJ}(\mathrm{t}+\mathrm{e}) / \mathrm{tU}$ for the hypothetical shale project with $\mathrm{S}=0$, he performed his fit using intensities of 1.0 and $20.0 \mathrm{TJ}(\mathrm{t}+\mathrm{e}) / \mathrm{tU}$ for the two mines when deriving his model. It is unclear why Chapman chose to do this ${ }^{\mathrm{cc}}$, but in this review the latter numbers will be used as well (following Figure 3 in [Chapman 1975]). The fit is in fact just an algebraic solution of two instances of equation C. 1 for the coefficients $\mathrm{e}_{\text {mine }}$ and $\mathrm{e}_{\text {mill, }}$, for Chapman had only the two data points available.

In any case, the coefficients he found are given in Table C.2. At the time Chapman wrote, ISL technology had not emerged as a major uranium production technique. Likewise, Chapman did not differentiate between surface and underground mining; such an effort would have been impossible given the limited

cc. An educated guess as to why Chapman modified the numbers: if the first set of values were used, the coefficients would become $\mathrm{e}_{\text {mine }}=0.017 \mathrm{GJ} / \mathrm{t}$ and $\mathrm{e}_{\text {mill }}=2.10 \mathrm{GJ} / \mathrm{t}$, so that the energy intensity of the mining step would have been more than a factor of four lower than the values Chapman published. This would have led to a greatly reduced, in fact near-negligible, dependence of the energy intensity on mining regardless of stripping ratio, and it seems Chapman may have felt this result to be non-physical. (Indeed, employing this 'version' of the model on the Chattanooga shale indeed gives the correct total energy consumption, as it must, but the mining-to-milling energy split it predicts becomes $0.7 \%$ mining, $99.3 \%$ milling!) 
data available at the time. Using the fuel cycle model employed in [Chapman 1975], the mined uranium would give rise to the production of $108 \mathrm{TJ}(\mathrm{e}) / \mathrm{tU}$ (compare against a contemporary value of $172 \mathrm{TJ}(\mathrm{e}) / \mathrm{tU}$ derived in Appendix A). Setting the extraction energy e in Equation C.1 equal to this electrical output and $\mathrm{S}=0$, Chapman arrived at his often-cited estimate, that the energy input to mining and milling alone would rise to equal the electrical output of the uranium product at around $\mathrm{G}=0.002 \%$ (viz. the trend in Figure C.1 at the end of the section).

Table C.2. Coefficients of Chapman model (equation C.1)

\begin{tabular}{|l|l|}
\hline $\mathrm{e}_{\text {mine }}$ & $0.071 \mathrm{GJ}(\mathrm{t}+\mathrm{e}) /$ tonne ore + overburden \\
\hline $\mathrm{e}_{\text {mill }}$ & $1.329 \mathrm{GJ}(\mathrm{t}+\mathrm{e}) /$ tonne ore \\
\hline
\end{tabular}

Thermal-to-electric breakdowns for the coefficients themselves are not estimated. Chapman concludes his discussion with the observation, "clearly a lot more data on different uranium mines, with different ore grades, different rock hardness etc is needed to substantiate this estimate."

Kellogg (as reported in [Rosa 2008]) in 1977 proposed two refinements to the original Chapman model for metal extraction. First, he incorporated a yield function, Y. Ranging between 0 and 1, Y describes the product recovery efficiency in the milling and refining processes. Second, he suggested that the mining energy intensity $\mathrm{e}_{\text {mine }}$ must be explicitly dependent upon the mining approach (e.g. underground versus surface), and the milling intensity $\mathrm{e}_{\text {mill }}$ must depend on the physical and chemical properties of the ore and process (hardness, choice of leaching agent). This would give rise to a set of $\mathrm{e}_{\operatorname{mine}}$ and $\mathrm{e}_{\text {mill }}$ coefficients corresponding to each possibility. In practice, it is difficult to implement when operating data is limited. It can be difficult to use in a predictive capacity as it requires additional forecasting of the mining strategies, ores to be milled, and processes to be used to mill them. Nonetheless, data found for this study indicates that differences between mining methods cannot be neglected and, in this study, they are taken into account via three distinct $\mathrm{e}_{\text {mine }}$ coefficients.

Chapman subsequently [Chapman 1983] took another step to refine his methodology, which he had originally developed to analyze the energy intensity of copper extraction where far more data was available. The formulation that appeared in [Chapman 1983] was

$$
e=\frac{e_{0}}{G \eta_{1}}+\frac{\Delta G i b b s}{\eta_{2}}
$$

Here $e_{o} / G[G J(t+e) / t U]$ is the theoretical minimum energy required for mining and milling and $\eta_{1}$ is the efficiency of energy use in the mining and milling processes. $\Delta \mathrm{Gibbs}(\mathrm{GJ}(\mathrm{t}) / \mathrm{tU})$ is the change in the Gibbs free energy from converting the mill concentrate to the final product, and $\eta_{2}$ is the efficiency of energy use in this refining process. Hence the refining step that leads to yellowcake production is for the first time explicitly accounted for. But the formulation (C.2) is not amenable to the top-down approach (i.e. fitting to observed mine data) used in this study since $\mathrm{e}_{\mathrm{o}}$ is a theoretical minimum value obtained via bottom-up simulations of model mines. An example of such a bottom-up simulation for a generic metal mine is discussed in Section 3 in the context of possible future efficiency improvements. No recent bottom-up simulations of uranium mines were found in the literature.

Interest in uranium extraction declined through the 1980s and 1990s and there follows a dormant period in the literature. Not until the 2000s did a new forecast appear, and its reliance upon 1970s-era studies, including some used by Chapman, is presumably due to the lack of contemporary data. The forecasters, Storm van Leeuwen and Smith (hereafter referred to as SLS) [Storm van Leeuwen 2005] modified Eq. (C.1) slightly to follow some of the recommendations made by Kellogg. The SLS model is 


$$
e=\frac{100}{0.848} \frac{e_{\min e}+e_{\text {mill }}(o)}{G Y}
$$

Although they did not differentiate between mining strategies, SLS incorporated an explicit dependence of the milling energy intensity upon ore hardness. Thus $e_{\text {mill }}(\mathrm{o})$ takes on distinct values for soft $(\mathrm{o}=\mathrm{soft})$ and hard $(\mathrm{o}=$ hard) ores in the SLS model. Note that the stripping ratio does not appear in Equation C.3; while SLS acknowledge the importance of S in their article, evidently it is only accounted for indirectly through an assumed (but not specified) industry-average stripping ratio embedded within $\mathrm{e}_{\text {mine. }}$. Thus in the SLS model $\mathrm{e}_{\text {mine }}$ applies to the mass of ore rather than the mass of ore and overburden and is unable to account for the varying effects of the stripping ratio on energy consumption

Taking values from studies published in 1973, 1975 and 1976, SLS present the coefficients given in Table C.3. It is not clear to what extent embodied energy is incorporated in these coefficients, although SLS compare their results against a bottom-up energy intensity estimate that they formulated for the Ranger mine. Their estimate includes embodied energy.

Table C.3. Model coefficients for Equation C.3

\begin{tabular}{lcc} 
Coefficient & \multicolumn{1}{c}{ Value \& Units } & \multicolumn{1}{c}{ Thermal-to-electric breakdown } \\
\hline $\mathrm{e}_{\text {mine }}$ & $1.06 \mathrm{GJ}(\mathrm{t}+\mathrm{e}) /$ tonne ore & \\
& & $89 \%(\mathrm{t}), 11 \%(\mathrm{e})$ \\
$\mathrm{e}_{\text {mill }}($ soft $)$ & $1.27 \mathrm{GJ}(\mathrm{t}+\mathrm{e}) /$ tonne ore & $88 \%(\mathrm{t}), 12 \%(\mathrm{e})$ \\
$\mathrm{e}_{\text {mill }}($ hard $)$ & $4.49 \mathrm{GJ}(\mathrm{t}+\mathrm{e}) /$ tonne ore & $9 \%(\mathrm{t}), 91 \%(\mathrm{e})$ \\
\hline
\end{tabular}

SLS proceed to compare their model forecast versus that of the bottom-up estimate and claim good agreement. However, the authors evidently did not verify their process model against operating data from Ranger itself, as their bottom up estimate predicts almost double the direct energy consumption - 355 $\mathrm{GJ}(\mathrm{t}+\mathrm{e}) /$ tonne $\mathrm{U}_{3} \mathrm{O}_{8}$ - as the direct consumption, $191 \mathrm{GJ}(\mathrm{t}+\mathrm{e}) /$ tonne $\mathrm{U}_{3} \mathrm{O}_{8}$, actually reported at Ranger over the same time period, 2005-06 [Mudd 2008]. Further, SLS estimates embodied energy in chemicals and equipment fabrication to be greater than direct energy, on a per unit product basis. This estimate is difficult to verify in the absence of a consistent approach to embodied energy assessment. Further, this lack of transparency and consistency arises when the SLS results are used to compare the life cycle emissions to those arising from competing energy sources such as combustion ofnatural gas, as has been done in the recent literature [Jacobson 2009].

Moreover, Equation C.3 overpredicts energy consumption by a factor of ten or more when compared to available data from mines operating at lower ore grades (Olympic Dam, Rossing, Beverley). Indeed, Storm van Leewen's model predicts that the Rossing mine $\left(\mathrm{G}=0.03 \% \mathrm{U}_{3} \mathrm{O}_{8}\right)$ should consume twenty to fifty times more energy than was actually reported, depending on whether soft or hard ore is assumed. Even allowing for embodied energy, large disagreement from operational data is evident.

Since the late 1990s, mine-reported direct energy consumption data has begun to appear in stakeholder reports and environmental assessments. Investigating this data, which spans mines operating on ores spanning four orders of magnitude in grade, Prasser [Prasser 2008] observed that the strictly inverse grade-to-energy correlation does not hold. Indeed, energy consumed per unit product differed between the lowest- and highest-consuming mines by only a factor of around five.

dd. Note that SLS mislabel the units of these coefficients as "energy/mass of U" in their article. 
Therefore, Prasser made an important change to the Chapman-type model: he explicitly included a term that was independent of the ore grade. Conceptually, Prasser attached this term to the refining step of the uranium production process; he advanced the claim that it reflected those steps in yellowcake production (concentration, elution, precipitation, drying) where the process mass flows were proportional to the mass of uranium product, not the mass of ore. Prasser's model takes the form

$e=\frac{100}{G Y}\left((1+S) e_{\min e}+e_{\text {mill }}\right)+e_{\text {refine }}$,

i.e. the Chapman model with the SLS yield function incorporated and refining term added (Prasser folds the U-to- $\mathrm{U}_{3} \mathrm{O}_{8}$ conversion into his coefficients). Prasser uses direct energy consumption data, ore grade and stripping ratio reported by the Rossing mine over 1999-2006 to perform a regression analysis that yields the coefficient values displayed in Table C.4.

Table C.4. Regression coefficients reported in [Prasser 2008]

\begin{tabular}{lll}
\multicolumn{1}{c}{ Coefficient } & \multicolumn{1}{c}{ Value } & \multicolumn{1}{c}{ Statistical Uncertainty (1 Std. Dev.) } \\
\hline $\mathrm{e}_{\text {mine }}$ & $0.023 \mathrm{GJ}(\mathrm{t}+\mathrm{e}) / \mathrm{t}$ ore + overburden & $+/-0.04 \mathrm{GJ}(\mathrm{t}+\mathrm{e}) / \mathrm{t}$ \\
$\mathrm{e}_{\text {mill }}$ & $0.045 \mathrm{GJ}(\mathrm{t}+\mathrm{e}) / \mathrm{t}$ ore & $+/-0.33 \mathrm{GJ}(\mathrm{t}+\mathrm{e}) / \mathrm{t}$ \\
$\mathrm{e}_{\text {refine }}$ & $52 \mathrm{GJ}(\mathrm{t}+\mathrm{e}) / \mathrm{tU}$ & $+/-123 \mathrm{GJ}(\mathrm{t}+\mathrm{e}) / \mathrm{t}$ \\
\hline
\end{tabular}

Since Prasser used data from only one mine, Rossing, to derive the coefficients, the statistical quality of his regression was not high: the uranium refining coefficient $e_{u}$, for example, had a value of $52 \mathrm{GJ}(\mathrm{t}+\mathrm{e}) / \mathrm{t}$ but a standard deviation of $123 \mathrm{GJ}(\mathrm{t}+\mathrm{e}) / \mathrm{t}$, meaning that the null hypothesis - overall energy consumption exhibits no dependence on uranium refining - cannot be rejected. At high ore grades where ore haulage and processing are associated with low mass throughput, uranium refining would be expected to become a stronger contributor to energy consumption, but since Prasser only utilizes data from a low ore grade mine his model cannot isolate the consumption associated with various portions of the production chain. Moreover, the statistical quality of the fit is also poor because the variations in the stripping ratio and ore grade at this single mine were small over the time period reported. ${ }^{\text {ee }}$ Therefore, each additional annual data point could be thought of as adding little new information to the model. A superior correlation would be obtained if the model were informed by a wider range of stripping ratios and grades.

Comparing his results to energy consumption data from the Beverley mine, Prasser noted that his model shows good agreement with in situ leach technique energy consumption where fluid pumping replaces overburden haulage as an energy consumer if the stripping ratio is taken to be zero (i.e. there is no overburden). Although Prasser does not formally distinguish between mining strategies in his model, this argument is sensible in that the product to be milled at an ISL mine is the pregnant leach liquor, the equivalent of the fluid obtained following the grinding, suspension and separation processes in conventional milling. On the other hand, Prasser's approach does not account for the lower yields (when the yield from the underground ore body is taken into account) observed in ISL extraction.

Finally, equation C.4 substantially underpredicts the energy consumption associated with higher-grade ores: errors of up to a factor of five are seen when compared with reported data for mines operating at $\mathrm{G}=0.1 \% \mathrm{U}_{3} \mathrm{O}_{8}$ or above. This error likely follows from the substantial statistical uncertainty surrounding Prasser's $\mathrm{e}_{\text {refine }}$ coefficient, which dominates his model at high grades.

ee. Indeed, after Prasser published his work, Rossing released data for 2007 and 2008. Adding these points to the 1999-2006 data set and repeating the regression approach carried out by Prasser, this author found that the refining coefficient erefine became negative! Physically, this would mean the refining process returns energy to the system, clearly a false result. Statistically, it is just an indication of the inadequacy of the data set to the purpose at hand. 
Figure C.1 summarizes the predictions of all three models. Mine-reported direct energy consumption data is superimposed for comparison, but note that only Prasser's model, which does not account for embodied energy, is directly comparable to the mine data. Regardless, it is evident that the Chapman and SLS models, tied as they are to a rigid assumption of a strictly inverse grade-to-energy correlation, do not capture the trends observed at the operating mines.

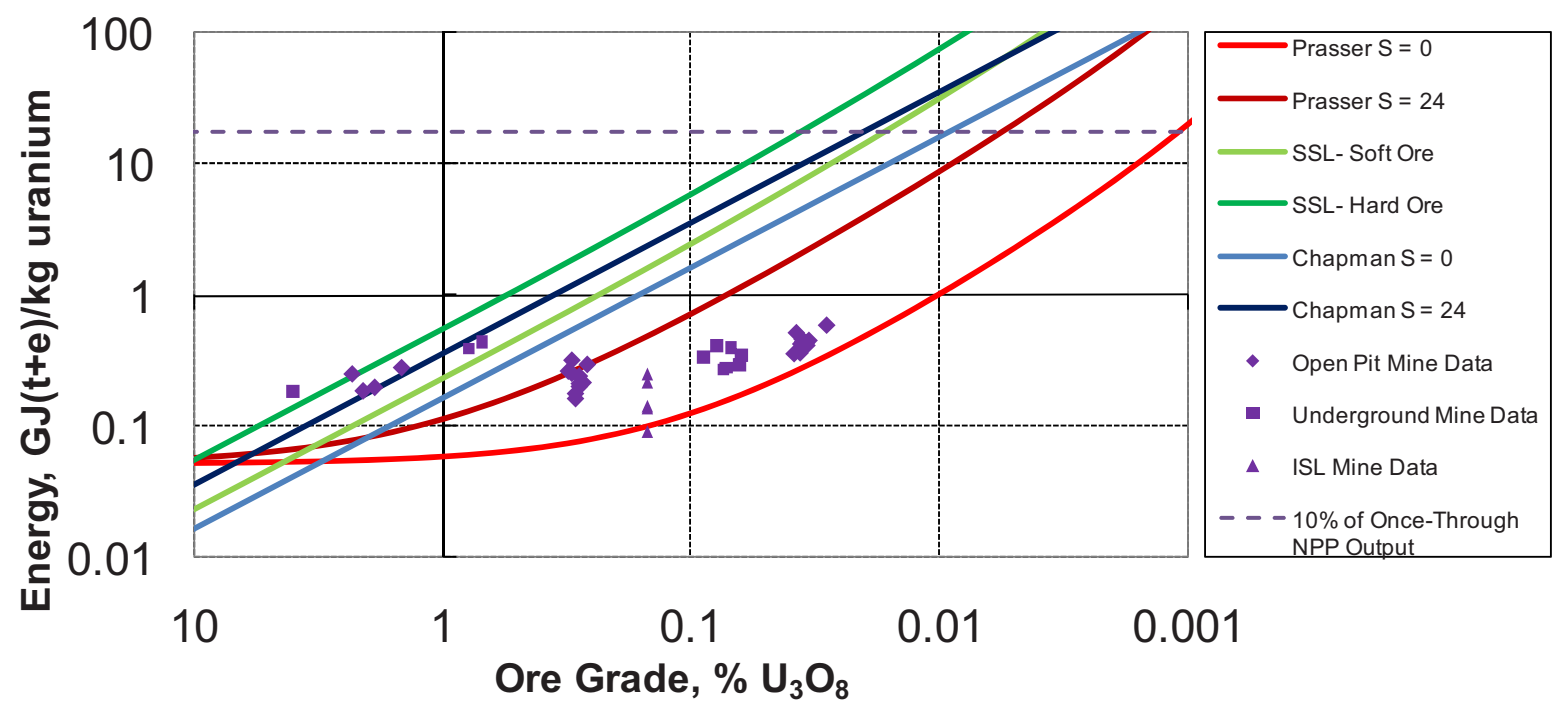

Figure C.1. Model predictions and mine data

The conclusion drawn from this review was as follows. Prasser's model is evidently best-suited to capturing the grade-to-energy trend over the full range of grades reported at contemporary mines. However, the Prasser model suffered from unacceptable statistical uncertainties due to an insufficiently large and comprehensive data set. Moreover, Prasser's interpretation of the $\mathrm{e}_{\text {refine }}$ coefficient may be too narrow. It is likely that this coefficient is describing more than just the energy expenditure in the final steps of the uranium production chain. The implication of the relatively large value of this coefficient is that it also depicts aspects of mine and mill operations and energy consumption that are proportional to the overall uranium output in addition to the grade being processed. This interpretation is pursued in the body of this report; hence the coefficient $\mathrm{e}_{\text {refine }}$ is named $\mathrm{e}_{\mathrm{u}}$ in Section 3 in token of its broader interpretation. Further investigation of this finding via bottom-up modeling is warranted.

\section{C-1. REFERENCES}

[Bieniewski 1971] Bieniewski, C. et al., "Availability of Uranium at Various Prices from Resources in the US,” US Bureau of Mines Information Circular 8501, 1971.

[Chapman 1975] Chapman, P.F., Energy Analysis of Nuclear Power Stations, Energy Policy, pp. 285298, Dec 1975.

[Chapman 1983] Chapman, P. F. and F. Roberts, "Metal Resources and Energy,” London:Butterworths, 1983.

[Everett 1963] Everett, F. D., "Mining Practices at Four Uranium Properties in the Gas Mills, Wyoming," US Bureau of Mines Circular B151, 1963.

[Jacobson 2009] Jacobson, M. and M. Delucchi, “A Path to Sustainable Energy by 2030,” Scientific American, November 2009. 
[Prasser 2008] Prasser, M H, S A Bayard, and R Dones, "Sustainability of Uranium Sources," International Conference on the Physics of Reactors "Nuclear Power: A Sustainable Resource," PHYSOR 2008, Casino-Kursaal Conference Center, Interlaken Switzerland, September 14-19, 2008.

[Rosa 2008] Rosa, R. and D. R. Rosa, "Exergy Cost of Mineral Resources," Int. J. Exergy, 5, 5/6, 532-55, 2008 .

[Storm van Leewen 2005] Storm van Leeuwen, J. W.,Smith, P. Nuclear Power, The Energy Balance, 2005. Revised 2007. available: http://www.stormsmith.nl/, webpage accessed January 30, 2010. 